\title{
Social IDENTITY IN the Provision AND PROtection of CULTURAL GOOdS
}

\author{
Dissertation \\ zur Erlangung des wirtschaftswissenschaftlichen Doktorgrades \\ der Wirtschaftswissenschaftlichen Fakultät \\ der Universität Göttingen
}

vorgelegt von

Marianna Bicskei

geboren in Zenta

Göttingen, 2014 
Erstgutachter: Prof. Dr. Kilian Bizer

Zweitgutachter: Prof. Dr. Markus Spiwoks

Weiteres Mitglied der Prüfungskommission: Prof. Dr. Achim Spiller

Tag der mündlichen Prüfung: 19. September 2014

Kapitel II dieser Dissertation gleichzeitig erschienen in International Journal of Cultural Property Bd. 19 Heft 1, Seiten 97-118, 2012, DOI: 10.1017/S0940739112000070.

Kapitel III dieser Dissertation gleichzeitig erschienen in The WIPO Journal Bd. 3 Heft 2, Seiten 222236, 2012, WIPO: Thomson Reuters. 


\section{TABLE OF CONTENTS}

\section{Chapter I}

Introduction and Summary

Chapter II

Protection of Cultural Goods - Economics of Identity

Coauthors: Kilian Bizer and Zulia Gubaydullina

Published in: International Journal of Cultural Property, Volume 19, Issue 1, 2012, pp. 97-118, DOI: $10.1017 /$ S0940739112000070

Previous versions also published in: Bendix, R., Bizer, K., Groth, S. (Eds.): Die Konstituierung von Cultural Property: Forschungsperspektiven. Göttingen: Universitätsverlag, 2010, pp. 135-150, and

In: Ferstl, P., Wedrac, S. (Eds.): Owning the Mind. Beiträge zur Frage geistigen Eigentums. Schriftenreihe der Società - Forum für Ethik, Kunst und Recht (1). Wien: Peter Lang 2010, pp. 69-94

Chapter III

Reform Proposals on the Geographical Indications of the European Union

for the Protection of Traditional Knowledge

Coauthors: Kilian Bizer, Katia Laura Sidali and Achim Spiller

Published in: The WIPO Journal, Volume 3, Issue 2, 2012, pp. 222-236, WIPO: Thomson Reuters 2012

Chapter IV

Are Protected Designation of Origin and Geographical Indication distinguished by Consumers? An Overview and Synthesis of Empirical Evidence

Working Paper

\section{Chapter V}

Cooperation Preferences in the Provision of Public Goods - An Experimental

Study on the Effects of Social Identity

Coauthors: Matthias Lankau and Kilian Bizer

Previous version published in: Cege Discussion Papers, Number 148, University of Göttingen, December 2012

\section{Chapter VI}

How Peer-Punishment Affects Cooperativeness in Homogeneous and Heterogeneous Groups - A Public Good Experiment with Social Identity

Coauthors: Matthias Lankau and Kilian Bizer

Previous version published in: Cege Discussion Papers, Number 200, University of Göttingen, March 2014 
Chapter VII

Negative Reciprocity and its Relation to Anger-Like Emotions

in Identity-Homogeneous and -Heterogeneous Groups

Coauthors: Matthias Lankau and Kilian Bizer

Previous version published in: Cege Discussion Papers, Number 203, University of Göttingen, March 2014

Re-submitted to the Journal of Economic Psychology on 27 October 2014, currently under review

Chapter VIII

Social Environment and Forms of Governance -

Monetary and Non-Monetary Punishment and the Role of Emotions

Coauthors: Matthias Lankau and Kilian Bizer

Published in: Cege Discussion Papers, Number 202, University of Göttingen, March 2014

\section{Publication that is not part of this dissertation:}

James O. Young: Cultural appropriation and the arts, Book Review

Published in: Journal of Cultural Economics, Volume 35, Number 3, 2011, pp. 233-236,

DOI: 10.1007/s10824-011-9137-3 6 


\section{ChAPTER I}

INTRODUCTION AND SUMMARY 


\section{INTRODUCTION AND SUMMARY}

This dissertation was developed within the realm of the Interdisciplinary Research Group on Cultural Property at the University of Göttingen. In particular, the subproject "The Law and Economics of Cultural Property: an Economic Analysis of the Institutions of Rule-Making"1 was devoted to the analysis of under what circumstances additional property rights should be granted for cultural goods. On this basis, the aim was to derive policy recommendations on how cultural property rights can be optimally structured and designed. In this respect, culture is defined "as a phenomenon consisting of different cultural goods" that are assumed to comprise tangible and intangible elements of cultural significance (Cheng 2006, p. 264). One of the outstanding characteristics of cultural goods distinguishing them from mere commodities or consumer goods is that they provide identity to individuals (UNESCO November 2001, Art. 8) and influence their actions. It is this very feature of cultural goods that this dissertation focusses on.

On the one hand, the first part of the dissertation analyses how the notion of social identity affects the respective demand for protection of cultural goods independent of its tangible or intangible nature (see Chapter II). In addition, since the implementation of property rights over tangible cultural goods (buildings, monuments, etc.) is less problematic and is already very advanced (e.g. cultural heritage management), this dissertation pays particular attention to intangible cultural goods. Typically, the protection of intellectual property is covered by classic intellectual property rights such as patents or copyright. Yet, many cultural goods such as traditional knowledge or traditional cultural expressions lack novelty and clear authorship since they have been transmitted from generation to generation. Accordingly, they require specific institutions of protection. In this respect, sui generis rights of geographical indications constitute a possible protection regime for traditional knowledge embodied in marketed culinary specialties. This dissertation thus critically reviews to what extent geographical indications are a suitable means for protecting such traditional knowledge (see Chapter III) and whether the provision of such rights can be justified from an information economics perspective (see Chapter IV).

On the other hand, many cultural goods bear the character of public goods. They are provided by members of a particular culture and their existence benefits all members of this society equally. This specific environment creates, however, a social dilemma situation. Since nobody can be excluded from the benefit the public good provides, purely rationally acting subjects will not contribute to the public good but rather free-ride on the group members' contributions. Thus, following only selfinterest bears the consequence of under-provision of public goods and thus a loss of welfare. To gain finer grained insights into the provision of cultural goods, the second part of the dissertation examines the influence of social identity. Four chapters (Chapter V, VI, VII, and VIII) test how social identity affects their provision dependent on whether subjects are interacting in identityhomogeneous (in-) or identity-heterogeneous (out-) groups. This takes place in a laboratory environment in the context of public goods experiments. The aim is to shed light on governance mechanisms that groups apply internally in order to secure their group members' cooperation.

\footnotetext{
${ }^{1}$ The project was funded by the Deutsche Forschungsgemeinschaft (DFG Research Unit 772).
} 
The following two sections briefly outline this dissertation's key results concerning the role of social identity in the provision and protection of cultural goods and derive policy recommendations.

\section{Social Identity and the Protection of Cultural Goods}

The international debate on how to protect cultural goods resulted in two different approaches. On the one hand, industrialized countries either seek to protect cultural goods with existing intellectual property rights or to leave them within the public domain. Other countries, mostly those of the global south, advocate the introduction of special sui generis property rights that address the insufficiencies of existing intellectual property rights (Bizer et al. 2011). So far, however, the political debate lacks clear normative arguments for protection. To this purpose, Chapter II "Protection of cultural goods - an economic approach" ${ }^{2}$ develops an economic perspective that details in which cases cultural goods require further protection if the social identity of their providers (carriers) is affected. To do so, the article incorporates identity as an economic variable that enters an individual's utility function (cf. Akerlof and Kranton 2000). On this basis, it assesses how consumption and production of cultural goods affect the utility of the three most relevant actors. These are, firstly, the culture carriers or insiders, i.e. the groups or individuals from whom the specific cultural good originates. Then, there are the consumers and reproducers of cultural goods. Both are entirely disconnected from the goods' emergence and thus are referred to as outsiders. Importantly, insiders and outsiders draw direct and indirect utility from the cultural good, and both groups value the good positively. The direct part of the utility includes monetary benefits from marketing the cultural good and according forgone benefits, which hinder to recover the costs invested in the production of a cultural good. Indirect utility comprises for instance a cultural good's option, existence or bequest value, which in sum provide identity for culture carriers. Evidently, cultural goods provide indirect utility to outsiders, as well. Nevertheless, such utility cannot be assumed to be as determinant as influencing the (fundamental) identity of outsiders. Accordingly, the article establishes that if only direct utility effects exist, total gains and losses should be weighed against each other. Considering the utility of all stakeholders to a cultural good, protection should only be implemented if it results in a net utility gain compared to a situation with no protection. Such an evaluation, however, requires a case by case examination. In case of indirect utility effects, their impact on the culture carriers' identity is of importance. If identity is affected, it must be determined whether it seriously impairs their fundamental identity or dignity. Only these cases require protection to exclude outsiders from consumption and restrict the commodification of these particular cultural goods. This could be achieved by international norms for cultural protection in the form of sui generis property rights. In sum, Chapter II thus provides insights into the regulatory choice problem faced by national legislators as well as the international community, who intend to identify how much protection of cultural goods should be targeted.

Regarding specific institutions to protect cultural goods, both Chapter III and IV pay attention to the sui generis rights of geographical indications (GIs). Generally, Gls aim at restricting the usage of names associated with culinary specialties of a particular demarcated geographical region. Thus, Chapter III on "Reform Proposals on the Geographical Indications of the European Union for the

\footnotetext{
2 The contribution of the author to this article is approximately 65 percent.
} 
Protection of Traditional Knowledge ${ }^{\prime 3}$ critically analyses to what extent the current regulation on Gls promoted by the European Union ${ }^{4}$ is a suitable tool for protecting traditional knowledge about distinctive features of local food culture. Specifically, based on an information- and cultural economics perspective, it investigates how transparency between the $\mathrm{Gl}$ instruments can be maintained and how the promotion of traditional knowledge attributed to a specific region can be better addressed. Overall, this chapter criticizes that the two current GI instruments, namely protected designation of origin (PDO) and protected geographical indication (PGI), constitute different grades of regional and thus cultural embeddedness. While PDO products must be entirely produced, processed and prepared within the region, which the indication stands for, in case of PGI only one step of the production is required to take place within the defined region. Yet, although they grant the same level of protection, differences between the instruments are hardly sufficiently indicated and communicated to consumers. Consequently, this article advocates modifying the existing regulations drastically and suggests keeping only one instrument, namely the PDO. This should draw on a definite geographical, but also a stricter cultural connection between the product and the region, thus strengthening the regional identity of all stakeholders. Additionally, the article is in favor of abolishing the label of Traditional Specialities Guaranteed (TSG). ${ }^{5}$ Apart from the fact that technically TSGs are no Gls, from the consumer perspective they are not clearly distinguishable from PDOs or PGIs. Abolishing them thus serves the purpose of increasing consumer transparency of the Gl system.

According to Chapter III's hypothesis, the differences between PDO and PGI instruments are not sufficiently clear to consumers to warrant to different GI instruments (labels). Thus, the risk of confusing consumers is high. Therefore, Chapter IV "Are Protected Designation of Origin and Geographical Indication distinguished by Consumers? An Overview and Synthesis of Empirical Evidence $^{\prime \prime}$ investigates whether consumers are able to clearly distinguish the grade of regional embeddedness of PDO and PGI protected products. From an information economics perspective this is of high importance since the basic economic rationale of protecting Gls is to dissolve the information asymmetry between producers and consumers as to the true origin of the products. On the basis of a qualitative literature review, the article approaches this question by overviewing and synthesizing the empirical evidence on consumers' awareness of and willingness to pay for PDO and PGI. The article shows that PDO and PGI are more or less similarly recognized among consumers. Nevertheless, due to serious analytical shortcomings of the current empirical literature, it concludes that the research question may not be satisfactorily answered. Consequently, the effectiveness of Gls in terms of solving information asymmetries remains hidden. Further extensive research is required, for which this article highlights some aspects.

\footnotetext{
${ }^{3}$ The contribution of the author to this article is approximately 55 percent.

4 The regulations considered: (1) Council Regulation 510/2006 of March 20, 2006 on the protection of geographical indications and designations of origin for agricultural products and foodstuffs (Regulation 510/2006) OJ L93/12 and (2) European Commission, Final Proposal for a Regulation of the European Parliament and of the Council on agricultural product quality schemes (Regulation Proposal), December 10, 2010, COM(2010)733.

${ }^{5}$ Council Regulation 509/2006.

${ }^{6}$ This contribution was entirely elaborated by the author.
} 


\section{Social Identity and the Provision of Cultural Goods}

Part II of the dissertation is dedicated to the better understanding of the influence of social identity in the provision of cultural goods. Due to their similarities with public goods this part applies laboratory experiments using public good games. As already briefly introduced, the provision of public goods constitutes a social dilemma situation in which individual interest is at odds with social interest. Evidently, the social optimum is reached if all group members contribute to the public good. However, from an individual perspective there are strong incentives for free-riding since irrespective of the level of contributions no one can be excluded from the public goods' benefits. Yet, despite the dominant strategy of free-riding, previous research has already established that individuals have diverging cooperation preferences. A considerable proportion of individuals do not aim at maximizing their own utility but are rather conditionally cooperative. Thus, they do contribute to the public good if their group members do so, as well (see Fischbacher et al. 2001, and Chaudhuri 2011 for an overview). Very importantly, it has been established that social identity - commonly defined as "the individual's self-concept derived from perceived membership in social groups" (Charness et al. 2007 , p. 1342) - fosters the provision of public goods. In particular, when subjects are interacting in identity-homogeneous (in-) groups, they typically reveal an in-group bias by favoring their in-group and discriminating against out-group members (cf. Tajfel and Turner 1979, Hoff and Pandey 2006). Specifically, subjects are willing to cooperate more with individuals who share the same identity than with individuals of different identities (see e.g., Solow and Kirkwood 2002, Wit and Wilke 1992, Chen and Li 2009). Additionally, subjects in in-groups are more likely to make social welfare maximizing choices as opposed to out-groups (Chen and Li 2009). Interestingly, the question to what extent this is due to differences in subjects' cooperation preferences has not been analyzed in a public good context, yet. Consequently, Chapter V asks whether the social environment influences subjects' preference for conditional cooperation, i.e. the extent to which they reciprocate their team members' contributions by an own contribution.

Next to social identity peer-punishment has also been identified as a successful institution to maintain cooperation in the provision of common resources (cf. Fehr and Gächter 2000, and Masclet et al. 2003). Specifically, the threat of costly peer-punishment induces subjects to increase their contributions. Until now, however, there is still no precise evidence in the public good context on how social identity and peer-punishment affects cooperation simultaneously. Thus, Chapter VI aims at closing this gap by analyzing how the institution of peer-punishment affects subjects' cooperativeness dependent on the social environment. Nevertheless, it must be also taken into account that peer-punishment may have important welfare consequences. The application of peerpunishment per se is costly for the punished and the punisher, as well. Due to its disciplining effect, investment in punishment thus constitutes a second order public good, whose provision might also be dependent on social identity. Since this link has received no particular academic attention, yet, Chapter VII picks up on this and examines in how far subjects - dependent on whether they are interacting in in- or out-groups - are willing to reciprocate the uncooperative behavior of their group members by investing in punishment (negative reciprocity). What is more, as emotions tend to play a decisive role in motivating behaviour (see Hopfensitz and Reuben 2009, Loewenstein 2000, Elster 1998), this chapter scrutinizes how emotions impact on punishment. Furthermore, to deepen the understanding of the impact of emotions on economic decisions, the last chapter (Chapter VIII) of the 
dissertation aims at analyzing the effect of emotions, not on triggering punishment, but rather on subjects' subsequent contributions when they have been punished. Peer-punishment is, however, divided into a monetary and a non-monetary component. The novelty of this split is that it allows dependent on the social environment - for disentangling the continuum along which groups apply social disapproval with or without monetary consequences or a mix of both for sustaining their members' cooperativeness. This is of high relevance since the groups' choice of governance bears serious consequences for the level of social welfare attained.

Summing up, the second part of the dissertation addresses the question of to what extent social identity influences subjects' economically relevant decision-making in the context of cultural goods provision. Methodologically, each chapter employs controlled laboratory public good experiments, which were conducted in the Göttingen Laboratory of Experimental Economics (GLOBE) at the University of Göttingen. In the basic decision situation of the public good game, after receiving 20 points, subjects have to make an unconditional decision on how much they want to contribute to the public good (framed as a project) and how much they want to keep on their private account. The payoff function is set so that each point invested into the public good returns only 0.4 points for each group member. Thus, for every individual it is more beneficial to contribute nothing to the public good leaving the entire endowment on their private account and to free-ride on the others' contributions. In addition, in Chapter V, VI and VII a conditional contribution decision is also requested (see Table 1). In particular, subjects are asked to make 21 entries in a contribution table stating how much they would contribute to the project if their group members invested on average 0-20 points. Due to the hypothetical nature of this question, this method is commonly referred to as the strategy method in public goods games (see Fischbacher et al. 2001). This provides, first of all, a possible measure for cooperativeness. Secondly, it helps to classify subjects into different cooperation types thereby widening our understanding of subjects' behavior. These public good games are complemented in Chapter VI, VII and VIII with a peer-punishment institution. Particularly, subjects are given the opportunity to express their disapproval about their group members' (mis-) behavior in terms of their cooperativeness.

Table 1 - Overview of the Experimental Designs

\begin{tabular}{cccccc}
\hline & $\begin{array}{c}\text { Type of Public } \\
\text { Good Game } \\
\text { (PGG) }\end{array}$ & $\begin{array}{c}\text { Type of } \\
\text { Contribution } \\
\text { Decision }\end{array}$ & Peer-Punishment & $\begin{array}{c}\text { Analysis of } \\
\text { Emotions }\end{array}$ & Size of Groups \\
\hline Chapter V & One-shot PGG & $\begin{array}{c}\text { Unconditional and } \\
\text { Conditional }\end{array}$ & - & No & 3 \\
Chapter VI & One-shot PGG & $\begin{array}{c}\text { Unconditional and } \\
\text { Conditional }\end{array}$ & Monetary & No & 3 \\
Chapter VII & One-shot PGG & $\begin{array}{c}\text { Unconditional and } \\
\text { Conditional }\end{array}$ & Monetary & Yes & 3 \\
Chapter VIII & 10-period PGG & Unconditional & $\begin{array}{c}\text { Monetary+Non- } \\
\text { Monetary }\end{array}$ & Yes & 4 \\
\hline
\end{tabular}


In order to control whether social identity is a causal element in these decision situations, each experiment follows a design that entails three matching protocols. In in-group matching subjects are interacting with their own identities, in out-group matching groups comprise individuals of different identities. Lastly, a random group assignment without any labeling serves as a control treatment. Instead of priming subjects' natural identity, each chapter builds up on an artificially induced identity, which is triggered by a simple group task that subjects solve jointly. This method has the advantage of better controlling subjects' identity (Li et al. 2011), which is naturally a blend of different identities (Pecchenino 2009). Evidently, priming would make one dimension of a natural identity salient (Li et al. 2011). Yet, possible existing attitudes and connotations towards it may influence subjects' behavior, which cannot be controlled. Consequently, based on insights of Eckel and Grossman (2005) and Chen and Li (2009), each chapter uses a design pioneered by Ibañez and Schaffland (2012). Particularly, subjects are randomly assigned to groups, which are labeled by a particular color indicated by a group flag. Group members then work together on finding hidden objects in a picture and have the possibility to discuss their location anonymously with each other via a chat tool. To increase the interaction of group members, answers are counted as correct only if each group member enters them correctly. All of these game rules follow the purpose of creating a positive group experience (Eckel and Grossman 2005) and of triggering feelings of group attachment and thus group identity.

After having demonstrated the economic relevance of each chapter of the second part of this dissertation and their methodological commonalities, the next sections briefly state their research question, unique experimental features and summarize their core results.

To begin with, Chapter V "Cooperation Preferences in the Provision of Public Goods - An Experimental Study on the Effects of Social Identity" ${ }^{7}$ analyzes the driving forces of higher contributions to common pool resources when social identity is present. To do so, the experiment follows a within-subject design based on one-shot public goods game in strategy method. The experimental design entails four stages. Stage 1 serves the purpose of classifying subjects as freeriders (those who always defect) and conditional cooperators (those who cooperate only if the others cooperate, as well) in a random group assignment that is unaffected from any influence of social identity. Subjects who cannot be so classified are called "others". Stage 2 proceeds with the induction of social identity. Subsequently, in Stage 3 and 4 subjects either interact firstly in in-group then in out-group matching or in a reverse order to control for treatment-order effects. Firstly, the article tests whether subjects in in-groups reveal a preference for higher levels of conditional cooperation than in out-group matching. Secondly, it asks whether subjects in in-groups show a higher propensity to be conditional cooperators and a lower propensity to be free-riders than in outgroup matching. The results reaffirm previous findings obtained outside the public good context (cf. Chen and Li 2009), namely that social identity affects subjects' degree of positive reciprocity. Especially, subjects in in-groups exhibit significantly higher levels of conditional cooperation at all levels of others' average contribution and thus less self-serving bias than subjects of out-groups. What is more, while the propensity to be a conditional cooperator is stable, the data reveals a slightly

\footnotetext{
${ }^{7}$ The author's contribution to this article constitutes approximately 25 percent.
} 
higher propensity for subjects to be free-riders when interacting with different identities than with common identities. In sum, these results advocate devising policy institutions, which stress the belonging to a particular group in order to elevate subjects' conditional cooperativeness and thus the overall level of social welfare.

Chapter VI "How Peer-Punishment Affects Cooperativeness in Homogeneous and Heterogeneous Groups - A Public Good Experiment with Social Identity" ${ }^{\prime 8}$ investigates subjects' cooperativeness measured by their conditional contributions under the threat of peer-punishment. The experiment follows a between-subject design and is based on one-shot public good games in strategy method. It contains Punishment (P) and No-Punishment (NP) treatments, both of which include three stages. Firstly, in each treatment subjects randomly assigned to a group play a one-shot public good game in strategy method following the same logic as outlined for Chapter $V$ above (Stage A). After social identity is induced in Stage B, subjects are assigned either to in-, out- or random groups (Stage C). Then, in the NP-treatments subjects play a one-shot public good game similar to Stage A. In the Ptreatments, this game is extended with the possibility of distributing punishment points that subjects can assign to each of their group-members after being informed about their contributions. Not only being punished but also the infliction of punishment is costly, which ensures that purely selfish subjects will never punish. The results highlight, first of all, that the social environment is a determinant of how the threat of peer-punishment influences cooperation. Especially, subjects in identity-heterogeneous groups increase their contributions the most. In particular, free-riders, presumably anticipating a comparably strong punishment by out-group members upon uncooperative behavior seem to be responsible for that. Secondly, the in-group bias, which is a commonly observed characteristic for situations without punishment and equally present in the NPtreatments, tends to be eroded by peer-punishment. Consequently, it renders out-group members to be as cooperative as members of in-groups. Lastly, the results emphasize the complementarity of social identity and peer-punishment. Compared to the control treatment, in- and out-group members' cooperativeness is increased. Thus, combining social identity with peer-punishment seems to be a useful tool to maintain cooperation thus social welfare as opposed to situations when social identity is not salient.

While the previous two chapters pay particular attention to subjects' cooperation behavior, Chapter VII "Negative Reciprocity and its Relation to Anger-Like Emotions in Homogeneous and Heterogeneous Groups" ${ }^{\prime \prime}$ rather examines subjects' punishment behavior and its underlying factors. Correspondingly, this article asks whether social identity affects individuals' willingness to sanction deviating group members in a public good context. Similar to the previous chapters' focus on cooperativeness, sanctions are equally seen as conditional behavior. They capture individuals' proclivity to punish behavior perceived as unkind even if it does not yield future benefits and is costly (cf. Falk and Fischbacher 2006), which bears important welfare consequences. What is more, this article uniquely delivers insights into how anger-like emotions (anger, contempt and irritation) influence negative reciprocity dependent on the social environment. To that purpose, subjects had to

\footnotetext{
${ }^{8}$ The author's contribution to this article constitutes approximately 45 percent.

9 The author's contribution to this article constitutes approximately 65 percent.
} 
indicate their emotions after being informed on the other group members' contribution and before the infliction of punishment. The results of the experiment provide first evidence that social identity does affect negative reciprocity in a public good context. Subjects in in-groups punish much less frequently and in smaller amounts than in out-groups when facing contributions smaller than their own. Moreover, the probability to inflict punishment is higher in out-groups than in in-groups. Next, the data reveals that deviant behavior does not evoke different intensities of anger-like emotions dependent on the social context. The article rather highlights that anger-like emotions trigger negative reciprocity much stronger in identity-heterogeneous as opposed to identity-homogeneous groups. In sum, these insights approve that social identity not only forms subjects' preferences for positive but also for negative reciprocity in a public goods context. Thus, public policy addressing one's social identity might influence social welfare negatively depending on the group composition.

Lastly, Chapter VIII "Social Environment and Form of Governance - Monetary and Non-Monetary Punishment and the Role of Emotions" ${ }^{\prime 10}$ analyses to what extent social identity affects whether subjects govern their group by monetary sanctions or non-monetary sanctions. This question is addressed within a framework of a 10-period public goods experiment in a between-subject design. For this purpose, Stage 1 induces social identity. Then in Stage 2 subjects play the public goods game either in in-group, out-group or random group assignment with group composition remaining stable during the entire time horizon. In each round, after the total of punishment points assigned to a subject is revealed, subjects are required to state their emotions. The results of Chapter VIII show that apart from the initial periods, identity-heterogeneous groups tend to contribute more to the public good than identity-homogeneous groups. Moreover, the article establishes that subjects in identity-heterogeneous groups display their disapproval more frequently and with higher intensity by monetary punishment as opposed to identity-homogeneous groups. Conversely, in-groups tend to rely more on non-monetary sanctions than out-groups. In total, this differing cooperation and punishment behavior bear the consequence that out-groups reach similar welfare as in-groups. Next, the results are the first to show that the emotions of anger and guilt have differing impacts on subsequent contributions dependent on the social environment. Especially, after being punished the presence of anger does not influence subsequent contributions in in-groups. On the contrary, in outand random groups it negatively impacts contributions. Similarly to Chapter VII, this also provides a hint that a common group identity leads subjects to control their anger-like emotions mitigating their negative consequences on welfare. On the contrary, when subjects were punished, they were more likely to increase their contributions if they felt guilty than if they did not. Surprisingly, when interacting in identity-heterogeneous groups feeling guilty leads subjects to increase subsequent contributions to a higher extent than in identity-homogenous groups. With respect to previous findings, the article demonstrates, first of all, that under the possibility of both monetary and nonmonetary punishment, welfare reached is higher than in situations without any punishment institutions and it does not decrease over time. Secondly, this institutional setting eliminates the ingroup bias that is characteristic for situations without any punishment possibility. Thus, from a policy perspective introducing a peer-punishment institution and splitting it into a monetary and nonmonetary component can be a useful tool of enhancing welfare.

\footnotetext{
${ }^{10}$ The author's contribution to this article constitutes approximately 65 percent.
} 
Concluding, the second part of the dissertation reveals that in a public good context social identity does play an important role in subjects' cooperative and punishment behaviour, which has determinant consequences on social welfare dependent on the group composition. Very importantly, these findings stress that group composition is of high relevance when public policy addresses one's social identity. Overall, these findings show that social identity might be of crucial importance in terms of voluntarily maintaining cultural goods within cultural groups, which are assumed to be identity-homogeneous in this respect. 


\section{RefERENCES}

Akerlof, G. A.; Kranton, R. E. (2000): Economics and Identity. In Quarterly Journal of Economics 115 (3), $715-$ 753.

Bizer, K.; Lankau, M.; Spindler, G.; Zimbehl, P. (2011): Sui Generis Rights for the Protection of Traditional Cultural Expressions - Policy Implications. In Journal of Intellectual Property, Information Technology and ECommerce Law (JIPITEC) 2 (2), 114-119.

Charness, G.; Rigotti, L.; Rustichini, A. (2007): Individual behavior and group membership. In American Economic Review 97 (4), 1340-1352.

Chaudhuri, A. (2011): Sustaining cooperation in laboratory public goods experiments: a selective survey of the literature. In Experimental Economics 14 (1), 47-83.

Cheng, S.-W. (2006): Cultural goods creation, cultural capital formation, provision of cultural services and cultural atmosphere accumulation. In Journal of Cultural Economics 30 (4), 263-286.

Chen, Y.; Li, S. X. (2009): Group Identity and Social Preferences. In American Economic Review 99 (1), 431-457.

Eckel, C. C.; Grossman, P. J. (2005): Managing diversity by creating team identity. In Journal of Economic Behavior \& Organization 58 (3), 371-392.

Elster, J. (1998): Emotions and Economic Theory. In Journal of Economic Literature 36 (1), 47-74.

European Union (2006): Council Regulation 510/2006 of March 20, 2006 on the protection of geographical indications and designations of origin for agricultural products and foodstuffs. In OJ L93/12.

European Union (2006): Council Regulation 509/2006 of March 20, 2006 on agricultural products and foodstuffs as traditional specialities guaranteed. In OJ L93/1.

European Union (14.12.2012): Regulation (EU) No 1151/2012 of the European Parliament and of the Council of 21 November 2012 on quality schemes for agricultural products and foodstuffs. In OJ L343.

Falk, A., Fischbacher, U. (2006): A theory of reciprocity. In Games and Economic Behavior 54 (2), $293-315$.

Fehr, E.; Gächter, S. (2000): Cooperation and Punishment in Public Goods Experiments. In American Economic Review 90 (4), 980-994.

Fischbacher, U.; Gächter, S.; Fehr, E. (2001): Are people conditionally cooperative? Evidence from a public goods experiment. In Economics Letters 71 (3), 397-404.

Hoff, K.; Pandey, P. (2006): Discrimination, Social Identity, and Durable Inequalities. In American Economic Review 96 (2), 206-211.

Hopfensitz, A.; Reuben, E. (2009): The Importance of Emotions for the Effectiveness of Social Punishment. In The Economic Journal 119 (540), 1534-1559.

Ibañez Diaz, M.; Schaffland, E. R. (2012): Group identity and leadership: An experimental analysis. Unpublished Manuscript. Georg-August-Universität Göttingen.

Li, S. X.; Dogan, K.; Haruvy, E. (2011): Group identity in markets. In International Journal of Industrial Organization 29 (1), 104-115.

Loewenstein, G. (2000): Emotions in Economic Theory and Economic Behavior. In American Economic Review $90(2), 426-432$.

Masclet, D.; Noussair, C.; Tucker, S.; Villeval, M.-C. (2003): Monetary and Nonmonetary Punishment in the Voluntary Contributions Mechanism. In American Economic Review 93 (1), 366-380.

Pecchenino, R. A. (2009): Becoming: Identity and spirituality. In The Journal of Socio-Economics 38 (1), 31-36.

Solow, J. L.; Kirkwood, N. (2002): Group identity and gender in public goods experiments. In Journal of Economic Behavior \& Organization 48 (4), 403-412. 
Tajfel, H.; Turner, J. (1979): An Integrative Theory of Intergroup Conflict. In: Worchel, S.; Austin, W. (Eds.): The Psychology of Intergroup Relations. Monterey: CA: Brooks/Cole, 33-47.

UNESCO (November 2001): Universal Declaration on Cultural Diversity. Source: Paris.

Wit, A. P.; Wilke, H. A. M (1992): The effect of social categorization on cooperation in three types of social dilemmas. In Journal of Economic Psychology 13 (1), 135-151. 
ChAPTER II

Protection of CULTURAL GoOdS - ECONOMICS OF IDENTITY

Marianna Bicskei, Kilian Bizer, Zulia Gubaydullina 


\section{INTRODUCTION}

In the Intergovernmental Committee on Traditional Knowledge, Genetic Resources and Traditional Cultural Expressions of the World Intellectual Property Organization (WIPO-IGC), nations from all parts of the world are discussing whether to provide more protection for cultural goods. In the Convention on the Protection and Promotion of the Diversity of Cultural Expressions, the United Nations undertook "to protect and promote the diversity of cultural expressions, ... and to give recognition to the distinctive nature of cultural activities, goods and services as vehicles of identity, values and meaning. ${ }^{\prime 1}$ Moreover, the protection of culture is part of the international agenda in different aspects and constellations. How can this be interpreted from an economic point of view?

Many cultural expressions, such as sacred rituals or sand paintings, play an important role in the identity of certain groups and should be protected from misappropriation and misuse. Such cultural practices might require specific protection measures.

While some countries would like cultural goods to receive more protection, other countries argue that cultural goods belong to the public domain. The latter argue that most, if not all, cultural goods should be available for everybody as long as standard intellectual property rights are not infringed upon. Take, for example, yoga as a meditation practice used around the world despite the fact that it originates in India. Should yoga be reserved for the Indian population only? Should everybody else be required to apply for a yoga permit or even pay a "yoga dime" for practicing it? ${ }^{2}$ As another example, take any language: Should someone willing to learn to speak it pay an additional charge or ask for permission because the language "belongs" to another culture?

Of course, many doubt that cultural expressions should be commodified at all. But in the contemporary world temples as well as their rituals, villages, or tribes and their celebrations, dances, theatre, or sacred drawings come to the attention of tourists, designers, and other outsiders and in practice are turned into commodities. In the process of commodification certain aspects of the culture may very well get lost. This loss may form the difference between the original cultural expression and the commodified one, and can be relevant for the identity of members of a specific group. Such loss can take the form of identity loss and thus serve as a source of justification for protecting cultural goods. We use the phrase cultural goods in what follows to direct our attention toward goods and services derived from culture in the broadest sense. In order to avoid misunderstanding, we do not use the term goods in any other sense.

In this article we analyze from an economic perspective whether cultural goods require further protection if we take effects on identity into account. We develop a framework allowing us to assess different effects on three of the most relevant groups affected by cultural goods. We distinguish these groups as culture carriers, outsider consumers, and culture reproducers, which are not the same as producers of classic goods and services. Such an assessment provides insights into the regulatory choice problem faced by national legislators as well as the international community, who intend to identify how much protection of cultural goods should be targeted in general. According to our analysis of the utility of cultural carriers, only cultural goods that are essential to identity and dignity require additional protection. This is due to the fact that culture reproducers and outsider consumers negatively affect the identity and thus the dignity of the culture carriers. In these cases, rights are required to exclude these actors from consumption and restrict the commodification of these particular cultural goods. 
To investigate this topic, the rest of the article proceeds as follows: The second section discusses identity as an economic variable, which is said to determine the valuation of the protection of cultural goods. The third section deals with the utility derived from consuming and reproducing cultural goods. In the fourth and fifth sections, we address different protection issues regarding cultural goods while classifying cultural goods according to their direct and indirect effects. In the final section we arrive at several conclusions.

\section{PROTECTION OF CULTURAL GOODS－LITERATURE REVIEW}

In drawing on the concept of identity to develop an economic argument about the protection of cultural goods, we feel it is necessary to analyze identity in an economic context and incorporate identity into the economic (utility) function. This is necessary because identity is of high importance in a cultural context. To understand the behavior of individuals or groups, the impact of others on their identity must be scrutinized more deeply.

The descriptive literature on identity and its utility relies on the theses of Akerlof and Kranton, ${ }^{3}$ the most widely accepted account of the relationship between identity and economic outcomes. These authors suggest that identity might be recognized as a determinant factor in utility functions. In their model, the utility function $\left(U_{j}\right)$ consists of three variables. ${ }^{4}$ The first, identity or self-image $\left(I_{j}\right)$, is determined by social categories such as gender or occupation as well as their features and typical characteristics since members of a given social category or group are often expected to exhibit specific physical or cultural characteristics and attitudes. The second variable refers to a person's actions $\left(a_{j}\right)$ undertaken to maximize the person's own utility while complying with the prescriptions of his social category. The third identifies the actions of others $(a-j)$, which, combined with the second variable, have an impact on a person's consumption of goods and services. It is assumed that a particular social category has an impact on a person's identity, thereby affecting the person's socalled identity-related behavior. ${ }^{5}$ Consequently, identity plays an important role in the utility function because a person's own actions affect the person's utility, which is to some extent based on the actions' impact on identity. According to the model of Akerlof and Kranton, identity-based payoffs can arise from a person's own actions as well as from those of others. The result is that the actions of others can affect a person's utility and identity at the same time, a finding that needs further investigation.

In our article, we focus on the changes in utility caused by (other) third parties not belonging to the particular social category. According to the literature mentioned in the preceding paragraph, "those who try to change social categories and prescriptions may face similar derision because the change may devalue others' identity." ${ }^{16}$ In the model of Akerlof and Kranton there is the possibility for a person to have a limited choice over his or her identity. They argue that without distinctive characteristics, it is possible to join other social categories, but also that this possibility is limited with respect to physical appearance or accent. We assume that different cultures, as a kind of social category not only sharing common characteristics but also constituting a social group, ${ }^{7}$ comprise individuals whose common features form a basis for their interaction with one other, and that these are fundamentally based on cultural goods. The consumption and production of cultural goods within a particular culture are based on the choices and actions of individuals or a group of individuals, which induce changes in their utility function and thus in their identity. According to this argument, the impact of cultural-goods-related actions by an outsider to the group on another person's group identity deserves further attention. In this context Akerlof and Kranton identify a loss of identity if 
somebody violates a person's internalized values ("prescriptions"). Therefore, these actions of others produce "externalities," against which there is no protection. Activities of persons related to cultural goods who are not members of the particular culture are the basis of our analysis. In our view, these actions may need to be regulated by institutions such as the World Intellectual Property Organization (WIPO).

The literature on cultural goods shows a broad scale of approaches mostly based on international trade. Francois and van Ypersele ${ }^{8}$ approach the issue of protecting cultural goods and their impact on welfare from a different perspective. Their work is based on the different valuation of cultural goods by insiders (home country) and outsiders (abroad), produced under economies of scale, and is exemplified by trade in movies. In their example, Hollywood films, which can unintentionally disturb traditional or indigenous cultures, are valued the same by both sides (local and foreign people). This means, for instance, that consumers in both the United States and France are willing to pay for consumption of Hollywood films. In contrast, the valuation of domestically produced films is not homogeneous between consumers at home and abroad. According to that example, not all French consumers prefer French auteur films or are willing to pay a premium for them. ${ }^{9}$ In their two-country (United States, France)/ three-cultural-goods (mainstream Hollywood films, French auteur films, U.S. auteur films) model, they explore whether protection of cultural goods (in this case, auteur films) could increase welfare for all parties and whether it can be Pareto improving for all parties if countries introduce a cultural tariff on Hollywood films. If a tariff or quota is introduced, traditional film production, in which fixed costs are very high, would not be crowded out by blockbuster producers, whose market share takes up most of the world. From the perspective of domestic groups in both countries, the restriction would imply that the local auteur cinema would still be available for the local population, which values this good highly. Moreover, consuming locally produced goods is required in order to keep domestic culture alive. At the same time, export potential is provided, which increases the well-being of the population. In this article, great importance is attributed to the valuation of cultural goods. This valuation is fundamental to the different social groups and must be reflected when investigating the protection of cultural goods.

Another important contribution to the issue of protecting cultural goods is provided by Janeba, ${ }^{10}$ who analyzes the impact of free trade of cultural goods on cultural identity. In his article, cultural goods are defined as goods that interconnect individual consumption decisions and thus contribute to the formation of a cultural identity. For example, consuming a cultural good could make consumption more attractive for other consumers. Identity is built if all individuals within the society consume the same cultural good (a culturally homogeneous good). The identity function could be described as a network externality. For instance, Germans drink beer, which is identified as a common tradition in Germany. If everybody in the society consumes the same good, the loss in identity is zero, but consumption is influenced by the factors of price and social punishment. This consumption may change in the case of trade liberalization leading to changes in the homogeneous consumption behavior of a specific society, therefore causing a loss of identity. Janeba favors a protectionist approach toward cultural goods based on welfare analysis both in closed and open economies. Considering one model of international trade and assuming different technologies and economies of scale, he deducts inter alia that in the case of cultural homogeneity (homogeneous taste and consumption of cultural goods), trade cannot have a Pareto-improving effect on closed economies (autarky). In sum, the model demonstrates that while social consumption behavior changes due to the imported cultural goods, individuals consuming the exported good lose out on 
trade liberalization. Janeba argues that consumers of cultural goods produced and consumed locally are those that oppose trade liberalization the most. He further concludes that globalization has a negative impact on national culture and individual identities. In order to preserve a culture, the consumption of locally produced goods must be supported.

The public debate concerns the preservation of culture and cultural identity through the protection of cultural goods. The economic discussion takes this up while seeking the utilityproviding effect of cultural goods. Against this background, we focus on the central question: What exactly is it that requires protection? We answer this question by introducing an economic approach to cultural goods and their protection. We suggest a set of criteria that help to determine whether a cultural good should be protected or not. These criteria include considerations of direct effects as well as indirect effects of cultural goods' consumption. We also distinguish between certain groups affected by the consumption and reproduction of cultural goods.

\section{UTILITY FROM CULTURAL GOODS}

Culture is a phenomenon that is not easy to define. The United Nations define culture as "diverse forms across time and space; this diversity is embodied in the uniqueness and plurality of the identities and cultural expressions of the people and societies making up humanity." ${ }^{11}$ We define culture within the scope of this article as a phenomenon consisting of different goods (cultural goods) that "are considered to consist of tangible and intangible items of cultural significance. ${ }^{12}$ The specific feature of cultural goods lies above all in the fact that they must be treated as vectors of identity and not as mere commodities or consumer goods. ${ }^{13}$ Of course, immaterial cultural goods are more problematic, as most material goods are already protected by classic property rights, but both intangible and tangible parts of cultural goods are the subjects of our examination.

FIGURE 1. Classification of the actors in the categories of insider and outsider.
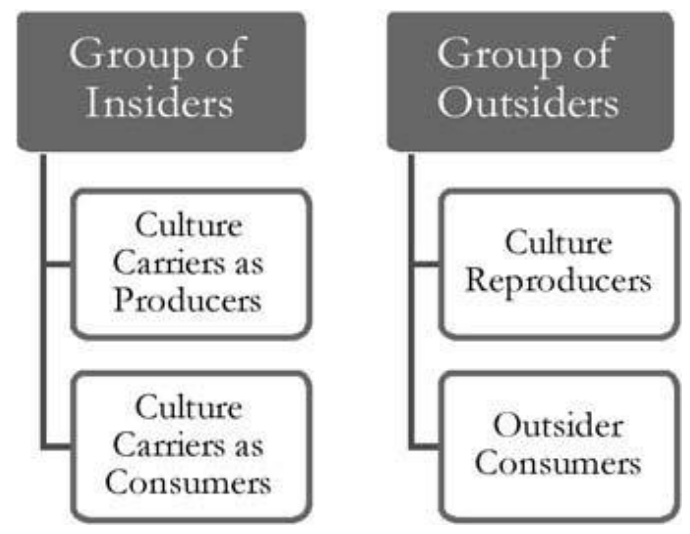

For our analysis, we introduce the notions of culture carriers, culture reproducers and outsider consumers (consumers others than culture carriers). Culture carriers are defined as the groups or individuals from whom the cultural good originates. They could also be called insiders, as they belong to the group or society ${ }^{14}$ in which a certain cultural good emerges. As they are the holders and custodians of particular cultural goods, they consequently consist of both producers and consumers. They produce cultural goods that they sell as a private good and/or provide for the public domain. For simplicity of argumentation we refer to these insider actors as "culture carriers." As part of the group of outsiders, the so-called outsider consumers and the culture reproducer (reproducer of 
cultural goods) are defined as societies, groups, or individuals using the cultural good but who are entirely disconnected from its emergence. Both groups, insiders and outsiders (see figure 1), draw utility from cultural goods, and both groups value the cultural good in question positively.

Let us first take a closer look at the utility of culture carriers. To address this we introduce a "cultural utility function" of culture carriers who share the same cultural identity based on particular cultural goods.

We assume that cultural goods provide both direct and indirect utility to culture carriers. The direct part of the utility includes monetary benefits from cultural goods. These arise when any outsider consumer is willing to pay for using a cultural good such as dancing lessons, a copy of a traditional pattern, music, or a picture of some historical monument produced by culture carriers. This utility can also be described as "direct consumption benefit" or "direct market benefit."15 Arguing in this manner, it is clear that if outsider consumers use a cultural good without paying for it, such as illegally uploading copyrighted cultural songs, it has a negative impact on the (direct) utility of the culture carrier who intended to sell it. In cases in which no income or revenue is generated, culture carriers might face the problem of not being able to recover the costs invested in the production of that cultural good. In the long run, this could have a negative effect on the incentives to create cultural goods. ${ }^{16}$ As a result, this can imply an overall economic loss. Moreover, if other individuals or groups other than culture carriers (defined as reproducers of cultural goods) begin to reproduce the same cultural goods without permission and seize benefits from them (copying a cultural song and selling it), it reduces the direct part of the utility of the culture carriers even more. ${ }^{17}$ These factors play a role above all when, for instance, immaterial property rights are infringed.

In our analysis from the regulatory perspective, the utility of outsider consumers and reproducers also plays an important role and must be considered within the direct component of the cultural utility function. ${ }^{18}$ Thus, if the culture carriers' direct utility decreases but is in turn overcompensated by the utility increase of the outsiders, it can be overall economically reasonable to allow for outside consumption. In other words, if the social $\operatorname{costs}^{19}$ restricting the outside consumption of the particular cultural good are greater than the social benefits, the economic reasoning is the same as in the case of monopoly regulation: Even if the monopolist loses his revenues, it makes sense to restrict his actions.

Let us turn our focus to the crucial part of the cultural utility function: the indirect component. Indirect utility is constituted of different effects, which, in sum, provide identity for the culture carriers. ${ }^{20}$ These effects include intrinsic values such as option, existence, bequest, prestige and education values. These are so-called nonmarket, nonuser benefits. ${ }^{21}$ The utility drawn from identity defined in this way enters the cultural utility function of the culture carriers. Identity as part of the utility function was already discussed by Akerlof and Kranton ${ }^{22}$ in the labor market context and can also be applied to the cultural utility function. However, according to Throsby ${ }^{23}$ it is quite difficult to determine the value of identity in monetary terms because identity cannot be exchanged for other goods. This part of the cultural utility function is the most complicated one, as it consists of different effects. On the one hand, identity affects the consumption decisions of individuals and can therefore be seen as a consumption externality, similar to network externalities. ${ }^{24}$ Accordingly, it might simply mean the motivation to engage in and perform common practices or consume particular cultural goods. Moreover, on the other hand, some cultural goods could fundamentally affect the existential identity of a person, his dignity. Thus, destroying or misusing this kind of cultural good would imply a negative effect on the person's identity, thus causing a loss in utility. According to Harrison, ${ }^{25}$ 
identity-providing symbols (like cultural goods), which refer to all objects or customs used as signs or representatives of the social (cultural) identity, are validly authentic if maintained by the owners. ${ }^{26}$ The same actions by outsiders, however, are seen as imitations or as misappropriations of characteristics and qualities of the owner's group, which can be interpreted as a depreciation or devaluation of the identity. Consequently, the impact of outsiders, both on direct and indirect utility of the culture carriers, needs further investigation.

\section{CLASSIFICATION OF CULTURAL GOODS}

From an economic point of view, cultural goods can be classified according to the extent to which outsiders make use of them and in doing so affect the culture carriers' utility. Once the cultural utility functions are clearly stated, the question of protecting cultural goods can now be analyzed with the help of these as well as their relationships. Based on the described utility effects of cultural goods in section 3 , it is possible to divide them into different groups depending on the cultural outsiders' effect on the culture carriers' utility.

Thus, first with focus on direct utility, it can increase, decrease or remain unchanged as outsider consumers use cultural goods. Speaking of the indirect part of the cultural goods' utility-providing impact, the so-called identity-providing part, we scrutinize the effect of the cultural consumption by outsiders on indirect utility. According to that, cultural goods can be divided into three different types:

1. Cultural consumption by outsiders has a positive effect on the utility of culture carriers: The indirect utility of cultural goods rises with the number of other users. This type of cultural goods can be identified for example if the group "owning" this cultural good (culture carrier) is willing to disseminate it to other individuals, groups, or societies (to outsiders). For example, a language spoken by other groups produces network externalities; ${ }^{27}$ the adoption of a religion by another community ensures comparable values and norms, and the like. Christianity, which was and is disseminated actively by missionaries, is an example of such a cultural good from a Christian point of view. ${ }^{28}$

2. The utility of cultural goods could also be independent of usage by outsiders. These kinds of cultural goods are rarely found. For example, Buddhism as a religion or spiritual philosophy is very peaceful. According to the doctrine of Buddhists, it is important to find the middle path in themselves and escape from negative feelings. The aim is to attain nirvana, but this path must be reached alone. Therefore, the fact that this religion is used by other than insider consumers does not have any effect whatsoever on Buddhists' indirect or direct utility.

3. The utility of cultural goods can diminish as outsider consumers use them. For example, if sacred rituals are performed by outsiders, they may lose their meaning for the culture carriers. According to de Beus, ${ }^{29}$ who investigated the impact of national identity, it can even influence their feeling of belonging, dignity, and identity. The question of what kinds of cultural goods have this strong identity- or dignity-providing effect cannot be answered without analyzing particular cases. The secrecy of cultural goods can serve as an indication for this effect: Culture carriers trying to restrict the access of others (outsider consumers, or groups willing to produce the same cultural good) to their cultural good (and by no means aiming to sell this good themselves) could be seen as evidence in favor of protection. ${ }^{30}$ As "individuals are the best judges of their own welfare, ${ }^{131}$ the effort to keep a cultural good secret indicates that it must have a large influence on their identity. 
An example for such a kind of cultural good is the turtle as a religious symbol of Ganalbingu people. This was misappropriated by an outsider textile producer which negatively affected the identity of that group. ${ }^{32}$ Mike Tyson or Robbie Williams wearing a Maori tattoo ${ }^{33}$ (moko) exemplify other cases in which outsider consumption of a particular cultural good negatively affects the indirect utility of culture carriers since ta moko illustrates identity and serves particular meaning such as recognition of difference by the Maori people. ${ }^{34}$ Accordingly, outsider consumption or production in the new context change "the meaning and significance" of these goods.

If we further differentiate between the direct and indirect utility of culture carriers, which can be positively or negatively affected by outsider consumption, we arrive at the classification presented in figure 2 .

The matrix in figure 2 combines the effects of outsiders' consumption and reproduction on the direct and indirect utility of culture carriers. The effect of cultural consumption or production by outsiders on the direct utility of culture carriers is shown on the $x$-axis, while the effects on indirect utility are depicted on the $y$-axis.

In the first quadrant (I) there is no need for any regulation, as both direct and indirect utility of culture carriers are positively affected by cultural outsider consumption. Additional cultural production has the same effect, as it generates additional cultural consumption, which again is positive.

FIGURE 2. Utility effects on the culture carriers' utility caused by outsiders and the protection area for cultural goods (shaded).

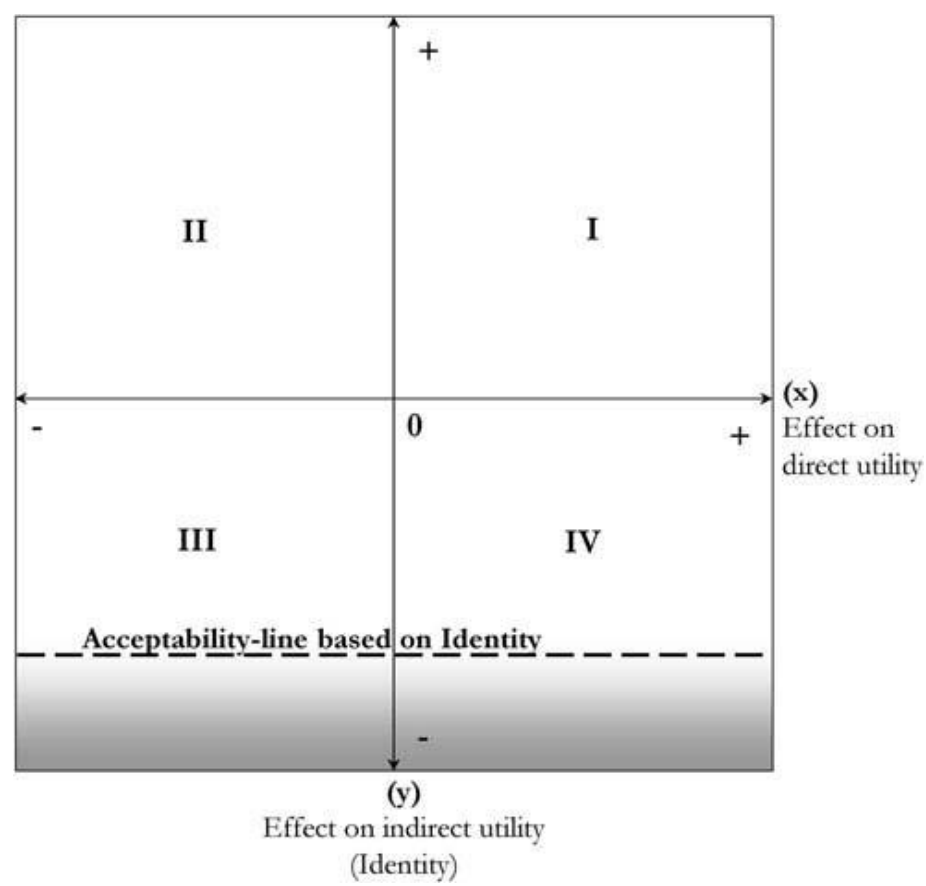

An example is language as a part of culture. The culture carriers of a certain language could be interested in its dissemination and usage, as it facilitates trade between cultures and offers a possibility of reducing the costs of engaging third parties. ${ }^{35} \mathrm{~A}$ common language is necessary for international/domestic communication and trade, ${ }^{36}$ and the importance of it grows with time, so the effects in the long run as well as in the short run are positive. 
In the second quadrant (II) the indirect utility is positive, while the direct utility of culture carriers is negatively affected by cultural outsider consumption. Therefore, the culture carriers' direct utility should be considered in comparison to the utility of outsider consumers and culture reproducers. Furthermore, the long-run welfare effects of consumption and additional production must be analyzed. In this part of the analysis, a detailed consideration of the culture carriers' direct utility, the outsider consumers' utility, and the culture reproducers' utility is necessary. If the only motivation of the culture carriers seeking protection of cultural goods is to maintain their monopolistic position regarding the production of cultural goods, it could be rational to allow other culture reproducers to enter the market and generate additional benefits for society. However, additional culture reproducers may increase the supply of cultural goods and achieve a sustained price reduction or may even destroy the good's cultural content, thus not implying any additional benefits for society in the long run. Or, in contrast, additional (re-)production of cultural goods by outsiders may act as a marketing tool to advertise and increase the value of the original cultural goods (made by culture carriers), thus creating or broadening the market for cultural products in the long run. ${ }^{37}$

Another possibility is that if the utility of outsider consumers exists only if culture carriers are the producers of a certain cultural good, then there is no need for regulation, as this feature of the utility function serves as an entry barrier for additional culture reproducers. However, the distinguishing character between an original or authentic (made by culture carriers) and a perfect copy (produced by an outsider) of a cultural good is questionable according to Mas-Colell. ${ }^{38} \mathrm{He}$ argues that a perfect description of the object is infeasible and, accordingly, that the unique characteristics of an original are hard to identify. Valuations of the goods are dependent on the intrinsic motivation of both culture carriers and outsiders, but he argues that the owners are not always interested in preventing the property from being copied because the spreading of copies can still raise the value of the original (as already mentioned here).

In this quadrant, existing legal tools can be useful in solving the problem. For example, the system of fair trade ensures that goods from a particular part of the world that were produced according to the legality of fair trade cannot be produced and sold by another person who is not involved. ${ }^{39}$ Moral rights in, for instance, Australia or the United Kingdom give opportunities to creators to protect their integrity right and their work's underlying knowledge and content from infringement. ${ }^{40}$ This means that reproduction and alteration of the work is only allowed under the supervision of the author, which arguably prevents misuse and misrepresentation.

The history of origin of the Quileute in America can provide an example for this quadrant. Due to Stephenie Meyer's vampire chronicles, this group of people has become very well-known and famous. ${ }^{41}$ The Twilight story, which is based on the creation saga of the Quileute, has generated enormous revenues from books, movies, and other products. ${ }^{42}$ The Quileute have not profited from these activities as yet, although the core of these products is based on their cultural property. The fame of the Quileute has encouraged other producers (reproducers) to begin to use the name Quileute as a symbol for other products such as jewelry or hoodies without the permission of the Quileute. The Quileute are ready to share parts of their culture with outsiders with the exception of burial grounds and religious ceremonies, according to their tribal law, which are "sacred and not to be entered." ${ }^{43}$ The situation, in which the Quileute wish to make their certain cultural goods publicly accessible and commercialize it to earn money, means that the influence of outsiders has no identity destroying effect. The interest of these people lies above all in benefiting from the profit earned 
through their culture. From an identity-economics point of view, additional preventive measures are not necessary at this point.

The third quadrant (III) represents the most complicated cases in the analysis. The consumption and production of cultural goods by outsiders have negative effect on both direct and indirect utility of culture carriers.

It is very important to distinguish among different effects on indirect utility, because not every attack on identity immediately equals an attack on the dignity of a person. In other words, not every kind of cultural consumption and reproduction by outsiders that has a negative impact on indirect utility is at the same time a violation of dignity. For this reason, we separate the effects on indirect utility into two parts, which are divided by the acceptability-line (see figure 2). This acceptability-line varies from nation to nation (or culture to culture) according to their respective constitutional norms and the accompanying administration of justice. This line is a flexible concept; the definition of the exact position and meaning of this line reflects existing norms in society and could vary in different societies. It is therefore subject to discussions and judgments of courts of justice in a particular country. In short, "dignity does not depend on personal favours and occasional balances of power, but on social openness guaranteed by the rule of law, vigilant public debate, the plurality of associations, and social rights. ${ }^{44}$

The self-determination of a cultural group's own identity in accordance with their tradition and customs was recognized in the Declaration on the Rights of Indigenous Peoples of the United Nations. ${ }^{45}$ Furthermore, the connection between the culture and the dignity of the culture carriers was considered. According to this declaration, these groups "have the right on the dignity and diversity of their cultures, traditions, histories and aspirations." ${ }^{46}$ Dignity is a person's fundamental right. Other fundamental rights such as privacy or religion are based on the concept of dignity. In the case when a cultural good is an inseparable component of a culture and the fundamental identity of the culture carriers is thereby influenced, the protection-worthiness of that cultural good would be corroborated. The position of the line reflecting these identity-and dignity-essential characteristics of the cultural goods is defined by an acceptance of those involved. Therefore, this line will take other positions within different cultures and cultural groups. This approach is supported by the following UN directive concerning Human Rights: "recognizing, respecting, valuing their customs, rules is essential to their identity, dignity." ${ }^{\prime 77}$ This effect becomes disastrous below the acceptability-line on the basis of identity in figure 2 .

The gray shaded area below the acceptability-line contains those cultural goods that need protection on the basis of identity. Here, the effect of outsiders on the identity and the dignity of the culture carriers is so strong that the losses of the culture carriers cannot be tolerated any more. Therefore, protection is justified, as in these cases the dignity of a person is endangered.

Let us exemplify this by the original Hopi or Navajo tradition of sweat lodges, in which a cleansing of body and spirit takes place. According to the traditional tribal law, it was forbidden to charge any fees for this holy and intimate ceremony. ${ }^{48}$ The mere fact of outsiders consuming and even reproducing this sacral ritual resulted in an outcry by the indigenous people. Because it concerns a ritual, the Navajos are offended ${ }^{49}$ and suffer a loss in their identity if an outsider carries out the same ritual as a measure of well-being. From the point of view of indigenous leaders, "most hallowed ideas and rituals" constitute goods "which cannot diffuse to others without suffering harm." ${ }^{50}$ Therefore, it seems obvious that cultural goods below the acceptability-line in this quadrant are in need of protection. 
In cases above the acceptability-line, where the dignity, that is, the fundamental identity of a person or group, is not affected, an economic analysis can help to find an optimal solution. Therefore, there are three groups relevant to economic consideration ${ }^{51}$-culture carriers, culture reproducers, and outsider consumers. However, in connection with the direct, economic benefit, the United Nations stress that the cultural groups should be the beneficiaries of a commercial use of their cultural goods. ${ }^{52}$

The problem could consist in a positive correlation of the outsider consumers' utility with the importance of the cultural goods for the culture carriers, so that cultural goods with potential identity-destroying effects could be especially valuable to outsider consumers. ${ }^{53}$ Therefore, it is crucial to distinguish these different aspects of the cultural utility function of culture carriers. The analysis of our second quadrant applies in cases where there is no indication of cultural consumption or additional cultural reproduction by outsiders with an identity-destroying effect (cases above the acceptability-line). As an example, take the noble stratum of the Toraja society, marapuan, who are identified by owning a tongkonan, a traditional Toraja house. The tongkonan is an impressive and complex structure; the creation of such a building requires skill and vast resources. ${ }^{54}$ The noble marapuan enjoy the privileges of decorating their houses in a special way (with paintings and carvings) and pursuing funeral rituals. The size of the tongkonan and the quality of its decorations, carvings and paintings displays rank, honor, and social prestige. ${ }^{55}$ Large-scale emigration in the 1970 s and the resultant remittances sent home changed the social landscape-Toraja families of low status were now able to build large tongkonans and organize expensive, imposing funeral ceremonies (thus acting as additional culture reproducers). These in turn attracted a growing number of foreign tourists (as outsider consumer). The noble marapuan are critical of this development and would like to protect their traditional social position, ${ }^{56}$ which is closely related to the rights to build tongkonans and organize imposing funeral rituals. Nevertheless, previous research does not reveal the extent to which the nobility seeks protection of its privileges. ${ }^{57}$ The identity-providing effect is in fact clear, but seems to be rising with the number of outsider consumers. Thus, there is no clear reason to believe that the fundamental part of the group's identity or dignity is affected. Therefore, the overall economic effect for the whole region is higher, if additional culture reproducers enter the market and attract more tourists. Its distributional consequences for society and the reinvigorating effect on tradition are additional positive effects of no protection.

In the fourth quadrant (IV) are cases in which outsiders cause positive effects on the direct part of utility and at the same time induce losses in indirect utility. Above the acceptability-line as in the third quadrant are cases for which the analysis of the second quadrant should be applied. Below the line an example could be the case of "selling one's soul to the devil," identity-destroying effects still has some positive effects with respect to payment. In the story of Timm Thaler or the Sold Laughter ${ }^{59}$ the youthful protagonist sells his laughter to an impersonation of the devil and consequentially wins every bet, but soon discovers the value of his laughter and wants to cancel the transaction. At least as long as transactions are completely voluntary and do not exploit the situation (the devil entices a youngster to sell his laughter), such cases in the fourth quadrant might remain an exception because cultural carriers will weigh the positive direct effects against the negative identity effects and can decide for themselves. Further regulation is required only if representation within groups is problematic. Apart from that, another example for a good containing a strong identity or dignity character attached to its culture carriers is to be considered. For example, the peak of the Kailas Mountain has not been climbed because of its sacredness. ${ }^{60}$ Nevertheless, 
outsider tourisms would generate revenues for both the culture carriers and the whole region. On the other hand, climbers or other persons on the top would destroy the soul and dignity of the culture carriers. In such a scenario a protection-worthy good exists and requires additional protection measures justified by the negative impacts on the identity and dignity of the culture carriers.

This classification based on direct and indirect utility effects shows that only cultural goods of the third and fourth quadrants need protection. Within these quadrants we have distinguished between cultural goods that influence the fundamental identity and thereby dignity of a person or a group, consequently requiring protection, and cultural goods for which a cost-benefit analysis can help to find an optimal solution (regarding whether consumption or production for outsiders can be allowed). In these latter cases additional regulation may be necessary to adequately represent the interests of the groups involved.

\section{PROTECTION OF CULTURAL GOODS}

Within the debate around the protection of cultural goods, the most important arguments are those that analyze, primarily, trade with cultural goods and the overall economic effects, not the protection worthiness of the cultural goods per se. However, our approach focuses on the characteristic of cultural goods to also provide indirect utility based on identity and dignity. Consequently, we ascertain a protective need first of all only for those cultural goods that are essential to identity and dignity. We come to this result because we recognize a connection between the dignity of the person and certain cultural goods. Indeed, by no means do all cultural goods have a direct influence on the identity and with it the dignity of individuals. Therefore, only few goods are located below the acceptability-line of figure 2 for which additional preventive measures are to be introduced.

Since only a minority of cultural goods requires protection, those affecting the fundamental identity and dignity of persons and groups, some questions arise:

1) How can we determine whether a cultural good possesses a fundamental identity-or dignityproviding effect, which would justify protection by law?

As far as different cultural goods belonging to different societies or groups are concerned, no general rule can be applied. The decision of whether a cultural good has this characteristic or not can only be made in a single case analysis by a court of law, in which the interests of culture carriers should be combined with opinions of independent experts and other interested groups.

The definition of what cultural goods are identity-critical can be determined by the groups themselves. According to the United Nations, cultural groups have the right to take part in the decision-making processes concerning their rights. ${ }^{61}$ Basically, this entails that culture carriers or their representatives must become the most important actors in the process of assessing and recognizing these cultural goods. Culture carriers should have "a legitimate interest in exercising a duty of care or 'stewardship' over resources"62 that represents their collective cultural identity or "peoplehood." The sacred goods and spiritual elements, which presumably form the majority of the protection-worthy goods below the acceptability-line, should stand in the center of these investigations. Examining particular cases for such protection must take central stage within the decision process. To take the interest of other parties (outsiders) into account and not to threaten the public domain unnecessarily by granting additional protection for all cultural goods, the secrecy and the connected strong values of these goods to the cultural community must be clearly identifiable. As Carpenter et al. ${ }^{63}$ suggest, in 
some cases tribal customary law clearly identifies "certain resources as critical to the community and thereby necessitating human care." Of course, this is just one possibility for obtaining evidence of the need for protection of these particular goods.

Summing up, as stated by Brown, ${ }^{64}$ there is a need to separate the claims regarding economic justice and those regarding respectful treatment of cultural elements. Therefore, in cases where the objections of culture carriers against outsider consumption and reproduction of particular goods are not of an economic nature, this could serve as evidence for further investigation of protectionworthiness.

2) If a cultural good does not have any fundamental identity- or dignity-providing effect, how should the market be regulated?

Cultural goods show quite a few similarities to intellectual property, mostly because of their immaterial character. However, protecting cultural goods with the same instruments as intellectual property rights cannot be a suitable mechanism, as criteria of novelty (patents) or individual authorship (copyright) are not met. Some cultural goods like paintings, sculptures, buildings or monuments are safeguarded by the instrument of the UNESCO World Heritage Site. However, while this does not always imply optimal protection, it rather offers commercialization opportunities. ${ }^{65}$ In cases of the first and second quadrants, and above the acceptability-line of the third and fourth quadrants for immaterial cultural goods, where the privacy of the culture carriers is not at stake, the UNESCO Convention for the Safeguarding of Intangible Cultural Heritage ${ }^{66}$ provides an adequate instrument. On the international level, it aims "at ensuring the viability of the intangible cultural heritage" and "to ensure recognition of, respect for, and enhancement of the intangible cultural heritage ... of the communities groups or individuals concerned." However, these legislations are not sufficient for cases located below the acceptability-line.

3) What role does the international community play within the regulation process for cultural goods under the acceptability-line?

The international community should feel responsible for creating a legal environment, in which particular cases can be scrutinized and enforced. This in turn would facilitate communicating the importance and the role of culture and cultural goods in the respective societies.

Additionally, the market for cultural goods is not limited to a specific country. The actors such as consumers and producers can be situated abroad, thus making multilateral and bilateral international consultations necessary. Brown ${ }^{67}$ argues that a global market also requires a global controlling regime going beyond mere bilateral solutions.

Another challenge consists in the fact that not all societies or indigenous groups are recognized by their own country. The international level could provide a venue for particular cases which require mediation. Particular societies should take the initiative (as a private initiative) in the case of disagreement with their own government. Otherwise, the state level is entitled to solve the problem. The Indigenous Caucus of the WIPO provides a stage with which international attention can be attracted, in which NGOs (nongovernmental organizations) and indigenous groups from the whole world point to the problem of insufficient protection of cultural goods.

4) What kind of rights can be granted for culture carriers' cultural goods that are worthy of protection? 
Speaking only about cultural goods under the acceptability-line, negative effects on identity and dignity need to be avoided. For this, culture carriers are required to be able to control and supervise the consumption of their cultural goods by outsiders and restrict access to their holy or spiritual cultural goods, which are strongly connected to their identity or dignity. Because of the special nature of these cultural goods, general property rights are not a sufficient tool to prevent the commercialization of cultural goods. However, property rights are required to exclude others from consuming and producing these cultural goods. Thus, to some extent, searching for such "defensive" legal instruments as sui generis rights seems to support these goals. The international regime has already turned its focus on these special property rights granting moral rights to culture carriers while recognizing group ownership and ensuring protection lasting in perpetuity. ${ }^{68}$ Under the auspices of WIPO, the elaboration of a draft proposal for sui generis rights for the protection of traditional cultural expressions (TCEs) ${ }^{69}$ (defined as of material or immaterial nature, or a combination of these) is currently on the agenda. Article 3 (alternative 3) of this preliminary version addresses to some extent the mentioned cultural goods proposing a provision of "adequate and effective [legal or practical] measures ... to prevent the [unauthorized fixation, disclosure, use or other exploitation] disclosure of secret traditional cultural expressions," while as overall objectives recognizing that these "cultural communities consider their cultural heritage to have intrinsic value, including social, cultural, spiritual ... values" and promoting "respect ... for the dignity, cultural integrity" of these traditional cultures and communities. ${ }^{70}$ Rights to and authority over cultural goods providing identity and dignity (such as secret and sacred cultural goods) is a necessary requirement to keep outsiders out, which thus avoids a consumption and commercialization of these cultural goods by the latter. Granting perpetual rights, as sui generis model laws do, however, is not a preferable solution given the dynamical nature of culture. It requires that people will always ascribe sacredness to certain cultural goods or declare cultural goods as providing identity and dignity. However, culture carriers and their identity are dynamic as well. Some cultural goods lose their meaning to culture carriers over time and the group of culture carriers who value a particular culture good need not be stable. These time limits and community limits (the changing character of groups valuing such goods) are important and should be incorporated in the legislation to avoid the additional social costs caused by unnecessary curtailing of the public domain.

\section{CONCLUSION}

The international debate on the protection of cultural goods is in need of an answer to the question of what exactly is required to provide specific protection in addition to existing property rights. The international debate focuses on so-called sui generis property rights. ${ }^{71}$ However, in this article we suggest an a priori distinction between direct and indirect effects of cultural goods. Direct effects can be quantified as the monetary value arising from marketing a cultural good. Even though in many cases it is not easy to determine such values, there is a broad literature on values of cultural goods. ${ }^{72}$ Indirect effects occur as negative or positive effects on identity. Indirect effects also include option values, prestige values, and so forth, ${ }^{73}$ which are much more difficult to express in monetary terms.

If only direct effects exist, positive and negative effects should be weighed against each other. Protection should be implemented if net benefits outweigh net costs and if this net gain is higher than in a situation with no protection of cultural goods including the consideration of the utility of all stakeholders. Such an evaluation of net benefits must take place on a case by case basis and cannot be solved by introducing international standards. 
If indirect effects do exist, the priority is to check their impact on identity. If identity is affected, it is crucial to determine whether the impacts on identity go as far as seriously impairing the personal fundamental identity or dignity of culture carriers. If and only if this is the case, international norms for cultural protection should be implemented in the form of sui generis rights. We suggest that a serious impact on dignity can be assumed if the culture carriers show, for example, serious efforts to keep a certain cultural good a secret. The respective acceptability-line must be established by the particular states and groups based on cultural borders and local specifics.

All in all, we conclude that in very limited cases, cultural goods may require additional protection in the form of sui generis rights. However, the introduction of sui generis cultural property rights on an international level should be restricted only to cases where the dignity of culture carriers is seriously endangered. This has the advantage of not threatening the public domain and thus upholding the valuable dissemination of cultural knowledge and innovation. Beyond this category, however, there is a wide field in which regulatory interventions can facilitate the arrival of market actors at sensible decisions.

ACKNOWLEDGMENTS. This research is part of the Interdisciplinary Research Group on Cultural Property funded by Deutsche Forschungsgemeinschaft (DFG). We gratefully acknowledge the constructive comments by two anonymous referees, the editor Alexander Bauer, participants at the 2010 ACEl conference in Copenhagen, the Società conference at the University of Vienna, and the International Symposium on Cultural Property in Göttingen. We are also grateful for many helpful discussions and comments by Regina Bendix, Ejan Mackaay, Dorothy Noyes, Rosemary J. Coombe, and the Interdisciplinary Cultural Property Research Group.

\section{ENDNOTES}

1. UNESCO Convention (2005), Article 1(a) and (g).

2. See the resent achievements on the yoga dispute at WIPO: WIPO, "WIPO and India Partner or WIPO, "About the Traditional Knowledge Digital Library."

3. Akerlof and Kranton, "Economics and Identity."

4. The utility function is described as $U j=U j(a j, a-j, l j)$.

5. Akerlof and Kranton, "Economics and Identity," 721.

6. Akerlof and Kranton, "Economics and Identity," 725.

7. The difference between social category and social group is explained in Davis, Theory of the Individual in Economics. There exist internalist and externalist types of definition of the individual (p. 17). "Defining individuals as socially embedded explains them in terms of their external relations to one another": the difference between social categories and social groups is of importance to signal this embeddedness.

8. Francois and van Ypersele, "On the Protection of Cultural Goods."

9. See also Francois and van Ypersele, "On the Protection of Cultural Goods."

10. Janeba, "International Trade and Cultural Identity."

11. UNESCO Convention (2005), 1.

12. Cheng, "Cultural Goods Creation," 264.

13. UNESCO, Universal Declaration (2001), Article 8.

14. This article does not address the question of who belongs to such a cultural group, it rather assumes that a group is homogeneous and values a particular cultural good homogeneously. Deviating behaviour and its impacts within the group is not part of this analysis.

15. Frey, "What Values Should Count in the Arts?" 265.

16. See Koppel, “Patente-Unverzichtbarer Schutz Geistigen Eigentums”; Liebig, "Geistige Eigentumsrechte aus der Perspektive der Entwicklungsländer." 
17. To judge whether a particular cultural good (such as a story or a song) belongs to one particular culture and whether this culture (cultural group) is the only beneficiary to commercialize it, is not a subject of this article. See discussion about this topic in Young, Cultural Appropriation and the Arts; Brown, Who Owns Native Culture?

18. Further classification of the utility of outsiders into direct and indirect utility is not necessary since in the case of outsiders the acceptance of identity in regard with a particular cultural good emerging from insiders is not of relevance.

19. In this case, social costs should be understood as loss of utility by exclusion from consumption and the follow-up costs such as limitation of public domain, and thus the restriction of creativity and innovation. See Lechner et al., "The Allocation of Property Rights."

20. As the individuals of the particular cultural group value a specific cultural good similarly, the culture carriers share the same cultural identity.

21. Frey and Meier, "The Economics of Museums," 1022.

22. Akerlof and Kranton, "Economics and Identity"; Akerlof and Kranton, "Identity and the Economics of Organizations."

23. Throsby, "Determining the Value of Cultural Goods."

24. See Janeba, "International Trade and Cultural Identity."

25. Harrison, "Identity as a Scarce Resource." 240.

26. Also, we are aware of the fact that the conceptual definitions serve as a tool for operationalization. However, the ethnographically documentable social environment is provided with far less clear border drawings.

27. See Janeba, "International Trade and Cultural Identity."

28. At this point, we neglect the negative effects, because as a rule the "new Christians" earlier belonged to another religion, with which they then caused a suitable utility loss.

29. de Beus, "The Value of National Identity."

30. Harrison, "Identity as a Scarce Resource"; Brown, "Heritage Trouble."

31. Throsby, "Determining the Value of Cultural Goods," 276.

32. See Janke, Minding Culture: Case Studies, case study 3.

33. See Meijl, "Maori Intellectual Property Rights"; or further discussion "Tyson's Moko Draws Fire From Maori," New Zealand Herald. (http://www.nzherald.co.nz/nz/news/article.cfm?c_id=1\&objectid=10727836> (25 May 2011) accessed on 2 August 2011.

34. See Pritchard, Culture, Knowledge, Property, 51-84.

35. Lazear, "Culture and Language."

36. Ridler, "Cultural Identity and Public Policy."

37. See the investigation of this issue in Young, Cultural Appropriation and the Arts; Carpenter et al., "Clarifying Cultural Property."

38. Mas-Colell, "Should Cultural Goods Be Treated Differently?"

39. WFTO, IFAT Standards (2007).

40. Janke, Minding Culture: Case Studies, $20 \mathrm{ff}$.

41. Riley, A. R., "Sucking the Quileute Dry," New York Times, February 82010.

42. See Carpenter et al., "Clarifying Cultural Property."

43. See Riley, "Sucking the Quileute Dry."

44. de Beus, "The Value of National Identity," 177.

45. United Nations Declaration (2007), Article 33.

46. United Nations Declaration (2007), Article 15.

47. United Nations Report (2000), Principle 4.

48. Rehfeld, "Tod in der Heiler-Welt," Financial Times Deutschland, 22 October 2009.

49. See Brown, Who Owns Native Culture? 6.

50. See Brown, Who Owns Native Culture?

51. Further differentiation of outsider consumers (such as on the national or international level) is also possible and adds more parameters to the maximization task.

52. United Nations Report (2000).

53. Harrison, "Identity as a Scarce Resource"

54. Scarduelli, "Dynamics of Cultural Change," 390ff.

55. Scarduelli, "Dynamics of Cultural Change," 392.

56. Adams, "Constructing and Contesting Chiefly Authority." 
57. Oral communication from field studies in Indonesia by Beate Engelbrecht (2009).

58. Ejan Mackaay pointed this out at a conference held near Göttingen, Germany, on 12-15 Nov.2009.

59. Krüss, Timm Thaler oder Das Verkaufte Lachen.

60. For some ideas about the Kailas Mountain, see Hamsa, The Holy Mountain.

61. United Nations Declaration (2007), Articles 2 and 18.

62. See in Carpenter et al., "Clarifying Cultural Property," 582, referring to Carpenter et al., "In Defense of Property."

63. See Carpenter et al., "Clarifying Cultural Property," 587.

64. See Brown, Who Owns Native Culture? 234.

65. See discussions in Berger, Erb.Gut?

66. UNESCO Convention (2003), Art. 1(a), (b), and 14(a).

67. Brown, "Heritage Trouble."

68. See discussion in Bizer et al., "Sui Generis Rights."

69. WIPO, The Protection of Traditional Cultural Expressions: Draft Articles (2011).

70. See WIPO (2011), The Protection of Traditional Cultural Expressions: Draft Articles, Objectives

(i) and (ii).

71. Brown, "Heritage Trouble."

72. See, for instance, Throsby, "Determining the Value of Cultural Goods"; Frey, "What Values Should Count in the Arts?"

73. See Frey and Meier, "The Economics of Museums." 


\section{BIBLIOGRAPHY}

Adams, Kathleen M. "Constructing and Contesting Chiefly Authority in Contemporary Tana Toraja, Indonesia." In Chiefs Today, edited by Geoffrey Miles White and Lamont Lindstrom, 264-75. Stanford, CA: Stanford University Press, 1997.

Akerlof, George A., and Rachel E. Kranton. "Economics and Identity." The Quarterly Journal of Economics 115, no. 3 (2000): 715-53.

- - . "Identity and the Economics of Organizations." Journal of Economic Perspectives 19, no. 1 (2005): 9-32.

Berger, Karl C. Erb.Gut? Kulturelles Erbe in Wissenschaft Und Gesellschaft; Referate Der 25. Österreichischen Volkskundetagung Vom 14-17.11.2007 in Innsbruck. Edited by Karl C. Berger, Margot Schindler and Ingo Schneider. Vol. 23, Buchreihe Der Österreichischen Zeitschrift Für Volkskunde; N.S., 23. Wien: Selbstverl. des Vereins für Volkskunde, 2009.

Bizer, Kilian, Matthias Lankau, Gerald Spindler, and Philipp Zimbehl. "Sui Generis Rights for the Protection of Traditional Cultural Expressions Policy Implications." jipitec 2 (2011).

Brown, Michael F. Who Owns Native Culture? Harvard University Press, 2003.

---. "Heritage Trouble: Recent Work on the Protection of Intangible Cultural Property." International Journal of Cultural Property 12, no. 01 (2005): 40-61.

Carpenter, Kristen A., Sonia K. Katyal, and Angela R. Riley. "In Defense of Property." The Yale Law Journal 118, no. 6 (2009): 1022-125.

-_- "Clarifying Cultural Property." International Journal of Cultural Property 17, (2010): 581-98.

Cheng, Sao-Wen. "Cultural Goods Creation, Cultural Capital Formation, Provision of Cultural Services and Cultural Atmosphere accumulation." Journal of Cultural Economics 30, (2006): 263-86.

Davis, John B. The Theory of the Individual in Economics: Identity and Value. London: Routledge, 2003.

De Beus, Jos. "The Value of National Identity." In The Value of Culture, edited by Arjo Klamer, 16686. Amsterdam: Amsterdam University Press, 1996.

Francois, Patrick, and Tanguy van Ypersele. "On the Protection of Cultural Goods." Journal of International Economics 56, no. 2 (2002): 359-69.

Frey, Bruno S. "What Values Should Count in the Arts? The Tension Between Economic Effects and Cultural Value." In Beyond Price, edited by Michael Hutter and David Throsby, 261-69. New York: Cambridge University Press, 2008.

Frey, Bruno S., and Stephan Meier. "The Economics of Museums." In Handbook of the Economics of Art and Culture, edited by Victor A. Ginsburgh and David Throsby, 1017-47. Amsterdam: Elsevier, 2006.

Hamsa, Bhagwān Shri. The Holy Mountain: Being the Story of a Pilgrimage to Lake Mānas and of Initiation on Mount Kailās in Tibet. With an Introduction by W. B. Yeats. Delhi: Pilgrims Book, 1997.

Harrison, Simon. "Identity as a Scarce Resource." Social Anthropology 7, no. 3 (1999): 239-51.

Janke, T. Minding Culture: Case Studies on Intellectual Property and Traditional Cultural Expressions: World Intellectual Property Organization, 2003.

Koppel, Oliver. "Patente-Unverzichtbarer Schutz Geistigen Eigentums." Wirtschaftsdienst 88, no. 12 (2008): $775-80$.

Krüss, James. Timm Thaler Oder Das Verkaufte Lachen [Timm Thaler or the Sold Laughter]. Hamburg: Oetinger, 1962. 
Lazear, Edward P. “Culture and Language.” Journal of Political Economy 107, no. 6 (1999): S95.

Lechner, Sebastian, Zulia Gubaydullina, and Kilian Bizer. "The Allocation of Property Rights to Intangible Cultural Assets.” In Discussion Paper Series, 1-16. Göttingen: Universität Göttingen, 2008.

Liebig, Klaus. "Geistige Eigentumsrechte Aus Der Perspektive Der Entwicklungsländer: Ein Zwiespältiges Instrument." Wirtschaftsdienst 88, no. 12 (2008): 780-83.

Mas-Colell, Andreu. "Should Cultural Goods Be Treated Differently?” Journal of Cultural Economics 23, (1999): 87-93.

Meijl, Toon von. "Maori Intellectual Property Rights and the Formation of Ethnic Boundaries." International Journal of Cultural Property 16, (2009): 341-55.

Pritchard, Stephen. Culture, Knowledge, Property. North Melbourne, Victoria: Australian Scholarly Publishing, 2008.

Ridler, Neil B. "Cultural Identity and Public Policy: An Economic Analysis." Journal of Cultural Economics 10, no. 2 (1986): 45-56.

Scarduelli, Pietro. “Dynamics of Cultural Change among the Toraja of Sulawesi." Anthropos (2005): 389-400.

Throsby, David. "Determining the Value of Cultural Goods: How Much (or How Little) Does Contingent valuation Tell Us?" Journal of Cultural Economics 27, (2003): 275-85.

UNESCO. Universal Declaration on Cultural Diversity. Paris: UNESCO, 2001.

- - C Convention for the Safeguarding of the Intangible Cultural Heritage. Paris: UNESCO, 2003.

- - Convention on the Protection and Promotion of the Diversity of Cultural Expressions. Paris: UNESCO, 2005.

United Nations. Commission on Human Rights, Human Rights of Indigenous Peoples, Report of the Seminar on the Draft Principles and Guidelines for the Protection of the Heritage of Indigenous People. Geneva: UN, 2007.

- - - United Nations Declaration on the Rights of Indigenous Peoples. Resolution adopted by the General Assembly 61/295. New York: UN, 2007.

World Fair Trade Organization. IFAT Standards for Fair Trade Organizations. Belgium: World Fair Trade Organization, 2007.

- - - "WIPO and India Partner to Protect Traditional Knowledge from Misappropriation.

"Geneva/ New Delhi, 2011. http://www.wipo.int//pressroom/en/

articles/2011/article_0008.html> accessed 18 July 2011.

World Intellectual Property Organization. "About the Traditional Knowledge Digital Library (Information Courtesy of the Council of Scientific and Industrial Research)." http://www.wipo.int/meetings/en/2011/wipo_tkdl_del_11/about_tkdl.html> accessed 18 July 2011.

- - - Intergovernmental Committee on Intellectual Property and Genetic Resources, Traditional Knowledge and Folklore. The Protection of Traditional Cultural Expressions: Draft Articles. Document prepared by the Secretariat. Geneva, 2011.

Young, James O. Cultural Appropriation and the Arts. Wiley-Blackwell, 2010. 


\section{ChAPTER III}

\section{Reform Proposals on the Geographical Indications of the EURopean Union for the PROTECTION OF TRADITIONAL KNOWLEDGE}

Marianna Bicskei, Kilian Bizer, Katia Laura Sidali, Achim Spiller 


\section{THE “REGULATORY CHOICE PROBLEM”-INTRODUCTION}

Geographical indications (GIs) are instruments that provide consumers information about special qualities of a product that are not identifiable either before or after a product's consumption. Thus, they constitute a special kind of credence good. ${ }^{1}$ As consumers cannot determine the real origin and the specific traditional manufacture of a product, producers have to credibly convey information on the product's attributes in additional ways. Gls are meant to resolve this situation of information asymmetry by protecting consumers from being misled and by reducing the consumer's costs of obtaining information similarly to trademarks, ${ }^{2}$ thus supporting a well-informed decision. Gls therefore generate additional value for consumers and facilitate price premiums for producers. The extent to which producers can obtain the price premium depends on the consumers' willingness to pay. This is determined by the market value of the products, which is again influenced by the information-providing effect of Gls. In addition, Gls can offer a high level of protection against imitation, thus maintaining producers' income which benefits rural regions as it counteracts rural depopulation by providing jobs. ${ }^{3}$

Current research on GIs is based on Regulation 510/2006 on the Protection of Geographical Indications and Designation of Origin for Agricultural Products and Foodstuffs. ${ }^{4}$ That Regulation has replaced its similarly titled predecessor Regulation 2081/92 $2^{5}$ which was not conforming to the international trade rules of the WTO. Currently, a further amendment is being discussed in the European Union, ${ }^{6}$ which is also dealt with in this article.

By implementing Gls beyond the original provision of information on a product's quality, reputation and traditional production method, Regulation 510/2006 enables producers to differentiate their products from others in many ways. ${ }^{7}$ Nevertheless, it comes as a surprise that neither the original 1992 Regulation nor the currently effective Regulation address the protection of traditional knowledge, although many international fora discuss Gls in this context. ${ }^{8}$ To some extent the Regulation Proposal of 2010 compensates for this by aiming to preserve the quality and diversity of traditional products as "living cultural and gastronomic heritage". ${ }^{9}$ Thus, Gls are seen as an instrument enabling commodification, but by no means forcing it.

\footnotetext{
${ }^{1}$ For the classification of goods into search, experience, and credence goods based on information asymmetry, see Phillip Nelson, "Information and Consumer Behavior" (1970) 78 (March-April) Journal of Political Economy 311; Michael R. Darby and Edi Karni, "Free Competition and the Optimal Amount of Fraud" (1973) 16(1) Journal of Law and Economics 67.

${ }^{2}$ For the economic function of trademarks, see William M. Landes and Richard A. Posner, The Economic Structure of Intellectual Property Law (Cambridge, Mass: Harvard University Press, 2003), Ch.7.

3 Roland Herrmann, Thilo Marauhn and Ramona Teuber, "Der Schutz geographischer Herkunftsangaben: Herausforderungen für agrarökonomische, rechtswissenschaftliche und interdisziplinäre Forschung" (2008) 57(7) Agrarwirtschaft 321

${ }^{4}$ Council Regulation 510/2006 of March 20, 2006 on the protection of geographical indications and designations of origin for agricultural products and foodstuffs (Regulation 510/2006) [2006] OJ L93/12.

${ }^{5}$ Council Regulation 2081/92 of July 14, 1992 on the protection of geographical indications and designations of origin for agricultural products and foodstuffs [1992] OJ L208/1.

${ }^{6}$ European Commission, "Final Proposal for a Regulation of the European Parliament and of the Council on agricultural product quality schemes" (Regulation Proposal), December 10, 2010, COM(2010)733.

7 Dwijen Rangnekar, "The Socio-economics of Geographical Indications: A Review of Empirical Evidence from Europe" (2004) UNCTAD-ICTSD Project on IPRs and Sustainable Development, Issue Paper No.8, available at http://ictsd.net/downloads/2008/07/a.pdf [Accessed March 25, 2012].

${ }^{8}$ As part of the WTO's Review of Gls under art.24, members "have highlighted the relevance of human factors to matters such as quality, traditional methods of production, vinicultural practices and methods of production, preparation and cultivation". See World Trade Organization, "Review under Article 24.2 of the application of the provisions of the section of the TRIPS Agreement on geographical indications", November 24, 2003, IP/C/W/253/Rev.1, p.44. See also World Trade Organization, "Issues related to the extension of the protection of geographical indications provided for in Article 23 of the TRIPS agreement to products other than wines and spirits", May 18, 2005, TN/C/W/25, pp.13 and 18, directly raising the issue of traditional knowledge.

${ }^{9}$ See Regulation Proposal, p.13, para. (1).
} 
While a GI does not save products from having to prevail on the market, it makes it easier, as reliable information on origin, production and quality generally facilitates a higher price. Specific preferences on behalf of consumers for authentic, traditionally manufactured products are documented in the Regulation Proposal ${ }^{10}$ and also in the empirical literature. ${ }^{11}$ Precisely for this reason, GI goals should also focus more on the traditional knowledge. Gls support the sustainability of traditional knowledge or cultural heritage, but they rather indirectly encourage valuing such knowledge instead of directly protecting it. They achieve this by identifying the content or the production method of products in the product specification. Gls safeguard such products by protecting them from free riding on the product's reputation, thus maintaining their existence. But the definition and the protection of food-cultural particularities does not imply a preservation strategy freezing methods of production and thus local knowledge similar to a museum. Instead they rely on the market to determine which goods prevail. Therefore, a well-functioning market is a basic requirement to successfully use the $\mathrm{Gl}$ instrument. ${ }^{12}$

Unlike in other contexts of cultural property, Gls do not aim to directly protect particular actors and groups of actors such as indigenous groups. They rather provide protection rights for a certain region, thus also allowing external actors to benefit from protection if they move to the area and conform to the code of practice. ${ }^{13}$ Moreover, not only small scale producers are able to apply for Gls, but industrial producers are also able to do so. In practice, this occurs frequently-for example in the case of the largest French dairy firm Lactalis, ${ }^{14}$ the Swiss Emmi AG and the Swiss sausage company Bell AG. All of these leading international actors aim to enrich their products' portfolio with attractive Gls. As a result, the regions benefit in terms of employment. At the same time, cultural idiosyncrasies are preserved if traditional production knowledge and regional pre-products lead to particular specialties for the end consumer.

In summary, Gls provide a different protection potential than other "sui generis" rights that are based on copyright law. ${ }^{15}$ While the former favour actors generally in a specific region when manufacturing certain products, the latter protect the rights of specific actors identified as the carriers of cultural practices. ${ }^{16}$

Precisely the fact that GIs are not ascribed to specific actors provides further potential to maintain and protect knowledge and the associated products that are already in the public domain and whose actual creators are not identifiable. ${ }^{17}$ Nonetheless, Gls offer considerable protection potential for cultural property, as they facilitate a commodification of entirely different products than the "sui generis" rights derived from copyright law. In this context, they complement the instruments

\footnotetext{
${ }^{10}$ See Regulation Proposal, p.2, art.1.1 (Grounds for and Objectives of the Proposal).

${ }^{11}$ See e.g. Sean Beer, "Authenticity and Food Experience-Commercial and Academic Perspectives" (2008) 19 Journal of Foodservice 153; Stephen Brown, Robert V. Kozinets and John F. Sherry Jr, "Teaching Old Brands New Tricks: Retro Branding and the Revival of Brand Meaning" (2003) 67(July) The Journal of Marketing 19.

12 David R. Downes, "How Intellectual Property Could Be a Tool to Protect Traditional Knowledge" (2000) 25 Columbia Journal of Environmental Law 253; Shivani Singhal, "Geographical Indications and Traditional Knowledge" (2008) 3(11) Journal of Intellectual Property Law \& Practice 732

${ }^{13}$ C. Bramley and J.F. Kirsten, "Exploring the Economic Rationale for Protecting Geographical Indicators in Agriculture" (2007) 46(1) Agrekon 69, available at http://ageconsearch.umn.edu/bitstream/10128/1/ 46010069.pdf [Accessed March 25, 2012].

${ }^{14}$ See Alexander Wirsig, Adriano Profeta, Anna Häring and Roman Lenz, "Indigenous Species, Traditional and Local Knowledge and Intellectual Property Rights" (2010) 9th European IFSA Symposium, Vienna, p.1724.

${ }^{15}$ E.g. Tunis Model Law on Copyright for Developing Countries 1976 (UNESCO); Model Provisions for National Laws on the Protection of Expressions of Folklore Against Illicit Exploitation and Other Prejudicial Actions 1985 (UNESCO and WIPO); Intergovernmental Committee on Intellectual Property and Genetic Resources, Traditional Knowledge and Folklore, The Protection of Traditional Cultural Expressions/Expressions of Folklore: Outline of Policy Options and Legal Mechanisms (Geneva: WIPO 2004).

${ }^{16}$ See Kilian Bizer, Matthias Lankau, Gerald Spindler and Philipp Zimbehl, "Sui Generis Rights for the Protection of Traditional Cultural Expressions" (2011) 2 JIPITEC 114.

17 Singhal, "Geographical Indications and Traditional Knowledge" (2008) 3(11) Journal of Intellectual Property Law \& Practice 732.
} 
available for the protection of cultural property below the level of formal property rights like those for material property.

By analysing and evaluating the EU regulations, this article develops ideas for improvement and possible alternatives, which were partly discussed by the European Union. ${ }^{18}$ It arrives at a recommendation contradicting the Regulation Proposal previously suggested by the European Commission. This article examines the regulations from two different perspectives: an information economic perspective and a cultural property perspective. The article proceeds as follows: after discussing the EU system of origin-labelling, different reform proposals are derived. Finally, alternatives and policy recommendations are evaluated and summarized.

\section{THE EU SYSTEM OF ORIGIN-LABELLING FOR FOOD SPECIALITIES}

As one of the strongest supporters of Gls on the international level, ${ }^{19}$ the European Union commands three instruments to obtain the goals previously outlined: Protected Designations of Origin (PDO), Protected Geographical Indications (PGI) and Traditional Speciality Guaranteed (TSG). ${ }^{20}$ These elements of the European Union's quality policy provide information on the specific characteristics and the associated quality of the products. In the narrow sense, only PDO and PGI are considered qualified $\mathrm{Gls}^{21}$; TSG designates traditional characteristics of a product and not necessarily the product's actual origin ${ }^{22}$ even if the denominations often point to a region. Therefore, only a qualified label of origin requires a close link between the geographically (and traditionally) identified origin and specific product characteristics (such as quality, production method, reputation) (terroir). ${ }^{23}$ This enables a labelled product to differentiate itself from products from other regions or countries. The fact that this close relationship (cf. "intrinsic link") ${ }^{24}$ cannot be clearly measured poses a central problem for the origin-labelling system. ${ }^{25}$ In practice, scientific links in terms of a measurable correlation between origin and qualities are more the exception than the rule. ${ }^{26}$

On the demand side, these three instruments should convey different information on origin, quality and traditional production method of the protected products to consumers. It is compulsory to use the indications PDO, PGI and TSG or their symbols where the associated products are marketed under the registered name. ${ }^{27}$ However, the respective EU labels are very similar to each

\footnotetext{
${ }^{18}$ For an overview of the discussed alternatives of the EU, see European Commission, "Impact Assessment on Geographical Indications", December 10, 2010, SEC(2010)1524, Commission staff working paper; European Commission, "Impact Assessment on Traditional Specialities Guaranteed", December 10, 2010, SEC(2010)1525, Commission staff working paper.

${ }_{19}$ See e.g. Christophe Geiger, Daniel Gervais, Norbert Olszak and Vincent Ruzek, "Towards a Flexible International Framework for the Protection of Geographical Indications" (2010) 1(2) WIPO J. 147, discussing the EU position in the WTO; see also Tim Josling, "The War on Terroir: Geographical Indications as a Transatlantic Trade Conflict" (2006) 57(3) J. Ag. Econ. 337, 349-359.

20 Regulated by Council Regulation 510/2006 of March 20, 2006 on the protection of geographical indications and designations of origin for agricultural products and foodstuffs [2006] OJ L93/12, and Council Regulation 509/2006 of March 20, 2006 on agricultural products and foodstuffs as traditional specialities guaranteed (Regulation 509/2006) [2006] OJ L93/1.

${ }^{21}$ See Regulation 510/2006 art.2 (Definitions of PDO and PGI).

${ }^{22}$ See Regulation 509/2006 art.2 (Definitions) and art.4 (Requirements as Regards Products and Names).

${ }^{23}$ For an extensive discussion on the French concept of "terroir", see e.g. Justin Hughes, "Champagne, Feta, and Bourbon: The Spirited Debate about Geographical Indications" (2006) 58 Hastings L.J. 299; Josling, "The War on Terroir" (2006) 57(3) J. Ag. Econ. 337.

${ }^{24}$ See Regulation Proposal, p.16, para. (17).

${ }^{25}$ See the argumentation in Adriano Profeta, Richard Balling, Volker Schoene and Alexander Wirsig, "The Protection of Origins for Agricultural Products and Foods in Europe: Status Quo, Problems and Policy Recommendations for the Green Book" (2009) 12(6) J. World Intell. Prop. 622.

${ }^{26}$ See the discussion to apply the multi-isotope analysis in the wine sector and its contradictory results in Simon Kelly, Karl Heaton and Jurian Hoogewerff, "Tracing the Geographical Origin of Food: The Application of Multi-element and Multiisotope Analysis" (2005) 16 Trends in Food Science \& Technology 555, 563.

${ }^{27}$ See Regulation 510/2006 art.8.2; Regulation 509/2006 art.12.2
} 
other and only differ slightly. ${ }^{28}$ The difference between the content of the labels is not recognizable without additional information. The risk of confusing consumers is correspondingly high and empirically confirmed. ${ }^{29}$ Further, various studies have already pointed towards a lack of public awareness and the low recognition level of GI labels. ${ }^{30}$ To a certain extent, the great differences in the ways in which Member States utilize the system depends on a country's particular agricultural background, as those with a strong tradition in agriculture feature products with a high awareness level regardless of the EU labels. To initiate a protection procedure the awareness level of a product among consumers and the reputation of a product should be measured. Some authors point out the necessity of consumer surveys as suggested in the Guide to Community Regulations of the Commission Services. ${ }^{31}$

In addition, the labelling of origin system bears problems on the supply side as well-for instance, the low participation of small scale producers due to arduous efforts, costly controls and the necessity to implement specified requirements. ${ }^{32}$ To some extent, the European Union has recognized the challenge of harmonizing competition conditions for products of the same category and balancing or counterbalancing the cost advantages of established enterprises (monopolists). Therefore, it aims to strengthen and recognize the role of cooperatives (groups), particularly in terms of modifying specifications, supervising the enforcement of the protection of the registered names and complying with the production requirements. ${ }^{33}$

Although it is suggested that the registration procedures for PDO, PGI and TSG should be more transparent, the existing reform proposal continues to ignore a substantial problem, as the difference between PDO and PGI remains vague. The same protection level is given for these instruments despite the fact that the regional connection of the product is substantially different between PDO and PGI. Thus, different information should be provided on the actual product origin. This article therefore approaches the fundamental disparities between PDO and PGI and elaborates several reform alternatives, which are presented below.

\footnotetext{
${ }^{28}$ Commission Regulation 628/2008 of July 2, 2008 amending Regulation 1898/2006 laying down detailed rules of implementation of Council Regulation 510/2006 on the protection of geographical indications and designations of origin for agricultural products and foodstuffs [2008] OJ L173/3, has introduced different colour schemes for Gls. Accordingly, the PDO label is identifiable with the combination of colours of red and yellow, while PGI with colours of blue and yellow. Nonetheless, as the labels are used in black and white or in negative, the difference between PDO and PGI remains only in the small wording inside the symbols. Interestingly, TSG labels use the same colours as PGI labels. Further, regarding the style and the design of the GI labels, there are no distinguishing characteristics, and TSG labels differ only slightly from them.

${ }^{29}$ See the analysis of the impacts on consumers in London Economics, Evaluation of the CAP Policy on Protected Designations of Origin (PDO) and Protected Geographical Indications (PGI): Final Report (London: 2008).

${ }^{30}$ Such as Ramona Teuber, "Producers' and Consumers' Expectations towards Geographical Indications-Empirical Evidence for Hessian Apple Wine", presentation at the 113th EAAE Seminar: "A Resilient European Food Industry and Food Chain in a Challenging World", Greece, 2009; Christos Fotopoulos and Athanasios Krystallis, "Quality Labels as a Marketing Advantage: The case of the 'PDO Zagora' Apples in the Greek Market" (2003) 37(10) European Journal of Marketing 1350; London Economics, Evaluation of the CAP Policy on Protected Designations of Origin (PDO) and Protected Geographical Indications (PGI) (2008).

${ }^{31}$ See Adriano Profeta and Richard Balling, "Evaluierung der Übergangsregelung des Herkunftsschutzes bei Agrarprodukten und Lebensmitteln in Europa gemäß Verordnung (EG) Nr. 510/06 und Verbesserungsvorschläge für die anstehende Modifikation" (2007) 56(4) Agrarwirtschaft 213, referring to the European Commission, Protection of Geographical Indications, Designations of Origin and Certificates of Specific Character for Agricultural Products and Foodstuffs: Guide to Community Regulations, 2nd edn. (2004), Commission services working paper, p.14.

${ }^{32}$ See Rangnekar, "The Socio-economics of Geographical Indications" (2004) UNCTAD-ICTSD Project on IPRs and Sustainable Development, Issue Paper No. 8; Stéphan Marette, "Can Foreign Producers Benefit from Geographical Indications under the New European Regulation?" (2009) 10(1) The Estey Centre Journal of International Law and Trade Policy 65; Anselm K. Sanders, "Incentives for and Protection of Cultural Expression: Art, Trade and Geographical Indications" (2010) 13(2) J. World Intell. Prop. 81; G.E. Evans, "The Strategic Exploitation of Geographical Indications and Community Trade Marks for the Marketing of Agricultural Products in the European Union" (2010) 1(1) WIPO J. 159; see also European Commission, "Impact Assessment on Geographical Indications", Commission staff working paper, SEC(2010)1524.

${ }^{33}$ See Regulation Proposal, p.20, para. (57).
} 


\section{POSSIBLE REFORM ALTERNATIVES}

Gls can generate additional values for consumers if the instruments are transparent and trustworthy. While the intention of the EU reform proposal to strengthen controls and requirements supports the reliability of the instruments itself, information on fundamental characteristics remains unknown if producers do not provide any further details about the production stages taking place within the region apart from the label. In this case, consumers are not able to clearly distinguish the grade of regional embeddedness of PDO from PGI protected products. Therefore, our analysis focuses on the question of how transparency between instruments of PDO and PGI can be increased and the EU GI system can provide efficient information to consumers as a requirement for higher willingness to pay.

Apart from the fact that TSGs are not technically included as Gls, they also need to be considered as they are closely related to PDOs and PGIs and exhibit similar characteristics. From the consumer perspective the label seems to be very similar although the focus is quite different. For this reason, abolishing the TSG label is seen as an opportunity to clarify the information-providing effect of Gls (PDO and PGI).

Table 1: Overview of reform options analysed ${ }^{34}$

\begin{tabular}{|c|l|l|}
\hline Instrument & \multicolumn{1}{|c|}{$\begin{array}{c}\text { Option 1 } \\
\text { Origin transparency and differentiation } \\
\text { based on tradition }\end{array}$} & $\begin{array}{c}\text { Option 2 } \\
\text { Concentration on one protection form } \\
\text { (PDO) }\end{array}$ \\
\hline PDO & $\begin{array}{l}\text { Concentrating on developed specialities (EC } \\
\text { Regulation 510/2006) }\end{array}$ & $\begin{array}{l}\text { Maintaining and specifying the EC } \\
\text { Regulation 510/2006 }\end{array}$ \\
\hline PGI & $\begin{array}{l}\text { Clearly labelling the origin of raw materials } \\
\text { and a stronger focus on developing food- } \\
\text { cultural specialities (EC Regulation 510/2006) }\end{array}$ & Abolition and transformation into PDO \\
\hline TSG & Abolition (EC Regulation 509/2006) & Abolition (EC Regulation 509/2006) \\
\hline
\end{tabular}

In addition to abolishing TSGs, this article discusses two reform proposals (see Table 1). While the first alternative aims to increase transparency for PGIs more specifically than currently suggested in the Regulation Proposal, the second recommends further modifying the existing regulation. This also suggests abolishing the PGI category and transforming part of it into PDOs, with the result of maintaining and specifying solely the PDO instrument. Its implementation constitutes a considerably greater challenge for the community and still leaves many questions unanswered. However, this focus seems particularly reasonable from a cultural property perspective since it provides the greatest commodification potential for regions without risking the establishment of an uncontested monopoly. After all, a PDO can always be challenged by external actors buying regional companies or relocating to the region.

\footnotetext{
${ }^{34}$ The reform alternatives analysed here were partly discussed during the process of the revision of the EU agricultural quality policy: (1) Abolition of TSG was suggested in European Commission, "Impact Assessment on Traditional Specialities Guaranteed", 2010, Policy Options 4.3; (2) "Status quo accompanied with streamlining of procedures and clarification of PDO/PGI rules" (see European Commission, "Impact Assessment on Geographical Indications", 2010, Policy Options 5.2.3). The option merging definitions of PGI and PDO were also discussed, suggesting the abolition of PDO (see Policy Options 5.5). As it can be assumed from the current EU reform proposal, the EU quality system will further function in its current construction maintaining all three instruments (PDO, PGI and TSG) with slight modifications regarding Regulations 510/2006 and 509/2006.
} 


\section{JUSTIFYING THE ABOLITION OF TSGs}

In order to avoid consumer confusion and to keep information on Gls transparent, the abolition of TSGs is necessary. In this light it is important to state that with TSGs' lower level of protection, ${ }^{35}$ which is limited to the production method without any regional connection, TSGs benefit from the clearly stricter requirements of PDO and PGI, which require an obvious regional link of the raw materials. As TSGs do not need to fulfil this requirement, they could be suspected of free-riding on the other, more demanding categories. If only for this reason, abolishing TSGs seems a legitimate step that could increase the trustworthiness of the other labels.

From the cultural property perspective TSGs also provide the least protection of certain methods of production. They do not even aim to commodify regional raw materials, thus providing neither actor-related nor region-related protection. Under current law, TSGs aim to commodify the production method only, i.e. the recipe. For this reason, abolishing the TSG label is seen as an opportunity to advance the information-providing effect of GIs (PDO and PGI) without notably weakening the protection of cultural property.

In summary, abolishing the TSG is reasonable from an information economic perspective, since the instrument confuses consumers, as is outlined in the following:

\section{Conflict with origin:}

According to Regulation 509/2006, products with characteristics based on origin or regional provenance cannot be registered as TSGs. ${ }^{36}$ TSG labels (which have the same colours blue and yellow and can be mistaken for PGI) do not inform the consumer about the origin of the product, but about their traditional production method as the name "traditional speciality" alludes to. Further, the production does not have to contain a link with the geographical origin. Accordingly, production is not limited to a certain region, but open to all producers. Precisely for this reason, TSGs are of little economic interest and are not used very much. ${ }^{37}$

\section{No clear differentiation from Gls:}

Eventually, there is no valid reason why an additional category needs to be kept for products without a geographical origin; yet, as Bérard and Marchenay note, ${ }^{38}$ in every country in the world, a geographical origin is linked to the product. Moreover, the previously mentioned restriction outruling registration of products with a reference to a specific geographical origin in the Regulation Proposal even strengthens the contradiction as $\mathrm{Gl}$ instruments also reflect the elements of tradition. The differences between PDO, PGI and TSG thus become even more blurred, further increasing the risk of consumer confusion. ${ }^{39}$

\footnotetext{
${ }^{35}$ According to Regulation 510/2006 Gls are protected inter alia "against any direct or indirect commercial use of a registered name ... any misuse, imitation or evocation, even if the true origin of the product is indicated or if the protected name is translated or accompanied by an expression such as 'style', 'type', 'method', 'as produced in', 'imitation'" ... (art.13.1(a), (b)). Meanwhile, Regulation 509/2006 leaves the protection of TSG very unspecified stating that "registered names shall be protected against any practice liable to mislead the consumer" (art.17(2)).

${ }^{36}$ Regulation 509/2006 art. 4(1).

${ }^{37}$ To date a total of 37 products are registered as TSG products. See http://ec.europa.eu/agriculture/quality/door [Accessed March 25, 2012].

${ }^{38}$ Laurence Bérard and Philippe Marchenay, "Local Products and Geographical Indications: Taking Account of Local Knowledge and Biodiversity" (2006) 58(187) International Social Science Journal 109, 110.

${ }^{39}$ See the current example of Dutch "Boerenkaas", a cheese from a farm distinguishing itself not with actual qualitative particularities, but a requirement that at least 50 per cent of the milk must originate from the farm producing the cheese. Here, the TSG is used to protect direct marketing (although a proper label for direct marketing products is currently considered, too).
} 


\section{Limited perception of tradition:}

In terms of cultural traditions, other problems support the abolition of the instrument: currently the criterion of being a traditional product requires at least 25 years of documented history on the domestic market. ${ }^{40}$

Considering the Regulation Proposal, it seems likely that this period will be extended to 50 years as it demands that only tradition passed on at least over two generations be recognized as culturally significant; ${ }^{41}$ PDOs and PGIs on the other hand have no such requirements. Again, GIs and TSGs prove to be inconsistent. In the case of Gls, the existence of a tradition and its meaning does not depend on an arbitrarily set time period, although like TSGs these instruments also describe traditional production methods. From this view, TSGs seem to set higher requirements regarding cultural and traditional connections than Gls. This again can be confusing as the qualitative requirements are otherwise rather less demanding.

In total, given the blurry differences between the Gl types and the TSG and the resulting consumer confusion, the continued existence of TSGs cannot be justified. In the end, TSGs are merely "secondclass" Gls. Nevertheless, abolishing TSGs requires an adequate transitional arrangement: in cooperation with all possible actors, regulations for companies holding TSGs would have to be modified to enable PGI recognition-or if possible PDO recognition-so as to facilitate transborder nomination as provided also by TSG. This might entail a long negotiation process, but should prove viable in many cases. ${ }^{42}$ Products not fulfilling the requirements of a PDO or PGI nomination could resort to the facultative quality specifications of the EU and international harmonization, i.e. within the Codex Alimentarius (food codex). While their scope of protection may be narrower, they are specifically tailored to preserve product identities without regional delimitation. Building private brands may be another opportunity, especially for industrial processors.

\section{OPTION 1: TRANSPARENCY REGARDING THE ORIGIN OF RAW MATERIALS AND DIFFERENTIATING THE TYPES OF PROTECTION}

In the light of the suggested abolition of the TSG norm, this article discusses a first alternative solution that is dedicated to the differences between PDO and PGI, which is seen as critical in the literature. ${ }^{43}$ This option aims at considerably improving transparency between PDO and PGI by specifying the differences between the two instruments and highlighting them. This is of great relevance should both instruments be retained as envisaged by the current Regulation Proposal. Only if consumers possess sufficient information on the product identity producers can expect rents appropriate to the product characteristics. ${ }^{44}$

For this purpose, information on protected Gls needs to be fundamentally improved:

\section{Regarding protection criteria:}

Protection via PGI can only be granted for the geographical name of a product "which possesses a specific quality, reputation or other characteristics attributable to that geographical origin" and for which "the production and/or processing and/or preparation of which take place in the defined geographical area". ${ }^{45}$

\footnotetext{
${ }^{40}$ Regulation 509/2006 art.2(1)/b.

${ }^{41}$ Regulation Proposal, p.23, art.3(3).

${ }^{42}$ See for instance the case of traditional-type mozzarella cheese. The name "Mozzarella di Bufala Campana" was entered successfully in the DOOR database as a PDO product in 1996. Besides, the name of "Mozzarella" has also been registered as TSG in 1998. For more information, see http://ec.europa.eu/agriculture/quality/door [Accessed March 25, 2012].

${ }^{43}$ See Profeta, Balling, Schoene and Wirsig, "The Protection of Origins for Agricultural Products and Foods in Europe" (2009) 12(6) J. World Intell. Prop. 622; Geiger, Gervais, Olszak and Ruzek, "Towards a Flexible International Framework for the Protection of Geographical Indications" (2010) 1(2) WIPO J. 147; Evans, "The Strategic Exploitation of Geographical Indications and Community Trade Marks for the Marketing of Agricultural Products in the European Union" (2010) 1(1) WIPO J. 159.

${ }^{44}$ As proposed by Regulation Proposal, p.24, art.4(a).

${ }^{45}$ Regulation 510/2006 art.2(1); Regulation Proposal, p.24, art.5(1), defining PDO and PGI.
} 
In contrast, PDO requires that the "quality or characteristics" of the product be "essentially or exclusively due to a particular environment with its inherent natural and human factors", with "the production, processing and preparation" all taking place in the demarcated geographical area. Both differentiation criteria are problematic. The connection between origin and product characteristics (quality) is challenging in almost all cases-also with respect to PDOs. It is very difficult, if not impossible, to prove that specific characteristics or quality differences are explicitly attributable to the region. ${ }^{46}$ In practice, PDOs strongly rely on the reputation closely connected to the region as initially envisaged for PGIs. ${ }^{47}$ Accordingly, on an international level the instrument is applied unequally: while the same categories of products are registered in northern EU Member States as PGIs, they can be found as PDOs in southern Member States.

Moreover, it is not unusual that some PGI products exhibit stricter quality criteria than some PDO products. ${ }^{48}$

If both protection norms are to be maintained, obviously the differentiation cannot be based only on the existing or non-existing link between (scientifically measurable) product characteristics and the region. Instead, a cultural differentiation with respect to a tradition's link with the region might be a sustainable solution. So far, both concepts include the image of a regional specialty that should be preserved. This contradicts the results of research on cultural property, ${ }^{49}$ according to which establishing a consortium to use the protection rights is the first step to reinventing the regional tradition to be preserved with the GI. ${ }^{50}$ Especially in regions with a low level of food-cultural tradition like in many northern and eastern European Member States, Gls today are a driving force for constituting specialties.

In this context, a clear differentiation of the two protection norms seems highly recommendable (see Table 2). The PDO should focus on traditions exhibiting a stronger link with the region as all production stages must take place within the region and a corresponding reputation. From a cultural property perspective, that would make PDO the instrument of propertisation of a historically anchored food-cultural speciality. In this case, requirements should be kept high. These could include proof of a traditional production of that good on the domestic market with regard to intergenerational transmission similar to the time period criteria currently suggested in the TSG.

The PGI should then take on the character of an instrument for the promotion of food-cultural diversity. This would imply low requirements for evidence of relevant traditions since this protection scheme would also capture isolated and/or buried knowledge that are only the rudimentary nucleus for the constitution of PGI products. In this light, it is easy to argue in favour of limiting the scope of protection regarding name rights and only allowing for combinations of origin and rather generic product names (when for instance referring to "Allgäuer Emmentaler"). The PGI would also provide a protection for buried knowledge, which is deemed critical by the existing literature. ${ }^{51}$

\footnotetext{
${ }^{46}$ This fact is especially contested in the wine sector. See Herrmann, Marauhn and Teuber, "Der Schutz geographischer Herkunftsangaben" (2008) 57(7) Agrarwirtschaft 321; Rangnekar, "The Socio-economics of Geographical Indications" (2004) UNCTAD-ICTSD Project on IPRs and Sustainable Development, Issue Paper No.8.

47 Rangnekar, "The Socio-economics of Geographical Indications" (2004) UNCTAD-ICTSD Project on IPRs and Sustainable Development, Issue Paper No.8.

${ }^{48}$ Profeta, Balling, Schoene and Wirsig, "The Protection of Origins for Agricultural Products and Foods in Europe" (2009) 12(6) J. World Intell. Prop. 622.

49 Stefan Beck and Leonore Scholze-Irrlitz, "Wie der Europäer is(s)t. Europäisierung durch Molekularisierung, Standardisierung und kreative Traditionalisierung von Nahrung und Ernährung" in Susanne Bauer et al. (eds), Essen in Europa (Berlin: Transcript Verlag, 2010).

${ }^{50}$ V. Amilen and A.W. Hegnes, "The Cultural Smell of Fermented Fish: About the Development of a Local Product in Norway" (2004) 2(1) Journal of Food, Agriculture and Environment 141.

${ }^{51}$ See e.g. Singhal, "Geographical Indications and Traditional Knowledge" (2008) 3(11) Journal of Intellectual Property Law \& Practice 732; Downes, "How Intellectual Property Could Be a Tool to Protect Traditional Knowledge" (2000) 25 Colum. J. Envtl. L. 253.
} 
Table 2: Reform option 1- Differentiating the instruments with help of particular criteria

\begin{tabular}{|l|l|l|}
\hline Criterion/Instrument & \multicolumn{1}{|c|}{ PDO } & \multicolumn{1}{c|}{ PGI } \\
\hline Geographical link & $\begin{array}{l}\text { High: entire value added } \\
\text { chain is situated in the } \\
\text { region }\end{array}$ & $\begin{array}{l}\text { Low: only one of the production steps is } \\
\text { required to take place in the region } \\
\text { (requirements of labelling the production } \\
\text { steps make this transparent) }\end{array}$ \\
\hline Traditional linkage & $\begin{array}{l}\text { High requirements: } \\
\text { profound linkage or } \\
\text { tradition across } \\
\text { generations }\end{array}$ & $\begin{array}{l}\text { Low requirements: } \\
\text { buried/scattered knowledge, } \\
\text { isolated traditions }\end{array}$ \\
\hline $\begin{array}{l}\text { Reputation/prevailing } \\
\text { opinion }\end{array}$ & $\begin{array}{l}\text { High level of awareness } \\
\text { or high reputation }\end{array}$ & First nucleus for constitution or recognition \\
\hline
\end{tabular}

\section{Regarding product labelling:}

The PGI also creates consumer confusion as the origin of the raw materials is not common knowledge $\mathrm{e}^{52}$ and is not legally specified. While it is legally sufficient for one production step to take place in the respective region, many PGI consortiums call for all raw materials to exhibit a regional link and thus do not take advantage of the opportunities of acquiring inexpensive raw materials from low cost regions. However, PGIs are also awarded to products for which it is impossible to obtain all the necessary raw materials from the region, i.e. Lübecker Marzipan. As a result, consumers cannot be sure of how much of the production process takes place in the respective region for PGIs. In future, more information on Gls should be displayed; such display will also act to strengthen the geographical link of the products. This would also require providing information on which part of the manufacturing process takes place in the mentioned region. All important raw materials and production processes for the product should be labelled according to their region (abbreviated on the product as well as in a detailed form in the barcode). This would enable an actual product identity and also a comprehensible origin authenticity supporting the purchase decisions of consumers. In addition, this would provide a further incentive for regionalisation. The product's origin considerably influences purchase decisions concerning preferences for products from particular countries or regions. Mostly, the PGI's name refers to the region in which the last production step took place (e.g. Black Forest Ham). An instrument making it obligatory to localise raw materials and production steps would provide an efficient solution honouring the prevailing opinion of the consumers by PGI products. ${ }^{53}$

In total, the first option supports two different labels. On the one hand, the value of PGls for consumers is increased by more information on origin and production steps, which highlights the link between product and region. Because the requirements regarding a tradition described in the product specification as a protection criterion are limited, they provide an opportunity to recognize products based on scattered or buried knowledge. On the other hand, PDOs are recognized for developed specialties with a historical tradition (proved existence of the production on the domestic market) and a corresponding reputation (prevailing opinion of the consumers), which count as existing cultural and gastronomic heritage as proposed by the Regulation Proposal. ${ }^{54}$

\footnotetext{
${ }^{52}$ London Economics, Evaluation of the CAP Policy on Protected Designations of Origin (PDO) and Protected Geographical Indications (PGI) (2008), p.33.

${ }^{53}$ See Profeta, Balling, Schoene and Wirsig, "The Protection of Origins for Agricultural Products and Foods in Europe" (2009) 12(6) J. World Intell. Prop. 622; Profeta and Balling, "Evaluierung der Übergangsregelung des Herkunftsschutzes bei Agrarprodukten und Lebensmitteln in Europa gemäß Verordnung (EG) Nr. 510/06 und Verbesserungsvorschläge für die anstehende Modifikation" (2007) 56(4) Agrarwirtschaft 213.

${ }^{54}$ See Regulation Proposal, p.13, para. (1).
} 
The second option results from a drastic proposal of some authors arguing in favour of abolishing both instruments of Gls. ${ }^{55}$ Furthermore, such radical demands were discussed in the course of the Commission's preparatory work as well, ${ }^{56}$ a fact that points to the fundamental regulatory deficits. Apart from the stronger and yet more culturally justified differentiation of the two forms of Gls suggested by option 1 , option 2 concentrates solely on one protection scheme, namely the PDO. This stricter alternative argues for maintaining and further specifying the PDO regime while aiming to abolish the PGI instrument. ${ }^{57}$

\section{Information economic aspects:}

Concentrating on one protection scheme creates an environment in which the PDO instrument fulfils the function of providing entire or unambiguous information on the product's actual origin. As all production steps take place in the region signalled by the protected name, consumers on the national and international level are not misled in terms of the true product identity as is possible in the case of PGIs. These PDO qualities imply that producers can obtain a higher price level for their products than in case of PGI products, ${ }^{58}$ since their unambiguous authenticity of origin allows for identifying not only the actual origin, but also the original tradition and the alluded reputation. This stronger concept can also be explained by the fact that "consumers increasingly look for authentic products produced using specific and traditional methods". ${ }^{59}$ This option would also prevent weaker instruments from free-riding on the PDO.

\section{Cultural property aspects:}

Currently, PDOs theoretically refer to products with "an intrinsic link ... between product or foodstuff characteristics and geographical origin" ${ }^{60}$ However, in reality only a few PDO protected products are able to provide unambiguous evidence that climate and soil determine the product in a specific way rendering the product unique. Therefore, it seems necessary for this alternative solution to again focus on strengthening the link between the geographically delimited area and the product on a cultural basis as suggested in option 1 . This cultural link should be described in detail in the product specification ("code of practice") which at the same time represents the codification of local knowledge via interaction with nature and environment, ${ }^{61}$ including traditional production process and (traditional) raw materials. ${ }^{62}$

This option aims to protect the collective reputation of the goods and the region from misappropriation and dilution, ${ }^{63}$ enabling rights holders to obtain high price premiums. In overall, PDO products must meet three requirements (see fig.1):

1. High geographical link: requiring that the entire value added chain is situated in the region. ${ }^{64}$

2. Traditional anchorage: high requirements are of crucial interest regarding historical anchorage since the boundaries of the region of origin cannot be designated only on the basis of

\footnotetext{
${ }^{55}$ E.g. Profeta, Balling, Schoene and Wirsig, "The Protection of Origins for Agricultural Products and Foods in Europe" (2009) 12(6) J. World Intell. Prop. 622.

${ }^{56}$ See European Commission, "Impact Assessment on Geographical Indications", 2010, p.33, Policy Options 5.8. Accordingly the protection of geographical indications is suggested through a trademark system.

${ }^{57}$ This option is in contrast with the EU proposal of focusing only on the PGI scheme. See European Commission, "Impact Assessment on Geographical Indications", 2010, Policy Options 5.5.

${ }^{58}$ See Regulation Proposal; London Economics, Evaluation of the CAP Policy on Protected Designations of Origin (PDO) and Protected Geographical Indications (PGI) (2008).

${ }^{59}$ See Regulation Proposal, p.2, art.1.1 (Grounds for and Objectives of the Proposal).

${ }^{60}$ Regulation Proposal, p.16, para. (17).

${ }^{61}$ Bérard and Marchenay, "Local Products and Geographical Indications" (2006) 58(187) International Social Science Journal 109.

${ }^{62}$ Currently only TSG products must meet these requirements. See Regulation 509/2006 art.4(1).

${ }^{63}$ As argued by Rangnekar, "The Socio-economics of Geographical Indications" (2004) UNCTAD-ICTSD Project on IPRs and Sustainable Development, Issue Paper No.8, in general regarding Gls (not only referring to PDOs).

${ }^{64}$ An exception can be found in imports of raw materials. See the exemption clause of Regulation 510/2006 art.2(3) and Regulation Proposal, p.24, art.5(2).
} 
measurable scientific link between product quality and region. Profound linkage between the region and the product relating to the tradition of production across generations must be proved for a demarcated geographical area considering historical data and possible changes in the techniques of production in the past.

3. Corresponding reputational link to the region of origin and high level of awareness on the part of consumers is also an essential criterion for being a product worthy for PDO protection.

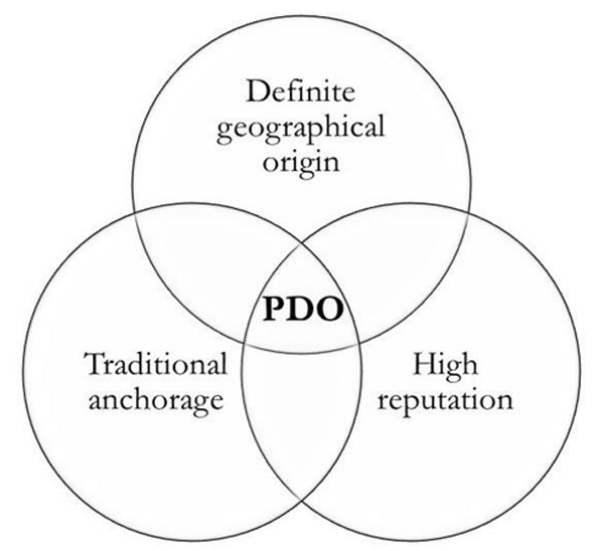

Figure 1: Reform option 2- Maintaining solely the PDO instrument based on a triple criterion $^{65}$

The demarcation of the region of origin is one of the crucial points in a registration process. Even if the delimitation of the authorized area rests upon more objective physical geographical particularities such as climate and geology, there are several disputes over precise boundaries due to the exclusion of potential producers. ${ }^{66}$ In the case of a more subjective cultural factors-based approach, as suggested above, the restriction of the protection area seems to be of a more complex nature. Since traditions change over time, several factors, such as the different development phases of the product in question or the development of production techniques per se, should be considered.

The case of Melton Mowbray Pork Pie exemplifies these challenges very well. ${ }^{67}$ After a long negotiation process, an area larger than the original area of production has been considered for registration. The rationale behind that lies in the fact that, in accordance with the method of production described in the product specification, a wider area has been engaged in production for 100 years demonstrated by extensive historical research. ${ }^{68}$ This case sheds light on the importance of not only a geographical but also on a traditional delimitation of a production area. This insight leads us to the following limitation regarding the notion of $\operatorname{tradition}^{69}$ : defining the protection area, historical evidence is recommended for the time period in which a somewhat stable recipe is identified. Specifically, in case the area is determined on a cultural basis, attention should be paid to a particular product (to the first historical disclosure of the associated name to be protected) and not to references about general production of such goods as is currently detectable by several products, thus diffusing the proof of origin. The collective action of all stakeholders is required to take such decisions about the delimitation of region of origin based on historical data.

\footnotetext{
${ }^{65}$ Source: Authors

${ }^{66}$ See Dev S. Gangjee, “Melton Mowbray and the GI Pie in the Sky: Exploring Cartographies of Protection” (2006) 3 I.P.Q. 291, for details on the complexity of problems relating to the demarcation of a PDO protection area.

${ }^{67}$ See Gangjee, "Melton Mowbray and the GI Pie in the Sky" (2006) 3 I.P.Q. 291.

${ }^{68}$ See the registration document of Melton Mowbray Pork Pie: "Publication of an application pursuant to Council Regulation 510/2006 art.6(2) on the protection of geographical indications and designations of origin for agricultural products and foodstuffs" [2008] OJ C85/17.

${ }^{69}$ As also suggested by Gangjee, "Melton Mowbray and the GI Pie in the Sky" (2006) 3 I.P.Q. 291.
} 
Accordingly, the question arises when the production of a particular product should count as "traditional". ${ }^{70}$ On the one hand, building up a corresponding reputation of a product takes some time; on the other hand, traditions are usually associated with intergenerational transmissions, at least 50 years or a two generation criterion seems to be a suitable requirement for a minimum existence of a product, as also suggested by the Regulation Proposal. ${ }^{71}$

In order for a single GI instrument (PDO) to be economically worthwhile, measures such as the following should additionally be taken into account:

- The exceptional rule that "certain geographical designations shall be treated as designations of origin where the raw materials for the products concerned come from a geographical area larger than, or different from, the processing area"72 shall be maintained. Here, a labelling of the origin of the raw material seems indispensable: provided that the import of raw materials is an essential part of the traditional production or that the production were not possible without these raw materials (see Lübecker Marzipan) and that this procedure is corroborated by tradition, the origin of these raw materials should be clearly designated to avoid consumer confusion (see above).

- Following up on the stronger focus on traditional links, it further seems meaningful to retain the exception-with a labelling obligation-that "traditional geographic names" can also be registered as PDOs as they define an agricultural product or foodstuff that has its culturally influenced origin in a geographically delimited area. ${ }^{73}$

- For products to which PDO regulations do not apply, facultative quality specifications would provide an opportunity to inform consumers about particular commodifying characteristics and thus differentiate them from other products (see above).

- Whereas many PGI products fulfil the criteria for PDO nomination, they are introduced as PGIs for strategic reasons in order to retain the option of switching between suppliers according to the economic conditions. ${ }^{74}$ As a result, many consumer protection watchdogs criticise these producers who decide against obtaining their raw materials from the same region for economic reasons despite its viability. ${ }^{75}$ For these products the "renomination" to PDO is reasonable and justified. Nonetheless, in case of undesirable and unseasonal weather conditions PDO products face a higher risk of insufficient supply of raw materials. Every seasonal product is taking this risk, to some extent.

Summing up, the introduction of only one instrument would entail the following advantages: Transparent designations of origin:

Abolishing PGls would prevent, as far as technically possible, production steps from taking place outside the region. Thus, the link between the products and the geographical origin is clearly specified and strengthened on the basis of a traditional linkage.

\footnotetext{
${ }^{70}$ Apart from the EU's standpoint, at the national level there are different assumptions on "tradition". For instance, Austria created a register for Traditional Austrian Specialties on its own initiative, which only regards products as "traditional" when their production exists for at least 75 years or over three generations. See "Bundesministerium für Land- und Forstwirtschaft, Umwelt und Wasserwirtschaft", available at

http://www.lebensministerium.at/lebensmittel/qs-lebensmittel/trad-lebensmittel/TraditionelleLM.html

[Accessed March 25, 2012].

${ }^{71}$ Regulation Proposal, p.23, art.3(3).

${ }^{72}$ Regulation 510/2006 art.2(3); Regulation Proposal, p.24, art.5(2).

${ }^{73}$ See Regulation 510/2006 art.2 (2). This exception clause is not considered in the Regulation Proposal.

${ }^{74}$ See Evans, "The Strategic Exploitation of Geographical Indications and Community Trade Marks for the Marketing of Agricultural Products in the European Union" (2010) 1(1) WIPO J. 159.

${ }^{75}$ Profeta, Balling, Schoene and Wirsig, "The Protection of Origins for Agricultural Products and Foods in Europe" (2009) 12(6) J. World Intell. Prop. 622.
} 


\section{Reliability:}

The extent of controls would apply to all production steps and render the control tasks easy to comprehend. This could enhance consumer trust. By using only one Gl label, consumers are protected from confusion due to the existence of various labels with differing information content. ${ }^{76}$ As a "mark of authenticity", 77 the label could further convey unambiguous information about the characteristics of the products (clear origin, proven tradition and high reputation).

\section{Spillover effects:}

If all production steps take place in a particular region, the product name obtains a collective reputation regarding all production steps. This implies concentrated cooperation of all actors and strengthens rural and regional identity, as well as cohesion. The reputation of a PDO product can have a positive effect on agri-tourism, ${ }^{78}$ as in the case of Italy where the consumption of Gl food products encouraged by the national law has turned regional gastronomic traditions into one of the main attractions of farm tourism. ${ }^{79}$ In this way, PDO products provide incentives to commodify regional products as well as traditional knowledge and can thus promote economic development in the region.

\section{Protection of local knowledge:}

Despite the fact that the PDO regime protects the name of the product directly, the vital element of the product specification manifests itself in the production procedure involving local knowledge and practices. $^{80}$

Many authors criticise that within a GI system local knowledge remains unrecognised as an object of protection, and therefore rests in the public domain. ${ }^{81}$ Consequently, traditional producers leaving the region cannot be stopped to produce similar or identical products from outside the region. Nevertheless, if requirements of traditional production methods with regional historical anchorage are fulfilled, the PDO does contribute to a certain extent to the protection of local knowledge (codified in the product specification) by protecting its reputation from free-riders.

The product and the associated local knowledge attributed to a geographically delimited area cannot be marketed under the same traditional name by producers outside the region. This creates an environment where culinary heritage is protected and the maintenance and sustainability of traditional knowledge is encouraged. From a cultural perspective it certainly does not imply a monopolization of knowledge or limits access to knowledge and innovation. The knowledge can be used under a different product name. ${ }^{82}$ The new regime establishes and protects a link to traditional knowledge, significantly influenced by the region, ${ }^{83}$ materialized in the product, and associated with the product name itself. Overall, a PDO system would oblige producers to adhere to the geographical and the stricter cultural limitations contributing to the preservation and persistence of regional traditional knowledge.

\footnotetext{
${ }^{76}$ See the discussions on the proliferation of Gl instruments in Marette, "Can Foreign Producers Benefit from Geographical Indications under the New European Regulation?" (2009) 10(1) The Estey Centre Journal of International Law and Trade Policy 65.

77 See Teshager Dagne, "Law and Policy on Intellectual Property, Traditional Knowledge and Development: Legally Protecting Creativity and Collective Rights in Traditional Knowledge Based Agricultural Products through Geographical Indications" (2010) 11(1) The Estey Centre Journal of International Law and Trade Policy 68, 99.

78 Josling, "The War on Terroir" (2006) 57(3) J. Ag. Econ. 337, 360, pointed this out, namely that particular Gls "are potentially useful in the development of agri-tourism, where the cultural identity bestowed by the mystique of terroir".

${ }^{79}$ See Katia L. Sidali, “A Sideway Look at Farm Tourism in Germany and in Italy" in Katia L. Sidali and Birgit Schulze (eds), Food, Agri-Culture and Tourism (Berlin: Springer, 2011).

${ }^{80}$ Bérard and Marchenay, "Local Products and Geographical Indications" (2006) 58(187) International Social Science Journal 109.

${ }^{81}$ See Sanders, "Incentives for and Protection of Cultural Expression" (2010) 13(2) J. World Intell. Prop. 81; Rangnekar, "The Socio-economics of Geographical Indications" (2004) UNCTAD-ICTSD Project on IPRs and Sustainable Development, Issue Paper No.8.

${ }^{82}$ See Bernard O'Connor, The Law of Geographical Indications (London: Cameron May Ltd, 2004). See also the successful marketing of Spanish Cava after it was prohibited from calling it "champagne".

${ }^{83}$ Daphne Zografos, Intellectual Property and Traditional Cultural Expression (Cheltenham: Edward Elgar, 2010).
} 


\section{POLICY RECOMMENDATION AND CONCLUSION}

The current Regulation Proposal of the European Community contains some modifications particularly affecting the level of controls, thus increasing the transparency of the GI system. In the eyes of the authors, however, this proposal does not constitute a viable legal basis to solve the numerous, widely discussed criticism by the literature and recognized by the European Union. The critique is focused on sufficiently qualified labels of origin. The previous policy of the European Union faces the dilemma of aiming to incorporate Gls in rural development policy, whereas regional protection rights are only granted in the case of a scientifically based justification for delimiting the product name to its specific region. Otherwise, the baseline of the European Common Market, the prevention of protectionism, is severely challenged. Nevertheless, it is precisely the unambiguous scientific link between origin and measurable product characteristics that is rather the exception than the rule.

The compromises arising from this fundamental contradiction between the previous two regional protection instruments (PDO and PGI) and TSG are not resolved convincingly. In recent years, the number of articles arguing in favour of a stronger differentiation between PDO and PGI ${ }^{84}$ or even in favour of merging or, in contrast, abolishing the two indications ${ }^{85}$ have increased. A study by London Economics, commissioned by the European Commission, shows interesting results ${ }^{86}$ : in many Member States, the slight differentiation between PDO and PGI is regarded as an additional cost of information gathering for consumers, an opinion shared by consumer associations (Belgium, Germany and Italy) as well as producer cooperatives.

This article argues for a more plausible regulation from an information economic perspective as well as a cultural property perspective. The current debate on an amendment of the Gls regulations of the European Union includes similarly radical ideas, which have, nonetheless, not been incorporated in the final version of the Regulation Proposal. On the one hand, this confirms that international or supranational negotiations produce minimal results, rather than merely radical reforms, a phenomenon apparently also applicable to the European Union. ${ }^{87}$ On the other hand, this minimal reform proposal reveals that an interdisciplinary perspective is required to provide evidence-based insights to the design of criteria for GI with regard to the years in existence, regional delimitation, etc. The pressure on international level in fora such as WIPO and WTO additionally points to the need for a more cultural-economic analysis of the Gl regime rather than pure information economics.

As a result, this article argues to drastically modify the existing regulations and suggests keeping only one instrument, namely the PDO, which not only draws on a definite geographical, but also a stricter cultural connection between the product and the region. While Gls generally do not allow for the protection of all types of traditional knowledge, ${ }^{88}$ this reform option would be able to contribute to protect at least one certain kind of traditional knowledge from misappropriation and dilution. The new PDO regime based on tradition could contribute to protecting knowledge attributed to a specific region and manifested in products. In order to evaluate which products fulfil the PDO requirements, it would be helpful to design and regularly apply consumer surveys

\footnotetext{
84 cf. Profeta and Balling, "Evaluierung der Übergangsregelung des Herkunftsschutzes bei Agrarprodukten und Lebensmitteln in Europa gemäß Verordnung (EG) Nr. 510/06 und Verbesserungsvorschläge für die anstehende Modifikation" (2007) 56(4) Agrarwirtschaft 213.

${ }^{85}$ Profeta, Balling, Schoene and Wirsig, "The Protection of Origins for Agricultural Products and Foods in Europe" (2009) 12(6) J. World Intell. Prop. 622.

${ }^{86}$ London Economics, Evaluation of the CAP Policy on Protected Designations of Origin (PDO) and Protected Geographical Indications (PGI) (2008), pp.160-166.

${ }^{87}$ Matthias Lankau, Kilian Bizer and Zulia Gubaydullina, “Die verborgene Effektivität minimaler Resultate in internationalen Verhandlungen: Der Fall der WIPO" in Regina Bendix, Kilian Bizer and Stefan Groth (eds), Die Konstituierung von Cultural Property: Forschungsperspektiven (Göttingen: Universitätsverlag Göttingen, 2010).

${ }^{88}$ Dagne, "Law and Policy on Intellectual Property, Traditional Knowledge and Development" (2010) 11(1) The Estey Centre Journal of International Law and Trade Policy 68; O'Connor, The Law of Geographical Indications (2008); Singhal, “Geographical Indications and Traditional Knowledge" (2004) 3(11) Journal of Intellectual Property Law \& Practice 732.
} 
measuring the perception of PDO candidates. As only agricultural products with a high reputation can prevail on the market, this is an important aspect. The protection of PDO products is justified since only products that have gained high reputation over years are at high risk of being copied and misappropriated.

For all formerly existing products that are no longer produced, acceptable evidence of an undisputed link of the local knowledge with the geographically delimited area should be discussed according to a still arbitrarily set time period, ${ }^{89}$ since in those cases reputation does not seem to be verifiable. How these alternative solutions would support the invention of new regional products and production methods requires further research.

In conclusion, using only one Gl instrument (PDO), in contrast to keeping both PGI and PDO as suggested by option 1 , facilitates a more efficient exchange of information between producers and consumers. This can help to maintain the price of the so-called "tradition-based, reputable" agricultural products, ${ }^{90}$ thus keeping them alive. It simultaneously contributes to the desired promotion of traditional knowledge attributed to products of culinary heritage.

\footnotetext{
${ }^{89}$ The degree of historical ties between GI regions and the product origin is already considered as a decision rule for disputes on whether to register a product as a PDO or a PGI. See Evans, "The Strategic Exploitation of Geographical Indications and Community Trade Marks for the Marketing of Agricultural Products in the European Union" (2010) 1(1) WIPO J. 159, 170, discussing the decision over Bavarian beer.

90 Dagne, "Law and Policy on Intellectual Property, Traditional Knowledge and Development" (2010) 11(1) The Estey Centre Journal of International Law and Trade Policy 68, 88.
} 


\section{CHAPTER IV}

Are Protected Designation of Origin and Geographical Indication DISTINGUISHED BY CONSUMERS?

AN OVERVIEW AND SYNTHESIS OF EMPIRICAL EVIDENCE

Marianna Bicskei 


\section{INTRODUCTION}

The basic rationale of providing geographical indications (Gls) from information economic perspective is to dissolve the information asymmetry related to the actual provenance of the products between producers and consumers. The intention of the European Union (EU) towards Gls is best observed in the fact that before the international community laid the foundation for a multilateral GI system with the Agreement on Trade Related Aspects of Intellectual Property Rights (TRIPS) in 1994 in the realms of the World Trade Organization, the EU had already passed its own regulation on Gls two years earlier. ${ }^{1}$ Up to now more than a thousand products are registered as Gls in the DOOR database ${ }^{2}$ turning the EU sui generis system into one of the most comprehensive supranational regimes.

While granting exactly the same protection level, ${ }^{3}$ the EU offers two instruments for products intended for human consumption. ${ }^{4}$ They may be protected either as designation of origin (PDO) or geographical indication (PGI). ${ }^{5}$ The requirements with regard to the product's grade of regional embeddedness are, however, quite different. To be registered as PDO, a product must be entirely produced in the region of origin, which the name of the product indicates. PGI products require at least one part of the production to be within the defined area.

The question of whether consumers distinguish between these quality schemes is of crucial interest to policy makers and producers. Especially, if consumers are not able to differentiate between PDO and PGI although having different levels of regional (geographical) anchorage, the presence of this dual system even seems to increase the risk of confusing, or misleading consumers as to the true origin of the products. Therefore, the article's objective is to investigate this question by providing a systematic review of empirical evidence related to two streams of literature. After examining the most important differences of these instruments from an information economics perspective, as first, it analyses differences in consumers' awareness and understanding of PDO and PGI. Secondly, the article investigates the comparison of consumers' willingness to pay (WTP) for PDO and PGI providing an additional approach to capture whether consumers distinguish between these instruments. The article's overall aim is to provide insights into the effectiveness of the EU Gls in terms of solving information asymmetries. Furthermore, it presents a guide for future research to justify the existence of these instruments from information economic perspective.

\footnotetext{
${ }^{1}$ Council Regulation No. 2081/92 of 14 July 1992 on the protection of geographical indications and designations of origin for agricultural products and foodstuffs and Council Regulation No. 2082/92 of 14 July 1992 on certificates of specific character for agricultural products and foodstuffs.

${ }^{2}$ The DOOR Database of the EU also includes the category of TSG (Traditional Speciality Guaranteed), which does not constitute a GI. See http://ec.europa.eu/agriculture/quality/door/list.html.

${ }^{3}$ In details, the EU guarantees inter alia protection against any direct and indirect commercial use of a particular name, where the exploitation of the reputation of the protected name is at stake; against any misuse, imitation or evocation even in translated form or accompanied by expressions "style", "type", "method", "as produced in", "imitation" or similar, including ingredients as well (EU Regulation 1151/2012, Art.13 - hereinafter it is referred to as "EU Regulation"). This is, however, a significantly broader scope of protection as envisaged by the TRIPS Agreement, Art. 21.

${ }^{4}$ EU Regulation, Title I, Article 1, Objectives 1, b.

${ }^{5}$ Hereafter commonly referred to them as "EU GIs".
} 


\section{THE EU GI SYSTEM FROM INFORMATION ECONOMICS PERSPECTIVE}

The provision of GIs is justified since geographically embedded products constitute a special kind of credence good. ${ }^{6}$ Unless reliable information is provided on the geographical origin of a product, there exists an information asymmetry between sellers, who (falsely) claim the regional provenance of their product, and its buyers. As shown by Akerlof (1970) such a situation leads to market failure due to adverse selection. Applying the same indication for low quality products (i.e. products of a different provenance) renders it impossible for high quality products having particular quality attributable to the region or origin to prevail on the market. Preventing the market to fail requires limiting the usage of Gls exclusively to those products that truly originate from the specific region. This transforms the region of origin cue, which is a credence attribute of a product, into search one (Crespi and Marette 2003, Teuber et al. 2011). Only this limitation can credibly inform consumers of a product's real provenance. Thus, similarly to trademarks public intervention promoting exclusive Gls prevents consumers from being misled and reduces their costs of obtaining relevant product information. $^{7}$ Overall, the provision of Gls raises social welfare by maintaining the quality of products, which have special characteristics attributable to a place of origin increasingly valued by consumers (Ilbery and Kneafsey 1998).

What is more, due to the fact that GIs are the collective property of all producers within a demarcated region who are allowed to produce GI products, they also require public interventions in order to prevent collective action problems (Olson 1971). It is necessary to coordinate producers of a particular regional product with high reputation in order to ensure a particular product quality for which exclusive rights have been granted (Gangjee 2012). Since collective reputation is at stake, institutions are required to determine and implement quality standards, which have become key elements to the functioning of market mechanisms (Bramley et al. 2009).

In order to address these protection rationales, the $\mathrm{EU}$ implements $\mathrm{PDO}$ and $\mathrm{PGI}{ }^{8}$ to protect geographical names. ${ }^{9}$ While granting the same protection level, ${ }^{10}$ these instruments require rather different degrees of geographical embeddedness. The name of PDO should refer to a product, whose "quality or characteristics are essentially or exclusively due to a particular geographical environment with its inherent natural and human factors". Meanwhile, PGI identifies a product "whose given quality, reputation or other characteristic is essentially attributable to its geographical origin". ${ }^{11}$ Concluding, both instruments should present an intrinsic link between the characteristics of a product and its geographical origin ${ }^{12}$ whatever this is based on. It could for instance reflect a regions'

\footnotetext{
${ }^{6}$ For more detail about credence goods see Nelson (1970) and Darby and Karni (1973).

${ }^{7}$ For the economic function of trademarks, see Landes and Posner (2003), Chapter 7.

${ }^{8}$ The EU has first refined the EC Regulation 2081/1992 in 2006 by passing the revised EC Regulation 510/2006 enabling to open up the EU sui generis system to non-EU countries as well. The second revision phase has been closed with the new EU Regulation No 1151/2012 in 2012 as a result of the review process launched by the European Commission in 2008. Please note that wine sector products are not covered by this EU Regulation. For this, see Regulation (EC) 491/2009; Regulation (EC) 479/2008; Regulation (EU) No 670/2011.

${ }^{9}$ The name should identify the specific product linked to a restricted geographical area in the form as it is used, independent of whether in trade or in common language. Moreover, historical languages are also permitted.

See furthermore EU Regulation, Art. 7.

${ }^{10}$ See footnote 4.

${ }^{11}$ EU Regulation, Art. 5, 1(b) and 2(b)

${ }^{12}$ EU Regulation, p. 2 (17)
} 
culture, know-how or a different kind of reputation. However, the precise distinguishing characteristics between the two instruments are merely based on subjective considerations opening up numerous ways of interpretations.

The requirements of the production steps (production, processing and preparation) are, however, less subjective and very different. A PDO must be related to a product whose entire production shall take place in the demarcated geographical area. Even the packaging itself is declared as a tool of safeguarding the overall quality of a product and must be within the defined region. ${ }^{13}$ Thus, the entire control procedure is carried out within this area offering higher food safety (Henseleit et al. 2007). In contrast, for products registered as PGI it is sufficient when at least one production step is resident in the geographical area the name covers. ${ }^{14}$ Without doubt, the limitation of necessary steps of production greatly reduces the relevance of the demarcated region for its specific products.

All in all, both in terms of a product's intrinsic link to a geographical region as well as its true provenance, PDO and PGI products must convey different information to consumers. Consequently, the question arises: Do consumers receive and understand this information?

In case the product's name is registered as PDO or PGI, it is not mandatory to communicate any additional information on the production steps than the Union GI symbols ${ }^{15}$ and the registered name. The EU Regulation merely allows that "depictions of the geographical area of origin (...) and text, graphics or symbols referring to the Members State and/or region in which that geographical area of origin is located" may appear on the labeling. ${ }^{16}$ This, even though voluntarily applied, leads clearly to help consumers to identify the products with geographical roots but only when the whole production process takes place within this depicted area. Nevertheless, it also does not ensure that, in case of PDO, information about raw materials coming from a geographical area other than the one indicated by the product name is delivered. In particular, the legislation permits the processing and usage of raw materials coming from other regions when its production area is defined and there are special conditions determined for their production. ${ }^{17}$ Moreover, in case of PGIs, even depictions do not explicitly inform whether the production and/or processing and/or preparation are carried out in the region mentioned.

In summary, if the labeling does not provide additional information about the detailed production process and thus about the regional anchorage, then only the compulsory EU GI symbols and the indications' designation of origin or geographical indication (or their abbreviations: PDO or PGI) are a source of information. Thus, solely based on these, consumers only gain information on whether or not they buy a product entirely produced in the geographical area the name of the product identifies, presupposing that they are aware of the clear differences between PDO and PGI products.

So, do consumers really distinguish between PDO and PGI? More precisely, are they protected from being misled as to the geographical origin of the products through the dual system implemented in its current form?

\footnotetext{
${ }^{13}$ EU Regulation, Art.7 (e)

${ }^{14}$ EU Regulation, Art. 5, 1(c), 2(c)

${ }^{15}$ For a comparison of PDO and PGI symbols, see Bicskei et al. (2012).

${ }^{16}$ EU Regulation, Art.12(4)

${ }^{17}$ This exception is only applicable for animals, meat and milk (see EU Regulation, Art. 5 (3)).
} 


\section{PROCEDURE OF THE SYSTEMATIC REVIEW}

To answer these questions the article considers empirical evidence, on the one hand, on consumers' awareness of the dual system in the $\mathrm{EU}$ and, on the other hand, on their' understanding of differences between the EU Gls. Furthermore, in order to control for customers' understanding, measuring the differences between these regimes through their market performance provides a promising approach. Consequently, the article compares consumers' WTP between PDO- and PGIlabeled products in their domestic market being the main destination of EU-GI-labeled products (AND-International 2012). Similarly to trademarks, Gls are expected to provide producers with a price premium above marginal costs (Correa 2002). Theoretically, consumers should be willing to reward producers for their efforts in maintaining distinct quality characteristics if they recognize Gls. Consequently, this article hypothesizes that consumers reveal higher WTP for PDO than for PGI products if they are able to distinguish between them. Since a PDO requires stricter criteria that producers should meet than PGIs, PDOs should increase the consumers' confidence and be perceived as indicating additional value. This must not only relate to the particularities of a products' provenance. Empirical research reveals that some consumers are ethnocentric and value domestic over foreign products in order to support domestic producers (see Teuber et al. 2011, van Ittersum et al. 2007, Lusk et al. 2006). Based on that, it is to be assumed that the WTP for PDO should be higher than for PGIs since it constitutes a stronger regional embeddedness.

To collect observations for answering the research question, the article draws on several databases such as AgEcon Search, ScienceDirect, SpringerLink, Wiley Online Library and Google Scholar. As the first step, studies identified with keywords "geographical indications", "protected geographical indications", "protected designation of origin", "awareness/ recognition" and "willingness to pay" (combined or in abbreviated form) were selected. Since the work done on Gls is immense, the focus was narrowed down to include only empirical studies conducted on Gls implemented by the EU. This eliminates a broad range of conceptual and theoretical considerations and research on associated topics such as country of origin, region of origin and trademarks. Next to these, particular attention was paid to studies funded or maintained by the EU itself, available of respective EU sites. ${ }^{18}$

\section{RECOGNITION OF PDO AND PGI IN THE EU}

In spite of the bulk of empirical research on Gls, only five studies specifically compare customers' recognition between PDO and PGI per se (see Table 1). Four of these studies apply face-to-face interviews as elicitation method. Only Verbeke et al. (2012) use an online-questionnaire. The consumer segment addressed varies across studies and findings are very diverse. In particular, comprehensive research with extensive observations in the early phase of the EU system, such as Eurobarometer 1998 (EC 1998), ${ }^{19}$ as well as recent studies such as Velčovská et al. $(2012)^{20}$, and Special Eurobarometer 2012 (EC 2012a), report a relatively low level of awareness of EU Gls among non-specified (usual) consumers. Accordingly, only a limited proportion of consumers has ever seen

\footnotetext{
${ }^{18}$ See www.europa.eu.

${ }^{19}$ The European Commission has been monitoring the evolution of public opinion in the Member States since 1973 addressing major topics concerning European citizenship. For the Public Opinion Analysis sector of the European Commission see http://ec.europa.eu/public_opinion/index_en.htm. Eurobarometers are based on random (probability) sample design.

${ }^{20}$ Non-probability sample design and judgment sampling technique was used.
} 
registered names and the recognition of the symbols. ${ }^{21}$ Interestingly, countries with a leading position in the EU GI registrations also have their own historically routed origin labeling regimes (such as Appellation d'Origine Contrôlée (AOC) in France, Denominazione di origine controllata (DOC) in Italy or Denominación de Origen (DO) in Spain). This shows that consumers of these countries are more sensitive to origin labeling than consumers of north European countries (Norway, for instance, see Verbeke et al. 2012).

Surprisingly, next to the simple examination of the awareness of EU Gls, the precise understanding of the major characteristics of these instruments has received very limited attention, yet. Most of the research mainly focuses rather on the general meaning of EU GIs not specifying for PDO and PGI (cf. London Economics 2008, van Ittersum et al. 2000). Studies, which pay attention to the understanding of PDO and PGI with regard to credibility (Velčovská et al. 2012), quality and traditional character of the products (Verbeke et al. 2012) are rather the exception. To the best of our knowledge, only one study (Eurobarometer 1998) investigates the precise differences between PDO and PGI concerning the production stages, being the most important factor. The data of Eurobarometer 1998 is, however, obtained in the very early phase of the Gl system and cannot reflect the recently increasing trend of consumer awareness of and interest in the instruments (Verbeke et al. 2012 referring to Arfini et al. 2011).

Summing up, empirical evidence highlights, on the one hand, that awareness of EU Gls might be dependent on the consumer segment addressed. Nevertheless, it can be asserted that general consumers are more or less equally aware of PDO and PGI. Although this awareness is increasing, the overall recognition level of EU Gls is insufficient and far behind other quality schemes such as Fair Trade and Bio (Velčovská et al. 2012, p. 55, London Economics 2008). On the other hand, consumers' understanding of the exact differences between PDO and PGI regarding the regional embeddedness remains undetectable based on the literature.

\section{WILLINGNESS TO PAY FOR EU GIS}

The assessment of consumers' WTP allows for capturing whether consumers distinguish between EU GIs. There is a plethora of case studies that compare consumers' WTP for PDOs and PGIs, which, however, apply diverging empirical methods.

Firstly, there exist choice experiments with hypothetical products, which would support to draw precise conclusions on whether consumers value the same product labeled with PDO more than with PGI. Generally, these studies provide information about the meaning of the labels in advance. Thus, consumers are fully aware about the differences between PDOs and PGIs when revealing their WTP. In such an environment Aprile et al. (2012) find that compared to non-labeled olive oils Italian consumers are willing to pay more on average for Gl-labeled products, and they value PDO even more than PGI. Also targeting olive oils, Menapace et al. (2011) identify the same trend for consumers in Canada. Yet, since WTP is expected to depend on the product type and sector in question (Correa 2002), for the robustness of these findings other product classes covered by the European legislation should be analyzed, as well.

\footnotetext{
21 The data is based on the national Omnibus surveys run by Ipsos. The Omnibus survey captures a representative sample of each Member State (London Economics 2008).
} 
Secondly, there is also a possibility to compare WTP for PDO and PGI by taking real products already registered in the EU from the same product class. For instance, Schamel et al. (2007) compare consumers' WTP for Parma ham (PDO), and black forest ham (PGI) based on auction market data. They find that PDO (Parma) ham sells at higher premium relative to PGI (Black Forest) ham. However, the interpretation of such results should be cautious: WTP for real products on the market carrying real names captures more information than simple hypothetical products. In case of Parma ham, inter alia the reputation of Italian products or the region Parma, and different methods of production can also be responsible for a higher WTP, not only the presence of PDO per se. In addition, it remains unknown whether the obtained difference in price premia is also valid for the period before $\mathrm{Gl}$ registrations. Clearly, different valuations of PDO and PGI products can also be independent of the GI registration. Even previously, customers could have valued Parma ham higher than black forest ham. Summing up, comparing price premia for real products taking other EU GI products as a reference, hardly allows precise comparisons of customers' awareness of differences between the Gl labels.

Another possibility to analyze perceived differences between EU GIs is to compare price premia for PDO or PGI labeled products with generic non-labeled ones of the same product class. Deselnicu et al. (2013) provide the only meta-analysis, ${ }^{22}$ which considers 61 products. ${ }^{23}$ The authors find that PDOs realize higher price premia than PGIs. For the interpretation of their result in the light of this article, however, some factors should be carefully considered. First of all, they also incorporate wines into the analysis, which constitutes a culinary specialty, which is not covered by EU Regulation (No 1151/2012). ${ }^{24}$ Furthermore, they even include such studies that do not focus on the presence or absence of PDO and PGI and its impact on price premia. They only vary the name of the region of origin per se for estimating WTP (such as Stefani et al. 2005, 2006, Santos and Riberio 2005). Consequently, these estimations are misleading and do not value the label per se. Thirdly, their analysis also covers studies, which include regional products as Gls although they have still not been registered as EU GIs at the time of the data collection (cf. Azeite do Alentejo Interior in Santos and Riberio 2005). Thus, the value of the Gl label per se is not possible to be evaluated. Fourthly, as the number of estimations for the products included in their analysis differs, the results they obtained are biased towards the products with many estimations (see Fotopoulos and Krystallis 2003, Loureiro and McCluskey 2000). Considering these particular shortcomings, Deselnicu et al.'s (2013) conclusion that PDO command higher price premia than PGI is not reliable. Consequently, their results are misleading and cannot answer this article's research questions.

As a result, in order to address whether there are differences in WTP for PDO and PGI, the following sections magnify those studies, which deal with products already registered as Gls in the DOOR Database at the time of the data collection. Another criterion is that they establish price premia by taking similar products without GI labels as a reference (i.e., synchronic evaluation, see Barjolle et al. 2009). ${ }^{25}$ Only ten case studies fulfill these requirements (see Table 2).

\footnotetext{
${ }^{22}$ Here, I would like to thank the authors for providing me with their dataset, which enabled me to precisely identify the case studies they considered to belong to PDO and PGI products.

${ }^{23}$ Within their study they included geographical indications covered by institutions other than the EU's, as well. Therefore, this number refers only to those products, which were identified as EU Gls in their database.

${ }^{24}$ See footnote 9.

${ }^{25}$ The data collection started in 2010 within the scope of the research of the Interdisciplinary Research Group on Cultural Property having no knowledge about the ongoing research of Deselnicu et al. (2011).
} 
In total, they examine 24 products of which 92 percent received Gl status between 1996 and 1998, and only 2 of them later than 2000.

Table 2 - Overview of the Products for which WTP was Estimated

\begin{tabular}{|c|c|c|c|c|c|c|}
\hline Product Name (estimates) & Product Class & PDO/PGI & Registr.Date & CoO* & Elic.Meth.** & Author of study (year) \\
\hline 1 Azafrán de la Mancha & 1.8. Other products*** & PDO & 2001 & ES & $R$ & Sanjuán-López et al. (2009) \\
\hline 2 Camembert de Normandie (3) & 1.3. Cheeses & PDO & 1996 & $\mathrm{FR}$ & $\mathrm{R}$ & $\begin{array}{l}\text { Bonnet and Simioni (2001); } \\
\text { Hassan and Monier-Dilhan (2006) }\end{array}$ \\
\hline 3 Casciotta d'Urbino & 1.3. Cheeses & PDO & 1996 & IT & $\mathrm{R}$ & Galli et al.(2011) \\
\hline 4 Fontina & 1.3. Cheeses & PDO & 1996 & IT & $\mathrm{R}$ & Galli et al.(2011) \\
\hline 5 Garda (Olive Oil) & 1.5. Oils and fats & PDO & 1997 & IT & $\mathrm{H}$ & Menapace et al.(2011) \\
\hline 6 Gorgonzola & 1.3. Cheeses & PDO & 1996 & IT & $\mathrm{R}$ & Galli et al.(2011) \\
\hline 7 Feta & 1.3. Cheeses & PDO & 2002 & GR & $\mathrm{H}$ & van Ittersum et al. (2007) \\
\hline 8 Montasio & 1.3. Cheeses & PDO & 1996 & IT & $\mathrm{R}$ & Galli et al.(2011) \\
\hline 9 Murazzano & 1.3. Cheeses & PDO & 1996 & IT & $\mathrm{R}$ & Galli et al.(2011) \\
\hline 10 Noord-Hollandse Edammer & 1.3. Cheeses & PDO & 1996 & $\mathrm{NL}$ & $\mathrm{H}$ & van Ittersum et al. (2007) \\
\hline 11 Opperdoezer Ronde (Potato) & 1.6. Fruit, vegetables & PDO & 1996 & $\mathrm{NL}$ & $\mathrm{H}$ & van Ittersum et al. (2007) \\
\hline 12 Parma Ham (2) & 1.2. Meat products & PDO & 1996 & IT & $\mathrm{H}$ & $\begin{array}{l}\text { Arfini (2000); } \\
\text { van Ittersum et al. (2007) }\end{array}$ \\
\hline 13 Parmigiano-Reggiano (2) & 1.3. Cheeses & PDO & 1996 & IT & $\mathrm{H}$ & $\begin{array}{l}\text { Arfini (2000); } \\
\text { van Ittersum et al. (2007) }\end{array}$ \\
\hline 14 Pecorino Romano & 1.3. Cheeses & PDO & 1996 & IT & $\mathrm{R}$ & Galli et al.(2011) \\
\hline 15 Pecorino Siciliano & 1.3. Cheeses & PDO & 1996 & IT & $\mathrm{R}$ & Galli et al.(2011) \\
\hline 16 Pecorino Toscano & 1.3. Cheeses & PDO & 1996 & IT & $\mathrm{R}$ & Galli et al.(2011) \\
\hline 17 Peza Irakliou Kritis & 1.5. Oils and fats & PDO & 1996 & GR & $\mathrm{H}$ & Fotopoulos and Krystallis (2001) \\
\hline 18 Raschera & 1.3. Cheeses & PDO & 1996 & IT & $\mathrm{R}$ & Galli et al.(2011) \\
\hline 19 Robiola di Roccaverano & 1.3. Cheeses & PDO & 1996 & IT & $\mathrm{R}$ & Galli et al.(2011) \\
\hline 20 Taleggio & 1.3. Cheeses & PDO & 1996 & IT & $\mathrm{R}$ & Galli et al.(2011) \\
\hline 21 Ternera Gallega (Galician veal) (6) & 1.1 Fresh meat & PGI & 1996 & ES & $\mathrm{H}$ & Loureiro and McCluskey (2000) \\
\hline 22 Terra di Bari (Olive Oil) & 1.5. Oils and fats & PDO & 1997 & IT & $\mathrm{H}$ & Menapace et al.(2011) \\
\hline 23 Toscano (Olive Oil) (2) & 1.5. Oils and fats & PGI & 1998 & IT & $\mathrm{H}$ & Menapace et al.(2011) \\
\hline 24 Mila Zagoras Piliou (Apples) (4) & 1.6. Fruit, vegetables & PDO & 1996 & GR & $\mathrm{H}$ & $\begin{array}{l}\text { Fotopoulos and Krystallis (2003); } \\
\text { van Ittersum et al. (2007) }\end{array}$ \\
\hline
\end{tabular}

Although having a coherent selection of studies, for the interpretation of the dataset in the light of the research question some factors deserve particular attention. To begin with, only 6 of a total of 23 possible product classes ${ }^{26}$ are covered by these case studies. What is more, the product class of cheeses is overrepresented since more than half of the observations (63 percent) relate to it. The categories "olive oils", "fresh meat and meat products", "fruits and vegetables" represent only 17, 8 and 8 percent of the sample, respectively. Furthermore, the sample only represents products of very few countries, namely Italy, Spain, Greece, France and the Netherlands. These are actually the biggest promoters of GIs (except the Netherlands) having the highest number of registrations in the EU DOOR register. ${ }^{27}$ Among these, Italy provides the highest number of products in the sample, particularly within the class of "oils and cheeses". Correspondingly, the representation of only few product types mostly of countries with long traditions in origin labeling does not allow precise interpretation the WTP data with respect to the consumers' valuation of PDO and PGI.

The biggest obstacle to shed light on whether consumers value PDO and PGI differently based on their WTP, is, however, that there are 8 estimations for PGI from two studies (Loureiro and McCluskey 2000, Menapace et al. 2011). These relate to only 2 products (Galician veal and Tuscan

\footnotetext{
${ }^{26}$ See the DOOR database: http://ec.europa.eu/agriculture/quality/door/list.html.

${ }^{27}$ The number of registered products per countries: 254 (IT), 200 (FR), 164 (ES), 99 (GR), and 9 (NL) inclusive the category of Traditional Speciality Guaranteed (TSG) according to the DOOR database, accessed on 25.07.2013.
} 
olive oil, respectively). The rest (22 products) of the sample's products is registered as PDO. Moreover, for PDO products there exist estimations based on both real (based on market data) and hypothetical purchase. For PGI only hypothetical WTP is available. Furthermore, taking into consideration how many years after the registration the study was conducted, there is an inconsistency between PDO and PGI, again. While in case of PDO the average time lag between the registration and the study is 7 years, the PGI Ternera Gallega (Galician veal) study has been conducted only one year after the registration, and the Toscano olive oil was examined 8 years after the registration, yielding an average 4.5 year time lag. Some time left after the registration is, however, required during which consumers develop their awareness and knowledge about EU GI products.

In conclusion, although the bulk of empirical research on WTP provides many approaches on how to assess those possible differences of PDO and PGI, it does not support the reliable determination of whether consumers differentiate between these instruments.

\section{SUMMARY AND CONCLUSION}

This article investigates whether consumers distinguish between PDO and PGI. This is of high relevance since even after two revision phases the European Union further maintains the dual GI system despite its serious shortcomings. Generally, Gls should serve as a tool to dissolve the information asymmetry between producers and consumers as to the true origin of the products. Yet, PDO and PGI constitute quite divergent degrees of geographical anchorage. The EU system, however, does not require the provision of information in addition to the Gl symbols and names, for instance, on the production stages within the geographical region. Thus, unless consumers recognize the precise qualitative differences between both instruments, there is a high risk of confusion as to the true origin of the products jeopardizing the information economic rationale behind the protection of Gls.

The article addresses this question by integrating and synthesizing empirical findings related to consumers' awareness of and willingness to pay for PDO and PGI. Based on that, it shows that PDO and PGI are more or less similarly recognized among general consumers. It is, however, unclear whether they precisely understand the differences regarding the geographical embeddedness of PDO and PGI due to the lack of relevant studies. The state-of-the-art of research on WTP, for instance, delivers insights into very few product types of mostly agricultural countries with long traditions in origin labeling. Consumers of these countries could thus be more sensitive to origin labeling and thus reveal a biased perception, which does not necessarily hold if interpreted for the entire EU. In addition, it is methodologically quite difficult to clearly quantify the difference in WTP in case of real products irrespective inter alia of the product's type, the sector in question, the production and marketing methods applied (Correa 2002). Consequently, research with hypothetical products of different types should be maintained in future research. Providing consumers with an explanation of PDO and PGI in advance could deliver evidence whether consumers value the same product with PDO differently than with PGI. Finally, there is a need for the promotion of the awareness of PDO and PGI per se and their relation to the region of origin. The existing practice of the EU, however, rather 
promotes particular projects related to registered products, not to the recognition of the EU dual system per se. ${ }^{28}$

Policy-makers and producers must understand how the GI instruments are valued by consumers in order to be aware of their effectiveness in terms of solving information asymmetries. In case consumers do not recognize the differences between PDO and PGI, it renders even the strongest instrument, the PDO, ineffective in its capability to provide better opportunities for economic success. Unfortunately, the existing empirical evidence is insufficient to draw a conclusion on whether consumers distinguish between these quality labels. Thus, it still remains unknown whether the existence of two Gl instruments is economically justified.

\section{ACKNOWLEDGEMENT}

This research is part of the Interdisciplinary Research Group on Cultural Property funded by Deutsche Forschungsgemeinschaft (DFG, FOR 772). I would like to gratefully acknowledge the constructive comments by Kilian Bizer, András Dobó, Matthias Lankau, participants at the International Symposium on Taste, Power, Tradition - Geographical Indications as Cultural Property in Tübingen (2013) and Marten von Werder for his great research assistance.

\footnotetext{
${ }^{28}$ Recently the EU approved again a $€ 27,15$ million EU support for the promotion of particular agricultural products in the European Union and in third countries inclusive for PDO and PGI products for a period of three years (EC 2012b).
} 


\section{REFERENCES}

Akerlof, G. A. (1970): The Market for "Lemons": Quality Uncertainty and the Market Mechanism. In: The Quarterly Journal of Economics 84 (3), 488.

AND-International (2012): Value of production of agricultural products and foodstuffs, wines, aromatised wines and spirits protected by a geographical indication (GI). Final Report, TENDER $\mathrm{N}^{\circ}$ AGRI-2011-EVAL-04.

Aprile, M. C.; Caputo, V.; Nayga Jr, R. M. (2012): Consumers' valuation of food quality labels: the case of the European geographic indication and organic farming labels. In: International Journal of Consumer Studies 36 (2), 158-165.

Arfini, F. (2000): The value of typical products: the case Prosciutto di Parma and Parmigiano Reggiano cheese. In: Sylvander, B.; Barjolle, D.; Arfini, F. (eds): The Socio-Economics of Origin Labelled Products in Agro-Food Supply Chains: Spatial, Institutional and Co-ordination Aspects. Paris: INRA, 10-45.

Arfini, F.; Albisu, L. M; Giacomini, C. (2011): Current situation and potential development of geographical indications in Europe. In: Barham, E.; Sylvander B. (eds.): Labels of origin for food: Local development, global recognition. Wallingford: CAB International, 29-44.

Barjolle, D.; Paus, M.; Perret, A. (2009): Impacts of Geographical Indications Review of Methods and Empirical Evidences. Paper presented at the IAAE Conference Beijing, China, August 2009. http://ideas.repec.org/p/ags/iaae09/51737.html.

Bicskei, M.; Bizer, K.; Sidali, K. L.; Spiller, A. (2012): Reform Proposals on the Geographical Indications of the European Union for the Protection of Traditional Knowledge. In: The WIPO Journal 3 (2), 224238.

Bonnet, C.; Simioni, M. (2001): Assessing consumer response to protected designation of Origin labelling: a mixed multinomial logit approach. In: European Review of Agricultural Economics 16 (4), 433-449.

Bramley, C.; Biénabe, E.; Kirsten, J. (2009): The economics of geographical indications: towards a conceptual framework for geographical indication research in developing countries. In: The Economics of Intellectual Property. Suggestions for Further Research in Developing Countries and Countries with Economies in Transition, WIPO, January, 2009, 109-149.

Correa, M. C. (2002): Protection of geographical indications in Caricom countries. Paper prepared for CARICOM. http://www.iadb.org/intal/intalcdi/PE/2009/03454.pdf.

Crespi, J. M.; Marette, S. (2003): Some economic implications of public labeling. In: Journal of Food distribution research 34 (3), 83-94.

Darby, M. R.; Karni, E. (1973): Free Competition and the Optimal Amount of Fraud. In: Journal of Law and Economics 16 (1), 67-88.

Deselnicu, O.; Costanigro, M.; Souza-Monteiro, D. M.; McFadden, D. T. (2011): A meta-analysis of geographical indication food valuation studies. What drives the premium for origin based labels? In: AAWE Working Paper No. 93.

Deselnicu, O.; Costanigro, M.; Souza Monteiro, D. M.; McFadden, D. T. (2011): What Determines the Success of a Geographical Indication? A Price-based Meta-Analysis for Gls In Food Products. In: 
Selected Paper prepared for presentation at the Agricultural \& Applied Economics Association's 2011 AAEA \& NAREA Joint Annual Meeting, Pittsburgh, Pennsylvania, July 24-26, 2011.

Deselnicu, C. O.; Costanigro, M.; Souza-Monteiro, D. M.; McFadden, D. T. (2013): A Meta-Analysis of Geographical Indication Food Valuation Studies: What Drives the Premium for Origin Based Labels? In: Journal of Agricultural and Resource Economics (Forthcoming).

European Commission (1998): Eurobarometer 50.1, November-December 1998. Information Society Services, Food Quality, the Family, and Aid to Development. Conducted by INRA, Brussels. GESIS Data Archive, Cologne. ZA3086 Data file Version 1.0.1, doi:10.4232/1.10828. (Eurobarometer 1998).

European Commission (2012a): Special Eurobarometer 389, March 2012. Europeans' attitudes towards food security, food quality and the countryside. Conducted by TNS Opinion \& Social, Brussels. (Special Eurobarometer 2012)

http://ec.europa.eu/public_opinion/archives/ebs/ebs_389_en.pdf.

European Commission (2012b): $€ 27.15$ million EU support for the promotion of agricultural products in the European Union and in third countries. Press release. Brussels, IP/12/1211.

European Union (14.12.2012): Regulation (EU) No 1151/2012 of the European Parliament and of the Council of 21 November 2012 on quality schemes for agricultural products and foodstuffs. In: OJ L343.

Fotopoulos, C.; Krystallis, A. (2001): Are Quality Labels a Real Marketing Advantage? A Conjoint Application on Greek PDO Protected Olive Oil. In: Journal of International Food \& Agribusiness Marketing 12 (1), 1-22.

Fotopoulos, C.; Krystallis, A. (2003): Quality labels as a marketing advantage: The case of the 'PDO Zagora' apples in the Greek market. In: European Journal of Marketing 37 (10), 1350-1374.

Galli, F.; Carbone, A.; Caswell, J. A.; Sorrentino, A. (2011): A Multi - Criteria Approach to Assessing PDOs/PGIs: An Italian Pilot Study. In: International Journal on Food System Dynamics 2 (3), 219-236.

Gangjee, D. S. (2012): Geographical Indications and Cultural Heritage. In: The WIPO Journal 4 (1), 92102.

Hassan, D.; Monier-Dilhan, S. (2006): National Brands and Store Brands: Competition Through Public Quality Labels. In: Agribusiness 22 (1), 21-30.

Henseleit, M.; Kubitzki, S.; Teuber, R.(2007): Determinants of Consumer Preferences for Regional Food. European Association of Agricultural Economists; 105th Seminar, March 8-10, 2007, Bologna, Italy.

Ilbery, B.; Kneafsey, M. (1998): Product and Place: Promoting Quality Products and Services in the Lagging Rural Regions of the European Union. In: European Urban and Regional Studies 5 (4), 329341.

Landes, W. M.; Posner, R. A. (2003): The economic structure of intellectual property law. Cambridge, Mass: Harvard University Press.

London Economics (2008): Evaluation of the CAP policy on protected designations of origin (PDO) and protected geographical indications (PGI).

Final report. http://ec.europa.eu/agriculture/eval/reports/pdopgi/. 
Loureiro, M. L.; McCluskey, J. J. (2000): Assessing consumer response to protected geographical identification labeling. In: Agribusiness 16 (3), 309-320.

Lusk, J. L.; Brown, J.; Mark, T.; Proseku, I.; Thompson, R.; Welsh, J. (2006): Consumer Behavior, Public Policy, and Country-of-Origin Labeling. In: Rev Agricultural Economics 28 (2), 284-292.

Menapace, L.; Colson, G.; Grebitus, C.; Facendola, M. (2011): Consumers' preferences for geographical origin labels: evidence from the Canadian olive oil market. In: European Review of Agricultural Economics 38 (2), 193-212.

Nelson, P. (1970): Information and Consumer Behavior. In: Journal of Political Economy 78 (Mar.Apr.), 311-329.

Olson, M. (1971): The Logic of collective action. Public goods and the theory of groups (2nd ed.). Cambridge, Mass: Harvard University Press.

Regulation (EC) 2081/92: Council Regulation 2081/92 of July 14, 1992 on the protection of geographical indications and designations of origin for agricultural products and foodstuffs [1992]. In: OJ L208/1.

Regulation (EC) 510/2006: Council Regulation 510/2006 of March 20, 2006 on the protection of geographical indications and designations of origin for agricultural products and foodstuffs. In: OJ L93/12.

Regulation (EC) 479/2008: Council Regulation (EC) No 479/2008 of 29 April 2008 on the common organisation of the market in wine, amending Regulations (EC) No 1493/1999, (EC) No 1782/2003, (EC) No 1290/2005, (EC) No 3/2008 and repealing Regulations (EEC) No 2392/86 and (EC) No 1493/1999. In: OJ L148.

Regulation (EC) 491/2009: Council Regulation (EC) No 491/2009 of 25 May 2009 amending Regulation (EC) No 1234/2007 establishing a common organisation of agricultural markets and on specific provisions for certain agricultural products (Single CMO Regulation). In: OJ L 154.

Regulation (EU) No 670/2011: Commission Implementing Regulation (EU) No 670/2011 of 12 July 2011 amending Regulation (EC) No 607/2009 laying down certain detailed rules for the implementation of Council Regulation (EC) No 479/2008 as regards protected designations of origin and geographical indications, traditional terms, labelling and presentation of certain wine sector products. In: OC L 183, 6-13.

Sanjuán-López, A. I.; Resano-Ezcaray, H.; Camarena-Gómez, D. M. (2009): Developing marketing strategiesfor Jiloca saffron: a price hedonic model. In: Spanish Journal of Agricultural Research 7 (2), 305-314.

Santos, J. F.; Riberio, J. C. (2005): Product attribute saliency and region of origin: some empirical evidence from Portugal. Paper prepared for presentation at the 99th seminar of the EAAE (European Association of Agricultural Economists), "The Future of Rural Europe in the Global Agri-Food System", Copenhagen, Denmark.

Schamel, G. (2007): Auction markets for specialty food products with geographical indications. In: Agricultural Economics 37, 257-264. 
Stefani, G.; Romano, D.; Cavicchi, A. (2005): Region of Origin and consumer willingness to pay for specialty foods: an economic approach applied to three Italian Spelt types. Working Paper, Department of Agriculture and Resource Economics, University of Florence, Italy.

Stefani, G.; Romano, D.; Cavicchi, A. (2006): Consumer expectations, liking and willingness to pay for specialty foods: Do sensory characteristics tell the whole story? In: Food Quality and Preference 17 (1-2), 53-62.

Teuber, R.; Anders, S.; Langinier, C. (2011): The Economics of Geographical Indications: Welfare Implications. RéseauSPAANetwork Working Paper, 2011-6.

van Ittersum, K.; Candel, M.; Thorelli, F. (2000): The market for PDO/PGI protected regional products: consumer attitudes and behaviour. In: Sylvander, B.; Barjolle, D.; Arfini, F. (eds): The Socio-Economics of Origin Labelled Products in Agro-Food Supply Chains: Spatial, Institutional and Co-ordination Aspects. Paris: INRA, 209-221.

van Ittersum, K.; Meulenberg, M. T. G.; van Trijp, H.; Candel, M. (2007): Consumers' Appreciation of Regional Certification Labels: A Pan European Study. In: Journal of Agricultural Economics 58 (1), 123.

Velčovská, Š.; Janáčková, H.; Larsen, F. R. (2012): Food Quality Labels; Insights from Customers in Two Selected European Countries. In: International Journal of Trade, Economics and Finance 3 (1).

Verbeke, W.; Pieniak, Z.; Guerrero, L.; Hersleth, M. (2012): Consumers' Awareness and Attitudinal Determinants of European Union Quality Label Use on Traditional Foods. In: Bio-based and Applied Economics 1 (2), 213-229.

World Trade Organization (1994): Agreement on Trade-Related Aspects of Intellectual Property Rights (TRIPS). Apr. 15, 1994, Marrakesh Agreement Establishing the World Trade Organization, Annex 1C, The legal texts: the results of the Uruguay round of multilateral trade negotiations 320 (1999), 1869 U.N.T.S. 299, 33 I.L.M. 1197 (1994). 


\title{
ChAPTER V
}

Cooperation Preferences in the Provision of Public Goods

- AN EXPERIMENTAL STUdY ON THE EFFECTS OF SOCIAL IDENTITY

\author{
Matthias Lankau, Marianna Bicskei, Kilian Bizer
}




\section{Introduction}

Recent literature on social identity demonstrates that social preferences vary depending on the social environment. Experimental research by Chen and Li (2009), for instance, shows that when interacting with individuals of a common identity subjects reveal a significantly higher degree of positive reciprocity than when interacting with individuals of different identities. Additionally, they are more likely to make social welfare maximizing choices. Although having immediate relevance for the provision of public goods, this relationship has not been experimentally analyzed, so far. Consequently, we ask whether subjects hold differing cooperation preferences in the provision of public goods under the institution of social identity, making salient the persons' identity with which an individual interacts. To this purpose, we induce social identity in the laboratory by having subjects solve a simple group identity task with anonymous communication via chat. The experiment features a within-subject design that is based on one-shot public good games using the strategy method, which is an often used method for the elicitation of cooperation preferences. ${ }^{1}$ Three matching protocols are in effect: in-group matching, when subjects interact with individuals of their own identity; out-group matching, when groups are composed of subjects of different identities and random matching, in which no identity is induced, serving as a control.

Our results clearly show that cooperation preferences in public good provision vary depending on the social environment. In particular, we find that when matched with individuals of a common identity, subjects consistently show the preference for higher levels of conditional cooperation and thus less self-serving bias than when interacting with individuals that are perceived to belong to different identities. What is more, we identify an elevated propensity to be a free-rider when being matched with individuals of a different identity than in in-group matching. These findings have direct relevance for positive predictions of policy effects. Social identity systematically activates different preferences to cooperate with one-another which directly influences social welfare. It is thus reasonable to devise institutions that stress the belonging to the group providing a public good.

The remainder of the article is organized as follows. Section 2 reviews the relevant literature on cooperation preferences in public goods provision as well as on social identity and formulates the research hypotheses. Section 3 presents the experimental design, which is followed by a detailed presentation of our results. The article concludes in section 5 and derives implications for economic policy.

\section{State of Research and Hypotheses}

\subsection{Literature Review}

Cooperation preferences in public goods provision were first empirically analyzed by Fischbacher et al. (2001). Using a variant of the strategy method (Selten, 1967) in a one-shot public good game the authors elicited subjects' contributions as a function of the average contributions of their group members. The authors find that 50 percent of the subjects can be classified as conditional cooperators, i.e. subjects whose contributions are positively correlated with the level of others'

\footnotetext{
${ }^{1}$ Obviously, preferences do not lend themselves to direct measurement. We are aware of the fact that all the strategy method may enable us is to observe subjects' responses to other subjects' hypothetical behavior and to measure cooperation strategies. However, these allow for an approximation of actual cooperation preferences (cf. Volk et al., 2012).
} 
average contributions, and 30 percent as free riders. ${ }^{2}$ Similar findings were reported in various replication studies, reviewed by Chaudhuri (2011).

While free-riding is best explained by assuming individuals maximize their own utility instead of the groups' utility based on purely selfish preferences, conditional cooperation may be understood best as social preference for positive reciprocity (cf. Falk, 2003, p. 147). ${ }^{3}$ As per Fehr and Fischbacher (2002, p. C3-C4) a positive reciprocal individual "[...] responds to actions that are perceived to be kind in a kind manner [...]". In that sense, conditional cooperators perceive high contributions of their remaining group members to be a kind action and reciprocate this kindness by high own contributions. It is to be noted, however, that even conditional cooperators show a self-serving bias to some extent since on average they do not reciprocate their team members' contributions by an equal own contribution (perfect conditional cooperation), but depart in the selfish direction. This has direct bearing on the amount of public good provided, especially in long term interactions. Fischbacher and Gächter (2010), for instance, argue that the self-serving bias alone may be responsible for decaying public good contributions in the long run. ${ }^{4}$

To which extent these heterogeneous cooperation preferences differ between institutional settings, has merely received little academic attention, so far. Existing studies typically compare individuals' decisions in different games or variants of the same game (cf. Blanco et al., 2011). Yet, to the best of our knowledge in case of public goods provision there exists no study that specifically examines differences in cooperation preferences in relation to social identity.

The origin of experimental economic research on social identity defined as "[...] a person's sense of self derived from perceived membership in social groups" (Chen and Li, 2009, p. 431), lays in the social identity theory pioneered by Tajfel and Turner (1979). This theory was developed in order to establish the psychological foundations of discriminatory behavior and comprises three components - categorization, identification and comparison. Categorization denotes the apparently quick process of placing individuals including oneself into certain social categories such as religious, ethnic or other groups. The second process, identification, characterizes the process by which individuals associate themselves with certain groups - the in-group(s). Conversely, out-groups are social groups that an individual does not identify with. In the last process of social comparison individuals start to compare their in-group with the out-group, which generally leads to in-group favoritism and out-group discrimination (cf. Tajfel and Turner, 1986; Chen and Li, 2009; Hoff and Pandey, 2006). ${ }^{5}$ This phenomenon, termed as in-group bias, is increasingly attributed to the different expectations on the behavior of in-group as opposed to out-group members (cf. Yamagishi et al., 1999; Yamagishi and Kiyonari, 2000; Jackson, 2011; loannou et al., 2012).

\footnotetext{
2 The remaining types are either "hump-shaped cooperators", i.e. individual whose contributions are positively correlated with the average of the others up to a maximum and then decline again, or belong to the class "others".

${ }^{3}$ Conditional cooperation may as well be explained by the social preference for inequity aversion, as modeled by Fehr and Schmidt (1999) and Bolton and Ockenfels (2000). Nevertheless, in this article we will proceed by referring to positive reciprocity.

${ }^{4}$ Additionally, the heterogeneity of cooperation types may explain decaying contributions to public goods as well. In the course of repeated interactions, conditional cooperators may get increasingly frustrated by interacting with individuals that are free-riding on their contributions and react with lower own contributions, as well (Burlando and Guala, 2005).

${ }^{5}$ See Chen and $\mathrm{Li}$ (2009) for a detailed account on theoretical and empirical findings on social identity theory.
} 
Studies outside the public goods environment show furthermore that social identity positively influences social welfare when individuals interact with in-group matches as opposed to random ${ }^{6}$ and/or out-group matching. These findings thus provide a hint that in case of public good provision subjects may exhibit a stronger preference for cooperation, as well. Firstly, studying the effects of social identity on social preferences in dictator and two-person response games, Chen and Li (2009) find that group identity has a significant positive effect on the likelihood of social welfare maximizing choices. The authors consequently predict that "in games with a unique Pareto-efficient outcome, people with salient group identities are more likely to choose cooperation when matched with an ingroup member" (Chen and Li, 2009, p. 447). Next, employing a two-player coordination game with induced social identity Charness et al. (2007) equally find that a salient group identity may enhance social welfare, depending on the institutional structure. They manipulate the saliency of group membership by varying whether the decision maker's group is present when decisions are made, whether feedback is given about the outcome of the game and whether there is payoff dependence. Similarly, McLeish and Oxoby (2007), verify that individuals show higher cooperation with in-group than with out-group matches, measured by the offers extended by the proposer in a two person response experiment with induced social identity. Making use of real identification with Swiss army platoons, Goette et al. (2006) similarly identify greater cooperation in a prisoners' dilemma game when individuals are matched with members of their own platoon. Lastly, Chen and Chen (2011) detect that in in-group matching individuals coordinate to the socially efficient high effort equilibrium in minimum-effort games. All in all, these findings demonstrate that social identity renders individuals more likely to strive for social welfare when matched with in-group members.

What is more, two studies establish a direct connection between social identity and the preference for conditional cooperation, by revealing that social identity impacts on subjects' preferences for positive reciprocity. Firstly, based on the results of a series of two-person response games in a within-subject design, Chen and Li (2009) find that when matched with in-group members individuals reward perceived "good behavior" to a higher extent than when matched with out-group members. Specifically, individuals exhibit a significant 19 percent increase in positive reciprocity (Chen and Li, 2009, p. 445). ${ }^{7}$ Secondly, relying on a between-subject design and a similar game setting Currarini and Mengel (2012) report a 34 percent higher positive reciprocity in in-group matching. Since positive reciprocity is the theoretical foundation for conditional cooperation, we similarly expect social identity to impact on subjects' preferences for conditional cooperation in public goods provision by increasing the amounts individuals reciprocate to the rest of the group given their alternative average contributions.

At the moment, however, there are only two studies focusing on how social identity impacts on public goods provision (Solow and Kirkwood, 2002; Eckel and Grossman, 2005). Yet, neither of them specifically allows drawing conclusion on its impact on cooperation preferences. Most insights can be gained from Eckel and Grossman (2005), who employ different treatments designed to induce increasing strengths of identity. The authors find that enhanced team identification yields consistently higher cooperation levels indicating less free-riding in general. Unfortunately, the

\footnotetext{
${ }^{6}$ In random matching subjects interact with others that are not perceived to belong to any particular identity.

${ }^{7}$ Additionally, subjects are significantly more forgiving for "bad behavior", i.e. they exhibit less negative reciprocity (Chen and Li, 2009, p. 445).
} 
authors analyze aggregate data only making it impossible to elicit whether increased contributions are due to differences in conditional cooperation or for instance because free-riders adjust their behavior.

\subsection{Research Hypotheses}

Based on the current state of literature we formulate the following research hypothesis. Drawing on Chen and Li (2009), subjects exhibit the preference for higher degrees of positive reciprocity in inthan in out-group matching. Consequently, we expect in-group matches to reciprocate others' average contributions to a higher degree than out-group matches.

HYPOTHESIS 1A: When matched with in-group members, subjects reveal the preference for higher levels of conditional cooperation than in out-group matching.

A matching of subjects at random, without identity influence, nevertheless creates a general feeling of belonging together, since individuals interact with others that are perceived as "group members". This feeling might be less strong than between in-group matches where subjects saliently belong to their own identity. Yet, it might be stronger than in out-group matching, because here subjects saliently belong to different identities (cf. Chen and Chen, 2011), which often leads to out-group discrimination (see Section 2.1). Therefore:

HYPOTHESIS 1B: When subjects are matched randomly, they will reveal the preference for less conditional cooperation than when matched with in-group members.

HYPOTHESIS 1C: When subjects are matched randomly, they will reveal the preference for more conditional cooperation than when matched with out-group members.

Depending on the strength of the identity effect on conditional cooperation, individuals might exhibit different propensities to be a certain cooperation type. Therefore:

HYPOTHESIS 2A: When matched with in-group members, subjects show a higher propensity to be a conditional cooperator and a lower propensity to be a free-rider than in out-group matching.

HYPOTHESIS 2B: In-group matching yields a higher relative share of conditional cooperators than out-group matching. Similarly, there will be less free-rider in in- than in out-group matching.

\section{Experimental Design}

Our experiment follows a within-subject design and is based on a public good game in strategy method (cf. Fischbacher et al., 2001). Generally, groups comprised three subjects each possessing 20 points that could be invested either in their private account $\left(20-g_{i}\right)$ or into a project, symbolizing the public good. The payoffs associated with this decision were given by the following formula:

$$
\pi_{i}=\left(20-g_{i}\right)+0.4 \sum_{j=1}^{3} g_{j}
$$

Accordingly, it is individually more beneficial to invest into the private account, because it returns 1 point for each point invested instead of 0.4 points returned by the project. Basically, subjects had to make two decisions, an unconditional and a conditional contribution to the public good. Their 
unconditional contribution was simply the decision of how many of their 20 points they would like to invest in the public good. Here, they were asked to state what they expect the remaining group members will invest unconditionally, as well. For their conditional contribution subjects were asked to fill out a contribution table consisting of 21 entries for which they had to decide how much they would invest if their group members invested on average (round to the next higher integer value) 0 20 points in the public good. After both decisions were taken, a random mechanism ${ }^{8}$ chose one group member that was to contribute according to her conditional contribution decision. The remaining two group members contributed according to their unconditional contributions.

The experimental design consisted of four stages in which subjects played the public good game in three different matching protocols (see Table 1). Please note that in each matching the game was played only once in order to directly conclude on subjects' cooperation preferences, ruling out any strategic or reputational motivations that might be prevalent in long term interactions with stable group membership (cf. Fehr and Fischbacher, 2002). ${ }^{9}$

\begin{tabular}{|c|c|c|c|}
\hline Stage & \multicolumn{2}{|c|}{ Identity (ID) Treatments } & Control Treatments \\
\hline 1 & \multicolumn{2}{|c|}{ Random Matching } & Random Matching \\
\hline 2 & \multicolumn{2}{|c|}{ Group Identity Task } & Random Matching \\
\hline 3 & $\begin{array}{c}\text { In-Group } \\
\text { Matching }\end{array}$ & $\begin{array}{c}\text { Out-Group } \\
\text { Matching }\end{array}$ & Random Matching \\
\hline 4 & $\begin{array}{c}\text { Out-Group } \\
\text { Matching }\end{array}$ & $\begin{array}{c}\text { In-Group } \\
\text { Matching }\end{array}$ & \\
\hline
\end{tabular}

Table 1 - The Experimental Design

In stage 1 the public good game was played with subjects being randomly assigned to different groups (random matching). In stage 2 we induced a strong form of social identity based on insights of Eckel and Grossman (2005) and Chen and Li (2009) using a design pioneered by Ibañez and Schaffland (2012). We randomly assigned subjects to different groups with each group having been given a different color. These groups were then given a joint problem solving task in order to create a positive group experience (Eckel and Grossman, 2005). Given 10 minutes time, subjects had to jointly find hidden objects in a picture and report coordinates of their location (row and column). ${ }^{10}$ To this purpose, subjects could discuss solutions with their group members via an online chat tool. In order to elevate subjects' propensity to coordinate and to render this task a true group exercise, our instructions explicitly stated that answers would only count as correct should each group member enter them correctly. The task was played as a tournament in which the group with the highest number of objects found won. In order to prevent negative associations from not winning this task, only the winning team received a congratulation message at the end of the experimental session. The remaining teams were not provided with information about their results and position relative to

\footnotetext{
${ }^{8}$ A dice was thrown by one participant in a session that determined the respective group member.

${ }^{9}$ We are aware that the strategy method could be demanding and that subject could be confused making their initial decisions. Yet, since we mainly analyze stage 3 and 4 we are confident that confusion was reduced to a minimum.

${ }^{10}$ Please see Appendix 6 for the instructions used in this experiment.
} 
the other groups. Lastly, there were no monetary incentives for winning this game avoiding any income effects.

In the following two stages ( 3 and 4 ) subjects were matched with individuals belonging to the same group that solved the identity task (in-group matching, stage 3 or 4 ) as well as with subjects belonging to different identities (out-group matching, stage 4 or 3). The individuals' identities were made salient by indicating the color of their group. In out-group matching for instance subjects thus saw that they interacted with two individuals of different color groups (blue, red and green, for instance). We switched the order of playing in-group and out-group matching to control for possible sequence effects. In order to compare in- and out-group with random matching accounting for the stages when decisions are made, we carried out control treatment, in which subjects played three times the one-shot public good game in random matching.

Since the instructions were handed in successively, subjects learned the matching procedure only during the experiment. Additionally, any information on payoffs was only revealed after the experiment's last stage. In case of the ID-treatments random matching was always played in stage 1 followed by the induction of social identity. Its main purpose is to identify player types without any identity influence, as done by Fischbacher et al. (2001), for instance, and to analyze their behavior in our ID-treatments. Please note that due to the different time stages our design does not allow a coherent comparison of decisions taken in in- or out-group matching with random matching of the ID-treatments. To this purpose we ran the control treatments.

The experiment was carried out in the Göttingen Laboratory of Experimental Economics (GLOBE) at the University of Göttingen from October 2011 to January 2012 using the software z-Tree (Fischbacher, 2007). We observed decisions of 135 subjects in ID-treatments and 42 subjects in control treatments. The sessions took approximately 1.5 hours and the subjects earned $14 €$ on average including a show-up fee of $2.50 €$.

\section{Results}

\subsection{Social Identity and the Level of Conditional Cooperation}

\subsubsection{Conditional Cooperation in In-Group and Out-Group Matching}

Containing the core result of our analysis, Figure 1 depicts a comparison of subjects' average conditional cooperation in the ID-treatments. In line with recent literature, using a within-subject analysis we find that across the whole range of others' contribution (0-20) subjects in in-group matching are willing to contribute on average more to the public good than in out-group matching. Applying a fixed-effects panel regression using in-group matching as the base category and controlling for initial decisions in Stage 1 reveals that this difference is significant and amounts to approximately 0.48 points (Table 2, Model 1 ). ${ }^{11}$ Moreover, it tends to be robust to the order of the ID-treatments (Models 2 and 3). Accordingly, when subjects are matched with individuals of their own identity, they show the preference for reciprocating their group members' contribution by

\footnotetext{
${ }^{11}$ The form of social identity that we induce in this experiment is still weak compared to social identity existing in real life, such family bonds or religious identification. Consequently, the rather small differences observed here provide a hint that real social identities invoke much stronger preference differences.
} 
higher own contributions. Conversely, interacting with individuals of different identities triggers preferences for lower levels of conditional cooperation.

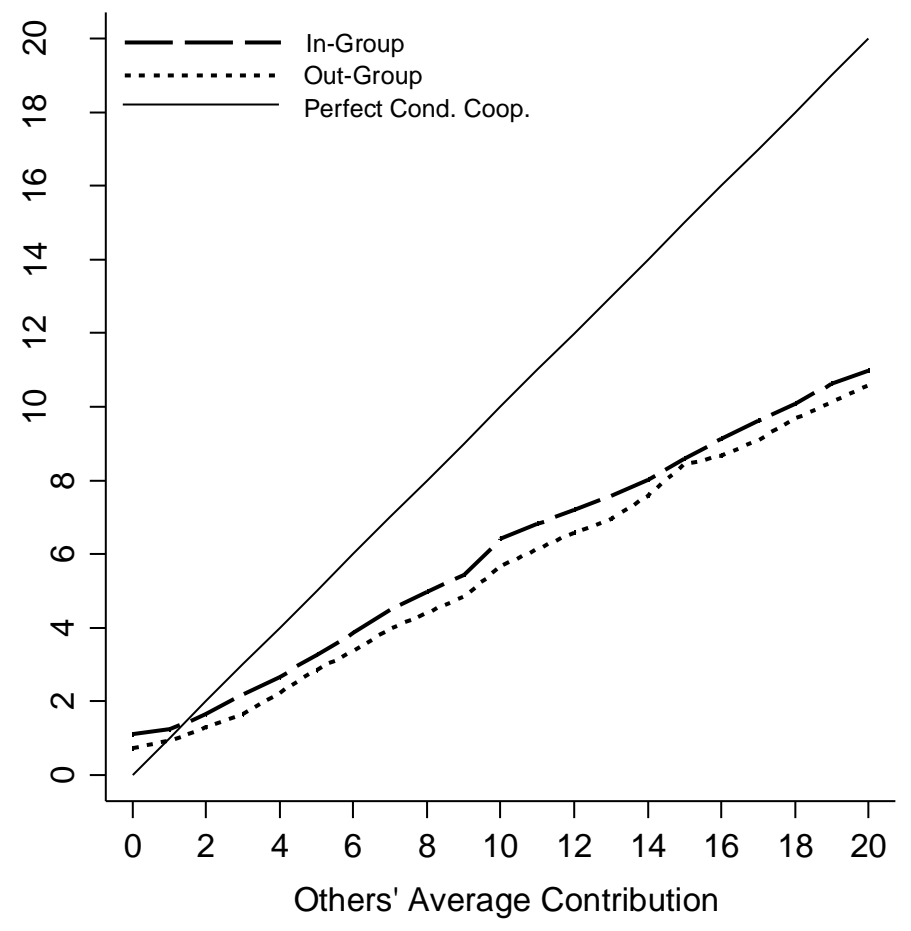

Figure 1 - The Degree of Conditional Cooperation in In- and Out-Group Matching (all subjects)

Fixed Effects Panel Regression

\begin{tabular}{|c|c|c|c|c|c|}
\hline \multicolumn{6}{|c|}{ Model } \\
\hline (1) & (2) & (3) & (4) & (5) & (6) \\
\hline All Subjects & $\begin{array}{l}\text { All Subjects } \\
\text { In-Group First }\end{array}$ & $\begin{array}{l}\text { All Subjects } \\
\text { Out-Group First }\end{array}$ & FRs & CCs & OT \\
\hline \multicolumn{6}{|l|}{ Contributions } \\
\hline $\begin{array}{l}0.0511 \\
(0.230)\end{array}$ & $\begin{array}{l}-0.2664 \\
(0.306)\end{array}$ & $\begin{array}{l}0.3831 \\
(0.343)\end{array}$ & $\begin{array}{c}-1.0714^{*} \\
(0.571)\end{array}$ & $\begin{array}{l}0.1533 \\
(0.282)\end{array}$ & $\begin{array}{l}0.5357 \\
(0.524)\end{array}$ \\
\hline$-0.4801^{\star *}$ & $-0.6453^{*}$ & $-0.3074^{* *}$ & $-0.6405^{\star}$ & $-0.5419^{\star}$ & -0.1735 \\
\hline (0.192) & $(0.351)$ & $(0.143)$ & $(0.327)$ & $(0.278)$ & $(0.244)$ \\
\hline $0.5303^{\star * \star}$ & $0.5017^{* \star *}$ & $0.5602^{\star \star \star}$ & $0.0506^{*}$ & $0.7891^{* * *}$ & 0.0687 \\
\hline$(0.038)$ & $(0.052)$ & $(0.057)$ & $(0.029)$ & $(0.032)$ & $(0.051)$ \\
\hline $0.6900^{*}$ & 0.7948 & 0.5804 & $0.5656^{\star \star *}$ & -0.0995 & $3.2318^{* * *}$ \\
\hline$(0.394)$ & $(0.558)$ & $(0.553)$ & $(0.129)$ & $(0.359)$ & $(0.468)$ \\
\hline 8,505 & 4,347 & 4,158 & 1,260 & 5,481 & 1,764 \\
\hline 0.445 & 0.433 & 0.460 & 0.095 & 0.725 & 0.022 \\
\hline 135 & 69 & 66 & 20 & 87 & 28 \\
\hline
\end{tabular}

R-squared

$135 \quad 69$

Note: Robust standard errors in parentheses, FR=Free-Rider, CC=Conditional Cooperator, OT=Others

Significance levels: ${ }^{* * *} p<0.01,{ }^{* *} p<0.05,{ }^{*} p<0.1$

Table 2 - The Effect of ID-Matchings on Conditional Cooperation (Fixed Effects Panel Regression)

RESULT 1: The level of conditional cooperation is consistently and significantly higher when subjects interact with members of their own identity than with individuals perceived to belong to different identities. 
Differences in cooperation preferences between in-group and out-group matches are not only identifiable when looking at all subjects, but also when scrutinizing the behavior of individual cooperation types. To this purpose, we used the contribution table entries of stage 1 (free of social identity influences) to classify subjects as conditional cooperators and free-riders ${ }^{12}$ and observed their behavior in the ID-treatments. As to be seen in Figure 2, in both ID-treatments free-riders on average depart from full free-riding. When matched with out-group members their average own contribution always remains below 1 point. Free-riders in in-group matching, however, reciprocate their group members' cooperation to a significantly higher degree (Model 4), which tends to increase with the level of others' cooperativeness. In full, this difference amounts to approximately 0.64 points. Consequently, even those subjects that exhibit purely selfish preferences turn to be more cooperative when interacting with individuals of their own identity than in out-group matching. Similarly, conditional cooperators reciprocate their in-group members' contribution to a significantly higher degree than when matched with out-group members (Model 5). This pattern holds for all levels of group members' contributions and overall amounts to approximately 0.54 points.

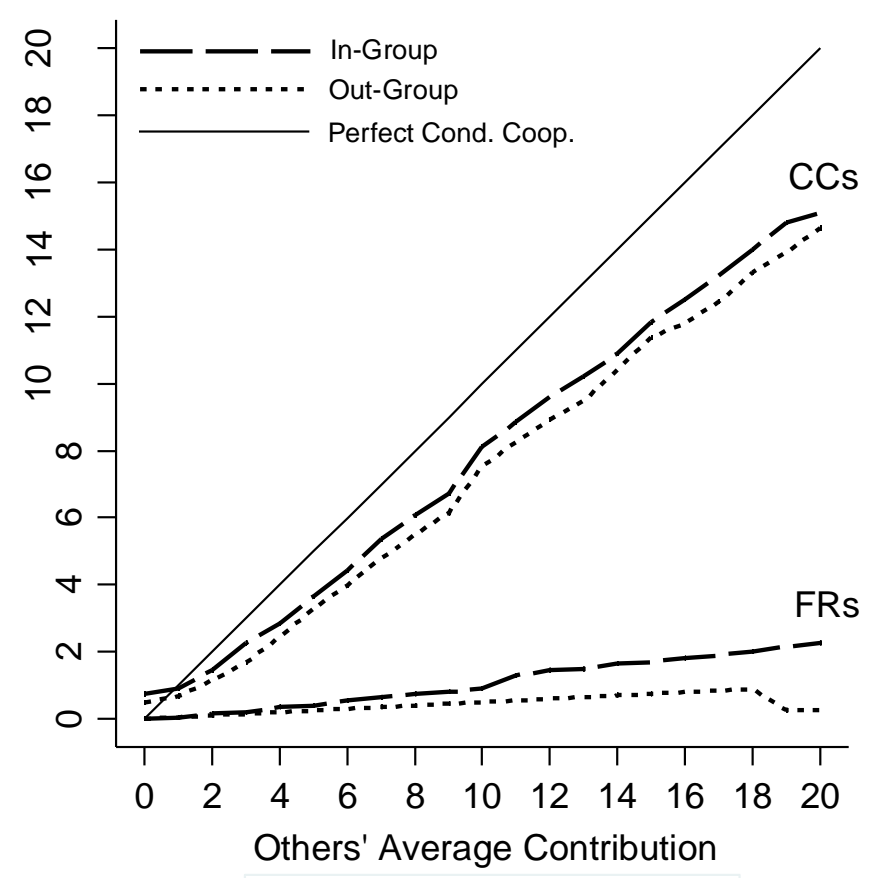

Figure 2 - The Degree of Conditional Cooperation of Free-Riders (FRs) and Conditional Cooperators (CCs) in In- and Out-Group Matching

RESULT 2: Free-riders and conditional cooperators are prone to show a preference for higher levels of conditional cooperation in in-group than in out-group matching.

All in all, we conclude that research hypothesis $1 \mathrm{~A}$ cannot be rejected. Our results clearly indicate that when matched with individuals of a common identity, subjects reveal the preference for

\footnotetext{
${ }^{12}$ We defined conditional cooperators as subjects who exhibit a positive significant Spearman rank correlation coefficient $(p<0.01)$ between own conditional contributions and others' average contributions. Subjects were classified as free-riders if they contributed nothing to the public good in any case.
} 
stronger forms of conditional cooperation and thus less self-serving bias than when matched with individuals of saliently different identities. These individuals will thus contribute more to the public good at a given level of (expected) contributions of their group members, leading to a higher social welfare. ${ }^{13}$ Accordingly, social identity can be a determining factor for cooperation in public goods, since it influences subjects' preferences for conditional cooperation.

\subsubsection{Conditional Cooperation in ID-Matchings and in Random Matching of the Control Treatments}

For comparing cooperation preferences in both ID-matching protocols with random matching, we revert to the stages when decisions are taken, separately. ${ }^{14}$ This necessitates switching from withinto across-subject analyses using the random matching decisions of the control treatments in stages 3 and 4. Yet, in order to keep as much within-information as possible, we analyze how subjects - in their relative treatments - adjusted their conditional cooperation strategy compared to the preceding stage that contained a public goods game (stage 1 and 3, respectively). Comparing these changes allows drawing conclusion regarding differences in conditional cooperation between the treatments. The following two graphs depict how subjects adjusted their cooperation strategy in stage 3 as opposed to stage 1 (Figure 3 ) and in stage 4 compared to stage 3 (Figure 4). In addition, Table 3 reports the results of an according OLS regression that tests for differences between treatments and uses in-group matching as the base category.

In both decision stages we find that when subjects are matched with in-group members, they consistently exhibit higher changes in conditional cooperation compared to the benchmark stage than when randomly matched. The differences between both treatments are more pronounced in stage 3 , with approximately 1.27 point, than in stage 4 ( 0.70 points). Yet, in both stages they are highly significant (see Table 3, Model 1 and 2). We thus conclude that hypothesis $1 \mathrm{~B}$ cannot be rejected. Individuals, who interact with group members sharing the same identity, show preferences for higher levels of conditional contributions than in case of random matching.

\footnotetext{
${ }^{13}$ This is supported by our findings on the level of unconditional contributions to the public good. In in-group matching subjects contribute significantly more points than in out-group matching (on average 6.92 and 6.07, respectively, $z=$ $16.934, p=0.000$, Wilcoxon signed-rank test). This holds true no matter if in-group or out-group matching is played first. Ingroup first yields: 6.81 (in) and 5.83 (out), $z=8.911, p=0.000$, Wilcoxon signed-rank test. Out-group matching first yields: 7.03 (in) and 6.32 (out), $z=15.422, p=0.000$, Wilcoxon signed-rank test).

${ }^{14}$ When analyzing subjects behavior in the control treatments, we find consistently falling conditional contributions in each decision stages (Wilcoxon signed-rank test, $\mathrm{p}_{1-3}=0.000, \mathrm{p}_{1-4}=0.000, \mathrm{p}_{3-4}=0.000$, subscripts denote decision stages). This highlights that in- and out-group matching may only be meaningfully compared with random matching if it takes place in identical decision stages. We thus use the random matching decisions of the control treatments in stage 3 and 4 , to compare these with in- and out-group matching.
} 


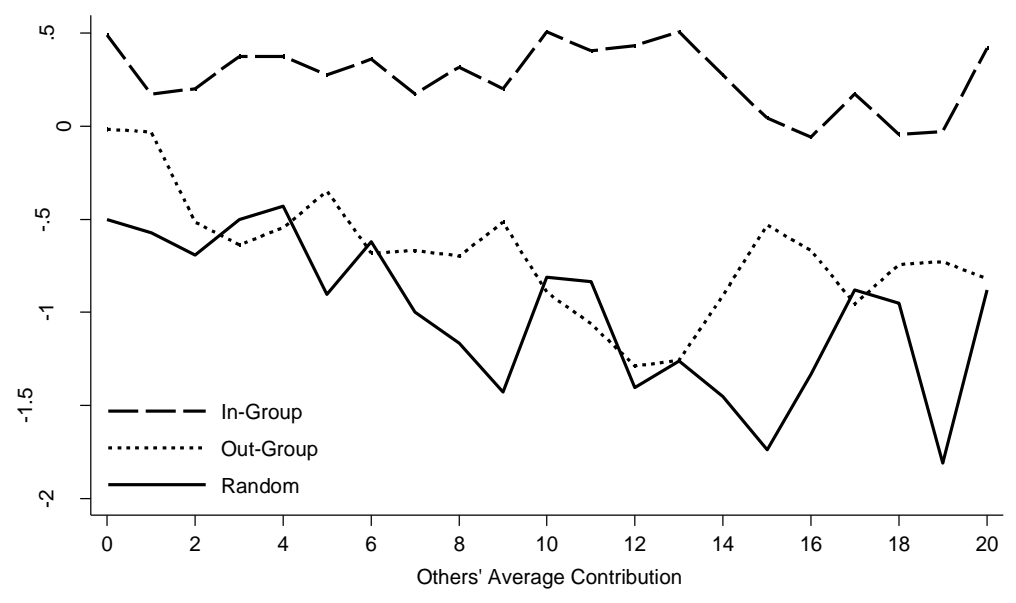

Figure 3-Average Change in Conditional Contribution of Stage 3 compared to Stage 1

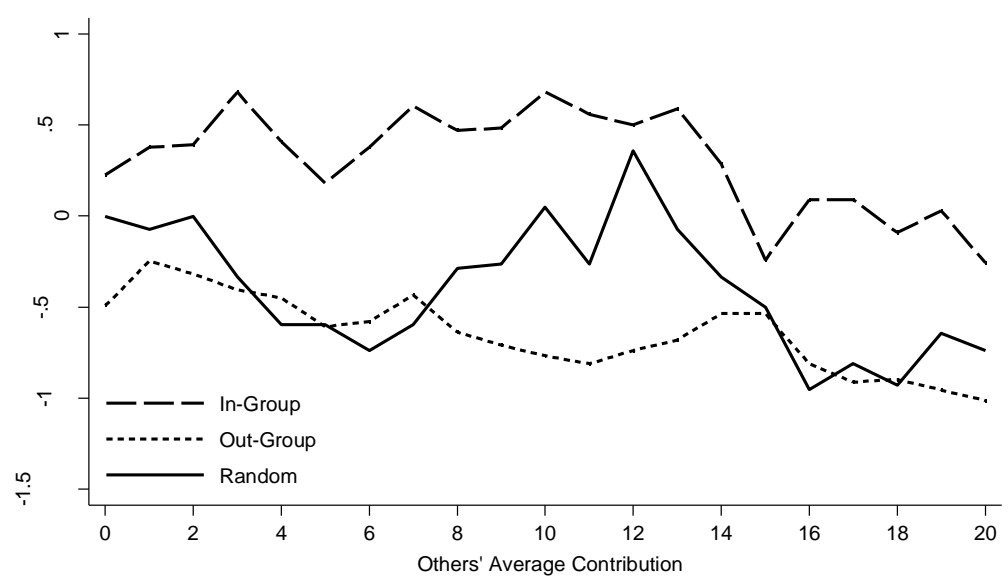

Figure 4 - Average Change in Conditional Contribution of Stage 4 compared to Stage 3

\begin{tabular}{ccc} 
Linear Regression (OLS) & \multicolumn{2}{c}{ Model } \\
\hline Dep. Var.: Change in & $(1)$ & $(2)$ \\
Conditional Cooperation from: & Stage 3 to Stage 1 & Stage 4 to Stage 3 \\
\hline \hline & & \\
Out-Group & $-0.9569^{* *}$ & $-0.9526^{* *}$ \\
& $(0.474)$ & $(0.377)$ \\
Random & $-1.2743^{* *}$ & $-0.7031^{* \star *}$ \\
& $(0.620)$ & $(0.254)$ \\
Constant & 0.2664 & $0.3074^{* *}$ \\
& $(0.305)$ & $(0.143)$ \\
& & \\
Out-Group - Random $=0$ & $\mathrm{p}=0.6266$ & $\mathrm{p}=0.5411$ \\
& & \\
Observations & 3,717 & 3,717 \\
R-squared & 0.018 & 0.020 \\
\hline \hline
\end{tabular}

Note: Standard errors (in parentheses) are clustered by individuals

Significance levels: ${ }^{* * *} p<0.01,{ }^{* *} p<0.05,{ }^{*} p<0.1$

Table 3 - The Effects of Matching Conditions of Changes in Conditional Cooperation (OLS Regression) 
RESULT 3: When matched with in-group members, subjects consistently show a preference for higher levels of conditional cooperation than in random matching.

When subjects are matched with out-group members, average changes in conditional cooperation in Stage 3 (compared to stage 1 ) tend to be higher than in random matching for most of the range of group members' contributions. In contrast, in stage 4 (compared to stage 3 ) they are mostly lower. Importantly though, in neither period are those differences significant (Table 3, Model 1 and 2). We thus conclude that there is no consistent difference between preferences for conditional cooperation in random and out-group matching. Consequently, we reject hypothesis $1 \mathrm{C}$, which derives that the level of conditional cooperation should be consistently lower in out-group than in random matching.

RESULT 4: The level of conditional cooperation in out-group and random matching is not consistently different.

Lastly, this analysis reveals significantly higher changes in conditional cooperation in case of in-group compared to out-group matching for both decision stages (Table 3, Model 1 and 2). This effectively reinforces the results of the previous section.

RESULT 5: The difference in cooperation preferences between subjects matched with in-group and out-group members is consistently identifiable across subjects, as well.

\subsection{Social Identity and Cooperation Types}

In order to deepen our knowledge about cooperation type stability, we analyze whether and how subjects switched cooperation type when matched with in- and out-group members. Overall, the relative share of conditional cooperators, free-riders and others ${ }^{15}$ in random matching of stage 1 , ingroup and out-group matching is in line with the literature. Conditional cooperators form the most common type (63 percent), followed by free-riders (approximately 19 percent) and others (approximately 18 percent) and no significant treatment effects on type distribution can be found. ${ }^{16}$ Consequently, we have to reject hypothesis $2 \mathrm{~B}$, which derives that in-group matching ought to yield higher shares of conditional cooperators and lower shares of free-riders. Thus, social identity as we have induced in the experiment does not affect the aggregate distribution of cooperation types.

RESULT 6: The distribution of cooperation types is relatively stable across all treatments.

Looking at the changes in cooperation types at individual level, Table 4 contains the nine possible combinations, which are expressed in actual frequencies (upper number) and frequencies that are expected to occur by chance alone (lower number). Both numbers represent the shares of total participants taking part in the ID-treatments (135). ${ }^{17}$ In terms of actual frequencies there is a rather high stability of cooperation types. 88.2 percent of all subjects did not change their cooperation type

\footnotetext{
${ }^{15}$ The category "others" subsumes all subjects of which there were too few to be included as a separate category, such as hump-shaped and unconditional cooperators.

${ }^{16}$ We tested for statistical differences using a chi-square test. Usually, it is only applicable for independent observations, which is why we simulated a test statistic distribution using the relative share of cooperation types observed in the control treatments. This non-significant result is robust to various ways of testing, for instance analyzing treatment sequences independently or comparing the ID-treatments with control treatments.

${ }^{17}$ Please note that we deliberately did not include random matching of stage 1 into this analysis, firstly because we are mainly interested in type shifts between the ID-treatments, yet also since random and ID matching never take place in identical decision stages.
} 
in response to whom they were matched with - in both treatments 58.5 percent were conditional cooperators, 15.6 percent remained to be free-riders and 14.1 percent stayed in the "other" category. Using Cohen's Kappa as a measure of stability, automatically correcting for frequencies that are expected to occur by chance alone, we confirm that there is a very high overall stability of cooperation types, no matter how subjects are matched. ${ }^{18}$ Nevertheless, the kappa score is statistically different from perfect agreement $(x=1)$, so that we cannot rule out completely that shifts take place. Indeed, 5.2 percent of subjects switched from being in-group conditional cooperators to free-riders in out-group matching. In comparison, only 0.7 percent of subjects switched from outgroup conditional cooperator status to being a free-rider in in-group matching. Though merely weakly significant $(p=0.0730)$, a sign test for matched pairs confirms that when matched with individuals that do not belong to their own identity, subjects are more likely to choose to free-ride on the contributions of others. ${ }^{19}$ In contrast, we do not find an even marginally significant difference in the propensity to be a conditional cooperator in the different treatments. Hence, we have to partially reject hypothesis $2 \mathrm{~A}$ according to which subjects show a higher propensity to be a conditional cooperator in in-group than in out-group matching, as well.

RESULT 7: While the individual propensity to be a conditional cooperator is stable no matter how subjects are matched, there is a marginally increased probability to be a free-rider when subjects are matched with out-group members compared to in-group matching.

\begin{tabular}{|c|c|c|c|c|}
\hline & \multicolumn{3}{|c|}{ Out-Group } \\
\hline & & CC & FR & ОТ \\
\hline \multirow{6}{*}{$\begin{array}{l}\text { 을 } \\
\text { 임 } \\
\text { 드 }\end{array}$} & co & 58.5 & 5.2 & 0.0 \\
\hline & & (39.6) & (14.1) & (9.9) \\
\hline & & 0.7 & 15.6 & 1.5 \\
\hline & & (11.0) & (3.9) & (2.7) \\
\hline & OT & 3.0 & 1.5 & 14.1 \\
\hline & & (11.6) & $(4.1)$ & (2.9) \\
\hline
\end{tabular}

Table 4-Combinations of Cooperation Types in In-and Out-Group Matching as Share of Total Sample Size (135). Upper (Lower) Numbers Denote the Observed (Expected) Frequency of Being Conditional Cooperator (CC), Free-Rider (FR), Other (OT)

Summing up, although there is an increased propensity to be a free-rider when matched with individuals of a different identity, we do not find strong evidence that social identity significantly impacts on cooperation types in global. Yet, this is not totally surprising, since the common definition of conditional cooperators subsumes many different forms of contribution strategies. Hence, even if subjects' degree of conditional cooperation drops considerably when going from in-group to outgroup matching, they may still be classified as conditional cooperators. Consequently, an analysis of types may only be secondary to finer grained analyses of the quality of conditional cooperation as demonstrated by the previous section.

\footnotetext{
${ }^{18} x_{\text {in,out }}=0.779$ (se= 0.0635, p=0.0000). See Landis and Koch (1977) for guidelines on the interpretation of Cohen's Kappa.

${ }^{19}$ As a robustness check we ran a fixed effects conditional logit regression on the probability to be a free-rider in the different matching settings (standard errors clustered around $n$ ). Here, we similarly find that there is an increased likelihood to become a free-rider when matched with out-group members, which is borderline significant $(t=0.103)$.
} 


\section{Conclusion and Policy Implications}

This article contributes to the understanding of cooperation preferences in the provision of public goods by empirically analyzing whether these vary in decision situations involving salient identities of the subjects one interacts with. In line with recent literature on social identities' effect on positive reciprocity (Chen and $\mathrm{Li}, 2009$ ), our results indicate that cooperation preferences are indeed dependent on the social environment. Specifically, when matched with individuals of a common identity, subjects across all levels of their group members' cooperativeness exhibit significantly higher levels of conditional cooperation and thus less self-serving bias than when matched with individuals of different identities. At a given level of (expected) contributions of their group members, subjects in identity homogeneous groups can thus be expected to contribute more to the public good than in identity heterogeneous groups. What is more, while individuals are equally likely to be conditional cooperators under both ID-treatments, we identify an elevated propensity for subjects to be a free-rider, when interacting within out-groups. Consequently, social identity seems to be a determining factor, which impacts on social welfare in the context of public goods provision by altering subjects' preference for conditional cooperation.

From a policy perspective these results are of importance. By means of positive belief management, economic policy already tries to exploit that most people are willing to cooperate if others do so, as well. Yet, this mainly addresses conditional cooperators. Still not having any indication how purely selfish people react to this institution, we provide evidence that not only conditional cooperators' but also free-riders' affinity for cooperation can be systematically increased simply by mitigating one's perceived feeling of belonging to the group one interacts with. In order to enhance the provision of public goods, social identity thus seems to be an effective tool, in addition to the instruments of belief management, for improving social welfare. 


\section{Appendix - Instructions to the Experiment ${ }^{20}$}

Welcome to the experiment! Thank you very much for your participation.

If you read the following instructions carefully, you get the chance of winning money additional to the $€ 2.50$, which you receive in any case. Your earnings will depend on your decisions and on those by the other players in your group. At the end of the experiment all sums of money, which you will have earned through your decisions, will be added and given to you personally and in cash.

It is forbidden to speak during the experiment. If you have any questions, please raise your hand. A member of our team will come to you and answer your question privately.

We will be talking about points rather than Euros in the course of the experiment. Hence, your total income will be calculated in points in the first instance. The total number of points which you will achieve during the experiment will be converted in Euros at the end, using the following equation:

1 point $=17$ Cents.

All participants will be divided in groups with 3 players each. Except for us, i.e. the conductors of the experiment, nobody will know who is in which group. All decisions will be made anonymously and your identity will neither be revealed during the experiment nor in public.

Each task of the experiment has its own instructions, which you have to read step by step. While doing so, please consider the respective hints which will appear on the monitor.

Please click on OK when you are ready.

\section{The Basic Decision Situation}

Later, you will be informed about the experiment's procedure in detail. At this point, we would like to introduce the basic decision conditions you will face in this experiment. Some example exercises can be found subsequently.

At each point in time, you will be a member of a group consisting of $\mathbf{3}$ players. In every task, you hold 20 points. Your task is to decide whether you invest these 20 points in a private account or whether you want to invest them fully or partly in a project. Each point which you do not invest in a project will be automatically deposited on your private account.

\section{Your income from your private account:}

For each point which you deposit on your private account (and, therefore, you do not invest in the project), you will earn one point. Hence, a deposit of 20 points on your private account will produce an income of 20 points from your private account. If you, for instance, deposit 6 points on your private account, you will earn 6 points from this account. Nobody except you will earn anything from your private account.

\section{Your income from the project:}

All group members will profit equally from your contribution to the project. Vice versa, you profit from the investments by other group members. The income every member gets from the project is calculated as follows:

Income from the project $=$ (sum of all contributions to the project $) \times 0.4$

Should the sum of all contributions to the project be, for example, 30 points then you and all other group members gain $(30 \times 0.4)=12$ points each from the project. Should the sum of all contributions to the project be, for example, 10 points then you and all other group members gain $(10 \times 0.4)=4$ points each from the project.

\footnotetext{
${ }^{20}$ Instructions in German are available upon request (Matthias.Lankau@wiwi.uni-goettingen.de).
} 
Your total income:

Your total income is the sum of your income from your private account and your income from the project.

Income from the private account (= 20 -your contribution to the project)

+ Income from the project $=$ (sum of all contributions to the project) $\times 0.4$

Total income

\section{Exercise Questions}

Please complete the following exercises. They do merely serve the purpose of familiarising you with the calculation of the different sorts of income, which may occur to you when making different decisions on the use of the 20 points starting capital.

Please complete all the exercises and always report your full mathematical procedure. While calculating, you may use the calculator function on the monitor. When you are done, you have to enter your results in the computer.

1. Each group member has 20 points at their disposal. Imagine that all three group members (including yourself) do not contribute anything to the project.

a. What is your total income? .....

b. What is the total income of each of the other group members? .....

2. Each group member has 20 points at their disposal. You invest 20 points in the project. The other two group members also contribute 20 points to the project.
a. What is your total income? .....
b. What is the total income of each of the other group members? .....

3. Each group member has 20 points at their disposal. The other two group members contribute 10 points each (i.e., 20 points in total) to the project.

a. What is your total income if you, additional to the 20 points, contribute 0 points to the project?

b. What is your total income if you, additional to the 20 points, contribute 5 points to the project?

c. What is your total income if you, additional to the 20 points, contribute 15 points to the project?

4. Each group member has 20 points at their disposal. You contribute 7 points to the project.

a. What is your total income if the other group members, additionally to your 7 points, contribute 1.5 points each, i.e., 3 points in total, to the project?

b. What is your total income if the other group members, additionally to your 7 points, contribute 4 points each, i.e., 8 points in total, to the project?

c. What is your total income if the other group members, additionally to your 7 points, contribute 9 points each, i.e., 18 points in total, to the project?

\section{First Task}

You are now the member of a group of three, which was put together randomly.

The task contains the decision, which was described at the beginning and is only conducted once.

As you know, you have $\mathbf{2 0}$ points at your disposal, which you can either invest in the project or deposit on your private account.

In this task, every group member has to make two types of decisions, which we will term (1) the "unconditional" contribution to the project, or the (2) "conditional" contribution to the project (the contribution table), respectively.

Both decisions are vital for your income from this task. So please make your decisions thoughtfully.

Step 1: Your Unconditional Contribution to the Project 
Please determine how many of your points you, without knowing the contributions of the other group members, want to invest in the project. Please enter this amount into the following computer screen:

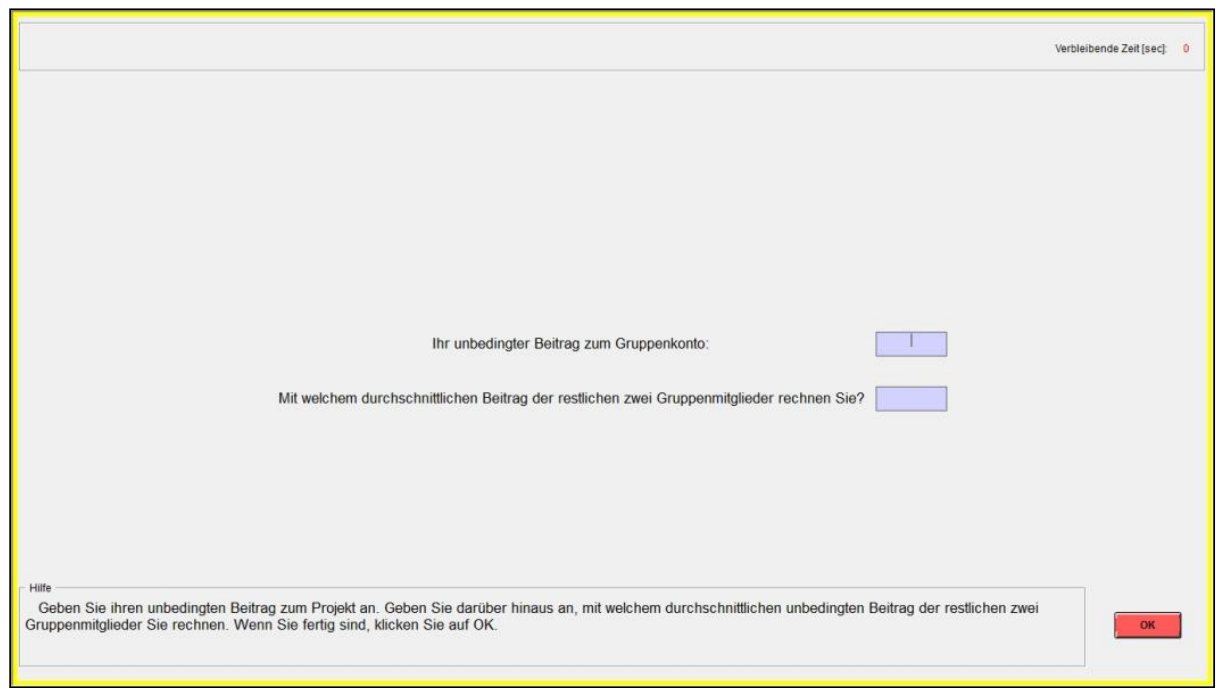

Please state what you expect each of the other two group members to contribute to the project (average amount of money they invest in the project).

Once you have made both statements, please click on OK.

\section{Step 2: Your Conditional Contribution to the Project - the Contribution Table}

With your second decision you have to fill in a contribution table. In the contribution table you have to enter your contribution to the project for every possible average contribution (rounded up) of the other group members. Hence, you can, dependent on the average contribution of the others, determine your decision on your contribution. You will get a clear hint of what to do when you take a look at the following screen.

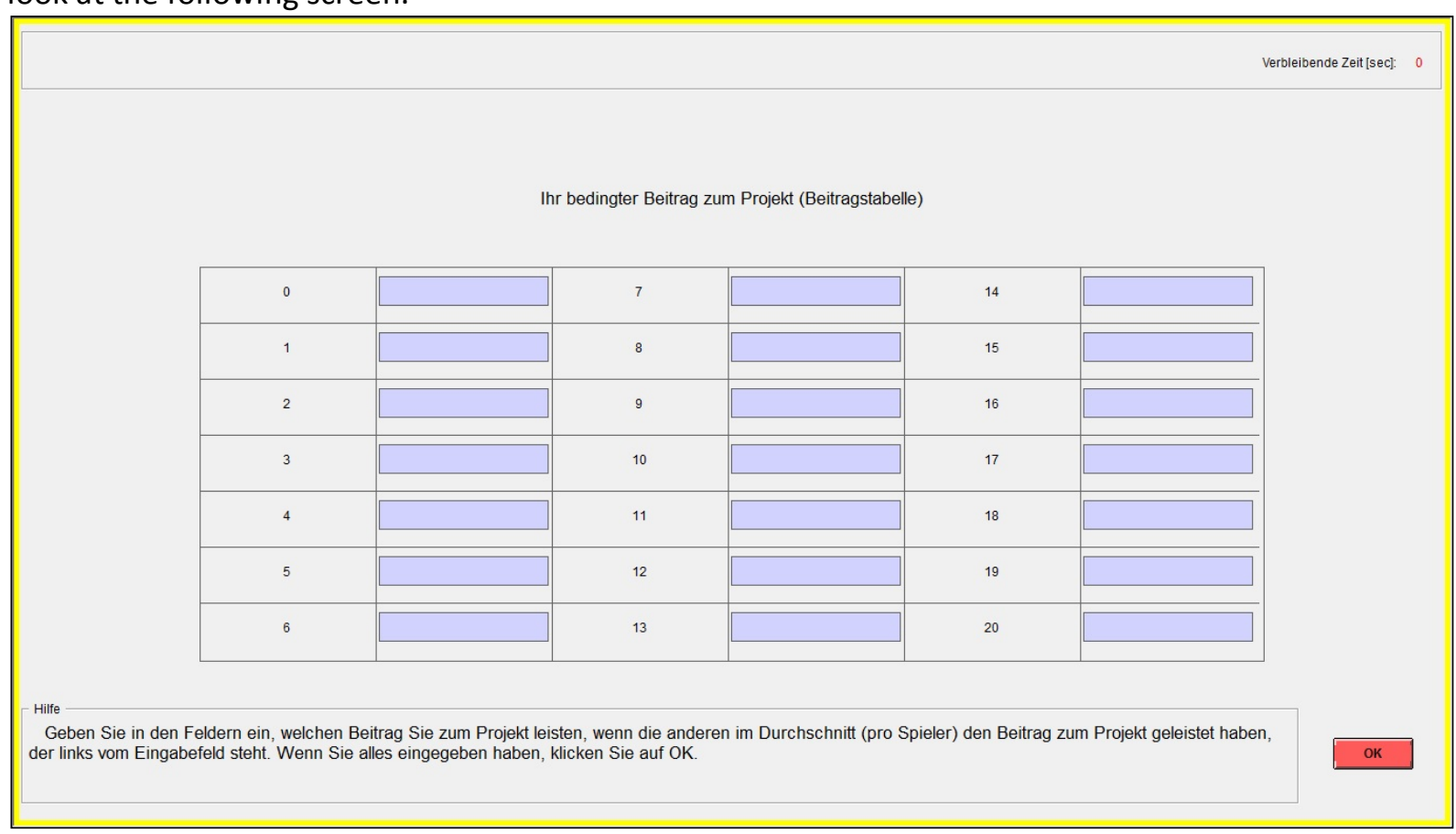


The numbers left to the boxes mark the possible average contributions, which the other members can make to the project. You just have to enter in each box how much you, under the condition that the others contribute the stated average amount, want to invest in the project. You have to make an entry in each box.

For example, you have to enter how many points you want to invest in the project if the other group members contribute 0 points; how many points you invest if the others contribute 1, 2 or 3 points and so on and so forth. You can enter integral numbers ranging from 0 to 20 in each box.

Once you have typed a number in each box, please click on OK.

After all participants in the experiment made their decision on their conditional contribution and filled in the contribution table, one member of each group is selected at random. For these selected members only the contribution table is relevant for their decisions and payoff. For the other two group members, who were not selected by the random choice mechanism, only the unconditional contribution is relevant for their decisions and payoff. The average of both unconditional contributions by these two group members defines which contribution by the selected member shall be invested in the project.

When you make the decision on your unconditional contribution and fill in the contribution table, you do of course not know if you will be picked at random. Hence, you have to make both decisions carefully, because both can become relevant for you. The following examples will explain the procedure:

Example 1: You are selected by the random choice mechanism. Therefore, the contribution table is relevant for your payoff. For the other two group members the unconditional contributions are relevant.

Let us assume that the other two group members invest 0 and 4 points in the project, which would mean an average contribution of two points. If you entered in the contribution chart that you would invest 1 point if the others averagely invested 2 points, then this would make a total contribution of $0+4+1=5$ points to the project. All group members would then earn $5 \times 0.4=2$ points from the project plus the respective incomes from their private accounts, in your case $20-1=19$ points. Your income would then be 21 points.

If you, however, stated that you would invest 16 points, if the others averagely invested 2 points, this would make a total investment of $0+4+16=20$ points in the project. As a result, all group members would receive a payoff of $20 \times 0.4=8$ points plus the income from their private accounts, in your case $20-16=4$ points. Your total income would then be 12 points.

Example 2: You are not selected by the random choice mechanism. For you and another group member then your unconditional contribution to the project is the relevant decision.

Let us assume that your unconditional contribution to the project is 16 points, the contribution by the other group member is 20 points. This makes an average contribution of 18 points to the project. Should the player who was selected by the random choice mechanism have stated that he or she would contribute 1 point to the project if the other group members averagely invested 18 points, then the total contribution to the project would be $16+20+1=37$ points. All group members then would earn $37 \times 0.4=14.8$ points from the project additional to their respective income from their private accounts. In your case you would earn $20-16=4$ points from your private account, which would then make a total income of 18.8 points.

Should the selected group member have stated an investment of 19 points to the project if the others averagely invested 18 points, then the total contribution to the project would be $16+20+19$ $=55$ points. Every group member would have a project income of $55 \times 0.4=22$ points plus their points from their private account, in your case 4 points. Your total income would then be 26 points. 


\section{The Random Choice Mechanism}

At the beginning of this game each group member receives a number between 1 and 3 . As you might remember, one participant, namely no. 8 , was selected at the beginning of the experiment. This participant will dice a number between 1 and 6 after all participants decided on their unconditional contribution and filled in the contribution table. The numbers 1 and 2 stand for group member one, 3 and 4 for group member two and 5 and 6 for member three. Participant no. 8 will enter these in the computer. In case no. 8 dices the numbers which correspond to your member number, the contribution table will be relevant for your decisions and payoff and for the other group members the unconditional contribution will be relevant. In any other case the unconditional contribution is relevant for you.

Please click on OK once you have read and understood the instructions.

\section{Second Task \\ Please note: Do not open the attached envelope before you are asked to do so!}

For the second task, you will be arbitrarily assigned a new group, which will be marked by a specific colour.

Only those solutions which are given correctly by ALL THREE group members will be considered correct in this group task.

During this task the group members are allowed to communicate with each other. By doing so, they can find a solution together. On the left hand side of the computer screen a chat box is positioned, which can be used for communication. Your conversation will be recorded. You have 10 minutes to solve the task. Only within this time span are you able to communicate with your team members. Please take into account that every group member has to type in the solutions which will have been found by your group. You have to click on OK before the 10 minutes have run out. The time left will be shown to you in the upper right hand corner of your screen.

All participants will be shown a picture and a list of objects. The task is to find the hidden objects in the picture. The inscriptions on the left and the upper side give the numbers of the lines and columns. You are asked to insert this information in the boxes which will be shown on the right hand side of the screen. The first box refers to a line, the second to a column. An example for this exercise is given below. 

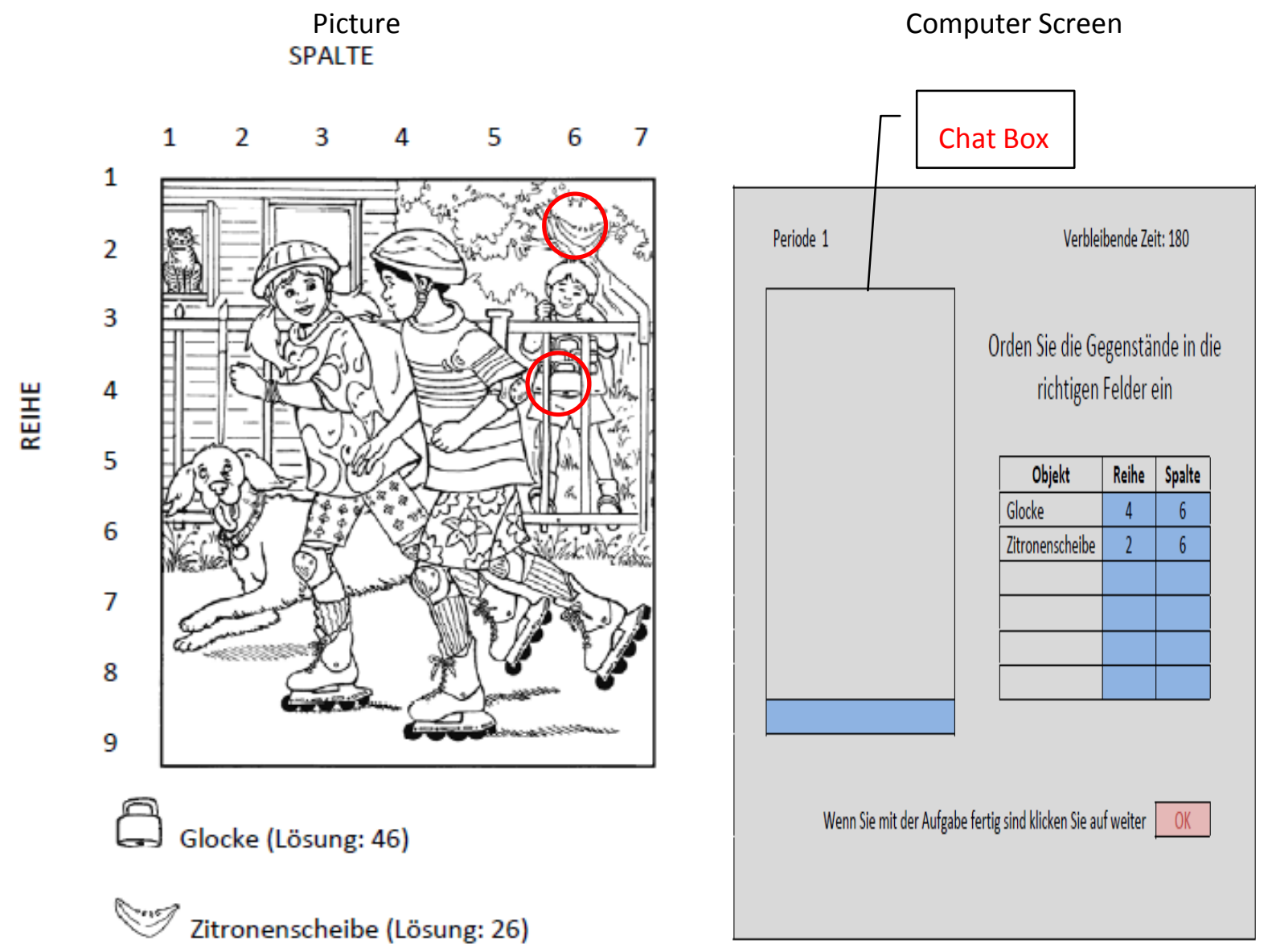

The group which finds most of the objects in the 10 minutes time is the winner group. At the end of the experiment you will be informed whether you are a member of the winner group. In this case, you will receive a congratulation message.

Please click on OK when you are ready.

\section{Third Task $^{21}$}

This task corresponds to the first one. It is conducted only once.

This time, however, you will only play together with members of your own group, with who you solved the picture puzzle in the second task.

Again, you hold a deposit of 20 points. Please decide how many points you want to invest in the project and how many you want to put on your private account.

This task also consists of two decisions, your (1) conditional contribution to the project and (2) the contribution table, with which you can make your decisions conditional on the other group members' contributions.

Please decide very carefully in both cases, for both the conditional contribution and your input into the contribution table are potentially relevant for the payoff. To determine the relevance of the decision, we will use the same random choice mechanism as before.

When you are ready, please click on OK.

\footnotetext{
${ }^{21}$ Three sessions of the experiment were played by matching subjects with in-group members in the third task and with out-group members in the fourth task. In another three sessions the order was reversed to control for possible sequence effects.
} 


\section{Fourth Task}

This task corresponds to the first one. It is conducted only once.

This time, however, you will only play together with members of different-coloured groups.

Again, you hold a deposit of 20 points. Please decide how many points you want to invest in the project and how many you want to put on your private account.

This task also consists of two decisions, your (1) conditional contribution to the project and (2) the contribution table, with which you can make your decisions conditional on the other group members' contributions.

Please decide very carefully in both cases, for both the conditional contribution and your input into the contribution table are potentially relevant for payoff. To determine the relevance of the decision, we will use the same random choice mechanism as before.

When you are ready, please click on OK. 


\section{References}

Blanco, M., Engelmann, D., Normann, H.T., 2011. A within-subject analysis of other-regarding preferences. Games and Economic Behavior 72 (2), 321-338.

Bolton, G.E., Ockenfels, A., 2000. ERC: A Theory of Equity, Reciprocity, and Competition. The American Economic Review 90 (1), 166-193.

Burlando, R., Guala, F., 2005. Heterogeneous Agents in Public Goods Experiments. Experimental Economics 8 (1), 35-54.

Charness, G., Rigotti, L., Rustichini, A., 2007. Individual behavior and group membership. The American Economic Review 97 (4), 1340-1352.

Chaudhuri, A., 2011. Sustaining cooperation in laboratory public goods experiments: a selective survey of the literature. Experimental Economics 14 (1), 47-83.

Chen, R., Chen, Y., 2011. The Potential of Social Identity for Equilibrium Selection. American Economic Review 101 (6), 2562-89.

Chen, Y., Li, S.X., 2009. Group Identity and Social Preferences. The American Economic Review 99 (1), 431-457.

Currarini, S., Mengel, F., 2012. Identity, Homophily and In-Group Bias. FEEM Working Paper No. 37.2012. http://papers.ssrn.com/sol3/papers.cfm?abstract_id=2088744 (accessed 17 August 2012).

Eckel, C.C., Grossman, P.J., 2005. Managing diversity by creating team identity. Journal of Economic Behavior \& Organization 58 (3), 371-392.

Falk, A., 2003. Homo Oeconomicus versus Homo Reciprocans: Ansätze für ein neues Wirtschaftspolitisches Leitbild? Perspektiven der Wirtschaftspolitik 4 (1), 141-172.

Fehr, E., Fischbacher, U., 2002. Why social preferences matter- the impact of non-selfish motives on competition, cooperation and incentives. The Economic Journal 112 (478), C1-C33.

Fehr, E., Schmidt, K.M., 1999. A Theory of Fairness, Competition, and Cooperation. Quarterly Journal of Economics 114 (3), 817-868.

Fischbacher, U., 2007. z-Tree: Zurich toolbox for ready-made economic experiments. Experimental Economics 10, 171-178.

Fischbacher, U., Gächter, S., 2010. Social preferences, beliefs, and the dynamics of free riding in public goods experiments. The American Economic Review 100 (1), 541-556.

Fischbacher, U., Gächter, S., Fehr, E., 2001. Are people conditionally cooperative? Evidence from a public goods experiment. Economics Letters 71 (3), 397-404.

Goette, L., Huffman, D., Meier, S., 2006. The impact of group membership on cooperation and norm enforcement: Evidence using random assignment to real social groups. The American Economic Review 96 (2), 212-216.

Hoff, K., Pandey, P., 2006. Discrimination, Social Identity, and Durable Inequalities. The American Economic Review 96 (2), 206-211.

Ibañez Diaz, M., Schaffland, E., 2012. Leadership Working Behavior and Group Cooperation: An Experiment of Group Identity: Unpublished Result.

Ioannou, C.A., Qi, S., Rustichini, A., 2012. Group Outcomes As A Public Signal, Focal Point Effects And Reciprocity, Discussion Series in Economics and Econometrics 1106. University of Southampton, GB. http://eprints.soton.ac.uk/174997/ (accessed 27 September 2012). 
Jackson, J.W., 2011. Intragroup cooperation as a function of group performance and group identity. Group Dynamics: Theory, Research, and Practice 15 (4), 343-356.

Landis, J.R., Koch, G.G., 1977. The Measurement of Observer Agreement for Categorical Data. Biometrics 33 (1), 159-174.

McLeish, K.N., Oxoby, R.J., 2007. Identity, cooperation, and punishment, IZA Discussion Paper 2572. Institute for the Study of Labor (IZA). http://papers.ssrn.com/sol3/papers.cfm?abstract_id=961379.

Selten, R., 1967. Die Strategiemethode zur Erforschung des eingeschränkt rationalen Verhaltens im Rahmen eines Oligopolexperiments. In: Sauerland, H. (Ed.). Beiträge zur experimentellen Wirtschaftsforschung, Tübingen: Mohr, 136-168.

Solow, J.L., Kirkwood, N., 2002. Group identity and gender in public goods experiments. Journal of Economic Behavior \& Organization 48 (4), 403-412.

Tajfel, H., Turner, J., 1979. An Integrative Theory of Intergroup Conflict. In: Worchel, S., Austin, W. (Eds.). The Psychology of Intergroup Relations, Monterey: CA: Brooks/Cole, 33-47.

Tajfel, H., Turner, J., 1986. The Social Identity Theory of Intergroup Behaviour. In: Worchel, S., Austin, W. (Eds.). The Psychology of Intergroup Relations, Chicago: Nelson-Hall, 7-24.

Volk, S., Thöni, C., Ruigrok, W., 2012. Temporal stability and psychological foundations of cooperation preferences. Journal of Economic Behavior \& Organization 81 (2), 664-676.

Yamagishi, T., Jin, N.a.K.T., 1999. Bounded Generalized Reciprocity: Ingroup Boasting and Ingroup Favoritism. Advances in Group Processes 16, 161-197.

Yamagishi, T., Kiyonari, T., 2000. The Group as the Container of Generalized Reciprocity. Social Psychology Quarterly 63 (2), 116-132. 


\section{CHAPTER VI}

How Peer-Punishment Affects Cooperativeness in Homogeneous and Heterogeneous Groups

- A PUBLIC GOOd EXPERIMENT WITH SOCIAL IDENTITY

Marianna Bicskei, Matthias Lankau, Kilian Bizer 


\section{INTRODUCTION}

When a public good is provided, the social optimum is reached if all group members bear the costs and contribute to its provision. However, since no one can be excluded from the benefits the public good generates there is a strong incentive for self-interested individuals to free-ride on their peers' contributions. Although free-riding does not reveal itself as prominent a behavioral pattern as classic economic theory predicts, experimental evidence suggests that there is still a considerable lack in cooperativeness lowering social efficiency. Nevertheless, previous research showed that individuals have a proclivity to adjust their behavior depending on the institutional environment in which the public good is provided. In this respect, two factors are of crucial importance. Firstly, social identity of group members with whom individuals interact influences cooperation. Recently, Lankau et al. (2012) demonstrated that individuals reveal the preference for consistently higher conditional cooperation when matched with group members with a common identity (in-group matching) as opposed to being matched with individuals saliently belonging to different social groups (out-group matching) or randomly matched individuals. This in-group bias in the propensity to cooperate seems to be a deeply rooted phenomenon of human interactions (Eaton, Eswaran, and Oxoby 2011) and has been confirmed by numerous contributions both in psychological and economic experimental research (cf. for instance Taifel and Turner 1979; Chen and Li 2009). Secondly, it is a well-established phenomenon that the possibility of costly decentralized punishment by individual group members for uncooperative behavior strongly enhances cooperation (cf. Fehr and Gächter 2000; Masclet et al. 2003). Clearly, both institutions impact on people's cooperativeness and are thus highly relevant to the maintenance of common resources. However, their interaction in a public good environment did not receive any academic attention, so far. Consequently, the goal of this article is to provide initial evidence on subjects' cooperativeness in the provision of public goods in case their social identity is salient and there is a possibility to punish group members for misbehavior. In particular, we ask how the institution of costly peer-punishment impacts subjects' cooperativeness in homogeneous groups composed of members sharing a common social identity and in heterogeneous groups consisting of members of different identities. For this purpose, we artificially induce social identity with the help of a simple group task that subjects solve jointly by communicating anonymously via chat. Our experiment is based on one-shot public good games using the strategy method (Fischbacher, Gächter, and Fehr 2001; Selten 1967), which allows us to observe contributions to the public good conditional on every possible average contribution level of the remaining group members. It thus elicits subjects' cooperativeness in more detail than unconditional contributions alone, and serves us as a preferred measure of cooperativeness. What is more, it enables us to classify subjects into different cooperation types depending on their initial cooperation strategy providing deeper insights into cooperative adjustments under different institutional settings.

In summary, our findings provide hints that group composition in terms of individuals' identity decisively influences to what extent subjects alter their cooperativeness under punishment compared to equal matching conditions that are free of peer-sanctions. In particular, we prove that subjects who are matched with out-group members increase their cooperativeness to the highest degree. Based on the example of free-riders we are able to show that this is predominantly caused by an anticipation of comparatively strong punishment for uncooperative behavior by group members of different identities. What is more, under punishment subjects' cooperativeness is equal 
within in- and out-groups essentially revealing that peer-punishment eliminates the in-group bias that is present without peer-punishment.

The remainder of the paper is structured as follows: Section 2 deals with the relevant literature and presents our hypotheses. While Section 3 introduces the experimental design, Section 4 discusses the relevant findings. The article ends with a conclusion in Section 5.

\section{LITERATURE REVIEW AND RESEARCH HYPOTHESES}

When people face social dilemmas, individual interest is at odds with social interest. Thus, much theoretical and empirical research has been devoted to understand how to enhance voluntary contributions to public goods. Research in experimental economics demonstrated that social identity as "the individual's self-concept derived from perceived membership in social groups" (Charness, Rigotti, and Rustichini 2007, 1342) and also peer-punishment are prone to foster cooperativeness in the provision of public goods.

To begin with, the experimental economic research on social identity is rooted in the social identity theory introduced by Tajfel and Turner (1979). The core element of this theory is the analysis of the psychological foundations of discriminatory behavior, which is determined through three processes. Accordingly, individuals relatively quickly sort themselves by certain social categories such as gender or race (categorization) and derive self-esteem from that (in-)group (identification). These processes are subsequently complemented by individuals comparing their in-group with out-groups they do not identify with (comparison). Taken together, these processes generally trigger in-group favoritism and thus out-group discrimination commonly referred to as in-group bias (cf. Tajfel and Turner 1986; Hoff and Pandey 2006). ${ }^{1}$ By now, there are several studies that focus on the effects of social identity on subjects' cooperativeness in a public good context. Firstly, Eckel and Grossmann (2005) study the impact of team identification on cooperation in a repeated-play public good game with various degrees of enhanced team identification. The authors find that strengthening team identification (e.g., prior group task before the game, creation of in-group/out-group conflict) yields consistently higher cooperation levels and less free-riding. Secondly, Lankau et al. (2012) explicitly study the impact of social identity on cooperation preferences in public goods provision. Using the strategy method in multiple one-shot public good games, the authors confirm the existence of an in-group bias. Specifically, they find that when subjects interact with members of their own identity they show a consistently higher preference for conditional cooperation and thus less self-serving bias $^{2}$ than when matched with out-group and random individuals. What is more, even the least socially oriented cooperation types, initially identified as free-riders, reveal higher levels of conditional cooperation in in-group matching. Other recent studies documenting subjects' increased cooperativeness in providing public goods when bound together by a common identity include Blackwell and McKee (2013), Chakravarty and Fonseca (2012 and 2013). Similarly, various other experiments outside the public goods context demonstrate that social identity positively influences social welfare when individuals interact with in-group members as opposed to out-group members (cf. Chen and Li 2009;

\footnotetext{
${ }^{1}$ See Chen and Li (2009) for a detailed account on theoretical and empirical findings on social identity theory.

2 Subjects reveal self-serving bias when they do not reciprocate their team members' contributions by an equal own contribution (perfect conditional cooperation), and depart in the selfish direction.
} 
Charness, Rigotti, and Rustichini 2007; McLeish and Oxoby 2011; Goette, Huffman, and Meier 2006; Chen and Chen 2011). ${ }^{3}$ In sum, the existing experimental research provides solid evidence that salient social identity in terms of group composition matters with regard to cooperativeness, and confirms the well-established in-group bias in human interactions. ${ }^{4}$

The possibility of costly decentralized punishment by individual group members without central authority has been identified as an effective instrument to maintain cooperation in the provision of public goods, as well. Initially, Fehr and Gächter (2000) studied the punishment institution in an environment where both the offender and the punisher bear tangible costs of the penalties, though one punishment point costs the offender three times more than the punisher. Specifically, the authors conducted two treatments with and without punishment and distinguished between stranger ${ }^{5}$ and partner matching. ${ }^{6}$ In both settings without punishment constraints they found that contributions to the public good decreased over the ten periods approaching almost complete freeriding. On the contrary, contribution levels steadily increased towards full cooperation under punishment in the partner matching condition. ${ }^{7}$ In another experiment Fehr and Gächter (2002) have identified similar tendencies for strangers, as well. ${ }^{8}$ Contribution levels increased under punishment, while they decreased when the opportunity to punish was removed. Likewise, Masclet et al. (2003) and Noussair and Tucker (2005) demonstrated that the fear of being punished drives subjects to increase their contribution to the public good. What is more, several other studies have replicated the experiments of Fehr and Gächter and by and large confirmed their findings (cf. Anderson and Putterman 2006; Bochet et al. 2006; Nikiforakis 2008; Page et al. 2005; Sefton et al. 2007). All in all, these findings confirm that costly peer-punishment motivates individuals to behave more cooperatively in long term interactions.

However, the question of how costly punishment precisely affects cooperation when social identity is salient and subjects are interacting either in homogenous or heterogeneous groups, has not been examined in a one-shot public goods environment, yet. ${ }^{9}$ Using two-person bargaining games in between-subjects design, McLeish and Oxoby (2007) provide some insight on how these institutions simultaneously influence cooperation. The authors induced group identity by letting groups jointly solve a series of questions via face-to-face communication. Next, pairs were randomly matched and

\footnotetext{
${ }^{3}$ For a detailed review of these studies, see Lankau et al. (2012).

${ }^{4}$ For further research on in-group favoritism see Hermann et al. (2012).

${ }^{5}$ Stranger matching meant a random group assignment in each period.

${ }^{6}$ The composition of the group was stable over the periods.

${ }^{7}$ Full cooperation was declared as a dominant behavioral standard regardless whether the punishment or the non-punishment treatment was conducted firstly. However, this behavioral norm was not found in the stranger treatment.

8 This experiment was designed identically to the previous experiment (Fehr and Gächter 2000) with the exception that punishment and non-punishment treatments were conducted only with strangers. In this study a subject could never meet another subject more than once during the game (perfect stranger matching).

${ }^{9}$ The interaction of social identity and third-party punishment has been the focus of a few studies already. See for instance Goette et al. (2006; 2012). In contrast to our emphasis on peer-punishment, the punisher in these studies is an individual whom the violation does not affect economically (Goette, Huffman, and Meier 2012). Additionally, Weng and Carlsson (2013) study endowment heterogeneity, peer-punishment and social identity in a work team environment using public good games. However, they do not include a treatment for identity heterogeneous groups.
} 
informed about the other's group affiliation. After the proposer decided how much of his endowment to keep for himself and how much to allocate to the responder, in the punishment treatment the responder had the opportunity to engage in costly punishment by reducing the proposer's income by 1.5 points for each point given. They demonstrated, first of all, that cooperation expressed by the level of offers extended both with and without punishment is higher within in-groups than in out-group matching. Secondly, they did not find significantly different cooperation levels between punishment and no-punishment treatments. This finding, however, contradicts previous research emphasizing that the threat of peer-punishment increases cooperation levels (see Fehr and Gächter 2000; 2002; Masclet et al. 2003 and Noussair and Tucker 2005). Summing up, these results provide only limited insights into two-person interactions. Evidently, they cannot be easily transferred to a public good environment involving groups of more than two persons. In contrast to two-person interactions investment in punishment constitutes a second order public good in group, because every group member benefits if an offender increases his cooperation due to received sanctions. Clearly, this entails incentives to free-ride on others' costly sanctioning efforts. Consequently, these subjects form different expectations on the likelihood to be punished than subjects paired with just one person, which in turn influences their cooperativeness differently. As a result, we still lack evidence whether the hitherto reported effects of peer-punishment are valid and stable across groups, in which social identity is salient. This is, however, highly relevant since in real life most interactions are multilateral rather than bilateral.

Based on previous findings, we formulate the following research hypotheses. As extracted from the literature on public good games, peer-punishment usually tends to influence cooperation positively. Thus, we hypothesize conservatively that peer-punishment uniformly increases cooperativeness independent of whether subjects are matched with in-group or out-group members.

Hypothesis 1 (Punishment Effect Hypothesis): The threat of peer-punishment equally impacts subjects' cooperativeness under social identity independent of group composition.

What is more, research on social identity has shown that subjects' cooperativeness is biased to their in-group members as opposed to out-group members. Consequently, in line with our Hypothesis 1 we expect that when peer-punishment is present identity-homogeneous groups tend to show higher cooperation than heterogeneous ones.

Hypothesis 2 (In-Group Bias Hypothesis): Under punishment-threat subjects reveal higher cooperativeness when matched with in-group members than in out-group matching.

\section{EXPERIMENTAL DESIGN}

To test the hypotheses presented above, our experiment features both within- and between-subject design elements and contains two types of treatments (see Table 1). The no-punishment (NP) treatments are based on a public good game in strategy method as introduced by Fischbacher et al. (2001). 
In the punishment $(\mathrm{P})$ treatments we complement this public good game with monetary peerpunishment relying on a design of Noussair and Tucker (2005). ${ }^{10,11}$

In total, the experiment consists of three stages (see Table 1). The participants of the experiment were assigned to groups comprising three subjects. In Stage A subjects were randomly assigned to groups (random matching) and played a one-shot public good game in strategy method without punishment - both in the $P$ and the NP-treatments. Each group member was endowed with 20 points, which could be invested either into a public good $\left(c_{i}\right)$, framed as a project or in their private account $\left(20-c_{i}\right)$. The following formula (Formula 1) denotes the payoff function without punishment for each individual $i$ :

\section{FORMULA 1:}

Payoff function without punishment

$$
\pi_{i}=20-c_{i}+0.4 \sum_{k=1}^{3} c_{k}
$$

Accordingly, it is more beneficial to contribute nothing to the project because every point invested returns only 0.4 points, while the private account yields exactly 1 point. Given 20 points endowment each, subjects were required to make two investment decisions, their unconditional and conditional contribution to the project. Hence, they were asked to decide how much of their endowment they would like to invest in the public good regardless of what the other group members contribute (unconditional contribution). Here, they were also asked for their expectations regarding the average unconditional contribution of the remaining group members. Next, subjects had to fill out a contribution table consisting of 21 entries asking them how much they would invest in the project if their two group members invested on average 0-20 points (conditional contribution). ${ }^{12}$ Afterwards, in order to render both decisions potentially payoff-relevant, a random mechanism ${ }^{13}$ chose one group member who had to contribute according to the conditional contribution decision. For the other two group members their unconditional contributions were thus applicable.

The main purpose of Stage A was to elicit subjects' initial cooperativeness independent of any identity or punishment influences, which facilitated analyses of treatment effects in later stages of the experiment. Furthermore, it helped classifying subjects based on their revealed cooperativeness

\footnotetext{
10 Please note that the NP- and P-conditions originate from two independent experiments (see Lankau et al. 2012 and Bicskei et al. 2013, respectively). The present paper merges both datasets in order to holistically analyze the effects of punishment on cooperation under social identity.

${ }^{11}$ We are really grateful that C. Noussair and S. Tucker as well as U. Fischbacher have provided us with their experimental protocols.

${ }_{12}$ Average investments of the other group members were rounded to the next higher integer value.

${ }^{13}$ One participant in each session rolled a dice to determine the respective group member. This served the purpose of making clear to the subjects that both investment decisions were to be taken seriously.
} 
into free-riders and conditional cooperators ${ }^{14}$ (cf. Fischbacher et al. 2001; 2010; Burlando and Guala 2005) allowing for a differentiated analysis of their behavioral adjustments in later stages.

TABLE 1

Experimental Design

\begin{tabular}{|c|c|c|c|}
\hline Treatments & Stage A & Stage B & Stage C \\
\hline \multirow{3}{*}{$\begin{array}{l}\text { No-Punishment } \\
\text { (NP) }\end{array}$} & \multirow{3}{*}{$\begin{array}{l}\text { Random Matching } \\
\text { without Punishment }\end{array}$} & \multirow{2}{*}{$\begin{array}{l}\text { Induction of } \\
\text { Social Identity }\end{array}$} & In-Group Matching (NP) \\
\hline & & & Out-Group Matching (NP) \\
\hline & & - & Random Matching (NP) \\
\hline \multirow{3}{*}{$\begin{array}{l}\text { Punishment } \\
\text { (P) }\end{array}$} & \multirow{3}{*}{$\begin{array}{l}\text { Random Matching } \\
\text { without Punishment }\end{array}$} & \multirow{2}{*}{$\begin{array}{l}\text { Induction of } \\
\text { Social Identity }\end{array}$} & In-Group Matching (P) \\
\hline & & & Out-Group Matching (P) \\
\hline & & - & Random Matching (P) \\
\hline
\end{tabular}

Stage B contained the group task, which served the purpose to induce social identity within the laboratory. The design we used was introduced by Ibañez and Schaffland (2012) and is based on insights from Eckel and Grossman (2005) and Chen and Li (2009). ${ }^{15}$ The subjects were randomly reassigned to groups of different colors and they had to jointly find hidden objects in a picture and report their location given 10 minutes time. Group members were in connection via chat enabling them to communicate anonymously and discuss solutions with their group members. The answers were counted as correct only if each group member entered them correctly. This was a necessary step to foster coordination and render this task a true group exercise. The winning group was the one, which found the most objects. Since this task was intended to induce positive group experience (Eckel and Grossman 2005), only the winning team received a message of congratulation at the end of the experimental session. ${ }^{16}$

In the NP-treatments of Stage C subjects played a public good game similar to Stage A. In the Ptreatments, after being informed how many points their group members contributed separately to the project, subjects had the possibility to distribute punishment points to each group member. ${ }^{17}$ On the one hand, the distribution of punishment points was costly for the punisher (see Table 2). On the other hand, each punishment point distributed reduced this stage's earning of the punished by $10 \%$. If a group member received 10 or more points his income from that stage was reduced by $100 \%$. In order to account for possible costs of this stage of the P-treatment, and also to avoid the possibility

\footnotetext{
${ }^{14}$ Technically, free-riders are those subjects that reveal a conditional contribution of zero independent of how much their group members contribute to the public good. Subjects are classified as conditional cooperators when showing a positive and significant $(p<0.01)$ spearman rank-correlation coefficient between own conditional contributions to the public good and the average contributions of their group members.

${ }^{15}$ We are thankful that M. Ibañez and E. Schaffland have provided us with the instructions to their identity game. Please see Appendix B for the instructions used in this experiment.

${ }^{16}$ In order to avoid any income effects, there were no monetary incentives for winning this game.

${ }^{17}$ During the experiment we used the neutral phrase of disapproval points to avoid any negative associations with punishment.
} 
of monetary losses, subjects received a one-off lump-sum payment of 60 points in addition to the basic endowment of 20 points (see Formula 2).

TABLE 2

Punishment Points $\left(P_{i k}\right)$ and Cost of Punishment $(K)$

\begin{tabular}{llllllllllll}
\hline $\mathrm{P}_{i k}$ & 0 & 1 & 2 & 3 & 4 & 5 & 6 & 7 & 8 & 9 & 10 \\
$\mathrm{~K}\left(\mathrm{P}_{i k}\right)$ & 0 & 1 & 2 & 4 & 6 & 9 & 12 & 16 & 20 & 25 & 30 \\
\hline
\end{tabular}

FORMULA 2

Payoff function with punishment

$$
\pi_{i}=\left(20-c_{i}+0.4 \sum_{k=1}^{3} c_{k}\right) \times \frac{\max \left\{0,10-\sum_{k \neq i} P_{k i}\right\}}{10}-\left(\sum_{k \neq i} K\left(P_{i k}\right)\right)+\text { lumpsumpayment }
$$

In Stage C, following a between-subject approach three different matching protocols were in effect (see Table 1). On the one hand, subjects were either matched with members of their own identity, with whom they shared the same color when solving the group identity task in Stage B (in-group matching); or with members of different colors, thus three different identities (out-group matching). Both matching conditions are together referred to ID matchings. In order to make group identity salient, the color of an individuals' group as well as the color of her group members was clearly indicated during the game both in in-group and out-group matching. On the other hand, we carried out a control treatment both in P- and NP-treatments, in which subjects were randomly assigned to a group (random matching) and played the same one-shot public good game as in the ID matching protocols, yet without participating in Stage B (see Table 1).

The instructions were handed out successively, so that subjects learned the group assignment rule and whether they were in a P- or NP-treatment only at the relevant stage during the experiment. What is more, in the NP-treatments any information on contributions and payoffs was only revealed after the experiment's last stage. The same holds true for the P-treatments with the exception that in Stage $C$ subjects were provided with necessary information on the contribution behavior of their group members in order to be able to make decisions about punishment points. At the end of Stage $C$, all subjects received detailed information on the earnings of Stage $A$ and $C$ and the final payment including the $2.5 €$ show-up fee. Moreover, in the P-treatments, subjects were only informed about the total sum of punishment points they received, yet they did not learn which group member punished them exactly.

\section{EMPIRICAL RESULTS}

The experiment was conducted in the laboratory of a European university from October 2011 to July 2012 using the software z-Tree (Fischbacher 2007). We collected the decisions of 384 subjects $^{18}$ from different faculties, specifically, 177 subjects participated in the NP- and 207 subjects in the

\footnotetext{
${ }^{18}$ The proportion of males was 48 percent, and the average age of the subjects was 24 years.
} 
P-treatments. ${ }^{19}$ Depending on the number of participants per session, the amount of groups and thus the number of color identities ranged from 3-8 per session. Our subjects were recruited from volunteers of the ORSEE system of the university and at the university's cafeteria. The sessions took approximately 1.5 hours and the subjects earned $15 €$ on average including the show-up fee.

\section{Effects of a punishment threat on cooperativeness under social identity}

At first, we investigate how the anticipation of peer-punishment affects subjects' cooperativeness in different group compositions under social identity compared to a setting without such threat (NPtreatment). Please note that although the basic decision situation of stage $\mathrm{C}$ was equally based on the 20 points endowment received in both $\mathrm{P}$ and NP-treatments, in contrast to the NP-treatment subjects in the P-treatment were given additional 60 points endowment in order to avoid bankruptcy (see section III). Consequently, differences in cooperativeness between the $\mathrm{P}$ and NP-treatments may be influenced by this lump-sum payment, as well. We assume, however, that this influence is equal independent of with whom subjects are matched. Given this assumption, any difference in the effect of punishment between the three matching conditions under social identity should then only be due to the effects of punishment in the respective matching. Therefore, our subsequent analyses focus on a difference-in-difference approach.

In order to keep as much within-information as possible we analyze how subjects - in their respective treatments - adjusted their conditional contributions in Stage $C$ as opposed to Stage $A$. Comparing these changes between the treatments allows drawing more precise conclusions regarding differences in cooperativeness than the analysis of behavioral strategies in the particular stages independently.

To this purpose, Figure 1 depicts to what extent subjects adjusted their conditional contributions in Stage $C$ as opposed to Stage $A$ with and without punishment in the three matching protocols. When interacting with out-group members, punishment seems to induce the highest increase in cooperativeness amounting to almost 5 points at its peak (i.e., when the average contribution of the others is twenty). Especially, when matched with in-group members behavioral adjustments to punishment seem to be lower. Running a diff-in-diff analysis confirms that the increase in cooperativeness is significantly higher in out-group than in in-group matching (see Table 3, Model A, row 10$)$.

Comparing out-group with random matching reveals that the changes in cooperativeness are higher when interacting with out-group members. Yet, this difference is not significant. All in all, we thus have to reject Hypothesis 1 . Our results clearly demonstrate that punishment has a differing effect on cooperativeness depending on group composition. ${ }^{20}$

Result 1: $\quad$ Under the threat of peer-punishment subjects increase their cooperativeness significantly stronger when matched with individuals saliently belonging to different identities than with individuals of their own identity.

\footnotetext{
${ }^{19}$ Appendix A contains summary statistics providing details on the number of sessions and subjects per session.

${ }^{20}$ Subjects reveal similar changes in unconditional contributions (see Appendix A for sum mary statistics).
} 
FIGURE 1

The Effects of Punishment on the Average Change in Conditional Contributions

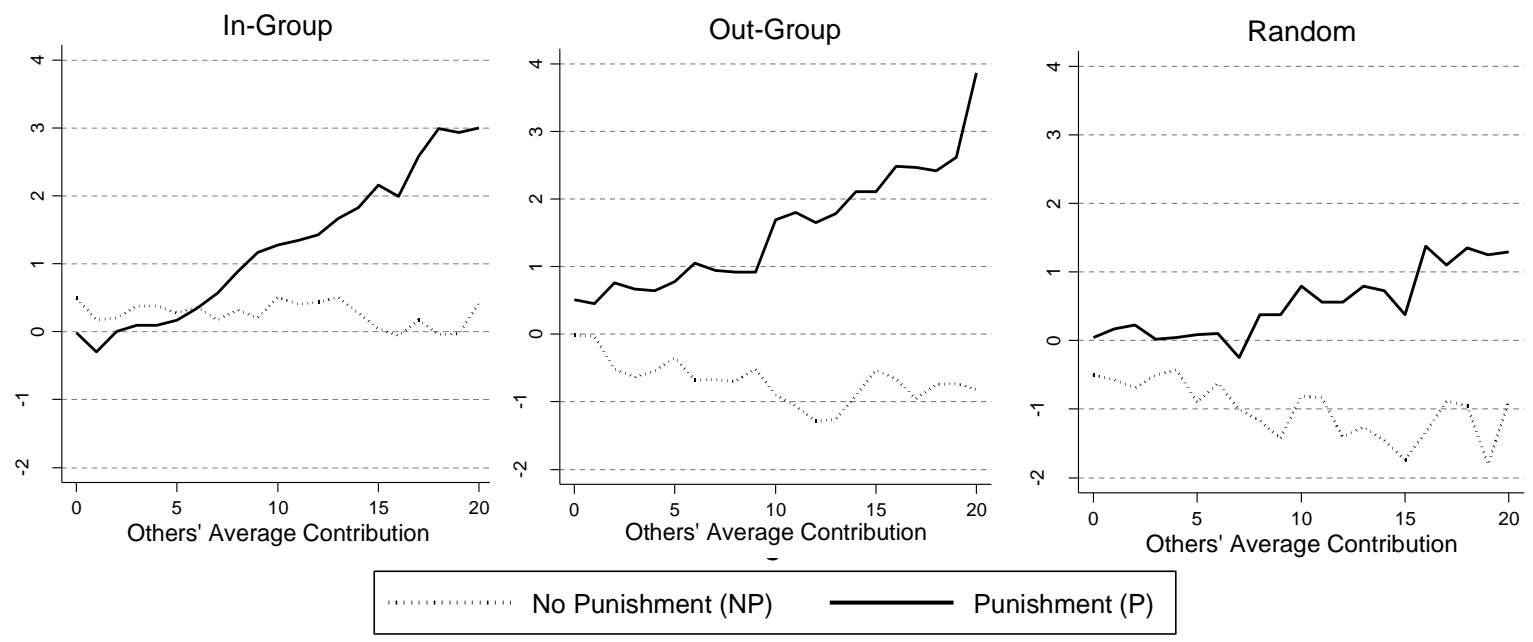

TABLE 3

The Impact of Punishment on Cooperativeness in Different Matching Conditions

\begin{tabular}{|c|c|c|c|c|c|c|c|}
\hline \multicolumn{3}{|l|}{ Linear Regression (OLS) } & \multicolumn{5}{|c|}{ Model } \\
\hline & & \multirow[b]{2}{*}{ Row } & \multirow{2}{*}{$\begin{array}{c}\text { (A) } \\
\text { All Subjects }\end{array}$} & \multirow{2}{*}{$\begin{array}{l}\text { (B) } \\
\mathrm{CCS}\end{array}$} & \multirow{2}{*}{$\begin{array}{l}\text { (C) } \\
\text { FRs }\end{array}$} & \multirow{2}{*}{$\begin{array}{c}\text { (D) } \\
\text { Others }\end{array}$} & \multirow{2}{*}{$\begin{array}{c}(E) \\
\text { No FRs }\end{array}$} \\
\hline Change in Conditional & I Cooperation & & & & & & \\
\hline & Punishment $(\mathrm{P})$ & 1 & $0.542 *$ & $0.475^{*}$ & 3.000 & -0.387 & 0.318 \\
\hline & & & $(0.312)$ & $(0.269)$ & $(1.870)$ & $(0.837)$ & $(0.271)$ \\
\hline & OUT $x$ P & 2 & $1.012^{*}$ & 0.322 & 3.250 & 0.218 & 0.341 \\
\hline & & & $(0.523)$ & $(0.468)$ & $(2.254)$ & $(0.970)$ & $(0.434)$ \\
\hline & $\mathrm{IN} \times \mathrm{P}$ & 3 & 0.705 & 0.287 & 1.056 & 1.400 & 0.506 \\
\hline & & & $(0.460)$ & $(0.463)$ & $(2.240)$ & $(1.001)$ & $(0.416)$ \\
\hline & No Punishment (NoP) & 4 & $-1.008^{*}$ & $-2.193^{* * *}$ & 1.177 & -0.179 & $-1.445^{* *}$ \\
\hline & & & $(0.540)$ & $(0.720)$ & (1.103) & $(0.888)$ & (0.583) \\
\hline & OUT x NoP & 5 & 0.317 & $1.468 *$ & -1.177 & -0.959 & 0.631 \\
\hline & & & $(0.651)$ & $(0.831)$ & (1.103) & $(1.567)$ & $(0.722)$ \\
\hline & IN x NoP & 6 & $1.274^{* *}$ & $2.365^{* * *}$ & 0.537 & -0.207 & $1.466^{* *}$ \\
\hline & & & $(0.620)$ & $(0.825)$ & $(1.494)$ & $(0.919)$ & $(0.656)$ \\
\hline & IN: P - NoP & 7 & $0.981^{*}$ & 0,589 & 2,342 & $1.400 *$ & $0.802^{*}$ \\
\hline & OUT: P-NoP & 8 & $2.244^{* * *}$ & $1.522 * * *$ & $6.25^{* * *}$ & 0,97 & $1.473^{* * *}$ \\
\hline & Control: P-NoP & 9 & $1.550^{*}$ & $2.668^{* * *}$ & 1,823 & $-0,207$ & $1.764^{* * *}$ \\
\hline \multirow[t]{3}{*}{ Diff-in-Diff Analyses } & OUT vs IN & 10 & $1.264^{*}$ & 0,933 & $3.908 *$ & -0.431 & 0.670 \\
\hline & OUT vs. Control & 11 & 0,695 & $-1,145$ & $4.427^{*}$ & $-1,177$ & -0.290 \\
\hline & IN vs. Control & 12 & $-0,569$ & $-2.078 * *$ & 0,519 & 1,608 & -0.960 \\
\hline \multirow[t]{2}{*}{ Punishment } & IN - OUT & 13 & -0.306 & -0.035 & -2.194 & 1,183 & 0,165 \\
\hline & & & $(0.540)$ & $(0.538)$ & $(1.767)$ & 0,736 & 0,462 \\
\hline \multirow[t]{2}{*}{ No Punishment } & IN - OUT & 14 & $0.957 * *$ & 0.898 & $1.714^{*}$ & 0,752 & 0,835 \\
\hline & & & $(0.474)$ & $(0.578)$ & (1.007) & $(1.312)$ & $(0.523)$ \\
\hline Number of obs & & & 8.064 & 5.334 & 1.134 & 1.596 & 6.930 \\
\hline R-squared & & & 0.058 & 0.060 & 0.390 & 0.022 & 0.038 \\
\hline
\end{tabular}

Note: standard errors clustered over individuals, Stat. Sign.: ${ }^{*} p<0.1,{ }^{* *} p<0.05,{ }^{* * *} p<0.01$

Coefficients as off row 7 are calculated using post-regression tests for linear combinations 
Next, we ask how certain cooperation types with differing social attitudes adjust their cooperativeness. To do so, we classify subjects - based on their initially revealed cooperativeness in Stage A of the experiment - into free-riders (FR) and conditional cooperators (CC). While free-riders reveal purely selfish cooperation preferences, conditional cooperators tend to be motivated by a social preference based on positive reciprocity (cf. Falk 2003; Lankau et al. 2012). Consequently, the more their group members contribute to the public good, the higher their own contribution is in return. Yet, even conditional cooperators do not perfectly reciprocate their group members' contributions and exhibit a certain self-serving bias by frequently contributing less to the public good than their group members (Fischbacher, Gächter, and Fehr 2001; Lankau, Bicskei, and Bizer 2012). Subjects, which fell into neither category, are termed "others". ${ }^{21}$ Table 4 summarizes the distribution of those cooperation types.

TABLE 4

Frequency and Distribution of Cooperation Types in Stage A

\begin{tabular}{lrr}
\hline Cooperation Type & Frequency & Percent \\
\hline Free-Rider (FR) & 54 & 14.06 \\
Conditional Cooperators (CC) & 254 & 66.15 \\
Other & 76 & 19.79 \\
\hline Total & $\mathbf{3 8 4}$ & $\mathbf{1 0 0}$ \\
\hline
\end{tabular}

Figure 2 and 3 show the impact of peer-punishment on free-riders' and conditional cooperators' cooperativeness in in-group, out-group and control treatments, respectively. We find, on the one hand, that independent of how free-riders are matched, peer-punishment increases their cooperativeness. The strongest behavioral adjustment is present when free-riders interact with outgroup members, which is significant at the 10 percent level (see Table 3, Model C, row 10). While they are not cooperative at all without the threat of peer-punishment, under punishment they are for instance willing to contribute 12 points on average to the public good if their group members contribute 20. When matched with in-group members or in random matching these differences are lower and merely amount to approximately 4 points on average. Indeed, the linear regression in Table 3 (Model C, row 10 and 11) confirms that the impact of punishment on free-riders' cooperativeness in out-group matching is significantly stronger than in the in-group or control treatment.

On the other hand, the punishment effect on conditional cooperators does not seem to be as pronounced as in case of free-riders (see Figure 3 and Table 3, Model B and C, row 7, 8). Moreover, we find that conditional cooperators reveal a very similar behavioral adjustment under punishment when matched with in-group and with out-group members (Table 3, Model B, row 10).

\footnotetext{
${ }^{21}$ In our analysis we neglect "others", since their behavior subsumes many different cooperation patterns, which occur too infrequently to form separate categories. Such patterns are for instance characterized by hump-shaped cooperation, yet also by behavior not following any inherent logic. Clearly, treatment effects on the category of others will not yield insightful results.
} 
Result 2: In ID matchings free-riders are prone to show stronger adjustments in cooperativeness in response to peer-punishment than conditional cooperators. It is strongest when matched with out-group members.

FIGURE 2

The Effects of Punishment on Average Changes in Conditional Contribution of Free-Riders

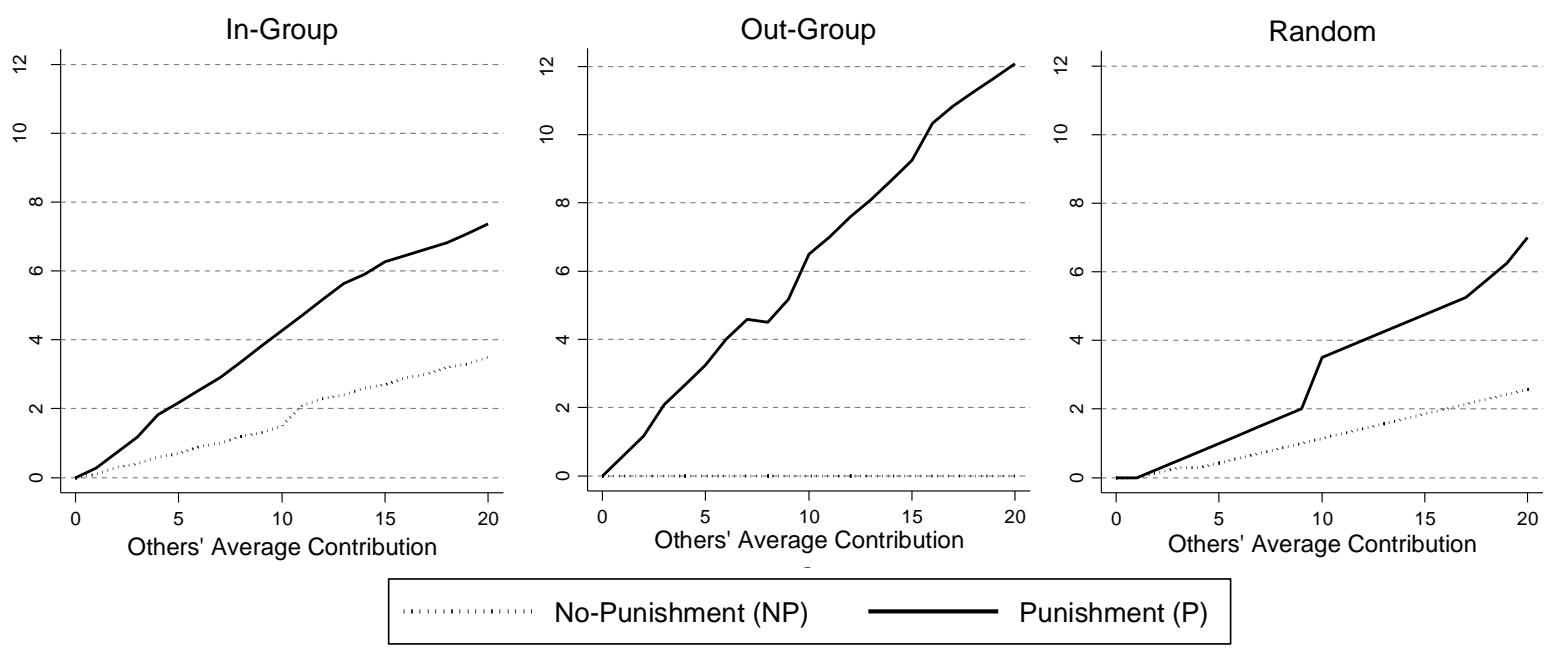

FIGURE 3

The Effects of Punishment on Average Changes in Conditional Contribution of Conditional Cooperators
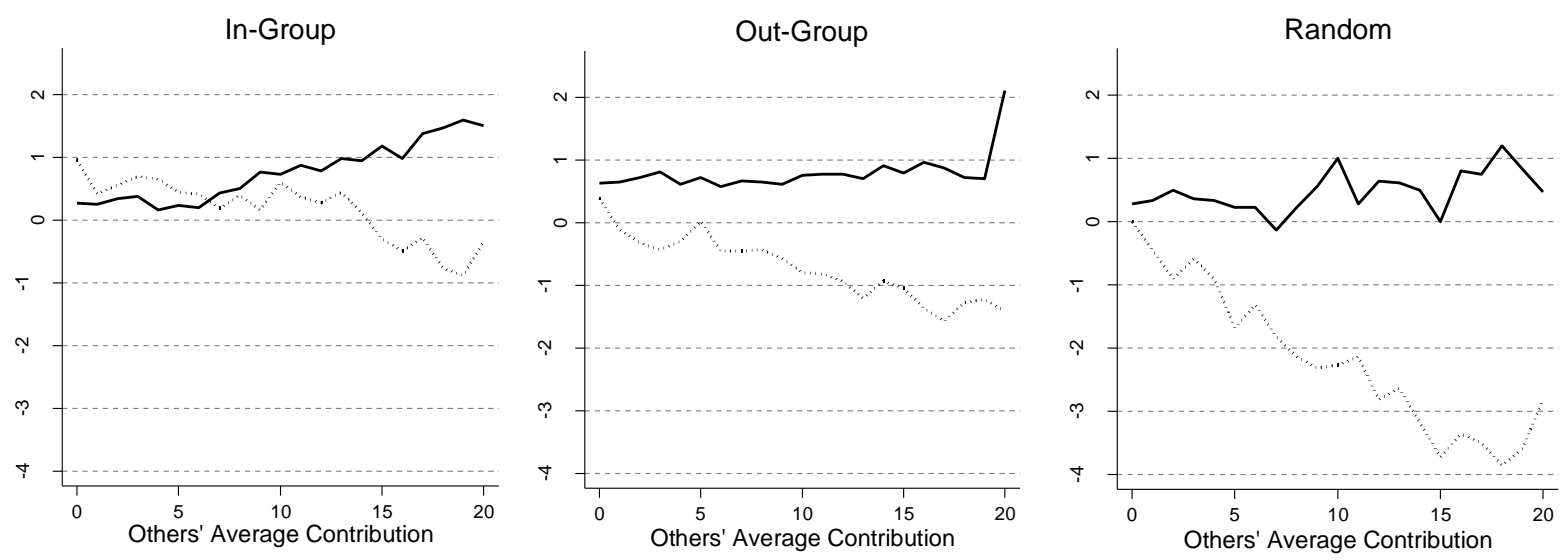

No-Punishment (NP)

Punishment (P)

In order to explain this differential reaction to punishment, we argue, on the one hand, that socially oriented conditional cooperators voluntarily contribute to the public good so that the threat of punishment does not evoke a particularly strong increase in their cooperativeness. Purely selfinterested free-riders, on the other hand, strongly adjust their cooperation strategy under punishment due to the perceived threat of monetary losses following their uncooperative behavior. This anticipation of peer-sanctioning seems to be especially strong in groups with individuals of differing identities. 


\section{Effects of Social Identity under Peer-Punishment-Threat}

After having established that peer punishment drives cooperativeness particularly in identity heterogeneous groups, we proceed by analyzing whether subject's cooperativeness differs dependent on group composition when a punishment threat is present. Figure 4 depicts the average change in conditional cooperation between Stage $C$ and $A$ under punishment as influenced by the three group assignment conditions (left panel) contrasted by the corresponding cooperativeness without punishment (right panel).

\section{FIGURE 4}

ID Matchings Effects on Changes in Conditional Cooperation with and without Punishment
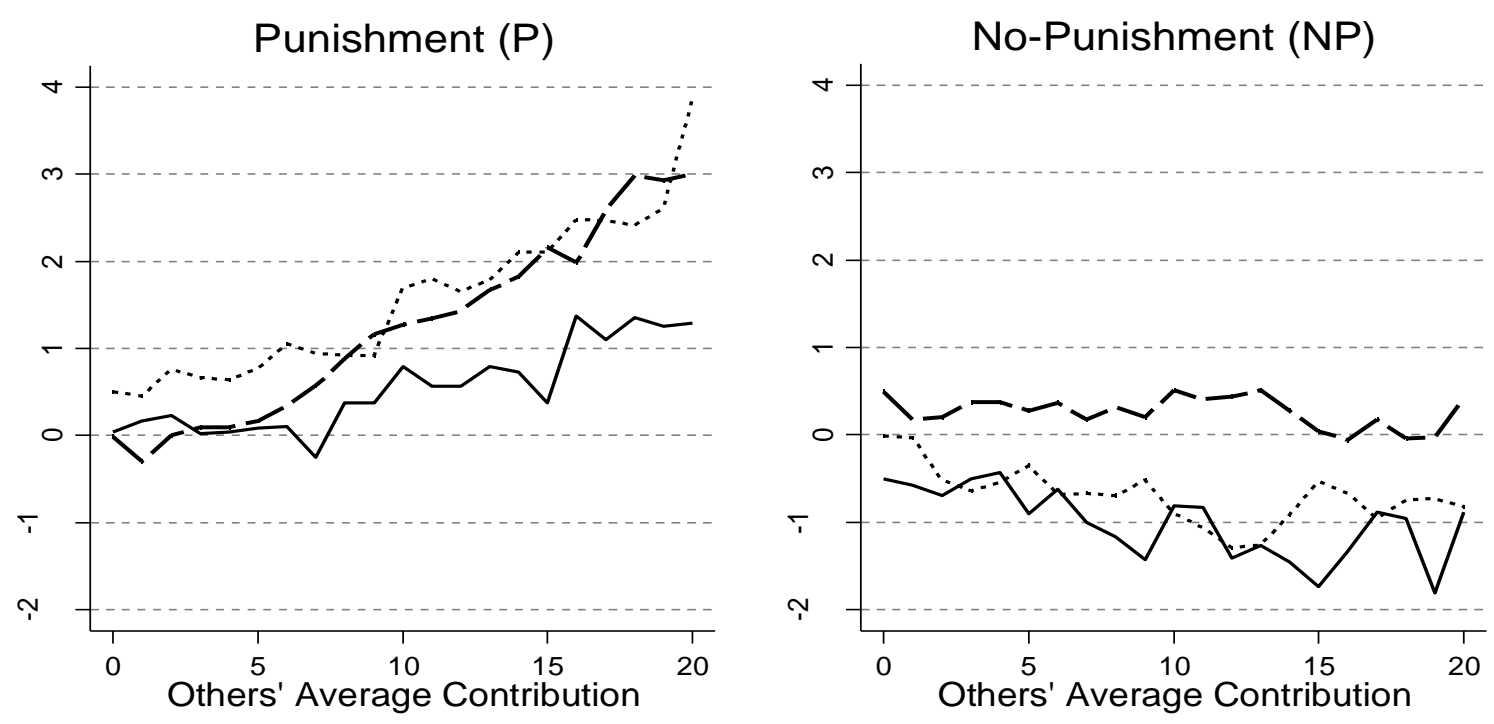

$$
\text { - - In-Group ……... Out-Group } \longrightarrow \text { Random }
$$

Firstly, under punishment subjects seem to be similarly cooperative in in- and out-group matching (left panel). For low levels of others' contribution to the public good they even contribute on average slightly more when matched with out-group members. On the whole, however, we do not find any significant difference in conditional cooperation between both ID treatments under punishment (see Table 3, Model A, row 13). This starkly contrasts the findings on subjects' cooperativeness without punishment. ${ }^{22}$ In line with prior research on the effects of social identity on cooperation (cf. Chen and Li 2009; Eckel and Grossman 2005), subjects' cooperativeness without punishment is significantly biased towards their in-group members (right panel, for regression result see Table 3, Model A, row

\footnotetext{
${ }^{22}$ One interesting reflection regarding our research design, pointed out to us by a commentator, is the fact that both ID-matching protocols entail a higher cooperativeness than the random matching protocol under punishment could be simply due the design of the control treatment. Specifically, it did not require subjects to take part in Stage B, so that missing the experience of solving the picture task explains the observed difference. Yet, if this was true we should observe similar differences between those treatments without punishment, as well. However, without punishment subjects in out-group matching reveal a similar cooperativeness as those of the control treatment (see Figure 4 and Table 3). Consequently, it is not the participation in Stage B but rather the identification created by it and punishment, which explain the observed effects.
} 
14). ${ }^{23}$ Consequently, we argue that the fear created by a punishment institution overrides the reluctance to cooperate with out-group members and renders individuals to be as cooperative as in in-group matching. Evidently, as summarized by Result 1, behavioral adjustments through punishment seem to be comparatively strongest when subjects are matched with out-group members. This is most likely due to an anticipation of higher punishment by individuals that do not belong to their own identity, which seems to be mainly driven by free-riders. They exhibit the highest increase in cooperativeness under punishment when matched with out-group members (Result 2). Indeed, when dropping free-riders from the regression analysis in Table 3 (Model E, row 10), we no longer find a significant difference in punishments' impact on subjects' cooperativeness in in-group and out-group matching.

Mild support for the claim that subjects fear comparably strong punishment by outsiders in response to antisocial behavior is given by considering their actual punishment behavior (see summary statistics in the Appendix A). Subjects in out-group matching distributed on average 2.34 punishment points to group members that contributed less than they did (non-spiteful punishment). In in-group and random matching non-spiteful punishment merely amounted to 1.51 and 2.25 points, respectively. ${ }^{24}$ Consequently, since members of identity heterogeneous groups tend to punish deviant behavior on average more severely than identity homogenous groups or randomly matched groups, it is not unreasonable to assume that subjects anticipate such reaction in response to unsocial behavior and adjust their cooperativeness accordingly. ${ }^{25}$

Overall, since we no longer observe an in-group bias, we have to reject Hypothesis 2, as well. This result is inconsistent with McLeish and Oxoby (2007) who find in two-person interactions that both with and without punishment cooperation is higher in in-groups than in out-groups. However, they did not find any punishment effect on cooperation either.

Result 3: $\quad$ The presence of peer-punishment eliminates the existence of an in-group bias, which is prevalent when social identity is salient and no punishment is available.

Lastly, subjects' cooperativeness under punishment both in in- and out-group matching is slightly elevated compared to random matching of the control treatment in which no social identity is induced (Figure 4, left panel). In in-group matching this difference is merely borderline significant (Table 3, Model A, row 3, $p=0.127$ ). In out-group matching significance is given at the 10 percent level (Table 3, Model A, row 2). Together, these results suggest that a simultaneous application of peer-

${ }^{23}$ The induction of social identity in Stage B was identical both in the NP as well as the P treatments. Consequently, the existence of an in-group bias without punishment clearly shows that the non-existence of such bias with punishment cannot be explained by an unsuccessful identity induction.

${ }^{24}$ Wilcoxon Rank Sum Tests: In vs. Out, $p<0.05$; Cont vs. In, $p<0.01$; Out vs. Cont, $p>0.1$. For a detailed discussion of subjects' punishment behavior and its relation to anger-like emotions see Bicskei et al. (2013).

${ }^{25}$ Please note that due to our experimental design, the actual amount of punishment points received cannot influence subjects' cooperativeness. Only after they make their contribution decisions do subjects learn how much they have been punished. It is thus impossible to directly conclude from punishment points to cooperativeness. It's much rather the anticipation of punishment that drives subjects' behavior. 
punishment and social identity is a viable option to boost cooperativeness in public goods provision. ${ }^{26}$

Result 4: $\quad$ Under punishment subjects seem to reveal an increased cooperativeness in in-and out-group matching compared to groups without saliency of social identity.

On the one hand, this result complements to some degree the findings by Noussair and Tucker (2005) who established that when peer-punishment is combined with another institution, namely with the possibility of non-monetary social sanctions, it results in a higher cooperativeness than when applied by itself. On the other hand, it contradicts Weng and Carlsson (2013), who find that punishment has a similar effect on cooperativeness in groups without a salient social identity and in groups sharing a common salient identity.

\section{CONCLUSION}

In this article, we investigate the question of how the threat of peer-punishment and social identity simultaneously affect cooperativeness in the provision of public goods. In particular, our aim is to provide insights on the influence of punishment on subjects' cooperativeness in homogeneous groups bound together by a common social identity and in heterogeneous groups consisting of individuals saliently belonging to different identities. To this purpose, we induce social identity in the laboratory and devise one-shot public good games using the strategy method both with and without the institution of costly peer-punishment. Our experiment is the first that asks for effects of peerpunishment in public goods provision dependent on whether subjects interact in identityhomogenous or identity-heterogeneous groups. In particular, it adds to McLeish and Oxoby (2007), who focus on two-person interactions, by incorporating the influence of a group setting on subjects' anticipated punishment and their cooperation under social identity. Punishment within groups itself constitutes a second order public good that incentivizes subjects to free-ride on group members punishment efforts.

The results of our study indicate first of all that group composition plays a crucial role in how a peerpunishment threat affects cooperation under social identity. The strongest increase in cooperativeness can be observed among subjects in out-group matching, especially for those who were classified as free-riders based on their initially revealed cooperativeness. This is most likely due to an anticipation of comparably strong punishment by individuals who do not belong to their own identity. Secondly, in contrast to the institutional setting without peer-punishment, in which individuals' cooperativeness is clearly biased towards members of their own identity (in-group bias), the anticipation of stronger peer-punishment by out-group members generally seems to erode this reluctance to cooperate with out-group members and renders individuals as cooperative as in ingroup matching. Lastly, our results indicate that social identity and peer-punishment complement each other. In in- and out-group matching under punishment subjects' cooperativeness is elevated compared to the control treatment, in which group members were randomly matched and no social

\footnotetext{
${ }^{26}$ Our results thus highlight that subjects who are randomly matched and form groups without salient identity exhibit rather different behavioral patterns under punishment and without it compared to the ID-treatments. Future research will have to shed light on the robustness of this finding.
} 
identity was induced. Concluding, the combination of social identity with a peer-punishment institution seems to be a viable option to foster subjects' cooperativeness compared to situations when social identity is not salient.

Summing up, it is empirically established that fragmentation and polarization of societies restrain the provision of public goods (Eaton, Eswaran, and Oxoby 2011) since individuals strongly identifying with particular groups are willing to cooperate less with members of different identities. We established, however, that implementing peer-punishment erodes the reluctance to cooperate in identity heterogeneous groups and renders people as cooperative as when being part of an identity homogenous group.

\section{APPENDIX}

\section{A. SUMMARY STATISTICS}

Summary Statistics

\begin{tabular}{|c|c|c|c|c|c|c|}
\hline & \multicolumn{3}{|c|}{ NP-Treatment } & \multicolumn{3}{|c|}{ P-Treatment } \\
\hline & IN & OUT & CONT & IN & OUT & CONT \\
\hline $\mathrm{n}$ & 69 & 66 & 42 & 84 & 75 & 48 \\
\hline Session \# & 3 & 3 & 3 & 7 & 6 & 3 \\
\hline Unconditional Contribution- Stage A & $\begin{array}{c}5.83 \\
(0.72)\end{array}$ & $\begin{array}{c}7.38 \\
(0.74)\end{array}$ & $\begin{array}{c}8.29 \\
(0.95)\end{array}$ & $\begin{array}{c}7.37 \\
(0.66)\end{array}$ & $\begin{array}{c}6.33 \\
(0.66)\end{array}$ & $\begin{array}{c}9.33 \\
(0.98)\end{array}$ \\
\hline Contribution (real)- Stage A & $\begin{array}{c}4.10 \\
(0.60)\end{array}$ & $\begin{array}{c}7.18 \\
(0.74)\end{array}$ & $\begin{array}{c}8.26 \\
(0.99)\end{array}$ & $\begin{array}{c}6.70 \\
(0.65)\end{array}$ & $\begin{array}{c}5.76 \\
(0.64)\end{array}$ & $\begin{array}{c}7.77 \\
(0.96)\end{array}$ \\
\hline $\begin{array}{l}\text { Change in unconditional Contributions } \\
\text { (Stage C - Stage A) }\end{array}$ & $\begin{array}{c}0.99 \\
(0.64)\end{array}$ & $\begin{array}{l}-1.06 \\
(0.60)\end{array}$ & $\begin{array}{l}-0.38 \\
(0.47)\end{array}$ & $\begin{array}{c}2.37 \\
(0.50)\end{array}$ & $\begin{array}{c}3.68 \\
(0.73)\end{array}$ & $\begin{array}{c}0.94 \\
(0.70)\end{array}$ \\
\hline $\begin{array}{l}\text { Change in real Contributions } \\
\text { (Stage C - Stage A) }\end{array}$ & $\begin{array}{c}1.22 \\
(0.66)\end{array}$ & $\begin{array}{l}-1.73 \\
(0.65)\end{array}$ & $\begin{array}{l}-1.52 \\
(0.85)\end{array}$ & $\begin{array}{c}2.55 \\
(0.56)\end{array}$ & $\begin{array}{c}3.61 \\
(0.77)\end{array}$ & $\begin{array}{c}1.21 \\
(0.82)\end{array}$ \\
\hline $\begin{array}{l}\text { Average Punishment received } \\
\text { (Stage C) }\end{array}$ & $\mathrm{n} / \mathrm{a}$ & $\mathrm{n} / \mathrm{a}$ & $\mathrm{n} / \mathrm{a}$ & $\begin{array}{c}2.14 \\
(0.35)\end{array}$ & $\begin{array}{c}2.60 \\
(0.38)\end{array}$ & $\begin{array}{c}2.83 \\
(0.43)\end{array}$ \\
\hline $\begin{array}{l}\text { Average Punishment distributed } \\
\text { (Stage C) }\end{array}$ & $\mathrm{n} / \mathrm{a}$ & $\mathrm{n} / \mathrm{a}$ & $\mathrm{n} / \mathrm{a}$ & $\begin{array}{c}1.07 \\
(0.15)\end{array}$ & $\begin{array}{c}1.30 \\
(0.18)\end{array}$ & $\begin{array}{c}1.42 \\
(0.22)\end{array}$ \\
\hline $\begin{array}{l}\text { Average Non-spiteful Punishment distributed } \\
\text { (Stage C) }\end{array}$ & $\mathrm{n} / \mathrm{a}$ & $\mathrm{n} / \mathrm{a}$ & $\mathrm{n} / \mathrm{a}$ & $\begin{array}{c}1.51 \\
(0.25)\end{array}$ & $\begin{array}{c}2.34 \\
(0.32)\end{array}$ & $\begin{array}{c}2.25 \\
(0.30)\end{array}$ \\
\hline
\end{tabular}

Note: Standard errors in parantheses.

\section{B. INSTRUCTIONS TO THE EXPERIMENT (NP-Treatment)}

Welcome to the experiment! Thank you very much for your participation.

If you read the following instructions carefully, you get the chance of winning money additional to the $€ 2.50$, which you receive in any case. Your earnings will depend on your decisions and on those by the other players in your group. At the end of the experiment all sums of money, which you will have earned through your decisions, will be added and given to you personally and in cash.

It is forbidden to speak during the experiment. If you have any questions, please raise your hand. A member of our team will come to you and answer your question privately.

We will be talking about points rather than Euros in the course of the experiment. Hence, your total income will be calculated in points in the first instance. The total number of points, which you will achieve during the experiment will be converted in Euros at the end, using the following equation:

1 point $=17$ Cents. 
All participants will be divided in groups with 3 players each. Except for us, i.e. the conductors of the experiment, nobody will know who is in which group. All decisions will be made anonymously and your identity will neither be revealed during the experiment nor in public.

Each task of the experiment has its own instructions, which you have to read step by step. While doing so, please consider the respective hints which will appear on the monitor.

Please click on OK when you are ready.

\section{The Basic Decision Situation}

Later, you will be informed about the experiment's procedure in detail. At this point, we would like to introduce the basic decision conditions you will face in this experiment. Some example exercises can be found subsequently.

At each point in time, you will be a member of a group consisting of $\mathbf{3}$ players. In every task, you hold 20 points. Your task is to decide whether you invest these 20 points in a private account or whether you want to invest them fully or partly in a project. Each point which you do not invest in a project will be automatically deposited on your private account.

\section{Your income from your private account:}

For each point which you deposit on your private account (and, therefore, you do not invest in the project), you will earn one point. Hence, a deposit of 20 points on your private account will produce an income of 20 points from your private account. If you, for instance, deposit 6 points on your private account, you will earn 6 points from this account. Nobody except you will earn anything from your private account.

\section{Your income from the project:}

All group members will profit equally from your contribution to the project. Vice versa, you profit from the investments by other group members. The income every member gets from the project is calculated as follows:

Income from the project $=$ (sum of all contributions to the project) $\times 0.4$

Should the sum of all contributions to the project be, for example, 30 points then you and all other group members gain $(30 \times 0.4)=12$ points each from the project. Should the sum of all contributions to the project be, for example, 10 points then you and all other group members gain $(10 \times 0.4)=4$ points each from the project.

\section{Your total income:}

Your total income is the sum of your income from your private account and your income from the project.

Income from the private account (= $20-$ your contribution to the project)

+ Income from the project $=$ (sum of all contributions to the project) $\times 0.4$

Total income

\section{Exercise Questions}

Please complete the following exercises. They do merely serve the purpose of familiarising you with the calculation of the different sorts of income, which may occur to you when making different decisions on the use of the 20 points starting capital.

Please complete all the exercises and always report your full mathematical procedure. While calculating, you may use the calculator function on the monitor. When you are done, you have to enter your results in the computer.

1. Each group member has 20 points at their disposal. Imagine that all three group members (including yourself) do not contribute anything to the project.

a. What is your total income? .... 
b. What is the total income of each of the other group members? .....

2. Each group member has 20 points at their disposal. You invest 20 points in the project. The other two group members also contribute 20 points to the project.

a. What is your total income? .....

b. What is the total income of each of the other group members? .....

3. Each group member has 20 points at their disposal. The other two group members contribute 10 points each (i.e., 20 points in total) to the project.

a. What is your total income if you, additional to the 20 points, contribute 0 points to the project?

b. What is your total income if you, additional to the 20 points, contribute 5 points to the project?

c. What is your total income if you, additional to the 20 points, contribute 15 points to the project?

4. Each group member has 20 points at their disposal. You contribute 7 points to the project.

a. What is your total income if the other group members, additionally to your 7 points, contribute 1.5 points each, i.e., 3 points in total, to the project?

b. What is your total income if the other group members, additionally to your 7 points, contribute 4 points each, i.e., 8 points in total, to the project?

c. What is your total income if the other group members, additionally to your 7 points, contribute 9 points each, i.e., 18 points in total, to the project?

\section{First Task}

You are now the member of a group of three, which was put together randomly.

The task contains the decision, which was described at the beginning and is only conducted once.

As you know, you have $\mathbf{2 0}$ points at your disposal, which you can either invest in the project or deposit on your private account.

In this task, every group member has to make two types of decisions, which we will term (1) the "unconditional" contribution to the project, or the (2) "conditional" contribution to the project (the contribution table), respectively.

Both decisions are vital for your income from this task. So please make your decisions thoughtfully.

Step 1: Your Unconditional Contribution to the Project

Please determine how many of your points you, without knowing the contributions of the other group members, want to invest in the project. Please enter this amount into the following computer screen:

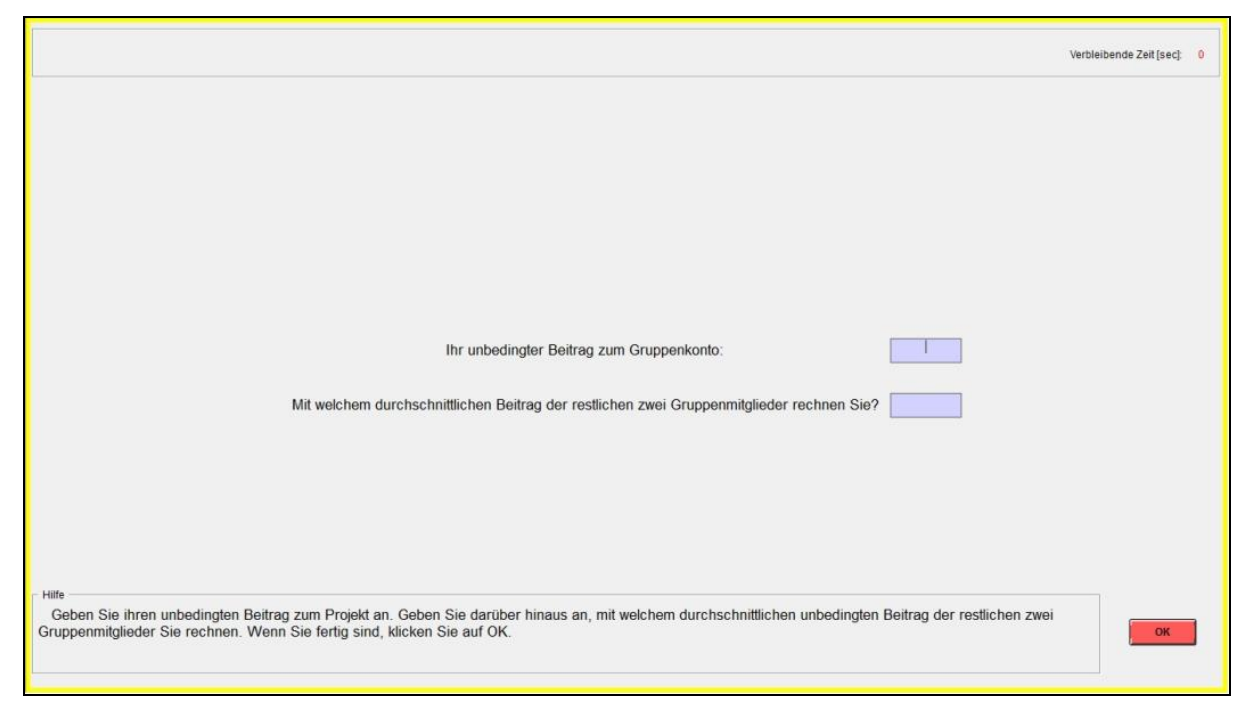


Please state what you expect each of the other two group members to contribute to the project (average amount of money they invest in the project).

Once you have made both statements, please click on OK.

\section{Step 2: Your Conditional Contribution to the Project - the Contribution Table}

With your second decision you have to fill in a contribution table. In the contribution table you have to enter your contribution to the project for every possible average contribution (rounded up) of the other group members. Hence, you can, dependent on the average contribution of the others, determine your decision on your contribution. You will get a clear hint of what to do when you take a look at the following screen.

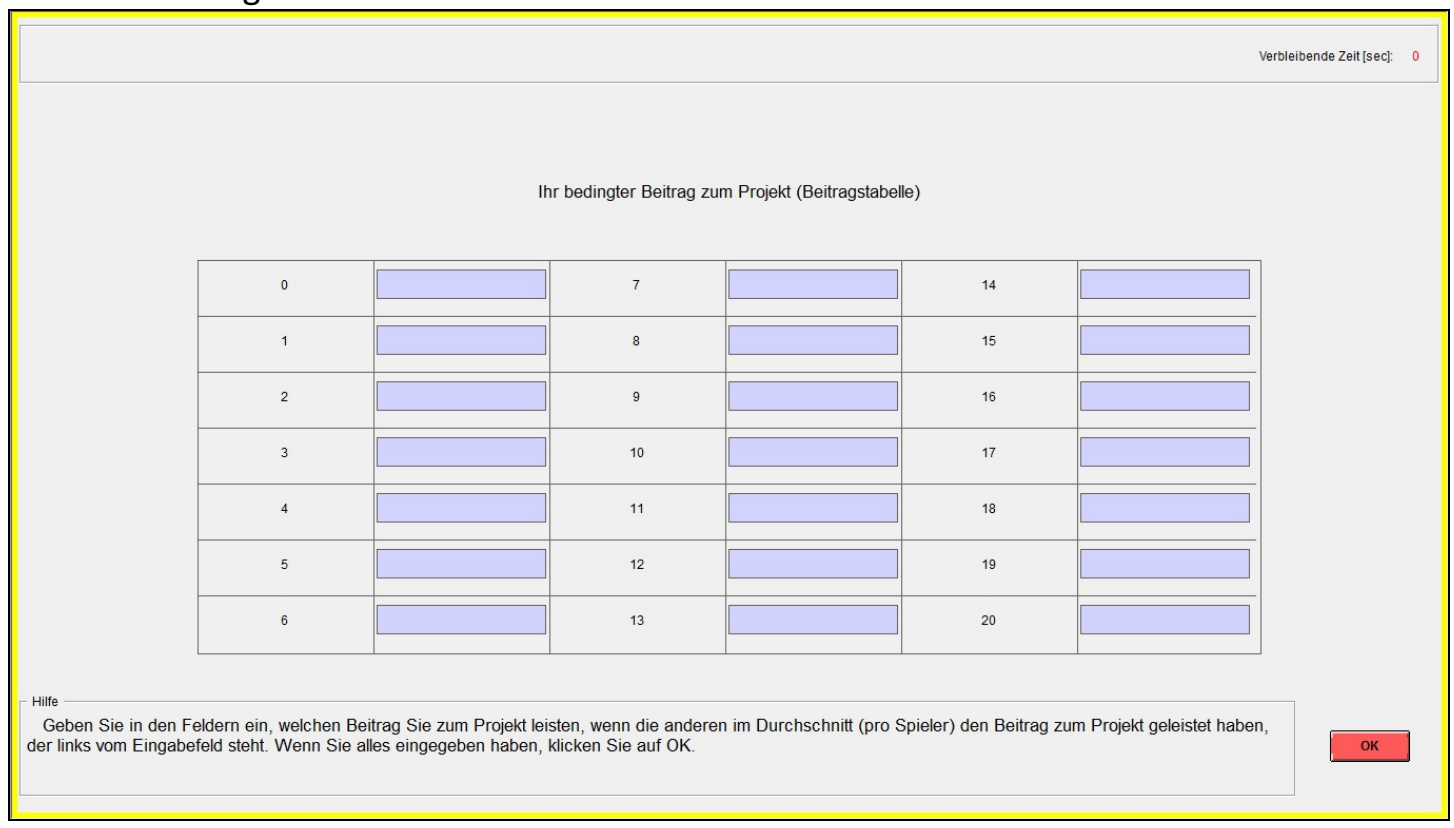

The numbers left to the boxes mark the possible average contributions, which the other members can make to the project. You just have to enter in each box how much you, under the condition that the others contribute the stated average amount, want to invest in the project. You have to make an entry in each box.

For example, you have to enter how many points you want to invest in the project if the other group members contribute 0 points; how many points you invest if the others contribute 1,2 or 3 points and so on and so forth. You can enter integral numbers ranging from 0 to 20 in each box.

Once you have typed a number in each box, please click on OK.

After all participants in the experiment made their decision on their conditional contribution and filled in the contribution table, one member of each group is selected at random. For these selected members only the contribution table is relevant for their decisions and payoff. For the other two group members, who were not selected by the random choice mechanism, only the unconditional contribution is relevant for their decisions and payoff. The average of both unconditional contributions by these two group members defines which contribution by the selected member shall be invested in the project.

When you make the decision on your unconditional contribution and fill in the contribution table, you do of course not know if you will be picked at random. Hence, you have to make both decisions carefully, because both can become relevant for you. The following examples will explain the procedure:

Example 1: You are selected by the random choice mechanism. Therefore, the contribution table is relevant for your payoff. For the other two group members the unconditional contributions are relevant. 
Let us assume that the other two group members invest 0 and 4 points in the project, which would mean an average contribution of two points. If you entered in the contribution chart that you would invest 1 point if the others averagely invested 2 points, then this would make a total contribution of $0+4+1=5$ points to the project. All group members would then earn $5 \times 0.4=2$ points from the project plus the respective incomes from their private accounts, in your case $20-1=19$ points. Your income would then be 21 points.

If you, however, stated that you would invest 16 points, if the others averagely invested 2 points, this would make a total investment of $0+4+16=20$ points in the project. As a result, all group members would receive a payoff of $20 \times 0.4=8$ points plus the income from their private accounts, in your case $20-16=4$ points. Your total income would then be 12 points.

Example 2: You are not selected by the random choice mechanism. For you and another group member then your unconditional contribution to the project is the relevant decision.

Let us assume that your unconditional contribution to the project is 16 points, the contribution by the other group member is 20 points. This makes an average contribution of 18 points to the project. Should the player who was selected by the random choice mechanism have stated that he or she would contribute 1 point to the project if the other group members averagely invested 18 points, then the total contribution to the project would be $16+20+1=37$ points. All group members then would earn $37 \times 0.4=14.8$ points from the project additional to their respective income from their private accounts. In your case you would earn $20-16=4$ points from your private account, which would then make a total income of 18.8 points.

Should the selected group member have stated an investment of 19 points to the project if the others averagely invested 18 points, then the total contribution to the project would be $16+20+19$ $=55$ points. Every group member would have a project income of $55 \times 0.4=22$ points plus their points from their private account, in your case 4 points. Your total income would then be 26 points.

\section{The Random Choice Mechanism}

At the beginning of this game each group member receives a number between 1 and 3 . As you might remember, one participant, namely no. 8, was selected at the beginning of the experiment. This participant will dice a number between 1 and 6 after all participants decided on their unconditional contribution and filled in the contribution table. The numbers 1 and 2 stand for group member one, 3 and 4 for group member two and 5 and 6 for member three. Participant no. 8 will enter these in the computer. In case no. 8 dices the numbers which correspond to your member number, the contribution table will be relevant for your decisions and payoff and for the other group members the unconditional contribution will be relevant. In any other case the unconditional contribution is relevant for you.

Please click on OK once you have read and understood the instructions.

\section{Second Task}

Please note: Do not open the attached envelope before you are asked to do so!

For the second task, you will be arbitrarily assigned a new group, which will be marked by a specific colour.

Only those solutions which are given correctly by ALL THREE group members will be considered correct in this group task.

During this task the group members are allowed to communicate with each other. By doing so, they can find a solution together. On the left hand side of the computer screen a chat box is positioned, which can be used for communication. Your conversation will be recorded. You have 10 minutes to solve the task. Only within this time span are you able to communicate with your team members. Please take into account that every group member has to type in the solutions which will have been found by your group. You have to click on OK before the 10 minutes have run out. The time left will be shown to you in the upper right hand corner of your screen. 
All participants will be shown a picture and a list of objects. The task is to find the hidden objects in the picture. The inscriptions on the left and the upper side give the numbers of the lines and columns. You are asked to insert this information in the boxes which will be shown on the right hand side of the screen. The first box refers to a line, the second to a column. An example for this exercise is given below.

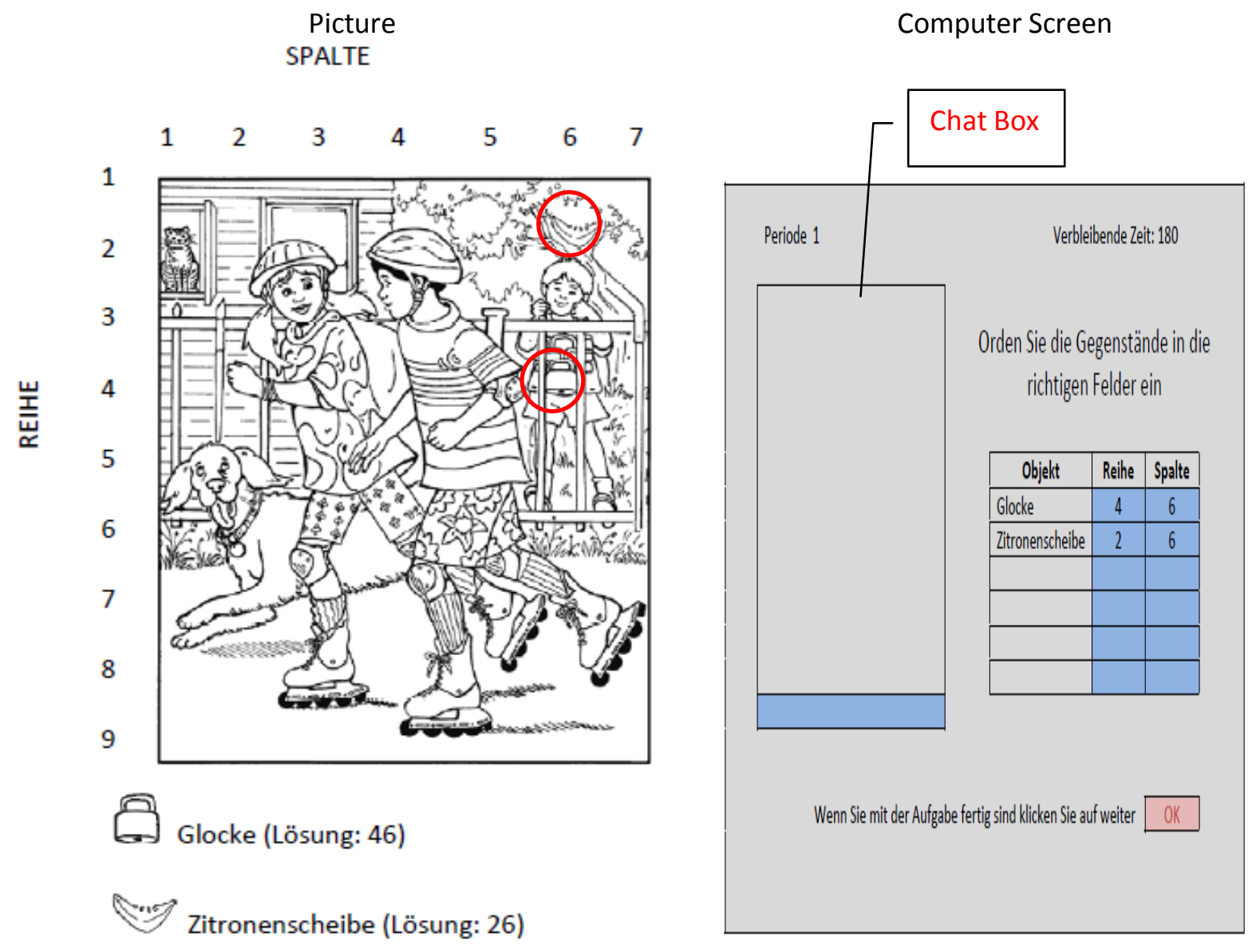

The group which finds most of the objects in the 10 minutes time is the winner group. At the end of the experiment you will be informed whether you are a member of the winner group. In this case, you will receive a congratulation message.

Please click on OK when you are ready.

\section{Third Task}

This task corresponds to the first one. It is conducted only once.

This time, however, you will only play together with members of your own group, with who you solved the picture puzzle in the second task.

Again, you hold a deposit of 20 points. Please decide how many points you want to invest in the project and how many you want to put on your private account.

This task also consists of two decisions, your (1) conditional contribution to the project and (2) the contribution table, with which you can make your decisions conditional on the other group members' contributions.

Please decide very carefully in both cases, for both the conditional contribution and your input into the contribution table are potentially relevant for the payoff. To determine the relevance of the decision, we will use the same random choice mechanism as before.

When you are ready, please click on OK. 


\section{Third Task (P-Treatment)}

This time, however, you will only play together with members of your own group, with who you solved the picture puzzle in the second task.

Again, you receive a basic endowment of 20 points.

In addition to this basic endowment, every participant receives an amount of 60 points (extra endowment) in this task. This one-off payment can be used to pay for possible costs during this task.

This task consists of two stages and is conducted only once.

\section{Stage 1:}

Please decide how many of your $\mathbf{2 0}$ points (basic endowment) you want to invest in the project and how many you want to put on your private account.

This task also consists of two decisions, your (1) unconditional contribution to the project and (2) the contribution chart, with which you can make your decisions conditional on the other group members' contributions.

Please decide very carefully in both cases, for both the unconditional contribution and your input into the contribution chart are potentially relevant for the payoff. To determine the relevance of the decision, we will use the same random choice mechanism as before.

Your income from this stage will be displayed on the screen.

\section{Stage 2:}

At the beginning of the second stage, you will receive information how much each of your group members contributed to the project. In this stage you have the opportunity to register your approval or disapproval of each other group member's decision by distributing points.

In this stage you have the opportunity to reduce or leave equal the income of each group member by distributing points. You can award a large number of points to any member of your group if you disapprove of his or her decision (10 points for the most disapproval, 0 points for the least disapproval). Each point you distribute to a particular player lowers his or her payment by $10 \%$. You incur a cost for allocating points to other members, which is discussed in detail below.

You must decide how many points to give to each of the other two group members and enter these into the following computer screening:

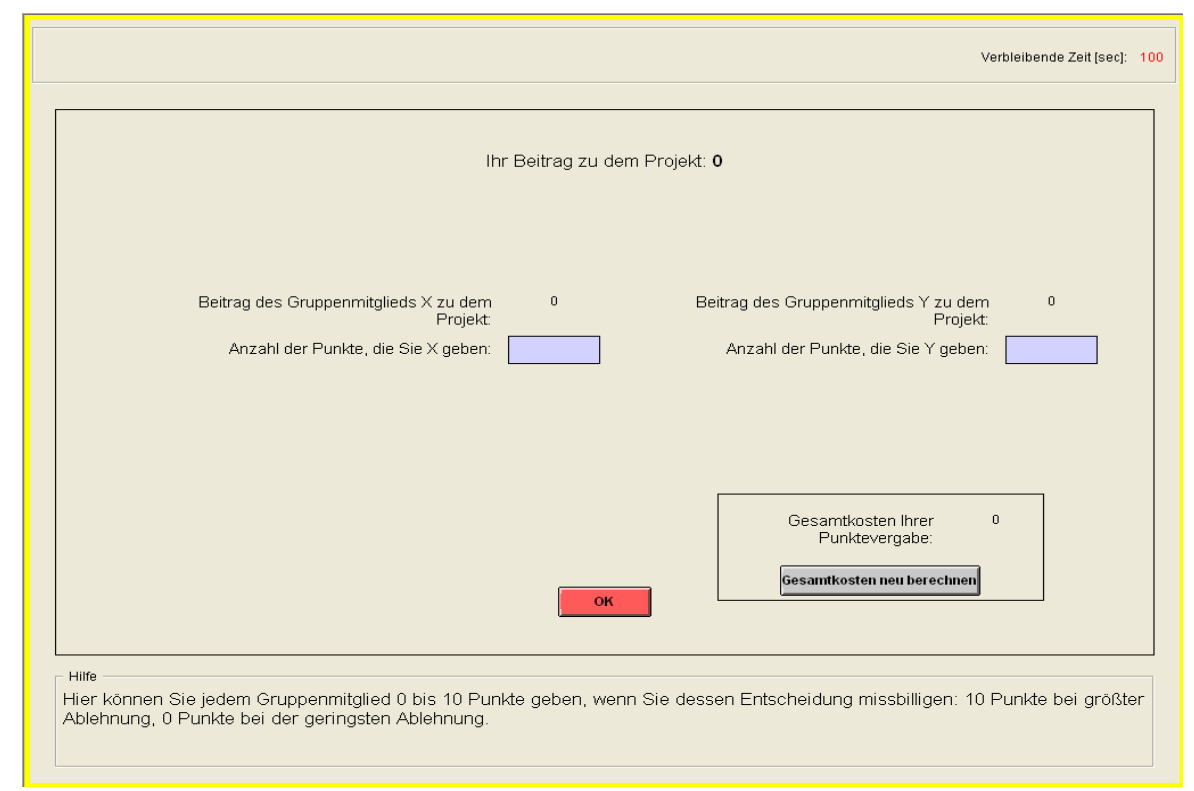


If you do not wish to change the income of a specific group member then you must enter 0 . If you distribute points, you have costs in points, which depend on the amount of points you distribute. You can distribute between 0 and 10 points to each group member. The more points you give to any group member, the higher your costs. Your total costs are equal to the sum of the costs of distributing points to each of the other two group members. The following table illustrates the relation between distributed points to each group member and the cost of doing so in points.

Suppose for example that you give 2 points to one member. This costs you 2 points. If you give 9 points to another member this costs you an additional 25 points. In this case your total costs of distributing points would be $27(2+25)$ points. Your total cost of distributing points can be calculated on the input screen (on the right hand side). As long as you have not pressed the ok button you can revise your decision.

If you choose 0 points for a particular group member, you do not change his or her income. However if you give a member 1 point (by choosing 1 ) you reduce his or her income by 10 percent, etc. The amount of points you distribute to each member determines therefore how much you reduce their income from the first stage.

Whether or by how much the income from the first stage is totally reduced depends on the total of the received points from all other group members. If somebody received a total of 3 points (from all other group members in this period) his or her income would be reduced by 30 percent. If somebody received a total of 4 points his or her income would be reduced by 40 percent. If anybody receives 10 or more points their income from the first stage will be reduced by 100 percent. The income from the first stage for this member would in this case be reduced to zero.

The other group members can also assign points to you if they wish to.

Please state hereafter what you consider how many points you will receive in total from the other two group members.

Your total income

Your total income from the two stages is therefore calculated as follows:

If you receive less than 10 points:

\section{Your total income}

$=[($ income from the 1 st stage $) \times(10-$ received points $) / 10]$

- (cost to you of points you distribute) + extra endowment

If you receive 10 or more points:

$=0-$ (cost to you of points you distribute) + extra endowment

After all participants have made their decision, your income from the task will be displayed on the screen.

\section{Exercises}

To check your understanding of the experiment, please answer the following questions. While calculating, you may use the calculator function on the monitor. When you are done, you have to enter your results in the computer.

1. Suppose in the second stage of this task, you distribute the following amounts of points to the other two group members: 9 and 5 . What is the total cost of the points you distribute?

2. What are your costs if you distribute a total of 0 points?

3. By how many percent will your income from the first stage be reduced, when you receive a total of 0 points from the other group members?

4. By how many percent will your income from the first stage be reduced, when you receive a total of 4 points from the other group members?

5. By how many percent will your income from the first stage be reduced, when you receive a total of 15 points from the other group members?

When you are ready, please click on OK. 


\section{REFERENCES}

Anderson, Christopher M., and Louis Putterman. 2006. "Do non-strategic sanctions obey the law of demand? The demand for punishment in the voluntary contribution mechanism." Games and Economic Behavior 54 (1) 1-24.

Bicskei, Marianna, Matthias Lankau and Kilian Bizer. 2013. Negative Reciprocity and Anger-Like Emotions in Homogenous and Heterogeneous Groups. Unpublished Manuscript.

Blackwell, Calvin, and Michael McKee. 2003. "Only for my own neighborhood? Preferences and voluntary provision of local and global public goods "Journal of Economic Behavior \& Organization 52 (1) 115-131.

Bochet, Olivier, Talbot Page, and Louis Putterman. 2006. "Communication and punishment in voluntary contribution experiments." Journal of Economic Behavior \& Organization 60 (1): 11-26.

Burlando, Roberto, and Francesco Guala. 2005. "Heterogeneous Agents in Public Goods Experiments." Experimental Economics 8 (1): 35-54.

Chakravarti, Surajeet, and Miguel A. Fonseca. 2012. "The effect of social fragmentation on public good provision: an experimental study" University of Exeter, Economics Department, Discussion Paper Series, Paper No. 12/07.

Chakravarti, Surajeet, and Miguel A. Fonseca. 2012. "Discrimination via Exclusion: An Experiment on Group Identity and Club Goods". University of Exeter, Economics Department, Discussion Paper Series, Paper No. 13/02.

Charness, G., L. Rigotti, and A. Rustichini. 2007. "Individual behavior and group membership." The American Economic Review 97 (4): 1340-52.

Chen, Roy, and Yan Chen. 2011. "The Potential of Social Identity for Equilibrium Selection." American Economic Review 101 (6): 2562-89.

Chen, Yan, and Sherry X. Li. 2009. "Group Identity and Social Preferences." The American Economic Review 99 (1): 431-57.

Eaton, B. C., Mukesh Eswaran, and Robert J. Oxoby. 2011. "Us and Them: the origin of identity, and its economic implications." Canadian Journal of Economics 44 (3): 719-48.

Eckel, C. C., and P. J. Grossman. 2005. "Managing diversity by creating team identity." Journal of Economic Behavior \& Organization 58 (3): 371-92.

Falk, Armin. 2003. "Homo Oeconomicus versus Homo Reciprocans: Ansätze für ein neues Wirtschaftspolitisches Leitbild?" Perspektiven der Wirtschaftspolitik 4 (1): 141-72.

Fehr, Ernst, and Simon Gächter. 2000. "Cooperation and Punishment in Public Goods Experiments." The American Economic Review 90 (4): 980-94.

-- . 2002. "Altruistic punishment in humans." Nature 415 (6868): 137-40. doi: 10.1038/415137a.

Fischbacher, Urs. 2007. "z-Tree: Zurich toolbox for ready-made economic experiments." Experimental Economics 10: 171-78.

Fischbacher, Urs, and Simon Gächter. 2010. "Social preferences, beliefs, and the dynamics of free riding in public goods experiments." The American Economic Review 100 (1): 541-56.

Fischbacher, Urs, Simon Gächter, and Ernst Fehr. 2001. "Are people conditionally cooperative? Evidence from a public goods experiment." Economics Letters 71 (3): 397-404. 
Goette, Lorenz, David Huffman, and Stephan Meier. 2006. "The Impact of Group Membership on Cooperation and Norm Enforcement: Evidence Using Random Assignment to Real Social Groups." American Economic Review 96 (2): 212-16.

- - . 2012. "The Impact of Social Ties on Group Interactions: Evidence from Minimal Groups and Randomly Assigned Real Groups." American Economic Journal: Microeconomics 4 (1): 101-15.

Harris, Donna, Benedikt Herrmann, and Andreas Kontoleon. 2012. "When to Favour Your Own Group? The Threats of Costly Punishments and In-group Favouritism." University of Exeter, Economics Department, Discussion Paper Series, Paper No. 628.

Hoff, Karla, and Priyanka Pandey. 2006." Discrimination, Social Identity, and Durable Inequalities." American Economic Review 96 (2): 206-211.

Ibañez Diaz, Marcela, and Elke R. Schaffland. 2012. Group identity and leadership: An experimental analysis. Unpublished Manuscript.

Lankau, Matthias, Marianna Bicskei, and Kilian Bizer. 2012. "Cooperation preferences in the provision of public goods: An experimental study on the effects of social identity." Cege Discussion Papers 148. http://papers.ssrn.com/sol3/papers.cfm?abstract_id=2191469.

Masclet, David, Charles Noussair, Steven Tucker, and Marie-Claire Villeval. 2003. "Monetary and Nonmonetary Punishment in the Voluntary Contributions Mechanism." American Economic Review 93 (1): 366-80.

McLeish, K. N., and R. J. Oxoby. 2007. "Identity, cooperation, and punishment." IZA Discussion Paper 2572. http://papers.ssrn.com/sol3/papers.cfm?abstract_id=961379.

McLeish, Kendra N., and Robert J. Oxoby. 2011. "Social interactions and the salience of social identity." Journal of Economic Psychology 32 (1): 172-78.

Nikiforakis, N. 2008. "Punishment and counter-punishment in public good games: Can we really govern ourselves?" Journal of Public Economics 92 (1-2): 91-112.

Noussair, Charles, and Steven Tucker. 2005. "Combining monetary and social sanctions to ptomote cooperation." Economic Inquiry 43 (3): 649-60.

Page, Talbot, Louis Putterman, and Bulent Unel. 2005. "Voluntary Association in Public Goods Experiments: Reciprocity, Mimicry and Efficiency." Economic Journal 115 (506): 1032-53.

Sefton, Martin, Robert Shupp, and James M. Walker. 2007. "The Effect of Rewards and Sanctions in Provision of Public Goods." Economic Inquiry 45 (4): 671-90.

Selten, Reinhard. 1967. "Die Strategiemethode zur Erforschung des eingeschränkt rationalen Verhaltens im Rahmen eines Oligopolexperiments." In Beiträge zur experimentellen Wirtschaftsforschung. Vol. 1. Edited by H. Sauerland, 136-68. Tübingen: Mohr.

Tajfel, Henri, and John Turner. 1979. "An Integrative Theory of Intergroup Conflict." In The Psychology of Intergroup Relations. Edited by Stephen Worchel and William Austin, 33-47. Monterey: CA: Brooks/Cole.

- - . 1986. "The Social Identity Theory of Intergroup Behaviour." In The Psychology of Intergroup Relations. Edited by Stephen Worchel and William Austin, 7-24. Chicago: Nelson-Hall.

Weng, Qian and Fredrik Carlsson. 2013. "Cooperation in teams: the role of identity, punishment and endowment distribution." University of Gothenburg, Department of Economics, Working Papers in Economics, Paper No. 551. 


\title{
ChAPTER VII
}

\section{Negative ReCiPROCITY AND ITS ReLATION to ANGER-LIKE EMOTIONS IN IDENTITY-HoMOgeNEOUS AND HETEROGENEOUS GROUPS}

\author{
Marianna Bicskei, Matthias Lankau, Kilian Bizer
}

The manuscript is currently under review by

the Journal of Economic Psychology 


\begin{abstract}
Several studies have shown that social identity fosters the provision of public goods and enhances the willingness to reciprocate the cooperative behavior of group members. Nonetheless, the question of how social identity affects negative reciprocity in identity-homogeneous and heterogeneous groups has only received little attention. Consequently, we seek to fill this gap by examining whether social identity affects individuals' willingness to sanction deviating group members in a public good context. Moreover, we devote particular attention to the role of anger-like emotions in negative reciprocity. To test our hypotheses, we employ one-shot public good games in a strategy method with induced social identity. Our results indicate that members of identityhomogeneous groups are prone to reveal less negative reciprocity than identity-heterogeneous groups when they face contributions smaller than their own. We also find that anger-like emotions much more strongly influence punishment behavior when individuals are matched with members of different identities than in identity-homogenous groups. These findings contribute to an increased understanding of the nature of social identity and its impact on reciprocity, improving economists' ability to predict behavior while taking emotions into consideration.
\end{abstract}

JEL classification:

PsycINFO classification:

Keywords:
A12; C91; C92; H41

$2360 ; 3020$

social identity; emotions; experiment; public goods;

negative reciprocity

\title{
Highlights
}

- How does social identity influence negative reciprocity in public goods provision?

- We conduct one-shot public good games with in-group, out-group and random matching.

- Higher negative reciprocity in out-groups than in in-groups.

- Higher behavioral influence of anger-like emotions in out-groups than in in-groups.

- Group composition is of relevance when public policy addresses one's social identity. 


\title{
CHAPTER VIII
}

\section{SOCIAL ENVIRONMENT AND FORMS OF GOVERNANCE \\ - Monetary and Non-Monetary Punishment ANd the Role of EMotions}

\author{
Marianna Bicskei, Matthias Lankau, Kilian Bizer
}




\section{Introduction}

In the private provision of public goods the long-term maintenance of cooperation is a real challenge. Experimental research has shown that contributions to common goods decrease over time (see e.g. Keser and van Winden 2000, Fischbacher and Gächter 2010, Lankau et al. 2013). Nevertheless, the possibility of peer-punishment imposed by group members without a central authority has been investigated as an effective institution providing incentive for compliance and enforcing long-term cooperation in social dilemma games. In a public good context, after observing the individuals' voluntary contributions, every subject has the possibility to punish other group members. In terms of the costs incurred by punishment two instruments are distinguished: Monetary punishment (MP) and non-monetary punishment (NMP). Firstly, assigning MP points to individuals reduces the earnings of the offender. Consequently, by lowering yields of self-interested behaviour it creates a monetary threat forcing subjects to increase their contributions (Noussair and Tucker 2005). Yet, MP also functions as a communication tool by signalling disapproval of an individuals' behaviour. This implies social pressure ${ }^{1}$ or social disapproval (the more points assigned, the greater the disapproval), which may equally raise contributions. Overall, MP has been considered as successful in overcoming the problem of shirking (see Ostrom et al. 1992; Fehr and Gächter 2000, 2002; Fehr and Fischbacher 2004). Nevertheless, its influence on social welfare is less clear-cut since MP points are costly not only for the offender but also for the punisher. Secondly, the assignment of points to group members without monetary consequences (NMP) also constitutes social pressure. NMP is also considered to be effective in boosting cooperation compared to situations without punishment (see experimental research of Masclet et al. 2003; Gächter and Fehr 1999, and former works e.g. of Barron and Gjerde 1997; Kandel and Lazear 1992). Nevertheless, especially in long-term interactions it appears to be hardly as effective as MP (cf. Noussair and Tucker 2005; Dugar 2013). Yet, due to the costliness of MP, the level of social welfare under threat of MP and NMP is comparable (see Noussair and Tucker 2005).

Summing up, MP and NMP create different strengths of threat for subjects and their application has diverging consequences for social welfare. Correspondingly, an analysis of an institutional environment including both sanctioning mechanisms (BP institution) helps to disentangle whether subjects choose to exert social pressure per se or rather additional monetary pressure. Clearly, in some cases NMP alone could be sufficient to influence subjects' contribution behaviour, which should affect especially those who are sensitive to social pressure. In these instances signalling disapproval by MP could even be too severe and counterproductive. However, in other cases disciplining subjects could require stronger social pressure that also implicates monetary consequences. To our best knowledge, there exists only one single study that combines MP and NMP in a public good context (see Noussair and Tucker 2005). Yet, it provides insights only for groups whose members are randomly selected and thus neglects the social environment in which subjects interact. However, extensive research has shown that group composition in terms of social identity does influence subjects' behaviour and impacts decisively on social welfare (e.g. Chen and Li 2009; Lankau et al. 2012). Therefore, the aim of this article is to gain evidence on which forms and strengths of governance groups tend to use dependent on the social environment. In particular, within the framework of a ten-period public goods game we analyse how subjects in identity-

\footnotetext{
${ }^{1}$ The impact of social pressure on behavior has been incorporated in several economic models. See Akerlof (1980) and Lindbeck et al. (1999).
} 
homogenous and identity-heterogeneous groups apply monetary and non-monetary sanctions and how this influences cooperation and social welfare. To this purpose, we induce group identity in the lab with the help of an identity group task based on Ibañez and Schaffland (2012), ${ }^{2}$ and apply three different matching protocols. Subjects either interact with common identities (in-group matching) or with individuals of different identities (out-group matching). Our control groups are randomly assigned without any identification (partner matching). Another novelty of our paper - besides the recognition of the specificity of social environment under BP institution - lies in the fact that we are the first to address the punished subject's emotions of anger and guilt and their influence on subsequent contributions. Generally, emotions have been proven to motivate behaviour (Hopfensitz and Reuben 2009). Consequently, our research sheds light on how these influence decision making in different social contexts and to what extent they determine long-term cooperation.

The article proceeds with deriving hypotheses based on previous literature (Section 2). Section 3 presents the experimental design. We discuss the main results of the experiment in Section 4. Its first section investigates the effectiveness of the identity group task, followed by the demonstration of the influence of social identity on contribution behaviour and social welfare. Afterwards, we analyze the form of governance via MP and NMP. The final section discusses the role of punishment and emotions on subsequent contributions. Lastly, the article summarizes and concludes in Section 5.

\section{Related Research and Hypotheses}

The recent stream of research on social identity has proved that the importance ascribed to the sense of belonging to a particular group influences individuals' connotations and behavior towards their own group (in-group) as well as towards other groups they do not belong to (out-group) (Bicskei et al. 2013a). ${ }^{3}$ In particular, when subjects interact in identity-homogenous groups they are likely to cooperate more with individuals that share the same identity than in identity-heterogeneous groups (see e.g., Solow and Kirkwood 2002; Wit and Wilke 1992; Lankau et al. 2012). What is more, they reciprocate the contributions of group members to a higher degree than out-group members (Lankau et al. 2012). Overall, in-group subjects are regarded as having a higher proclivity to make social welfare maximizing choices as opposed to subjects in out-groups (Chen and Li 2009). Moreover, recent empirical evidence suggests that social identity also affects subjects' behavior under the threat of peer-punishment. Particularly, Bicskei et al. (2013b) find that subjects anticipating MP behave differently in in- and out-groups. Under the threat of MP they observe a comparably higher increase in cooperativeness in out- than in in-groups, which even eliminates the in-group bias that is commonly observed without punishment. The authors claim that this is due to out-group members anticipating harsher punishment than in-group members. More importantly, Bicskei et al. (2013a) establish that in case anti-social behaviour is observed, in-group members punish less frequently and with lower intensity than out-group members. They confirm the findings of Chen and Li (2009) who demonstrate that group members are more forgiving towards defection by an in-group member and reveal less negative reciprocity. Currarini et al. (2012) also find in twoperson interactions that subjects are less likely to punish misbehaviour when caused by an in-group member than by an out-group member. Based on these studies, we thus assume that the social

\footnotetext{
${ }^{2}$ Herewith we thank M. Ibañez and E. Schaffland for providing us with their identity group task protocol.

${ }^{3}$ The social identity theory was pioneered by Tajfel and Turner (1979). See Chen and Li (2009) for an overview of theoretical and empirical evidence on social identity.
} 
environment influences how subjects disclose their disapproval when both MP and NMP are available. Especially, we expect that in-group members rather apply NMP than MP since it constitutes a lower level of negative reciprocity.

Hypothesis 1 (Governance): Compared to out-groups, subjects in in-groups are more likely to govern each other by NMP than by MP.

Prior research suggests that in-groups are more likely to reveal higher cooperation level than outgroups. Based on Hypothesis 1, we thus expect that in-groups also gain higher social welfare than out-groups, since NMP does not reduce subjects' earnings.

Hypothesis 2 (Social Welfare): Under the possibility of both MP and NMP identity-homogeneous groups reach higher social welfare than identity-heterogeneous groups.

Recently, a bulk of research demonstrated that emotions play a determinant role in decision making. In particular, various contributions investigated how emotions such as anger and irritation influence punishment behaviour in general (see Reuben and van Winden 2008; Bosman et al. 2005; Bosman and van Winden 2002). Yet, Bicskei et al. (2013a) highlight that emotions have different action tendencies based on the group composition. Specifically, they establish that anger-like emotions (anger, contempt and irritation) fuel punishment in out-groups more than in in-groups. They conclude that in-group matching mitigates the role of these negative emotions in triggering punishment. The question, however, of how emotions influence the effectiveness of punishment in terms of maintaining contributions has still been neglected in the literature. In fact, when an offender is detected through punishment internal peer pressure in form of guilt may cause disutility to this individual (Elster 1989). ${ }^{4}$ Such an emotion has, however, a high action tendency. It requests atonements or confession (Elster 1998). Therefore, we assume that in-group members are striving to maintain a positive social identity (Tajfel and Turner 1979). Feeling guilty forces them to rectify their selfish behaviour by increasing their contributions in the next period. Thus, in identity-heterogeneous groups the influence of guilt on subsequent contributions is likely to be much lower.

Hypothesis 3 (Guilt): In in-groups the emotion of guilt in reaction to being punished is more influential in motivating changes in subsequent contributions than in out-groups.

Being punished can trigger feelings of anger as well, which also tend to motivate behaviour (Zeelenberg et al. 1998; Hopfensitz and Reuben 2009). Whether it fosters or even lowers subsequent contributions is still an unanswered question. Yet, based on prior findings we know that in-group members are more forgiving than out-group members. Moreover, they are able to mitigate the impact of anger-like emotions on their behaviour (Bicskei et al. 2013a). Consequently, we expect that anger will affect contributions less in in-groups than in out-groups.

Hypothesis 4 (Anger): In in-groups the emotion of anger in reaction to being punished is less influential in motivating changes in subsequent contributions than in out-groups.

\footnotetext{
${ }^{4}$ Evidently, being detected through punishment can also trigger external peer pressure, thus shame (Elster 1989). This, however, forces subjects to hide and disappear. Due to the design specificity of a public good game in which punishment that a subject receives is only visible for this particular subject, the emotion of shame is assumed to be not of relevance.
} 


\section{Experimental Design}

To test these hypotheses the experiment consisted of two stages (Stage A and B, see Table 1). In each stage participants were assigned to groups consisting of four subjects. We conducted four treatments: An In-group and an Out-group treatment (together referred to as ID treatments or ID matchings), and two additional treatments. The RMID treatment served as a control for Stage A, and the Control treatment for Stage B.

Stage A had the purpose of inducing social identity in the lab. Both in In- and Out-group treatments participants were assigned randomly to groups distinguished with a particular color. ${ }^{5,6}$ Group members had to jointly solve a simple group task (ID task) of finding hidden objects in a picture and enter their coordinates within a given time of 8 minutes. They were in connection via chat so that they could discuss solutions anonymously. Importantly, an answer was only counted as a correct if each group member entered the objects' coordinates correctly, which intensified the interaction within the groups. Whichever group found most objects won this task. However, we communicated the outcome only at the end of the experiment in order to eliminate the negative consequences of not being in the winning group. ${ }^{7}$ To test the effectiveness of our ID task we designed the RMID treatment in which subjects were randomly assigned to groups. Yet, they had to solve this task individually. No colors were assigned and there was no possibility of communication with the group members. In the Control treatment, we excluded Stage A altogether (see Table 1).

Stage B consisted of a ten-period linear public goods game combined with MP and NMP institutions and a stable group membership over all periods of the game.

\begin{tabular}{|c|c|c|c|c|c|c|}
\hline \multirow{2}{*}{ Treatment } & \multirow{2}{*}{$\mathbf{n}$} & \multirow{2}{*}{ Session \# } & \multicolumn{2}{|c|}{ Stage A } & \multicolumn{2}{|c|}{ Stage B } \\
\hline & & & ID Task & Matching Protocol & PGG & Matching Protocol \\
\hline In-group (IN) & 80 & 6 & $\begin{array}{l}\text { Picture puzzle } \\
\text { jointly to solve }\end{array}$ & $\begin{array}{c}\text { Random + Color } \\
\text { labeling }\end{array}$ & $\begin{array}{c}10 \text { periods PGG } \\
\text { with Punishment }\end{array}$ & In-group \\
\hline Out-group (OUT) & 72 & 4 & $\begin{array}{l}\text { Picture puzzle } \\
\text { jointly to solve }\end{array}$ & $\begin{array}{c}\text { Random+ Color } \\
\text { labeling }\end{array}$ & $\begin{array}{c}10 \text { periods PGG } \\
\text { with Punishment }\end{array}$ & Out-group \\
\hline Control (CONT) & 52 & 4 & - & - & $\begin{array}{c}10 \text { periods PGG } \\
\text { with Punishment }\end{array}$ & Random (Partner) \\
\hline RMID & 52 & 4 & $\begin{array}{l}\text { Picture puzzle to } \\
\text { solve individually }\end{array}$ & Random & - & - \\
\hline
\end{tabular}

Table 1: Design of the Experiment

In the In-group treatment, group composition was identical to Stage A. Thus, subjects remained in the groups comprised of their in-group members (of the same color) with whom they solved Stage $A^{\prime}$ s task. In the Out-group treatment, however, subjects were assigned to groups consisting of four different identities, hence of four different colors. ${ }^{8}$ The Control treatment is actually the replication of the BP treatment of Noussair and Tucker (2005) and comprised groups randomly assigned without

\footnotetext{
${ }^{5}$ After being assigned to groups of four each group member was provided with two colors to vote for as a group color. The color chosen by the majority of group members won. In case of standoff a random mechanism determined the group color.

${ }^{6}$ This task served the purpose of generating more interaction between the group members. During the experiment the color of the group was always signalled by a flag.

${ }^{7}$ The winning group received only a congratulation message. Finishing this task, we asked four questions related to group attachment, which will be discussed in Section 4.1.

${ }^{8}$ The matching protocols for the ID treatments were only revealed at the beginning of Stage B.
} 
any identification and any color-labeling (partner matching). ${ }^{9}$ At the beginning of Stage B every subject received an initial lump-sum payment of 100 ECUs (Experimental Currency Units) in order to account for possible costs incurred during the game and reducing the possibility of bankruptcy. It was common knowledge that group composition remained stable throughout Stage B and that the game consisted of 10 periods. Each of these periods comprised two decisions parts. At first, each group member received an endowment of 20 ECUs, which could be invested in a project $\left(c_{i}\right)$ benefitting each group member equally. Each ECU, which a subject did not invest in the project, was automatically deposited on his private account $\left(20-c_{i}\right)$. The payoff associated with this investment decision is given by the following function (Formula 1):

$$
E_{i}=20-c_{i}+0.4 \times \sum_{k=1}^{4} c_{k}
$$

Formula 1: Payoff Function of Part 1

At the beginning of the second part, subjects were informed on how much each of their group members contributed to the project. ${ }^{10}$ Afterwards, they had the opportunity to indicate their disapproval of the other group members' decision by distributing MP and/or NMP points to them. In each case the scale ranged from 10 points for the most to 0 points for the least disapproval. ${ }^{11}$ Each MP point distributed to a particular player lowered his or her payment by $10 \%$. However, the punisher incurred cost for allocating MP points, as well, which is detailed in Table 2.

\begin{tabular}{llllllllllll}
\hline $\begin{array}{l}\text { Monetary points } \\
(\mathrm{P})\end{array}$ & 0 & 1 & 2 & 3 & 4 & 5 & 6 & 7 & 8 & 9 & 10 \\
\hline $\begin{array}{l}\text { Cost of monetary } \\
\text { points (K) }\end{array}$ & 0 & 1 & 2 & 4 & 6 & 9 & 12 & 16 & 20 & 25 & 30 \\
\hline
\end{tabular}

Table 2: Monetary Points and the Cost of these Monetary Points in ECU

At the same time subjects could also distribute NMP points. However, in contrast to MP, NMP points neither affect the punisher's earnings nor the earnings of the player receiving the NMP points. Subsequently, subjects were informed on the total amount of MP and NMP points they received and were required to indicate on a 7-points Likert-scale how intensely they felt (1-not at all, 7-very intensely) each of the following emotions: ${ }^{12}$ Shame, gratitude, irritation, happiness, guilt, surprise, disappointment and anger. ${ }^{13}$

\footnotetext{
${ }^{9}$ Here we gratefully acknowledge that C. Noussair and S. Tucker provided us with their instructions. We also asked for their data but it seemed to be not recoverable. See Appendix 9 for the instructions used in this experiment.

${ }^{10}$ The subject's contribution was displayed in the first column, while the contributions of the other group members of the period were shown in the remaining three columns. The contributions of the other group members were randomly listed and changed in each period. Thus, subjects were not able to track the behavior of one particular group member during the periods. This eliminated the possibility of direct retaliation against one particular group member. Also, subjects could not build a reputation in terms of their contribution during the periods.

${ }^{11}$ We framed the 0 punishment point as least disapproval, since we were interested in the impact of a punishment threat and did not want subjects to perceive 0 point as a reward (see argumentation in Dugar 2013).

12 Ben-Shakhar et al. (2007) establish that the use of self-reports is adequate to assess emotions.

${ }^{13}$ To eliminate an experimenter demand effect the list of emotions included different emotions both of negative and positive valence based on insights of Hopfensitz and Reuben (2009) and Reuben and van Winden (2008).
} 
At the end of each period the screen displayed the income from that particular period (see Formula 2 ), the total income from all periods inclusive that period and the lump-sum payment in terms of ECU. In order to keep each group members' identity as determined in Stage A salient, each subjects' group color was always signalled by a colored flag in the ID matchings throughout Stage B. Moreover, at the beginning of period 6 subjects were reminded of Stage A's group task and were asked to guess how many objects they found in Stage A. In case they guessed correctly, which was communicated only at the end of the experiment, they earned 2 ECUs. At the end of the experiment the entire earnings from the experiment (including the lump-sum payment and the show-up fee) was converted to Euros and immediately paid to the subjects in cash.

$$
E_{i}=\left(20-c_{i}+0.4 \times \sum_{k=1}^{4} c_{k}\right) \times \frac{\max \left\{0,10-\sum_{k \neq i} P_{k i}\right\}}{10}-\sum_{k \neq i} K\left(P_{i k}\right)
$$

Formula 2: Income of a Particular Period

\section{Results}

The experiments were conducted during July and August of 2012 in the Göttingen Laboratory of Experimental Economics (GLOBE) at the University of Göttingen. ${ }^{14}$ We recruited 256 subjects through the ORSEE system of the University of Göttingen and at the canteens of the campus. 80 subjects participated in In-group, 72 in Out-Group and 52 in the Control as well as in the RMID treatment (see Table 1). The sessions took approximately one hour (including the final payment) and participants earned approximately 12 EUR including the 2.5 EUR show-up fee.

\subsection{Induction of Social Identity}

The question of what drives possible treatment effects is very important. In this section, we analyse whether the induction of social identity was successful and thus whether we can assume social identity to have causal effects. We approach it by comparing subjects' self-reported identification with the particular group in Stage A between the pooled data of the ID matchings ${ }^{15}$ and the RMID treatment. ${ }^{16}$ In the latter we created the least possible group cohesion by assigning subjects to a group without any labeling and with no interactions between group members. Please note that subjects were asked for their feeling of identification with their group immediately after Stage $A$ in order to prevent experiences of ID matchings made in Stage B to bias judgement to statements including: (1) "I feel attached to this group"; (2) "I am an important member of this group". The answers were assessed on a 7-point Likert-scale (1-not at all, 7-very much). As the number of objects found in Stage A was disclosed only at the end of the experiment, we do not expect being unsuccessful in solving the task to influence the feelings of group attachment. Our data reveals that subjects of the RMID treatment felt significantly less attached to their group than in case of ID

\footnotetext{
${ }^{14}$ We designed our experiments with the software Z-tree (Fischbacher 2007).

${ }^{15}$ Both in In- and Out-group treatments the identical task was in effect and answers are statistically not different using Mann-Whitney Test $(p=0.50)$. If not noted otherwise, we henceforth always use Mann-Whitney Test.

${ }^{16}$ Please recall that subjects had the possibility to vote for a group color. To prove whether this task had a negative influence on group attachment, we compare the intensity of group attachment of those who were assigned a group color other than the one they voted for and those whose wish came true. We find no significant difference $(p=0.84)$ between individual group attachments.
} 
treatments ( $p_{\text {IDvsRMID }}<0.001$ ). What is more, they felt themselves to be a significantly less important member of the group, which is not surprising $(p<0.001)$.

In sum, this signals that the group task of Stage A with anonymous interactions between group members and a salient social identity highlighted by colored flags evokes stronger feelings of group attachment than in case of being simply assigned to a group in which no interactions take place. Since we find clear differences between reported group attachment of ID matchings and the RMID treatment, we consequently assume that our ID task of Stage A was successful. Thus, treatment effects are likely to be due to differing degrees of group attachment in our treatments.

Result 1: $\quad$ The induction of social identity successfully created higher feelings of group attachment in ID matchings than in the RMID treatment.

\subsection{Contributions to the Public Good and the Level of Social Welfare}

At first, we analyze the evolution of contributions to the public. As Figure 1 shows, the presence of BP institution eliminates the often documented downward trend of contributions over time (see Fehr and Gächter 2000; Keser and van Winden 2000; Vyrastekova 2011; Lankau et al. 2013), independent of the social environment. ${ }^{17}$

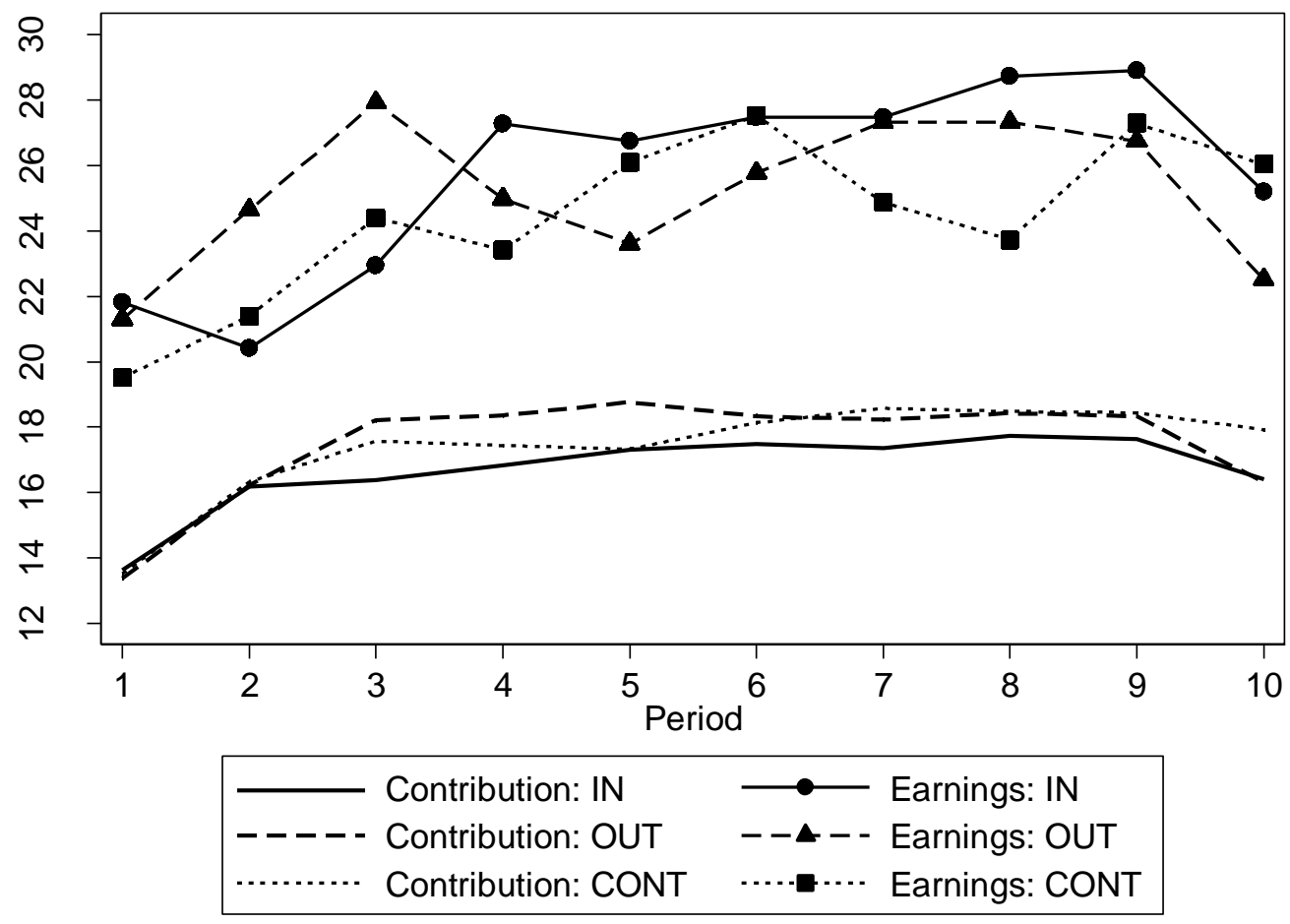

Figure 1 - Average per Period Contribution and Earnings by Treatment Type

The average contributions of the first period range between $55 \%$ and $68 \%$ of total endowment. Although starting contribution levels are very akin in the first two periods of all treatments, looking at the full time horizon, we find that out-group contributions lay above those of in-groups from period 3 onward till the penultimate period $(p<0.1){ }^{18}$ Except for period 2, contributions of the Control treatment lay between the ID treatments in the first 6 periods. Towards period 9, they

\footnotetext{
${ }^{17}$ For the evolution of each groups' average contributions per treatment, see Table A.1.

${ }^{18}$ The unit of observation was average individual contributions between periods 3 to 9 .
} 
converge to the level of out-groups. For periods 3 to 9 contributions of out-groups are only marginally greater than those of random groups $(p=0.1)$. Although contributions of the Control treatment are above those of in-groups for almost the entire time period, we do not find statistically significant differences. Lastly, since subjects were informed about the exact length of the game, not surprisingly, we observe a moderate end-game effect. Subjects' lowered their contributions in the last period, most likely because they did not anticipate subsequent punishment. The final contributions are not significantly different between the treatments.

Result 2a: In-and out-groups show different patterns of cooperation under the presence of both punishment institutions. Apart from the starting and last periods, out-group contribution levels are higher than those of in-groups.

Although under BP threat contributions in out-groups are different from in-groups for specific periods, we do not find that these elevated contributions increase social welfare in these periods significantly (see Figure 1). In particular, we find that average per period earnings are similar in each treatment. ${ }^{19}$ This indicates already that out-group members' punishment behaviour must differ from that of in-groups. Especially, the application of MP, which affects individual payoffs decisively, must be responsible for the equal welfare in both ID matchings.

Result 2b: In- and out-group members achieve similar per period welfare under BP disregarding the end-game effect.

Concluding, we have to reject our Social Welfare-Hypothesis that under the possibility of both MP and NMP identity-homogeneous groups reach higher social welfare than identity-heterogeneous groups.

\subsection{Governance via MP and NMP}

To gain evidence on how subjects in different social environments govern their groups, first of all, we analyze the relationship of MP and NMP assigned across treatments. In all treatments the average quantity of MP subjects assign is lower than of NMP (see Figure 2), and these differences are significant in each treatment (Wilcoxon signed-rank tests, $p<0.001$ ). ${ }^{20}$ This difference is not surprising since in contrast to MP distributing even very high amounts of NMP does not affect the punisher's payoffs.
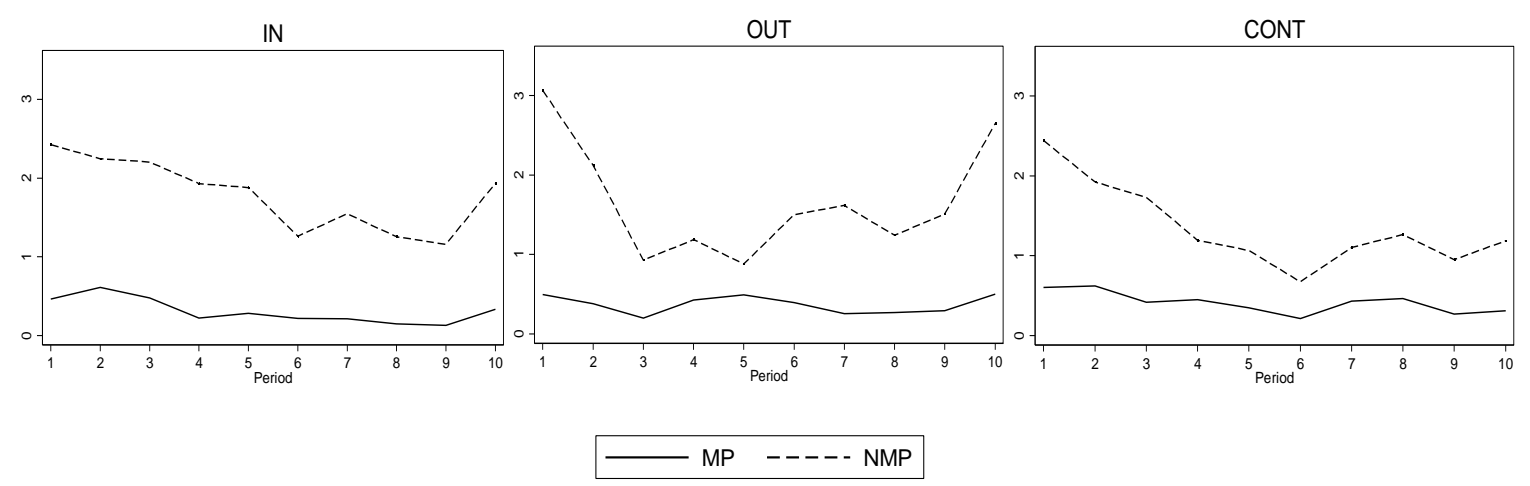

Figure 2 - Average Level of MP and NMP Points Assigned

\footnotetext{
${ }^{19}$ We find differences in per period individual earnings only in the last period: IN vs. OUT $(p<0.001)$; IN vs. CONT ( $p<0.1)$; OUT vs. CONT ( $p<0.001)$.

${ }^{20}$ The unit of observation is the average individual MP and NMP received over the 10 periods.
} 
As Figure 2 suggests, the evolution of MP and NMP is not completely correlated, which is most apparent in out-groups. This provides a hint that MP and NMP are rather used as substitutes than as complements. As a proof of this conjecture, Table 3 shows the number of instances in which subjects assigned a particular number of MP and NMP points per treatment. ${ }^{21}$ We find that in each treatment punishment occurs in very similar shares of possible punishment cases (29.2, 29.3 and 28.7 percent in the In-group, Out-group and Control treatment, respectively). What is more, the share of punishment involving both MP and NMP (BP) points at the same time only amounts to approximately one third of all punishment cases and is very similar in all treatments. ${ }^{22}$ Thus, if subjects choose to punish their peers' (mis-) behaviour they most often prefer using either MP or NMP alone instead of combining them (BP). Consequently, our results oppose Noussair and Tucker (2005) who find that subjects who were not assigned any NMP did not receive MP either. In each of our treatments there are many cases in which only MP (NMP) points were distributed without assigning any NMP (MP) points. As Table 3 illustrates, the exclusive application of NMP is most favoured in in-groups (412 obs.) accounting for 59 percent of all punishment cases. In out- and random groups this amounts to 50 and 52 percent, respectively. On the contrary, the exclusive use of MP is the highest in out-groups representing 15 percent of punishment cases, followed by the Control treatment with 10 percent. In in-group only a very small proportion of punishing subjects inflict MP exclusively (4 percent). Accordingly, the frequency of NMP regardless whether applied alone or combined with MP is significantly higher in in-groups compared to out- and random groups. ${ }^{23}$ The occurrence of MP (alone or together with NMP) is significantly higher in out-groups as well as in random groups compared to in-groups. ${ }^{24}$

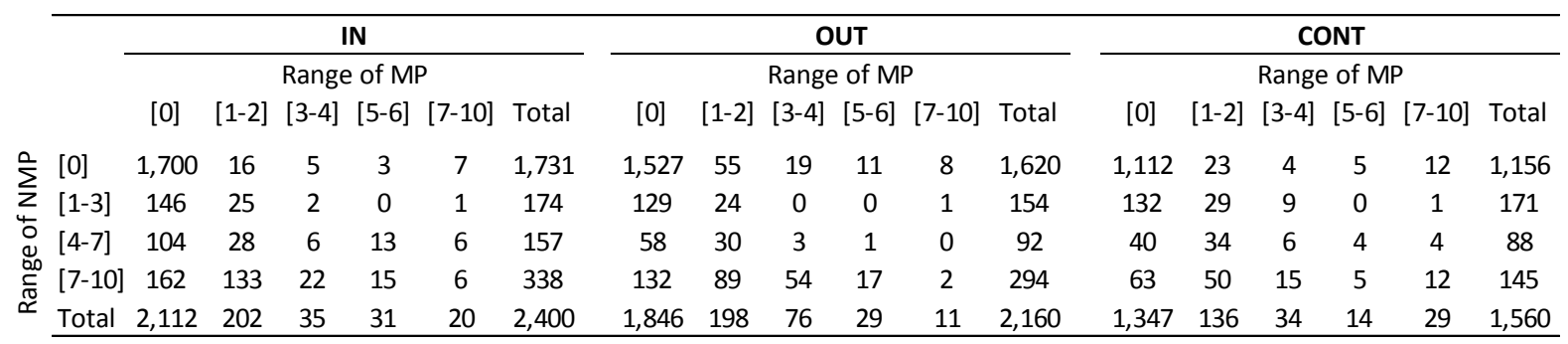

Table 3 - Frequency of MP and NMP Points

Result 3a: $\quad$ NMP is more frequently used in in-groups than in out-and random groups.

Result 3b: The frequency of MP is higher in out-and random groups compared to in-groups.

With regard to the strength of punishment Figure 3 depicts the evolution of NMP (left panel) and MP (right panel) over periods and across treatments. Obviously, the application of punishment in the last period cannot affect group members' behavior. Nevertheless, we observe a clear increase both in NMP and MP as a consequence of a drop in contributions in the last period (see Figure 1, Section 4.2). This is in line with Noussair and Tucker (2005) and Bochet et al. (2006) who argue that sanctions

\footnotetext{
${ }^{21}$ Overall, we have 6,120 possible punishment cases: 204 subjects can punish each of their three group mates in each period $(204 \times 3 \times 10)$.

${ }^{22}$ Cases of BP over any punishment: IN=257/700=36.7\%, OUT=221/663=33.3\%, CONT=169/448=37.7\%.

${ }^{23}$ Pearson's chi-square test, $\chi^{2}(1)=41.5, p_{\text {IN vs ouT }}<0.001 ; \chi^{2}(1)=13.01, p_{\text {IN vs conT }}<0.001$. The application of NMP in Control treatment is more frequent than in out-groups: $\chi^{2}(1)=5.62, \mathrm{p}_{\text {CONT vs OUT }}<0.05$.

${ }^{24}$ Pearson's chi-square test, $\chi^{2}(1)=9.61, p_{\mathrm{IN} \text { vs OUT }}<0.01 ; \chi^{2}(1)=4.55, \mathrm{p}_{\mathrm{IN} \text { vs } \text { cONT }}<0.05$. Significant difference in the infliction of MP between the Control and Out-group treatment is, however, not found.
} 
are mainly of non-strategic nature, since the last period's punishment will have no possible gains to the punisher.

Irrespective of the last period, NMP in in-groups follows a downward trend during almost the entire ten-period horizon, probably since corresponding contribution levels increase. In the first half of the game apart from the initially higher NMP level in out-groups, the average NMP is clearly higher in ingroup than in out-group $(p<0.001)$ as well as in the Control treatment $(p<0.1) .{ }^{25}$ What is more, due to a drastic drop from period 1 to period 3, NMP of the out-group is also smaller than of the Control treatment $(p<0.1)$. In the second half of the game we observe a similar trend of NMP in each treatment. Nevertheless, as the upward trend of contributions starts to stagnate (see Figure 1), subjects of out-groups in order to boost cooperation tend to distribute higher NMP points than ingroups $(p<0.01)$ as well as control groups $(p<0.001) .^{26}$
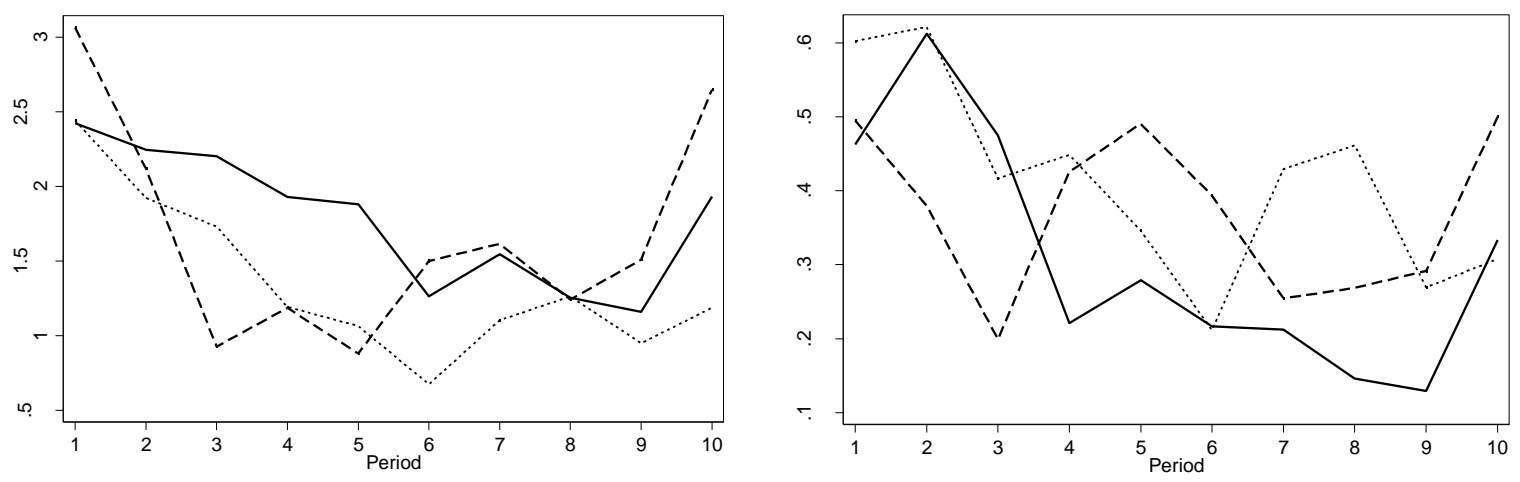

$$
\begin{array}{lllll}
\hline \text { IN } & ----- \text { OUT } & \cdots \cdots \cdots \cdots & \text { CONT } \\
\hline
\end{array}
$$

Figure 3 - Average NMP (left panel) and MP (right panel) Points Assigned (all subjects) ${ }^{27}$

The quantity of MP associated with monetary costs is changing drastically over the periods (Figure 3, right panel). However, as with NMP, MP also reveals a clear downward trend in in-groups since contributions increase. Overall, the strengths of MP distributed on average is greater in out-groups compared to in-groups taking the average over all periods as a whole $(p<0.1)$. This is somehow unexpected since contribution levels in out-groups are higher than in in-groups. It enlightens, however, why the welfare in out-groups does not exceed the welfare of in-groups. ${ }^{28}$ Although contributions do not differ between them, looking at the entire game as a whole the extent of MP of the Control treatment is significantly higher than of in-groups $(p<0.1)$. Lastly, there are no significant differences between MP of the Control and the Out-group treatment $(p=0.61)$.

Result 3c: The level of NMP in in-groups is higher than in out-and random groups in the first half of the game. In the second half the level of NMP of out-groups exceeds in-and random groups.

Result 3d: The extent of MP in in-groups is lower than in out- and control groups.

\footnotetext{
${ }^{25}$ Unit of observation is the average individual NMP point assigned over periods 1 to 5.

${ }^{26}$ Unit of observation is the average individual NMP point assigned over periods 6 to 10 . The hypothesis that the NMP level of In-group and Control treatments is equal in the second half cannot be rejected.

${ }^{27}$ See also Table A.2.

${ }^{28}$ Although the cost function of punishment is non-linear, the average cost of punishment shows a similar pattern in the treatments as the level of MP suggests (see Figure A.3).
} 
Summing up, our Governance-Hypothesis cannot be rejected. We find that subjects in in-group favour governance via NMP rather than via MP. Conversely, interaction in groups with different identities or with random subjects creates an environment in which subjects are prone to reveal their disapproval by MP with higher frequency and with greater intensity than in in-groups. In this respect the availability of both punishment institutions equalizes welfare in in- and out-groups, which is not typical for situations without any punishment mechanisms at all (see Chen and Li 2009; Lankau et al. 2012; Eaton et al. 2011).

\subsection{The Impact of Punishment and Emotions on Contributions}

The threat of punishment per se raises contributions to common resources in one-shot interactions (Bicskei et al. 2013b). Nevertheless, in long term interactions the reactions to received punishment will determine its effectiveness in maintaining cooperation too (Hopfensitz and Reuben 2009). Thus, we firstly investigate how subjects actually respond to received punishment dependent on the social environment. In particular, we are interested in whether in-groups are more sensitive to NMP as they are more likely to govern their groups by such a punishment institution. Secondly, we analyse the relationship of punishment and emotions and the effect of their interaction on subsequent contributions.

To begin with the former, we estimate the effect of received MP and NMP per se on the changes in contributions from period $t$ to $t+1$. As previous research has evidenced, both received punishment and the deviations of a subject' own contributions from the group's average $\left(c_{k t}-\bar{c}\right)$ may have an effect on subsequent contributions (e.g. Masclet et al. 2003; Fehr and Gächter 2000; Noussair and Tucker 2005). As received punishment is also dependent on deviation from group's average (see Table A. 4) they could not be included into the same equation. Therefore, we measure the effect of MP and NMP on contributions isolated of any effect of deviations of a subject' own contributions from the group's average (for a similar approach see Noussair and Tucker 2005). Thus, the independent variables of our estimation ( $\varphi_{k t}$ and $\omega_{k t}$ in Formula 3c) represent MP and NMP points subject $k$ receives in period $t$ excluding the effect of deviations in contribution from the group's average on punishment (see in Formula $3 a$ and $b$ ). Yet, as punishment is clearly equally dependent on the height of contributions subjects provide to public goods (e.g. Masclet et al. 2003; Fehr and Gächter 2000; Noussair and Tucker 2005), we conduct this regression separately for low contributors contributing less than the group's average and for high contributors who contributed at least the same amount as the group's average, as well as for the entire sample of the treatments (see Table 4).

$$
\begin{gathered}
\text { (a) } M P_{k t}=\alpha_{0}+\alpha_{1}\left(c_{k t}-\vec{c}\right)+\varphi_{k t} \\
\text { (b) } N M P_{k t}=\alpha_{2}+\alpha_{3}\left(c_{k t}-\vec{c}\right)+\omega_{k t} \\
\text { (c) } c_{k t+1}-c_{k t}=\beta_{0}+\beta_{1} \sum_{k} \varphi_{k t}+\beta_{2} \sum_{k} \omega_{k t}+\varepsilon_{t}
\end{gathered}
$$

Formula 3 - Estimation of the Average Change in Contribution

Our results for the Control treatment, which is equivalent to the BP treatment of Noussair and Tucker (2005), do not confirm their findings on the overall positive effect of MP. Moreover, the effect on high contributors is significantly negative, which opposes their results, as well. Yet, the significant 
and positive coefficient of MP reinforces their findings that low contributors increase their contribution upon receiving MP (Table 4, column 9).

Dep.Var.: Average Change in Individual Contribution $(t+1)-(t)$

\begin{tabular}{|c|c|c|c|c|c|c|c|c|c|}
\hline & (1) & (2) & (3) & (4) & (5) & (6) & (7) & (8) & (9) \\
\hline & \multicolumn{3}{|c|}{ IN } & \multicolumn{3}{|c|}{ OUT } & \multicolumn{3}{|c|}{ CONT } \\
\hline & ALL & High Contr. & Low Contr. & ALL & High Contr. & Low Contr. & ALL & High Contr. & Low Contr. \\
\hline \multirow[t]{2}{*}{ MP } & $-0.245^{* *}$ & $-0.214^{*}$ & -0.0496 & -0.147 & $-0.434 * * *$ & 0.116 & -0.0503 & $-0.429 * * *$ & $0.667 * * *$ \\
\hline & $(0.108)$ & (0.114) & $(0.180)$ & $(0.0990)$ & (0.138) & (0.173) & $(0.0864)$ & $(0.150)$ & (0.131) \\
\hline \multirow[t]{2}{*}{ NMP } & $0.0616^{*}$ & $-0.0663 * *$ & 0.0345 & $0.150 * * *$ & 0.0342 & 0.0421 & $0.107^{* *}$ & 0.0569 & -0.0244 \\
\hline & $(0.0342)$ & $(0.0260)$ & $(0.0444)$ & $(0.0391)$ & $(0.0266)$ & $(0.0928)$ & $(0.0425)$ & $(0.0509)$ & $(0.0576)$ \\
\hline \multirow[t]{2}{*}{ Constant } & $0.271^{* *}$ & $-0.788 * * *$ & $2.940 * * *$ & $0.442^{* * *}$ & $-0.628 * * *$ & $3.777 * * *$ & $0.645 * * *$ & -0.316 & $3.082 * * *$ \\
\hline & (0.107) & $(0.128)$ & $(0.349)$ & (0.135) & (0.173) & $(0.532)$ & (0.163) & $(0.213)$ & $(0.341)$ \\
\hline Observations & 720 & 537 & 183 & 648 & 522 & 126 & 468 & 358 & 110 \\
\hline R-squared & 0.017 & 0.070 & 0.002 & 0.036 & 0.045 & 0.010 & 0.020 & 0.100 & 0.160 \\
\hline
\end{tabular}

Robust standard errors in parentheses, clusered around individuals.

Significance levels: ${ }^{* *} p<0.01, * * p<0.05, * p<0.1$.

Table 4 - Change in Average Individual Contribution in Response to the Receipt of MP and NMP

Very importantly, the results for both ID matchings as well as the Control treatment show that the social environment influences the effects of punishment on contributions. In particular, for identityhomogenous groups we even identify an overall significant negative effect of MP on contributions. In identity-heterogeneous groups MP has no significant effect. What is more, in both ID matchings high contributors are likely to decrease their contribution due to received MP, which seems to be more severe in out- than in in-groups. The influence of MP on low contributors is ineffective in both ID matchings compared to randomly assigned groups. Generally, NMP has a positive effect on contributions when all subjects are looked at, which seems most influential in out-groups. Yet, in contrast to out-groups high contributors in in-groups even reduce their contributions by a very a small amount upon receiving NMP (see NMP, column 2). This suggests that highly cooperative subjects in in-groups are more sensitive to NMP than subjects in out- or control-groups. In particular, receiving NMP despite comparably high contributions could be perceived as unfair. This in turn could lead to a negative reciprocation by lowering contributions in the next period.

Summing up, we find evidence that, overall not MP but NMP maintains contributions in the following period although these effects seem to be quite moderate. ${ }^{29}$ Moreover, in in-group members even show an overall negative reaction to MP in terms of subsequent contributions. Both MP and NMP induce high contributors of in-groups to lower their subsequent contributions. Concluding, our assumption that identity-homogenous groups tend to be more sensitive to NMP and increase their contributions to a public good to a higher extent, is not supported by our data. In contrast, out-group members tend to show a stronger reaction to NMP.

Result 4a: Receiving NMP has an overall significant and positive influence on subsequent contributions. While the application of MP per se is ineffective in boosting cooperation in out- and randomly assigned groups, it even leads to decreasing contributions in in-groups.

\footnotetext{
${ }^{29}$ Please recall that these observations reflect the effect on MP and NMP that cannot be explained by deviations from group's average. Nevertheless, if deviations from group's average are also taken into consideration, with other words, if the effect of MP and NMP is not isolated from it, we gain similar tendencies (see Table A.5).
} 
Result 4b: $\quad$ Both MP and NMP induce high contributors of in-groups to lower their subsequent contributions.

Next, we will investigate to what extent emotions of guilt and anger are responsible for such differences in reactions to punishment. Firstly, Figure 4 illustrates how the type of punishment received influences subjects' emotions, which were elicited directly after being informed about the total MP and NMP points subjects received..$^{30}$ The fact that the average strength of anger is comparatively low when receiving only NMP in not surprising since NMP is not associated with costs. We find, however, that the intensity of anger in case of receiving BP is significantly higher in in-group and random matchings than in out-groups ( $\left.\mathrm{p}_{\mathrm{INvSOUT}}<0.001, \mathrm{p}_{\mathrm{CONTVSOUT}}<0.001\right)$. Nevertheless, the feeling of anger when receiving only MP or NMP points does not differ between the treatments.
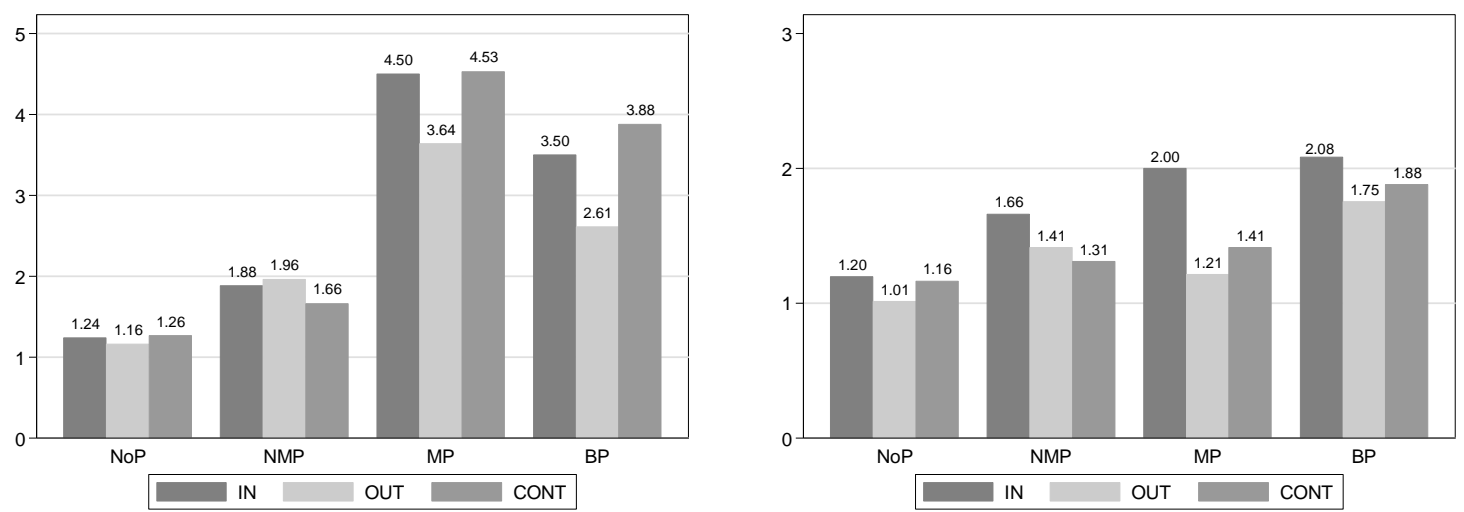

Figure 4 - Intensity of Anger (left panel) and Guilt (right panel) dependent on Punishment (NoP-No punishment, NMP-NMP only, MP- MP only, BP-Both Punishments)

With respect to the emotion of guilt, we establish that in-group subjects report a significantly higher level of guilt when they receive punishment than out- or control subjects ( $p_{\text {INvsOUT }}<0.001$ and $\mathrm{p}_{\text {INusCONT }}<0.01$ ). No matter whether subjects receive solely NMP, solely MP or both punishments at the same time, being punished always triggers a higher intensity of guilt in in-group than in out-group matching (for NMP: $p_{\mathrm{INvSOUT}}<0.1, \mathrm{MP}$ : $\mathrm{p}_{\mathrm{INvSOUT}}<0.1$, and BP: $\mathrm{p}_{\mathrm{INvSOUT}}<0.05$ ). Guilt is also greater in ingroups than in control groups when receiving NMP or BP (for NMP: $\mathrm{p}_{\text {INusCONT }}<0.1$ and BP: $\left.\mathrm{P}_{\mathrm{INvSCONT}}<0.05\right)$. This highlights that subjects in in-groups are more emotionally sensitive to NMP than subjects of the Out-group and the Control treatment.

Secondly, Figure 5 illustrates how this emotional sensitivity influences the effectiveness of punishment in different social environments. In particular, it depicts the change in contributions dependent on whether subjects were punished and whether they indicated feelings of anger and guilt. ${ }^{31}$ To this purpose, we classify subjects as angry and feeling guilty when they indicated an intensity of at least two on a seven-point Likert-scale. ${ }^{32}$ Our results show that when subjects were punished, contribution changes of angry and non-angry subjects differ neither in identityhomogenous nor in randomly assigned groups $\left(\mathrm{p}_{\mathrm{IN}}=0.94, \mathrm{p}_{\mathrm{CONT}}=0.61\right)$. Nevertheless, in out-groups

\footnotetext{
${ }^{30}$ We find that in case subjects received punishment disregarding type and strength, they had significantly higher intensity of negative emotions (shame, irritation, guilt, disappointment and anger) and a significantly lower intensity of happiness, gratitude and surprise ( $p<0.001$ for all treatments).

${ }^{31}$ For details about the effect of particular punishment types, see Table A.6 and Figure A.7.

${ }^{32}$ This classification yields similar results to choosing the mean of all subjects as a benchmark.
} 
anger induced subjects to contribute comparatively lower amounts to the public good as opposed to non-angry subjects ( $p_{\text {out }}<0.05$ ). Consequently, the emotional reaction to receiving punishment does shape out-group members' subsequent contribution. This documents that especially in this matching condition effects of punishment on contribution are not homogenous. In case subjects did not receive any punishment the feeling of anger triggered even lower level of contributions in the following period. In contrast to in-group matching, in the Out-group and Control treatment we even find that this difference between angry and non-angry subjects is significant, thus the decrease is more severe ( $p_{\text {OUT }}<0.001, p_{\text {CONT }}<0.05, p_{I_{N}}=0.15$ ). In sum, these insights suggest that in-group members are less susceptible to their anger than subjects of groups comprised of heterogenous identities or random subjects, who tend to lower subsequent contributions when angry upon punishment. Consequently, our hypothesis on anger that in-group members' emotion of anger to have less impact on subsequent contribution changes than those of out-group members, cannot be rejected. This finding is in line with Bicskei et al. (2013a), who find that a similar intensity of anger-like emotions influences behaviour less when individuals are matched with members of common identities than with members of different identities.

Result 4c: After being punished, the presence of anger does not influence subsequent contributions in in-groups. In groups of different identities and in randomly assigned groups it leads to lower subsequent contributions.
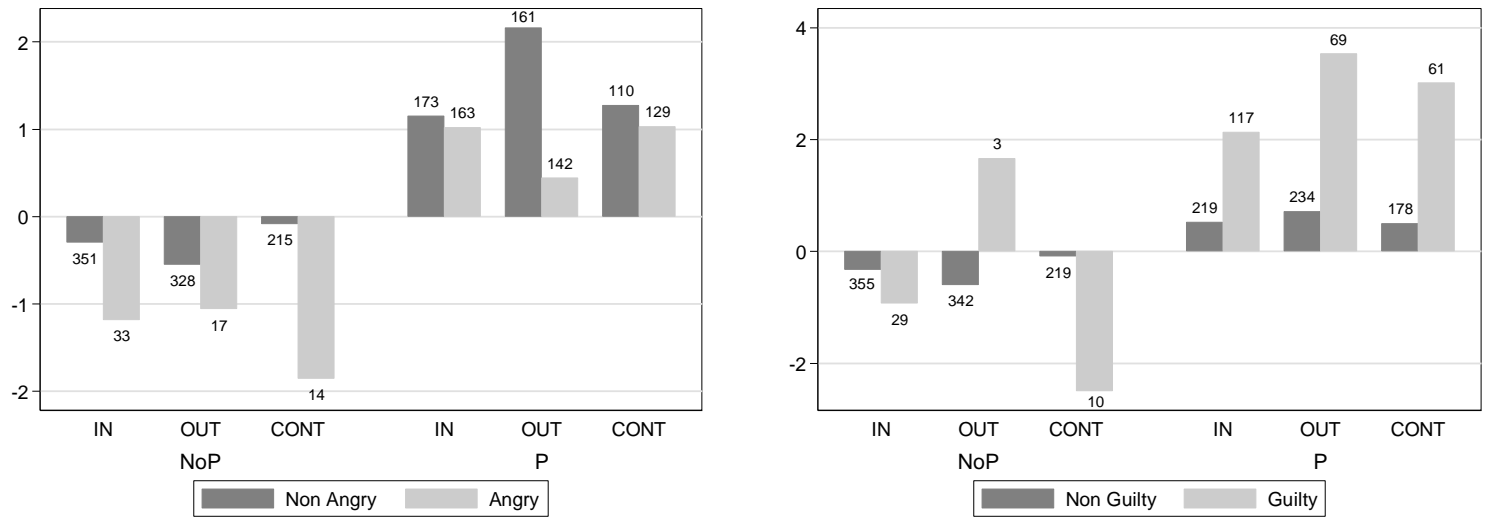

Figure 5 - Average Change in Contribution based on Emotions and Punishment Received (number above the bars indicate frequencies) ${ }^{33}$

Regarding guilt, we demonstrate that in each treatment if subjects were punished, they were more likely to increase their contributions if they felt guilty than if they did not (Pearson's chi-square test yielding $p<0.001$ for each treatment). ${ }^{34}$ Moreover, these subjects increased their contribution to the public good to a greater extent than those who felt no guilt ( $p_{\text {Guilty vs NonGuilty }}<0.001$ for each treatment). We notice, however, that punished out-group members who felt guilty were more likely to increase their contributions than in-group members feeling guilty (Pearson's chi-square test, $\chi^{2}(1)=$ $4.7, p<0.05)$. In this regard, the average increase in contributions is also significantly higher in outgroups than in in-groups $\left(\mathrm{p}_{\mathrm{INvSOUT}}<0.1\right) .{ }^{35}$ Unpunished subjects in in-groups who had no feelings of

\footnotetext{
${ }^{33}$ In out-group all negative deviations from the average were punished, thus the occurrence of observations, when no punishment was received but guilt was felt, is not expected (we have only 3 observations).

${ }^{34}$ See also Table A. 6 and Figure A.7 for differences between punishment types.

${ }^{35}$ For the robustness check, see Table A.8.
} 
guilt decreased their contribution to a similar extent as subjects of randomly assigned groups $\left(p_{\text {INvSCONT }}=0.27\right)$. This decrease was, however, weaker than that of out-group $\left(p_{\text {INvSOUT }}<0.1\right.$, POUTvsCONT $<0.01$ ). Interestingly, if subjects did not receive any punishment, although they had feelings of guilt, no differences can be found between in- and out-groups ( $p_{\text {INvsOUT }}=0.11, p_{\text {INvsCONT }}=0.22$, $p_{\text {OUTusCONT }}<0.1$ ). Thus, we establish that the presence of guilt forces subjects to increase their contributions in each treatment if punishment was assigned. In particular, out-group members feeling guilty when punished reveal stronger increases in their contributions than in in-groups. Consequently, our Hypothesis on Guilt, according to which subjects in in-groups tend to contribute more to the public good in the next period than out-groups if they feel guilty upon punishment, is not supported.

Result 4d: $\quad$ Although the level of guilt felt by subjects is significantly higher in in-groups as opposed to out-groups in case of receiving punishment of any kind, feeling guilty induces significantly higher positive changes in subjects' contributions in out- than in in-group matching.

Result 4e: When receiving punishment, the feeling of guilt triggers higher positive changes in subjects' contributions in the control treatment than in the In-group treatment.

\section{Conclusion}

This article provides initial insights on whether subjects in different social environments govern their groups rather by monetary sanctions or simply by non-monetary sanctions. Our data reveals that under the threat of both punishments, apart from the initial periods, identity-heterogeneous groups tend to contribute more to a public good than identity-homogeneous groups. This could be due to an anticipation of more severe punishment in out-groups as opposed to in-groups. Indeed, we establish that out-groups subjects display their disapproval more frequently and with greater intensity by monetary-punishment as opposed to in-groups. On the contrary, in-group subjects rely more on nonmonetary punishment. In total, these counteracting differences in contributions and in the application of monetary- and non-monetary punishment bear the consequence that identityhomogeneous and identity-heterogeneous groups reach a similar social welfare.

In connection with the question of how subjects actually respond to these governance mechanisms, we demonstrate that the application of monetary-punishment alone is ineffective in boosting cooperation, which contradicts previous findings. Rather the amount of NMP received positively influences subsequent contributions. Yet, contrary to our hypothesis subjects in identityhomogeneous groups are not outstandingly affected. Moreover, both monetary- and non-monetary punishment induce highly cooperative in-group members to lower their subsequent contributions, probably because they perceive punishment by in-group members as particularly unfair and retaliate by lowering contributions.

Furthermore, we establish that the social environment alters how anger drives subjects' behavior. Indeed, while after being punished the presence of anger does not influence subsequent contributions in in-groups, in out- and random groups it has a negative impact. Equally, the feeling of guilt when being punished differently affects subsequent contributions depending on the social 
environment. Surprisingly, when interacting in identity-heterogeneous groups, guilt leads subjects to increase subsequent contributions to a higher extent than in identity-homogenous groups.

From economic policy perspective our findings are of high relevance. We demonstrate that groups in different social environments make use of different forms and strengths of governance. Thus, the availability of both monetary and non-monetary punishment institutions leads identity-homogenous and identity-heterogeneous groups to achieve similar levels of social welfare. This is important, since it is typically lower in fragmented societies than in homogeneous ones. Moreover, in both social environments welfare is higher than typically observed without any punishment institution. All in all, an institutional environment, which combines both sanctioning systems, is beneficial in terms of social welfare in the long run.

\section{Acknowledgement}

We would like to thank Marcela Ibañez Diaz, Claudia Keser, András Dobó, Maximilian Riedl and Nadine Behncke for their valuable comments to the experimental design and previous versions of this article. 


\section{Appendix}

Table A.1: Average Group Contribution Level over Periods

\begin{tabular}{|c|c|c|c|c|c|c|c|c|c|c|c|}
\hline & & & & & & & & & & & \\
\hline & 1 & 2 & 3 & 4 & & 6 & 7 & 8 & 9 & 10 & Tota \\
\hline iro & & & & & & & & & & & \\
\hline & & & & & & & & & & & \\
\hline 1 & 17.5 & 7.5 & 19.5 & 20.0 & 20.0 & 20.0 & 20.0 & 20.0 & 20.0 & 20.0 & 19.5 \\
\hline 2 & 13.8 & 6.3 & .0 & 15.5 & & 2.5 & 3 & 0.0 & 0.0 & 0.0 & 12.7 \\
\hline 3 & 13.8 & 20.0 & 15.0 & 16.3 & & 17.5 & 16.3 & 17.0 & 15.3 & 8.5 & 15. \\
\hline 4 & 13.3 & 18.8 & 20.0 & 20.0 & 20.0 & 20.0 & 20.0 & 20.0 & 20.0 & 20.0 & 19.2 \\
\hline 5 & 17.5 & J & v & 18.8 & & 20.0 & 20.0 & 20.0 & 20.0 & 20.0 & 18. \\
\hline 6 & 1 & .0 & 0 & 20.0 & & .0 & 0 & .0 & 0 & 0.0 & 19. \\
\hline 7 & 17 & .0 & 0 & 20.0 & 0 & 20.0 & 0 & 20.0 & .0 & 15.0 & 19.3 \\
\hline 8 & 15.0 & 20.0 & 20.0 & 20.0 & 20.0 & 20.0 & 20.0 & 20.0 & 20.0 & 20.0 & 19.5 \\
\hline 9 & 11.3 & 14.5 & 3 & 15.8 & 16.5 & 17.3 & 18.8 & 19.8 & 20.0 & 19.3 & 16.8 \\
\hline 1 & & & & & & & & & & 9.0 & 18.7 \\
\hline 1 & 11.0 & 15.0 & 1 & 1 & 19.5 & 20.0 & 0 & .0 & 0 & 19.8 & 18.1 \\
\hline 12 & 13.8 & 16.0 & 18.8 & 19.8 & 19.5 & 20.0 & 20.0 & 20.0 & 20.0 & 15.0 & 18.3 \\
\hline 1 & 10.8 & 13.0 & 14.3 & 14.5 & 14.5 & 14.8 & 15.3 & 15.8 & 16.8 & 18.5 & 14.8 \\
\hline 1 & 12.5 & 15.0 & 18.8 & 20.0 & & 20.0 & 20.0 & 20.0 & 20.0 & 20.0 & 18. \\
\hline 1 & 16.3 & 18.5 & 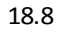 & 18 & & 20.0 & 20.0 & 20.0 & 0 & 16.3 & 18.8 \\
\hline 1 & 88 & 12.5 & 13.5 & 14.0 & 16.0 & 17.3 & 17.5 & 18.0 & 18.0 & 19.3 & 15.5 \\
\hline 1 & 16.3 & 16.3 & 16.3 & 15.0 & 20.0 & 20.0 & 20.0 & 20.0 & 20.0 & 20.0 & 18.4 \\
\hline 18 & 12.5 & 16.3 & & 15.0 & 16.3 & 17.5 & 16.3 & 20.0 & 20.0 & 20.0 & 16. \\
\hline 19 & 12.5 & 10.0 & 11.3 & 11.8 & 12.0 & 11.8 & 13.5 & 12.5 & 10.5 & 6.3 & 11.2 \\
\hline & & & & & & .0 & 1.8 & 2.0 & 2.0 & 1.3 & 3.4 \\
\hline tal & 13.6 & 16.2 & 16.4 & 16.8 & 17.3 & 17.5 & 17.4 & 17.7 & 17.6 & 16.4 & 16.7 \\
\hline
\end{tabular}

OUT

$\begin{array}{llllllllllll}1 & 13.0 & 15.0 & 17.8 & 15.5 & 17.3 & 15.3 & 17.3 & 18.5 & 14.3 & 16.8 & 16.1\end{array}$

$\begin{array}{lllllllllll}13.8 & 20.0 & 20.0 & 20.0 & 20.0 & 20.0 & 20.0 & 20.0 & 20.0 & 20.0 & 19.4\end{array}$

$\begin{array}{llllllllllll}3 & 8.8 & 12.3 & 14.5 & 18.3 & 19.3 & 20.0 & 20.0 & 20.0 & 20.0 & 18.8 & 17.2\end{array}$

$\begin{array}{lllllllllllll}4 & 15.5 & 20.0 & 20.0 & 20.0 & 20.0 & 19.8 & 20.0 & 20.0 & 20.0 & 15.0 & 19.0\end{array}$

$\begin{array}{llllllllllll}5 & 18.8 & 20.0 & 20.0 & 20.0 & 20.0 & 20.0 & 20.0 & 20.0 & 20.0 & 20.0 & 19.9\end{array}$

$\begin{array}{lllllllllllll}6 & 15.0 & 16.3 & 20.0 & 20.0 & 20.0 & 20.0 & 20.0 & 20.0 & 20.0 & 18.8 & 19.0\end{array}$

$\begin{array}{llllllllllll}7 & 10.5 & 11.5 & 14.5 & 15.3 & 14.5 & 14.0 & 14.5 & 14.8 & 11.3 & 10.3 & 13.1\end{array}$

$\begin{array}{lllllllllllll}8 & 9.5 & 10.3 & 13.5 & 14.8 & 15.3 & 16.0 & 16.5 & 16.8 & 17.3 & 17.5 & 14.7\end{array}$

$\begin{array}{llllllllllll}9 & 13.8 & 17.5 & 17.8 & 20.0 & 20.0 & 19.8 & 20.0 & 20.0 & 20.0 & 15.0 & 18.4\end{array}$

$\begin{array}{llllllllllll}10 & 9.5 & 15.0 & 20.0 & 17.5 & 20.0 & 20.0 & 20.0 & 19.8 & 19.8 & 19.8 & 18.1\end{array}$

$\begin{array}{llllllllllll}11 & 15.0 & 19.0 & 20.0 & 20.0 & 20.0 & 20.0 & 20.0 & 20.0 & 20.0 & 20.0 & 19.4\end{array}$

$\begin{array}{lllllllllllll}12 & 14.3 & 19.5 & 20.0 & 20.0 & 20.0 & 20.0 & 20.0 & 20.0 & 20.0 & 14.5 & 18.8\end{array}$

$\begin{array}{llllllllllll}13 & 14.5 & 20.0 & 20.0 & 20.0 & 20.0 & 20.0 & 20.0 & 20.0 & 20.0 & 17.5 & 19.2\end{array}$

$\begin{array}{lllllllllllll}14 & 12.5 & 14.8 & 19.5 & 15.5 & 16.3 & 12.0 & 14.0 & 11.5 & 15.8 & 15.5 & 14.7\end{array}$

$\begin{array}{lllllllllllll}15 & 14.5 & 13.8 & 19.0 & 20.0 & 20.0 & 18.3 & 12.5 & 16.3 & 16.8 & 16.3 & 16.7\end{array}$

$\begin{array}{lllllllllllll}16 & 17.0 & 19.8 & 20.0 & 20.0 & 20.0 & 20.0 & 20.0 & 20.0 & 20.0 & 15.0 & 19.2\end{array}$

$\begin{array}{llllllllllll}17 & 14.3 & 15.0 & 16.5 & 17.0 & 18.0 & 18.5 & 18.5 & 18.5 & 19.3 & 14.5 & 17.0\end{array}$

\begin{tabular}{llllllllllll}
18 & 10.8 & 12.5 & 15.0 & 16.8 & 17.3 & 16.5 & 15.0 & 15.8 & 15.8 & 8.8 & 14.4 \\
\hline
\end{tabular}

\begin{tabular}{lllllllllllll}
\hline Total & 13.4 & 16.2 & 18.2 & 18.4 & 18.8 & 18.3 & 18.2 & 18.4 & 18.3 & 16.3 & 17.5 \\
\hline
\end{tabular}

CONT

$\begin{array}{llllllllllll}1 & 14.3 & 18.3 & 19.5 & 20.0 & 20.0 & 20.0 & 20.0 & 20.0 & 20.0 & 20.0 & 19.2\end{array}$

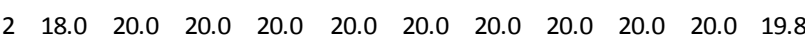

$\begin{array}{llllllllllll}3 & 11.3 & 13.3 & 18.0 & 11.3 & 2.5 & 13.0 & 17.3 & 17.5 & 14.5 & 10.0 & 12.9\end{array}$

$\begin{array}{lllllllllllll}4 & 12.8 & 13.0 & 13.5 & 12.8 & 12.8 & 12.5 & 13.0 & 12.8 & 11.3 & 9.3 & 12.4\end{array}$

$\begin{array}{llllllllllll}5 & 9.8 & 11.3 & 12.8 & 13.5 & 14.5 & 15.8 & 17.0 & 18.5 & 18.8 & 19.5 & 15.1\end{array}$

$\begin{array}{lllllllllllll}6 & 9.3 & 14.3 & 16.8 & 19.0 & 20.0 & 20.0 & 20.0 & 20.0 & 20.0 & 20.0 & 17.9\end{array}$

$\begin{array}{lllllllllllll}7 & 15.0 & 18.3 & 20.0 & 20.0 & 20.0 & 20.0 & 20.0 & 20.0 & 20.0 & 20.0 & 19.3\end{array}$

$\begin{array}{llllllllllll}8 & 15.5 & 18.8 & 20.0 & 20.0 & 20.0 & 18.8 & 18.8 & 20.0 & 18.8 & 17.0 & 18.8\end{array}$

$\begin{array}{lllllllllllll}9 & 17.8 & 18.0 & 19.5 & 20.0 & 20.0 & 20.0 & 20.0 & 20.0 & 20.0 & 20.0 & 19.5\end{array}$

$\begin{array}{llllllllllll}10 & 13.3 & 17.5 & 16.3 & 20.0 & 20.0 & 20.0 & 20.0 & 20.0 & 20.0 & 20.0 & 18.7\end{array}$

$\begin{array}{llllllllllllll}11 & 17.3 & 19.0 & 20.0 & 15.0 & 20.0 & 20.0 & 19.8 & 15.0 & 20.0 & 20.0 & 18.6\end{array}$

$\begin{array}{llllllllllll}12 & 13.5 & 16.0 & 17.0 & 17.3 & 18.0 & 18.0 & 18.0 & 17.8 & 17.8 & 17.8 & 17.1\end{array}$

\begin{tabular}{llllllllllll}
13 & 8.3 & 14.8 & 15.3 & 18.0 & 17.5 & 17.8 & 17.8 & 18.8 & 18.8 & 19.5 & 16.6 \\
\hline
\end{tabular}

\begin{tabular}{lllllllllllll}
\hline Total & 13.5 & 16.3 & 17.6 & 17.4 & 17.3 & 17.4 & 18.6 & 18.5 & 18.4 & 17.9 & 17.4 \\
\hline
\end{tabular} 
Table A.2: Average Punishment Points Assigned

\begin{tabular}{|c|c|c|c|c|c|c|c|c|c|c|c|c|}
\hline \multirow[t]{2}{*}{ Treatment } & & \multicolumn{10}{|c|}{ Period } & \multirow[b]{2}{*}{ Average } \\
\hline & & 1 & 2 & 3 & 4 & 5 & 6 & 7 & 8 & 9 & 10 & \\
\hline \multirow{2}{*}{ IN } & $\mathrm{MP}$ & 1.39 & 1.84 & 1.43 & 0.66 & 0.84 & 0.65 & 0.64 & 0.44 & 0.39 & 9 1.00 & 0.93 \\
\hline & NMP & 7.28 & 6.74 & 6.61 & 5.79 & 5.64 & 3.79 & 4.64 & 3.76 & 3.48 & 8.80 & 5.35 \\
\hline \multirow{2}{*}{ OUT } & $\mathrm{MP}$ & 1.49 & 1.14 & 0.60 & 1.28 & 1.47 & 1.18 & 0.76 & 0.81 & 0.88 & 31.50 & 1.11 \\
\hline & NMP & 9.19 & 6.36 & 2.78 & 3.56 & 2.64 & 4.50 & 4.85 & 3.72 & 4.53 & 3.94 & 5.01 \\
\hline \multirow{2}{*}{ CONT } & MP & 1.81 & 1.87 & 1.25 & 1.35 & 1.04 & 0.63 & 1.29 & 1.38 & 0.81 & 10.92 & 1.23 \\
\hline & NMP & 7.33 & 5.77 & 5.19 & 3.58 & 3.19 & 2.02 & 3.31 & 3.79 & 2.85 & 5.56 & 4.06 \\
\hline
\end{tabular}

Figure A.3: Cost of Punishment

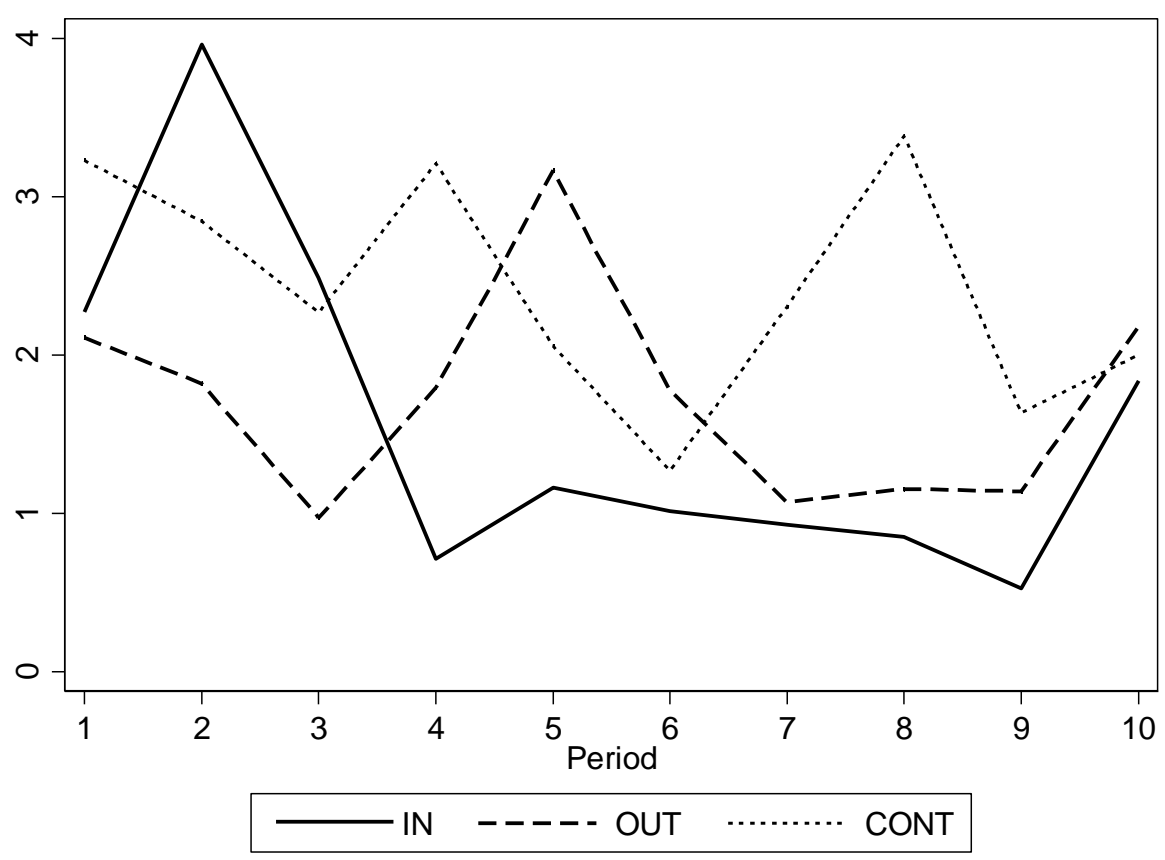


Table A.4: Determinants of Punishment of Period 1

Dep.Var.: Punishment assigned by subject i to subject k in Period 1

\begin{tabular}{|c|c|c|c|c|c|c|}
\hline & (1) & (2) & (3) & (4) & (5) & (6) \\
\hline & \multicolumn{2}{|c|}{ IN } & \multicolumn{2}{|c|}{ OUT } & \multicolumn{2}{|c|}{ CONT } \\
\hline & MP & NMP & MP & NMP & MP & NMP \\
\hline $\begin{array}{l}\text { Neg. Deviation from Group Avg. Contr. } \\
\qquad\left(c_{k}-\bar{c}<0\right)\end{array}$ & $\begin{array}{c}0.540 * * * \\
(0.149)\end{array}$ & $\begin{array}{c}1.148^{* * *} \\
(0.175)\end{array}$ & $\begin{array}{c}0.304^{* * *} \\
(0.084)\end{array}$ & $\begin{array}{c}0.811^{* * *} \\
(0.098)\end{array}$ & $\begin{array}{c}0.413^{* * *} \\
(0.130)\end{array}$ & $\begin{array}{c}1.012^{* * *} \\
(0.155)\end{array}$ \\
\hline $\begin{array}{l}\text { Pos. Deviation from Group Avg. Contr. } \\
\qquad\left(c_{k}-\bar{c}>0\right)\end{array}$ & $\begin{array}{c}0.071 \\
(0.240)\end{array}$ & $\begin{array}{l}-0.200 \\
(0.283)\end{array}$ & $\begin{array}{l}-0.305^{*} \\
(0.172)\end{array}$ & $\begin{array}{c}-0.659 * * * \\
(0.175)\end{array}$ & $\begin{array}{l}-0.263 \\
(0.220)\end{array}$ & $\begin{array}{l}-0.388 \\
(0.286)\end{array}$ \\
\hline $\begin{array}{l}\text { Others Average Contribution } \\
\text { (excluding subject k) }\end{array}$ & $\begin{array}{c}0.082 \\
(0.168)\end{array}$ & $\begin{array}{l}-0.252^{*} \\
(0.145)\end{array}$ & $\begin{array}{c}0.001 \\
(0.133)\end{array}$ & $\begin{array}{c}-0.533 * * * \\
(0.203)\end{array}$ & $\begin{array}{c}0.016 \\
(0.200)\end{array}$ & $\begin{array}{l}-0.161 \\
(0.187)\end{array}$ \\
\hline Constant & $\begin{array}{c}-7.678^{* *} \\
(3.202)\end{array}$ & $\begin{array}{c}0.119 \\
(2.360)\end{array}$ & $\begin{array}{l}-2.932 \\
(2.062)\end{array}$ & $\begin{array}{l}6.398 * * \\
(2.733)\end{array}$ & $\begin{array}{l}-3.747 \\
(2.705)\end{array}$ & $\begin{array}{c}0.960 \\
(2.921)\end{array}$ \\
\hline Sigma Constant & $\begin{array}{c}5.004^{* * *} \\
(0.889)\end{array}$ & $\begin{array}{c}5.641^{* * *} \\
(0.544)\end{array}$ & $\begin{array}{c}3.349 * * * \\
(0.532)\end{array}$ & $\begin{array}{c}5.635^{* * *} \\
(0.691)\end{array}$ & $\begin{array}{c}4.191^{* * *} \\
(0.899)\end{array}$ & $\begin{array}{c}4.763 * * * \\
(0.481)\end{array}$ \\
\hline Observations & 240 & 240 & 216 & 216 & 156 & 156 \\
\hline Log-likelihood & -177.5 & -365.7 & -182.9 & -355.2 & -150.4 & -255.8 \\
\hline Pseudo R2 & 0.0381 & 0.116 & 0.0788 & 0.131 & 0.0454 & 0.115 \\
\hline
\end{tabular}

Robust standard errors in parentheses. Tobit estimation with lower censoring.

$* * * p<0.01, * * p<0.05, * p<0.1 ; c-C o n t r i b u t i o n$

Table A.5: Average Change in Contribution based on Punishment received

Dep.Var.: Average Change in Inidividual Contrribution ((t+1)-t)

\begin{tabular}{|c|c|c|c|c|c|c|c|c|c|}
\hline & (1) & (2) & (3) & (4) & (5) & (6) & (7) & (8) & (9) \\
\hline & \multicolumn{3}{|c|}{ IN } & \multicolumn{3}{|c|}{ OUT } & \multicolumn{3}{|c|}{ CONT } \\
\hline & ALL & High Contr. & Low Contr. & ALL & High Contr. & Low Contr. & ALL & High Contr. & Low Contr. \\
\hline \multirow[t]{2}{*}{ MP } & -0.162 & $-0.239 * *$ & -0.0222 & $-0.140 *$ & $-0.390 * * *$ & 0.0837 & -0.0542 & $-0.456 * * *$ & $0.640 * * *$ \\
\hline & (0.116) & (0.119) & (0.193) & $(0.0815)$ & $(0.143)$ & (0.180) & (0.117) & $(0.160)$ & (0.141) \\
\hline \multirow[t]{2}{*}{ NMP } & $0.166^{* * *}$ & -0.0332 & $0.106^{* *}$ & $0.226 * * *$ & $0.0938^{* *}$ & 0.0552 & $0.248 * * *$ & $0.122^{*}$ & 0.0763 \\
\hline & $(0.0305)$ & $(0.0256)$ & $(0.0421)$ & $(0.0475)$ & (0.0354) & $(0.0883)$ & $(0.0548)$ & (0.0674) & $(0.0600)$ \\
\hline \multirow[t]{2}{*}{ Constant } & $-0.423 * * *$ & $-0.419 * * *$ & $1.686 * * *$ & $-0.580 * * *$ & $-0.544^{* * *}$ & $2.860 * * *$ & $-0.461^{* *}$ & -0.274 & 0.948 \\
\hline & $(0.154)$ & $(0.133)$ & $(0.363)$ & $(0.175)$ & (0.166) & (0.829) & $(0.208)$ & (0.182) & (0.619) \\
\hline Observations & 720 & 537 & 183 & 648 & 522 & 126 & 468 & 358 & 110 \\
\hline R-squared & 0.092 & 0.034 & 0.039 & 0.146 & 0.039 & 0.021 & 0.159 & 0.100 & 0.254 \\
\hline
\end{tabular}

Robust standard errors in parentheses, clustered around individuals.

$* * * \mathrm{p}<0.01, * * \mathrm{p}<0.05, * \mathrm{p}<0.1$ 
Table A.6: Average Change in Contribution based on Emotions and Punishment received (Avg. Change, Standard Deviations, and Frequencies)

\begin{tabular}{|c|c|c|c|c|c|c|c|c|c|c|c|c|c|c|c|}
\hline & \multicolumn{5}{|c|}{ IN } & \multicolumn{5}{|c|}{ OUT } & \multicolumn{4}{|c|}{ CONT } & \multirow[b]{2}{*}{ Total } \\
\hline & NoP & NMP & MP & $\mathrm{BP}$ & Total & NoP & NMP & MP & $\mathrm{BP}$ & Total & NoP & NMP & $\mathrm{MP}$ & $\mathrm{BP}$ & \\
\hline \multirow[t]{3}{*}{ Non-Angry } & -0.30 & 0.88 & 0.00 & 1.79 & 0.18 & -0.55 & 1.21 & -2.62 & 4.48 & 0.34 & -0.08 & 0.49 & 0.00 & 2.92 & 0.38 \\
\hline & 2.42 & 3.76 & 0.00 & 5.83 & 3.31 & 2.91 & 2.61 & 5.62 & 6.05 & 3.91 & 1.81 & 2.00 & 0.00 & 5.85 & 2.75 \\
\hline & 351 & 120 & 1 & 52 & 524 & 328 & 86 & 13 & 62 & 489 & 215 & 71 & 3 & 36 & 325 \\
\hline \multirow[t]{3}{*}{ Angry } & -1.18 & 0.39 & 0.00 & 1.36 & 0.65 & -1.06 & -0.46 & -2.13 & 1.92 & 0.28 & -1.86 & 0.26 & -2.5 & 1.8 & 0.75 \\
\hline & 3.35 & 2.81 & 0.00 & 5.51 & 4.61 & 2.36 & 6.09 & 4.28 & 5.3 & 5.32 & 3.7 & 3.17 & 6.22 & 6.65 & 5.92 \\
\hline & 33 & 51 & 5 & 107 & 196 & 17 & 37 & 30 & 75 & 159 & 14 & 31 & 12 & 86 & 143 \\
\hline \multirow[t]{5}{*}{ Total } & -0.37 & 0.74 & 0.00 & 1.50 & 0.31 & -0.58 & 0.71 & -2.28 & 3.08 & 0.33 & -0.19 & 0.42 & -2.00 & 2.13 & 0.49 \\
\hline & 2.52 & 3.50 & 0.00 & 5.60 & 3.71 & 2.89 & 4.04 & 4.66 & 5.77 & 4.29 & 2.01 & 2.4 & 5.61 & 6.42 & 4.00 \\
\hline & 384 & 171 & 6 & 159 & 720 & 345 & 123 & 43 & 137 & 648 & 229 & 102 & 15 & 122 & 468 \\
\hline & \multicolumn{5}{|c|}{ IN } & \multicolumn{5}{|c|}{ OUT } & \multicolumn{4}{|c|}{ CONT } & \\
\hline & $\mathrm{NoP}$ & NMP & MP & $\mathrm{BP}$ & Total & NoP & NMP & MP & $\mathrm{BP}$ & Total & NoP & NMP & MP & $\mathrm{BP}$ & Total \\
\hline \multirow[t]{3}{*}{ Non-Guilty } & -0.33 & 0.38 & 0.00 & 0.76 & 0.00 & -0.60 & 0.25 & -2.38 & 2.50 & -0.06 & -0.09 & 0.02 & -2.50 & 1.43 & 0.18 \\
\hline & 2.44 & 3.37 & 0.00 & 5.70 & 3.36 & 2.89 & 3.58 & 4.84 & 5.93 & 4.00 & 1.79 & 1.59 & 6.22 & 7.17 & 3.81 \\
\hline & 355 & 127 & 4 & 88 & 574 & 342 & 101 & 39 & 94 & 576 & 219 & 84 & 12 & 82 & 397 \\
\hline \multirow[t]{3}{*}{ Guilty } & -0.93 & 1.77 & 0.00 & 2.42 & 1.53 & 1.67 & 2.82 & -1.25 & 4.35 & 3.46 & -2.50 & 2.28 & 0.00 & 3.58 & 2.24 \\
\hline & 3.29 & 3.71 & 0.00 & 5.38 & 4.67 & 2.89 & 5.30 & 2.50 & 5.25 & 5.21 & 4.25 & 4.18 & 0.00 & 4.22 & 4.58 \\
\hline & 29 & 44 & 2 & 71 & 146 & 3 & 22 & 4 & 43 & 72 & 10 & 18 & 3 & 40 & 71 \\
\hline \multirow[t]{3}{*}{ Total } & -0.37 & 0.74 & 0.00 & 1.50 & 0.31 & -0.58 & 0.71 & -2.28 & 3.08 & 0.33 & -0.19 & 0.42 & -2.00 & 2.13 & 0.49 \\
\hline & 2.52 & 3.50 & 0.00 & 5.60 & 3.71 & 2.89 & 4.04 & 4.66 & 5.77 & 4.29 & 2.01 & 2.40 & 5.61 & 6.42 & 4.00 \\
\hline & 384 & 171 & 6 & 159 & 720 & 345 & 123 & 43 & 137 & 648 & 229 & 102 & 15 & 122 & 468 \\
\hline
\end{tabular}


Figure A.7: Average Change in Contribution based on Emotions and Punishment received
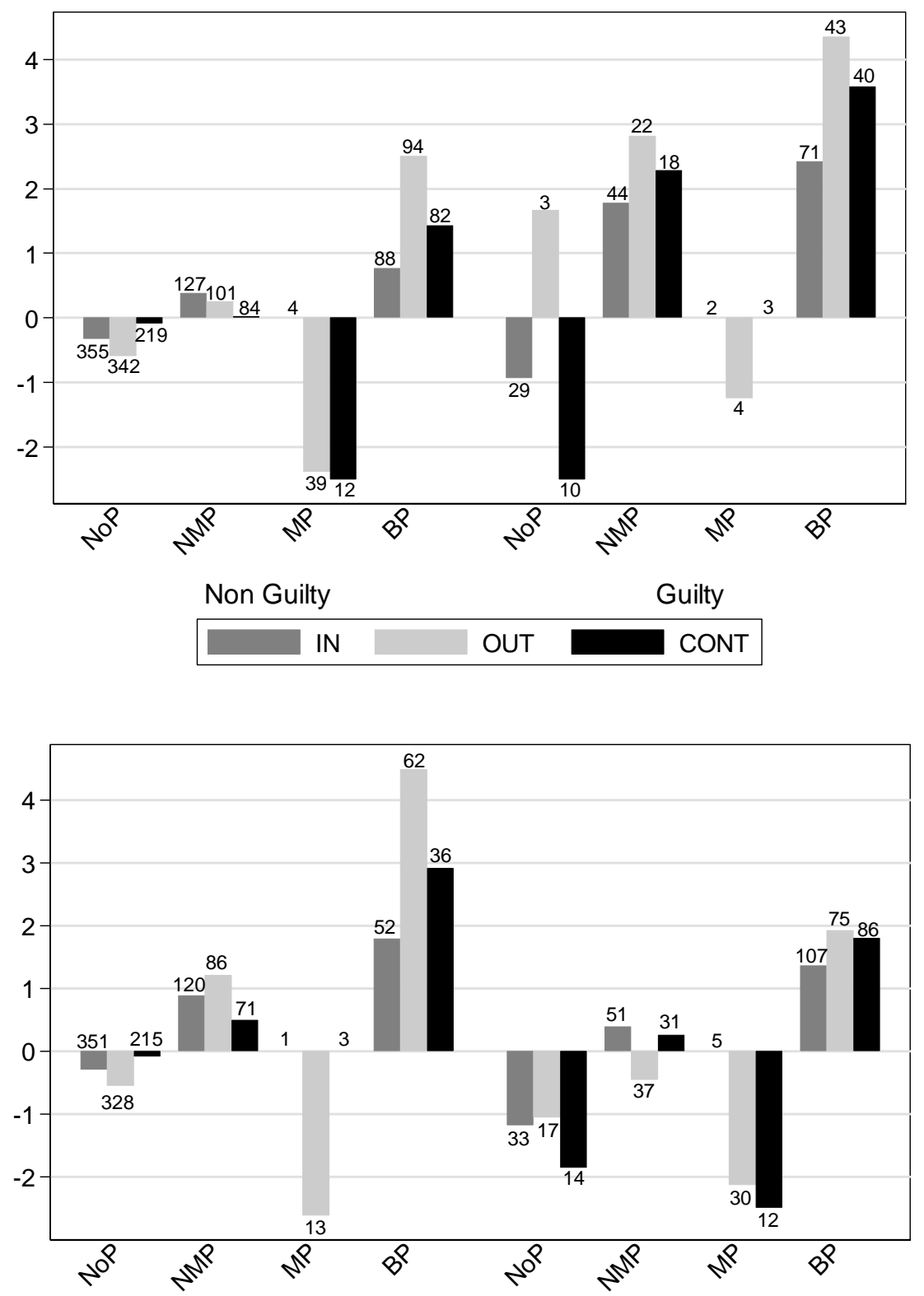

Non Angry

Angry

\begin{tabular}{|l|l|}
\hline IN & OUT \\
\hline
\end{tabular}


Table A.8: Average Change in Contribution based on Guilty (if Punishment received $>0$ )

Dep.Var.: Average Change in Indiv.Contr.

\begin{tabular}{lc} 
Guilt & $0.514^{* * *}$ \\
& $(0.152)$ \\
OUT & -0.565 \\
& $(0.587)$ \\
CONT & -0.329 \\
& $(0.553)$ \\
OUTxGuilt & $0.645^{*}$ \\
& $(0.344)$ \\
CONTxGuilt & 0.323 \\
& $(0.270)$ \\
Constant & 0.119 \\
& $(0.382)$ \\
& 878 \\
Observations & 0.049 \\
R-squared & \\
\hline Robust standard errors in parentheses. & \\
Clustered around individuals. \\
$* * *$ p $<0.01, * * p<0.05, * 0.1$
\end{tabular}

\section{A.9: Instructions to the Experiment (ID treatments)}

Welcome to the experiment! Thank you very much for your participation.

If you read the following instructions carefully, you have the opportunity of winning money additional to the $€ 2.50$ show-up fee, which you receive in any case. Your earnings will depend on your decisions and on those of the other players in your group. It is therefore very important that you read these instructions with care.

The instructions we have distributed to you are solely for your private information. It is forbidden to speak during the experiment. If you have any questions, please raise your hand. A member of our team will come to you and answer your question privately.

During the experiment we will be talking about ECUs (Experimental Currency Units) rather than about Euros. Hence, your total earnings will be calculated in ECUs in the first instance. At the end of the experiment the total amount of ECUs you have earned will be converted to Euros at the following rate:

$$
10 \mathrm{ECUs}=36 \text { Cents }
$$

Each participant receives a lump-sum payment of $100 \mathrm{ECUs}$ at the beginning of the experiment. This one-off payment can be used to pay for eventual losses during the experiment. At the end of the experiment your entire earnings from the experiment (which you will have earned through your decisions), plus the lump-sum payment, will be paid to you in cash immediately.

All participants will be divided in groups with $\mathbf{4}$ players each.

Please click on OK when you are ready. 


\section{Detailed Instructions}

The experiment consists of two tasks. Later, you will be informed about the first task's procedure in detail. Now, we would like to introduce the second task's basic conditions for your decisions.

The second task consists of exactly $\mathbf{1 0}$ periods. The number of the period will appear in the top left corner of the screen. In the top right corner you will see how many more seconds remain for you to make your decisions. You will be in a group with 3 other participants. Please note that the same three people will be in your group for all periods of the second task.

Each period of this task consists of two stages. In the first stage you have to decide how many of your ECUs you would like to contribute to a project. In the second stage you are informed on the contributions of the three other group members to the project. Afterwards, you can decide whether or not to express your approval or disapproval of each other group member's decision by distributing points to them. In the followings these decisions will be described in detail.

\section{The first stage}

At the beginning of each period each participant receives an endowment of 20 ECUs. Your task is to decide how to use this endowment. You have to decide how many of the 20 ECU you want to contribute to a project by choosing a number between 0 and 20. Each point, which you do not invest in a project will be automatically deposited on your private account.

Please state also what you estimate each of the other three group members to contribute to the project on average (e.g: $(5+15+20) / 3=13$, in this case you have to enter 13 as the average amount of money the others invest in the project). Once you have done this and pressed the OK button your decision can no longer be revised.

After all members of your group have made their decision your screen will show you the total amount of ECU contributed to the project by each of the four group members (including your contribution). This screen shows you how many ECU you have earned.

Your income consists of two parts:

1) the income from the private account: the sum of ECUs you have not invested in the project

2) the income from the project: 40 percent of the total contribution of all 4 group members to the project (the total includes your own contribution)

Income from the private account (=20 - your contribution to the project)

+ Income from the project ( $=0.4 *$ (sum of all contributions to the project))

Total income from stage 1

The income of each group member from the project is calculated in the same way, this means that each group member receives the same income from the project.

For example, suppose the total of the contributions of all group members is 60 ECUs. In this case each member of the group receives an income from the project of $0.4 * 60=24$ ECUs. If the total contribution to the project is 9 ECUs, then each member of the group receives an income of $0.4 * 9=3.6$ ECUs from the project.

For each ECU that you keep for yourself (and you do not invest it in the project) you earn an income of $1 \mathrm{ECU}$. For every ECU you contribute to the project instead, the total project contribution rises by one ECU. Your income from the project would rise by $0.4 * 1=0.4 \mathrm{ECU}$. However, the income of the 
other group members would also rise by $0.4 \mathrm{ECU}$ each, so that the total income of the group from the project would rise by 1.6 ECU. Your contribution to the project therefore also raises the income of the other group members. Likewise, you profit from each ECU contributed by the other members to the project. For each ECU contributed by any group member you earn $0.4 * 1=0.4$ ECUs.

\section{The second stage}

At the beginning of the second stage, you will be informed on how much each of your group members contributed to the project. Your contribution is always displayed in the first column, while the contributions of the other group members of this period are shown in the remaining three columns. The contributions of the other group members will be randomly listed and changed in each period, so that you are unable to track the behaviour of a particular group member during the periods.

In this stage you have the opportunity to express your approval or disapproval of each other group member's decision by distributing monetary and/or non-monetary points.

\section{Allocating Non-Monetary Points}

Here, you have the opportunity to express your approval or disapproval of each other group member's decision by distributing 0-10 non-monetary points. You can allocate a large number of points to any member of your group if you disapprove of his or her decision (10 points for the most disapproval, 0 points for the least disapproval). Each point you distribute to a particular player does not affect your earnings or the earnings of the player receiving the non-monetary points.

You will be informed how much each of your group members contributed to the project at the first stage. You must decide how many non-monetary points to give to each of the other three group members. If you do not wish to express disapproval of the decision of a specific group member then you must enter 0 . You do not have any costs in terms of ECUs for distributing non-monetary points to other members of your group.

The other group members can also assign points to you if they wish to do so.

\section{Allocating Monetary Points}

Here, you have the opportunity to reduce the income of each group member by distributing monetary points or to leave it equal. You can allocate a large number of points to any member of your group if you disapprove of his or her decision (10 points for the most disapproval, 0 points for the least disapproval). Each point you distribute to a particular player lowers his or her total income from stage 1 by $10 \%$.

You incur costs for allocating monetary points to other members, which is discussed in detail below.

You must decide how many monetary points to give to each of the other three group members. If you do not wish to change the income of a specific group member then you must enter 0 . If you distribute monetary points, you have costs in terms of ECUs, which depend on the amount of monetary points you distribute. You can distribute between 0 and 10 monetary points to each group member. The more monetary points you allocate to any group member, the higher your costs. Your total costs are equal to the sum of the costs of distributing monetary points to each of the other three group members. The following table illustrates the relation between distributed monetary points to each group member and the cost of doing so in ECUs. 


\begin{tabular}{llllllllllll}
\hline $\begin{array}{l}\text { Monetary points } \\
(\mathrm{P})\end{array}$ & 0 & 1 & 2 & 3 & 4 & 5 & 6 & 7 & 8 & 9 & 10 \\
\hline $\begin{array}{l}\text { Cost of monetary } \\
\text { points (K) }\end{array}$ & 0 & 1 & 2 & 4 & 6 & 9 & 12 & 16 & 20 & 25 & 30 \\
\hline
\end{tabular}

Suppose for example that you give 2 monetary points to one member. This costs you 2 ECUs. If you then give 9 points to another member this costs you an additional $25 \mathrm{ECUs}$; and if you give 0 points to the last group member this has no cost for you. In this case your total costs of distributing points would be 27 ECUs $(2+25+0)$. Your total cost of distributing monetary points can be calculated and is displayed on the input screen. As long as you have not pressed the OK button you can revise your decision.

If you choose 0 monetary points for a particular group member, you do not change his or her income. However, if you give 1 point (by choosing 1) to a member you reduce his or her income by 10 percent, etc. Consequently, the amount of monetary points you distribute to each member determines how much you reduce their income from the first stage.

Whether or by how much the income from the first stage is totally reduced depends on the total of the received monetary points from all other group members. If somebody receives a total of 3 points (from all other group members in this period) his or her income would be reduced by 30 percent. If somebody receives a total of 4 points his or her income would be reduced by 40 percent. If anybody receives $\mathbf{1 0}$ or more monetary points their income from the first stage will be reduced by 100 percent. The income from the first stage for this member would in this case be reduced to zero.

The other group members can also assign points to you if they wish to.

Afterwards, please state also what you expect how many monetary and non-monetary points you will receive from the other group members in total. After all participants have made their decisions, these amounts will be displayed on your screen.

\section{Income}

Your total income from the two stages is therefore calculated as follows:

\section{Your total income for the particular period (in ECUs)}

If you receive less than 10 monetary points:

$=\left[(\text { income from the } 1 \text { st stage })^{*}(10\right.$-received monetary points $\left.) / 10\right]$

- (cost to you of monetary points you distribute)

If you receive 10 or more monetary points:

$=-$ your costs of monetary points you distribute

Please note that your income in terms of ECUs at the end of the second stage can be negative, if the costs of the monetary points you distribute exceed your income from the first stage. You can, however, avoid such losses with certainty through you own decisions.

At the end of each period your income from the particular period and your total income from all periods (inclusive that period) will be displayed on your screen. 


\section{Exercises}

To make you more familiar with the decision situation, please answer the following questions and enter your results in the computer. While calculating, you may use the calculator function on the monitor.

1. Each group member has an endowment of 20 ECUs. Nobody (including yourself) contributes any ECUs to the project.

a) What is your total income (income from the private account + income from the project)?

b) What is the total income of each of the other group members for the period?

2. Each group member has an endowment of $20 \mathrm{ECUs}$. You contribute $20 \mathrm{ECUs}$ to the project. All other group members each contribute 20 ECUs to the project.

a) What is your total income for the period?

b) What is the total income of each the other group members for the period?

3. Each group member has an endowment of 20 ECUs. The other three group members contribute together a total of 40 ECUs to the project.

a) What is your total income if you, in addition to the $40 \mathrm{ECUs}$, contribute $0 \mathrm{ECU}$ to the project?

b) What is your total income if you, in addition to the $40 \mathrm{ECUs}$, contribute $15 \mathrm{ECUs}$ to the project?

4. Each group member has an endowment of 20 ECUs. You contribute 10 ECUs to the project.

a) What is your total income if the other group members together, in addition to your 10 ECUs, contribute a total of 5 ECUs to the project?

b) What is your total income if the other group members together, in addition to your 10 ECUs, contribute a total of $35 \mathrm{ECUs}$ to the project?

5. Suppose in the second stage of this task, you distribute the following amounts of monetary points to the other three group members: 10,5 and 1 . What is the total cost of the monetary points you distribute?

6. What are your costs if you distribute a total of 0 monetary points?

7. By how many percent will your income from the first stage be reduced, if you receive a total of 0 monetary points from the other group members?

8. By how many percent will your income from the first stage be reduced, if you receive a total of 3 monetary points from the other group members?

9. By how many percent will your income from the first stage be reduced, if you receive a total of 9 non-monetary points from the other group members?

10. By how many percent will your income from the first stage be reduced, if you receive a total of 11 monetary points from the other group members?

When you are ready, please click on OK. 


\section{First Task}

Please note: Do not open the attached envelope before you are asked to do so!

At the beginning of the first task, you will be arbitrarily assigned to a group of four and your group will be marked by a specific color. Your group has the possibility to choose its group color between two colors. Each group member will be provided with two colors to vote for. The color chosen by the majority of group members will be your group color. In case of standoff a random mechanism will determine the group color.

In this task only those solutions, which are entered correctly by ALL FOUR group members will be considered as correct. Please take into account that every solution must be approved by clicking on the "Eingabe speichern" ("Save input") button.

During this task the group members are allowed to communicate with each other. For this, a chat box is positioned on the left hand side of the computer screen. Your conversation will be recorded. You have 8 minutes to solve the task. Only in this time you may communicate with your group members. Please note that you are not allowed to chat about the second stage of the experiment. Violations of this rule will cause to lose your earnings and to be excluded from further experiments.

Please note that each group member has to enter the correct answers and approve them by pressing the "Eingabe speichern" ("Save input") botton. You have to click on "Seite verlassen" ("Leave page") before the 8 minutes have run out. Otherwise the results will not be saved. The time left will be shown to you in the upper right hand corner of your screen.

All participants will be shown a picture and a list of objects. The task is to find the hidden objects in the picture. The inscriptions on the left and the upper side give the numbers of the rows (Reihe) and columns (Spalte), respectively. You are asked to insert this information in the boxes of the screen, which will be shown on the right hand side of the screen. The first box refers to the row (Reihe), the second to the column (Spalte). An example for this exercise is given below. 

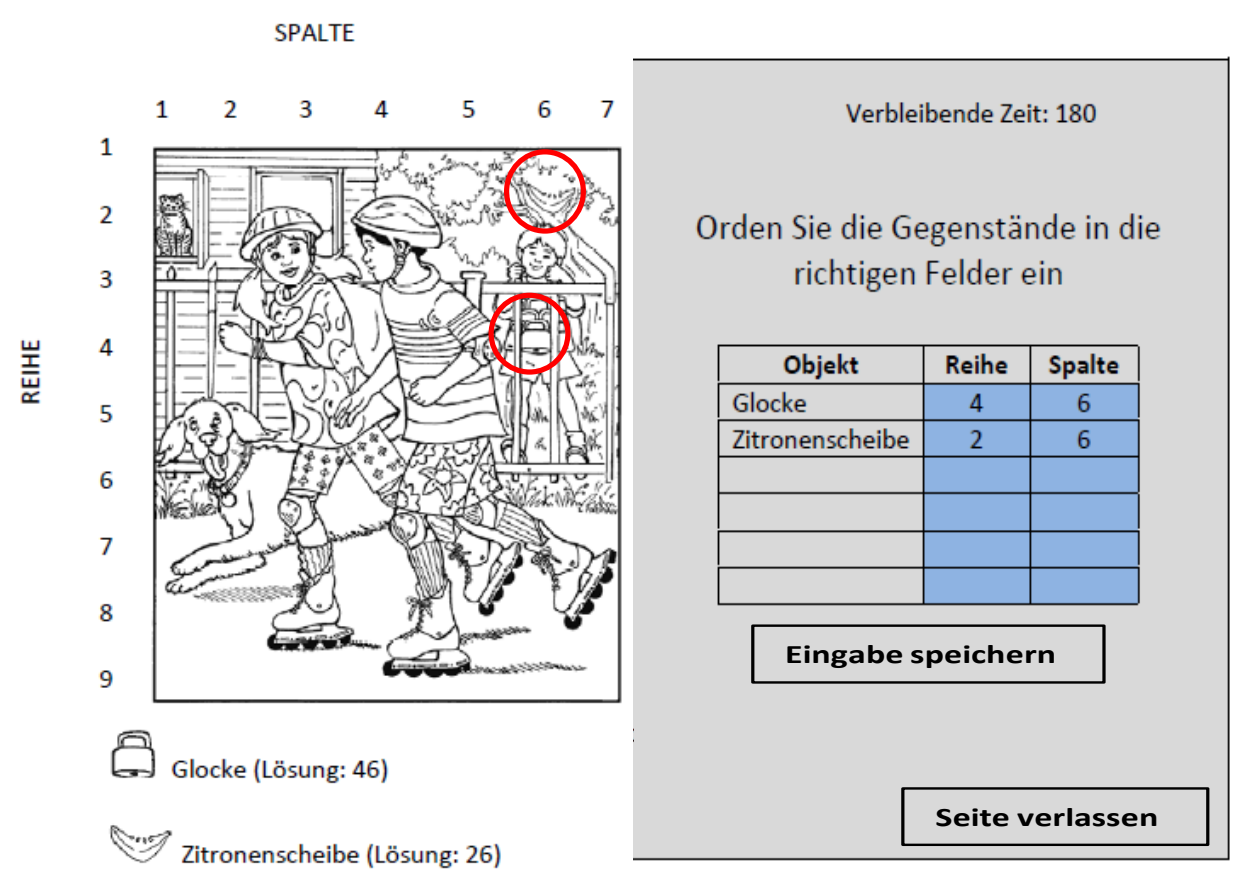

The group, which finds most of the objects in the $\mathbf{8}$ minutes time is the winner group. At the end of the experiment you will be informed how many objects each group of the experiment have found and whether you are belonging to winner group of this task. In this case, you will receive a congratulation message.

Please click on OK when you are ready. 


\section{References}

Akerlof, George A. (1980): A Theory of Social Custom, of Which Unemployment May be One Consequence. In The Quarterly Journal of Economics 94 (4), p. 749.

Barron, John M.; Gjerde, Kathy Paulson (1997): Peer Pressure in an Agency Relationship. In Journal of Labor Economics 15 (2), pp. 234-254.

Ben-Shakhar, Gershon; Bornstein, Gary; Hopfensitz, Astrid; van Winden, Frans (2007): Reciprocity and emotions in bargaining using physiological and self-report measures. In Journal of Economic Psychology 28 (3), pp. 314-323.

Bicskei, Marianna; Lankau, Matthias; Bizer, Kilian (2013a): Negative Reciprocity and Anger-Like Emotions in Homogenous and Heterogeneous Groups. Working Paper. University of Göttingen.

Bicskei, Marianna; Lankau, Matthias; Bizer, Kilian (2013b): How Peer-Punishment affects the Cooperativeness in Homogeneous and Heterogeneous Groups - A Public Goods Experiment with Social Identity. Working Paper. University of Göttingen.

Bochet, Olivier; Page, Talbot; Putterman, Louis (2006): Communication and punishment in voluntary contribution experiments. In Journal of Economic Behavior \& Organization 60 (1), pp. 11-26.

Bosman, Ronald; Sutter, Matthias; van Winden, Frans (2005): The impact of real effort and emotions in the power-to-take game. In Journal of Economic Psychology 26 (3), pp. 407-429.

Bosman, Ronald; van Winden, Frans (2002): Emotional Hazard in a Power-to-take Experiment. In Economic Journal 112 (476), pp. 147-169.

Chen, Yan; Li, Sherry Xin (2009): Group Identity and Social Preferences. In The American Economic Review 99 (1), pp. 431-457.

Currarini, Sergio; Mengel, Friederike (2012): Identity, Homophily and In-Group Bias. FEEM Working Paper No. 37.2012. Available online at

http://papers.ssrn.com/sol3/papers.cfm?abstract_id=2088744, checked on 17/08/2012.

Dugar, Subhasish (2013): Non-monetary Incentives and Opportunistic Behavior: Evidence from a Laboratory Public Good Game. In Economic Inquiry 51 (2), pp. 1374-1388.

Eaton, B. Curtis; Eswaran, Mukesh; Oxoby, Robert J. (2011): Us and Them: the origin of identity, and its economic implications. In Canadian Journal of Economics 44 (3), pp. 719-748.

Elster, John (1989): Social Norms and Economic Theory. In The Journal of Economic Perspectives 3 (4), pp. 99-117.

Elster, Jon (1998): Emotions and Economic Theory. In Journal of Economic Literature 36 (1), pp. 4774.

Fehr, Ernst; Fischbacher, Urs (2004): Social norms and human cooperation. In Trends in Cognitive Sciences 8 (4), pp. 185-190.

Fehr, Ernst; Gächter, Simon (2000): Cooperation and Punishment in Public Goods Experiments. In The American Economic Review 90 (4), pp. 980-994.

Fehr, Ernst; Gächter, Simon (2002): Altruistic punishment in humans. In Nature 415 (6868), pp. 137140.

Fischbacher, U.; Gächter, S. (2010): Social preferences, beliefs, and the dynamics of free riding in public goods experiments. In The American Economic Review 100 (1), pp. 541-556.

Fischbacher, Urs (2007): z-Tree: Zurich toolbox for ready-made economic experiments. In Experimental Economics 10 (2), pp. 171-178. 
Gächter, Simon; Fehr, Ernst (1999): Collective action as a social exchange. In Journal of Economic Behavior \& Organization 39 (4), pp. 341-369.

Hopfensitz, Astrid; Reuben, Ernesto (2009): The Importance of Emotions for the Effectiveness of Social Punishment. In The Economic Journal 119 (540), pp. 1534-1559.

Ibañez, D. M., \& Schaffland, E. R. (2012). Group identity and leadership: An experimental analysis: Unpublished Manuscript. University of Göttingen.

Kandel, Eugene; Lazear, Edward P. (1992): Peer Pressure and Partnerships. In Journal of Political Economy 100 (4), pp. 801-817.

Keser, Claudia; van Winden, Frans (2000): Conditional Cooperation and Voluntary Contributions to Public Goods. In Scandinavian Journal of Economics 102 (1), p. 23.

Lankau, Matthias; Bicskei, Marianna; Bizer, Kilian (2012): Cooperation Preferences in the Provision of Public Goods: An Experimental Study on the Effects of Social Identity. cege Discussion Papers, 148. University of Göttingen. Available online at http://www.uni-goettingen.de/de/sh/60864.html.

Lankau, Matthias; Bicskei, Marianna; Bizer, Kilian (2013): The role of expectations in the provision of public goods under the influence of social identity. Working Paper. University of Göttingen.

Lindbeck, A.; Nyberg, S.; Weibull, J. W. (1999): Social Norms and Economic Incentives in the Welfare State. In The Quarterly Journal of Economics 114 (1), pp. 1-35.

Masclet, David; Noussair, Charles; Tucker, Steven; Villeval, Marie-Claire (2003): Monetary and Nonmonetary Punishment in the Voluntary Contributions Mechanism. In American Economic Review 93 (1), pp. 366-380.

Noussair, Charles; Tucker, Steven (2005): Combining monetary and social sanctions to promote cooperation. In Economic Inquiry 43 (3), pp. 649-660.

Ostrom, Elinor; Walker, James; Gardner, Roy (1992): Covenants With and Without a Sword: SelfGovernance is Possible. In The American Political Science Review 86 (2), pp. 404-417.

Reuben, Ernesto; van Winden, Frans (2008): Social ties and coordination on negative reciprocity: The role of affect. In Journal of Public Economics 92 (1-2), pp. 34-53.

Solow, J. L.; Kirkwood, N. (2002): Group identity and gender in public goods experiments. In Journal of Economic Behavior \& Organization 48 (4), pp. 403-412.

Tajfel, Henri; Turner, John (1979): An Integrative Theory of Intergroup Conflict. In Stephen Worchel, William Austin (Eds.): The Psychology of Intergroup Relations. Monterey: CA: Brooks/Cole, pp. 33-47.

Vyrastekova, Jana; Funaki, Yukihiko; Takeuchi, Ai (2011): Sanctioning as a social norm: Expectations of non-strategic sanctioning in a public goods game experiment. In The Journal of Socio-Economics 40 (6), pp. 919-928.

Wit, Arjaan P.; Wilke, Henk A.M (1992): The effect of social categorization on cooperation in three types of social dilemmas. In Journal of Economic Psychology 13 (1), pp. 135-151.

Zeelenberg, Marcel; van Dijk, Wilco W.; Manstead, Antony S.R; van der Pligt, Joop (1998): The Experience of Regret and Disappointment. In Cognition \& Emotion 12 (2), pp. 221-230. 


\section{Eidesstattliche Erklärung}

Ich versichere an Eides Statt, dass ich die eingereichte Dissertation „Social Identity in the Provision and Protection of Cultural Goods" selbstständig verfasst habe. Anderer als der von mir angegebenen Hilfsmittel und Schriften habe ich mich nicht bedient. Alle wörtlich oder sinngemäß den Schriften anderer Autorinnen und/oder Autoren entnommenen Stellen habe ich kenntlich gemacht.

Szeged, den 11. November 2014 